\author{
Universidade de São Paulo \\ Instituto de Física
}

\title{
Estrutura de Microlâmpadas Energizadas em Escala Micrométrica
}

\author{
Vinicius Roberto de Sylos Cassimiro
}

Orientadora: Profa. Dra. Márcia Carvalho de Abreu Fantini

Tese de doutorado apresentada ao Instituto de Física da Universidade de São Paulo, como requisito parcial para a obtenção do título de Doutor em Ciências.

Banca Examinadora:

Profa. Dra. Márcia Carvalho de Abreu Fantini - Orientadora (IF-USP)

Prof. Dr. Alain André Quivy (IFUSP)

Prof. Dr. Valmor Roberto Mastelaro (IFSC/USP)

Prof. Dr. Flavio Cesar Vicentin (CNPEM/LNLS)

Prof. Dr. Rogério Junqueira Prado (IF/UFMT)

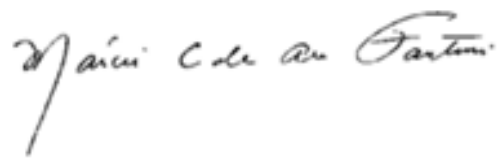


FICHA CATALOGRÁFICA

Preparada pelo Serviço de Biblioteca e Informação do Instituto de Física da Universidade de São Paulo

Cassimiro, Vinicius Roberto Sylos

Estrutura de microlâmpadas energizadas em escala micrométrica. São Paulo, 2020.

Tese (Doutorado) - Universidade de São Paulo. Instituto de Física. Depto. de Física Aplicada

Orientador: Profa. Dra. Márcia Carvalho de Abreu Fantini

Área de Concentração: Física.

Unitermos: 1. Espectroscopia de raio $X ; 2$. Sistemas microeletromecânicos; 3. Filmes finos. 


\title{
University of São Paulo \\ Physics Institute
}

\section{Structure of Energized Microlamps in Micrometric Scale}

\author{
Vinicius Roberto de Sylos Cassimiro
}

Supervisor: Prof. Dr. Márcia Carvalho de Abreu Fantini

Thesis submitted to the Physics Institute of the University of São Paulo in partial fulfillment of the requirements for the degree of Doctor of Science.

Examining Committee:

Prof. Dr. Márcia Carvalho de Abreu Fantini - Supervisor (IF-USP)

Prof. Dr. Alain André Quivy (IFUSP)

Prof. Dr. Valmor Roberto Mastelaro (IFSC/USP)

Prof. Dr. Flavio Cesar Vicentin (CNPEM/LNLS)

Prof. Dr. Rogério Junqueira Prado (IF/UFMT) 



\section{Agradecimentos}

Meus sinceros agradecimentos aos que colaboraram com a realização desta tese.

- À profa. Dra. Márcia Carvalho de Abreu Fantini, orientadora, com quem muito aprendi nesses anos de convivência

- A todos os colegas do laboratório de cristalografia: Dr. Luis Cides, Dr. José Miranda, Dr. Marlon Silva e Dr. Gabriel Magalhães.

- Aos amigos técnicos do laboratório: Sérgio Alexandre, Antônio Carlos e Tarsis Germano.

- Ao Srs. Vidal Affonso e João Leonel Ferreira pelo auxílio computacional.

- A todos os colegas do GNMD POLI-USP: Dra. Inés Pereyra; Dr. Marcelo Carreño; Dr. Marco Alayo; Dr. Gustavo Rehder; Rubens Cunha e Alexandre Lopes, pelo auxílio com a fabricação das amostras e toda a discussão científica.

- Ao Prof. Dr. Wanderlã Scopel pelos cálculos das estruturas amorfas e discussão científica.

- Ao Dr. Cleber Lima Rodrigues e ao Prof. Dr. Tiago Fiorini da Silva (LAMFI-USP) pelas medidas e análises de RBS.

- Ao Dr. Flávio Cesar Vicentin (LNLS) pelas medidas de XAS.

- Ao Dr. Carlos Alberto Perez (LNLS) pelas medidas de GIXRF e por compartilhar o código Python para análise.

- Ao Dr. Nicolas Trcera (SOLEIL) pelas medidas de XAS.

- À Modesta Inglesi, pela revisão textual, e à Juliana e Theodora pela convivência. 
À família e aos amigos 


\section{Resumo}

Essa tese apresenta um estudo sobre as características estruturais de filmes finos, aplicados como camada de proteção à oxidação em microlâmpadas, assim como as modificações químicas e estruturais induzidas pelo aquecimento decorrente da sua operação. As microlâmpadas estudadas foram produzidas no Grupo de Novos Materiais e Dispositivos (GNMD) da POLI-USP, e têm aplicações em microdispositivos. Sua fabricação consiste na deposição de filmes por Plasma Enhanced Chemical Vapor Deposition (PECVD) e sputtering, sobre substratos de silício. A camada de proteção analisada trata-se de um filme aplicado sobre um pequeno filamento de Cr. Quatro diferentes materiais foram utilizados como camada de proteção: a-SiC, a- $\mathrm{SiO}_{x} \mathrm{~N}_{y}, \mathrm{AlN}^{\mathrm{a}} \mathrm{TiO}$. A intensidade e duração da corrente elétrica aplicada ao dispositivo foram variadas (até $50 \mathrm{~mA}$ e por $10 \mathrm{~s}$ até 1,0 h). A linha de luz LUCIA, do síncrotron SOLEIL (França), utilizada nesse trabalho, possui feixe microfoco $\left(3 \times 3 \mu \mathrm{m}^{2}\right)$, o que permitiu avaliar, por espectroscopia de absorção de raios X (XANES), a microrregião termicamente afetada, exatamente sobre o filamento. Os resultados demonstraram que os filmes de a-SiO $\mathrm{S}_{x} \mathrm{~N}_{y}$ e $\mathrm{TiO}_{2}$ (rutilo) são os mais indicados para a aplicação, pois, além de termicamente estáveis, permitem menor dissipação de calor. As camadas de proteção de $\mathrm{AlN}$ e a-SiC mostraram alterações estruturais em decorrência do aumento da temperatura com a operação do dispositivo. Para auxiliar no estudo desses materiais, amostras adicionais de filmes finos, crescidos sobre substratos extensos convencionais, foram produzidas e estudadas pelas técnicas: espectroscopia de absorção de raios X (região XANES e EXAFS), fluorescência de raios X com incidência rasante (GIXRF) e espectroscopia de retroespalhamento de Rutherford (RBS). Uma pequena oxidação nos filmes de AlN das microlâmpadas foi observada com o aumento da temperatura e o material apresentou o início de um processo de cristalização em correntes maiores. As camadas de proteção de a-SiC demonstraram oxidação intensa e crescente com o aumento da duração e intensidade da corrente elétrica aplicada à microlâmpada. Adicionalmente, observou-se que o a-SiC apresentou diferenças estruturais na microrregião sobre o filamento, em comparação com um filme de referência, depositado sobre Si. Os resultados obtidos com os filmes finos adicionais indicaram a difusão de $\mathrm{Cr}$ e O no a-SiC. Espectros XANES teóricos de estruturas de a-SiC, elaboradas por dinâmica molecular, foram calculados com o software Finite Difference Method Near Edge Structure (FDMNES) com o objetivo de estudar as modificações induzidas pela presença do $\mathrm{Cr}$ e $\mathrm{O}$ no material. Concluiu-se que a forma construtiva das microlâmpadas resultou em um carbeto de silício, depositado por PECVD, fora das condições ideais, possivelmente devido à presença de uma cavidade abaixo do filamento, que reduziu a temperatura do substrato no momento da deposição. Tais condições, provavelmente, favoreceram a difusão de $\mathrm{Cr}$ e $\mathrm{O}$ na matriz do carbeto de silício, causando as modificações estruturais observadas.

Palavras-chave: Espectroscopia de raio X, Sistemas microeletromecânicos, Filmes finos. 


\section{Abstract}

This thesis presents a study about the structure of thin films, deposited to be a protection layer against oxidation of microlamps, as well as chemical and structural modifications induced by their heating under operation. The studied microlamps were produced in the Group of New Materials and Devices (GNMD) of POLI-USP, having applications in microelectromechanical systems. They were produced by Plasma Enhanced Chemical Vapor Deposition (PECVD) and sputtering, over silicon substrates. The analyzed protection layer is a film on top of a small Cr filament. Four different materials were used as protection layer: a-SiC, a-SiO$x \mathrm{~N}_{y}, \mathrm{AlN}$ and $\mathrm{TiO}_{2}$. The intensity and time interval of the electric current applied in the device were varied (up to $50 \mathrm{~mA}$ and during $10 s$ to $1,0 \mathrm{~h}$ ). The beamline LUCIA of the SOLEIL synchrotron (France), that was used in this work, has a microfocus beam $\left(3 \times 3 \mu m^{2}\right)$, allowing the evaluation of the micro region thermally affected, exactly on top of the filament, using X-ray absorption spectroscopy (XANES). The results demonstrated that the a- $\mathrm{SiO}_{x} \mathrm{~N}_{y}$ and $\mathrm{TiO}_{2}$ (rutile) films are the indicated ones for this application, because, besides their thermal stability, they dissipate less heat. The AlN and a-SiC protective films showed structural changes caused by the heating related to the device operation. To improve the studies of these materials additional thin films samples, deposited over ordinary large flat substrates, were produced and analyzed by X-Ray Absorption Spectroscopy (XANES and EXAFS region), Grazing Incidence X-Ray Fluorescence (GIXRF) and Rutherford Backscattering Spectroscopy (RBS). A small oxidation was detected in the AlN films with the increase in temperature and these films presented a beginning of crystallization process with higher currents. The a-SiC films showed an intense and increasing oxidation as the intensity and duration of the applied current in the microlamps were raised. In addition, structural differences in the a-SiC film were observed in the micro area over the filament, compared with a reference film deposited over $\mathrm{Si}$. The results achieved with the additional thin films revealed the diffusion of $\mathrm{Cr}$ and $\mathrm{O}$ into the a-SiC. Theoretical XANES spectra of a-SiC structures, constructed by molecular dynamics, were calculated by the Finite Difference Method Near Edge Structure (FDMNES) code, aiming to study the modifications induced by the presence of $\mathrm{Cr}$ and $\mathrm{O}$ into the material. The conclusion was that the microlamp design induced the grown of PECVD silicon carbide far from the best conditions, probably due to the presence of a cavity under the filament that reduced the substrate temperature during the deposition. This situation may have enhanced the $\mathrm{Cr}$ and $\mathrm{O}$ diffusion into de silicon carbide resulting in the structural changes observed.

Keywords: X-ray spectroscopy, Microelectromechanical systems, Thin-films. 


\section{Lista de Figuras}

1.1 Alguns exemplos de MEMS . . . . . . . . . . . . . . . . . . 3

1.2 Alguns exemplos de MOEMS . . . . . . . . . . . . . . . . . 4

1.3 Foto da microlâmpada . . . . . . . . . . . . . . . . . . . . 6

1.4 Processos de microfabricação utilizados em MEMS . . . . . . . . . . . 7

1.5 Oxidação do silício . . . . . . . . . . . . . . . . . 8

1.6 Esquema de um reator de sputtering . . . . . . . . . . . . 9

1.7 Principais etapas da fotolitografia . . . . . . . . . . . . 11

1.8 Sistemas de impressão da máscara em fotolitografia . . . . . . . . . . . . 12

1.9 Diferença entre o resiste positivo e negativo . . . . . . . . . . . 13

1.10 Etapa de lift off . . . . . . . . . . . . . . . . . . . . . . 14

1.11 Perfis resultantes da corrosão isotrópica e anisotrópica $\ldots$. . . . . . . 15

1.12 Corrosão anisotrópica do Si ～. . . . . . . . . . . . . . . 16

1.13 Perfil obtido com os diferentes tipos de corrosão seca . . . . . . . . . . . 17

1.14 Principais estruturas cristalinas do $\mathrm{SiC} \ldots \ldots \ldots$

1.15 Alguns resultados da literatura reportados para o a- $\mathrm{Si}_{1-x} \mathrm{C}_{x}: \mathrm{H} \quad \ldots \quad \ldots$

1.16 Fases do nitreto de alumínio . . . . . . . . . . . . . . . . 22

1.17 Fases do óxido de titânio . . . . . . . . . . . . . . . . . . . 23

1.18 Influência da composição química nas propriedades do $\mathrm{SiO}_{x} \mathrm{~N}_{y} \ldots \ldots 24$

2.1 Absorção de raios X e o coeficiente de absorção . . . . . . . . . . . . 26 
2.2 Seção de choque de absorção do Fe . . . . . . . . . . . . . . . 27

2.3 Estrutura fina do espectro de absorção . . . . . . . . . . . . . . . . . 28

2.4 Diferentes formas de tomada de dados de XAS . . . . . . . . . . . 29

2.5 Determinação experimental de $E_{0} \ldots \ldots \ldots$. . . . . . . . . 32

2.6 Etapas do processo de normalização e remoção do contínuo . . . . . 33

2.7 Exemplo da análise de XANES pela comparação de padrões conhecidos 35

2.8 Exemplo da análise de XANES pelo ajuste de picos . . . . . . . . . . 36

2.9 Análise de XANES pela combinação linear de padrões . . . . . . . . 37

2.10 Transformada de Fourier do sinal EXAFS . . . . . . . . . . . . . . . 39

2.11 Representação do procedimento adotado no FDMNES . . . . . . . . . . 41

2.12 Arranjo experimental utilizado em medidas de fluorescência de raios X . 42

2.13 Representação dos feixes incidente, refletido e refratado numa superfície entre dois meios . . . . . . . . . . . . . . . . . . . . 43

2.14 Parte real e imaginária de alguns meios . . . . . . . . . . . . 45

2.15 Amplitudes dos feixes refletido e refratado em filmes finos sobre um

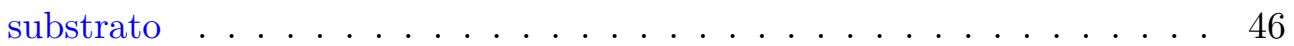

2.16 Exemplo da curva obtida por GIXRF para um filme de Cr sobre Si . . . 48

2.17 Arranjo experimental típico no RBS . . . . . . . . . . . . . . 49

2.18 Exemplo do espectro RBS . . . . . . . . . . . . . . . . 51

2.19 Exemplo da analise de diversos espectros simultaneamente com o Multi-

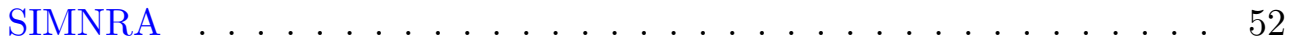

2.20 Medidas na ressonância do oxigênio . . . . . . . . . . . . . . . . 53

3.1 Esquema da Microlâmpada . . . . . . . . . . . . . . . . . . . 56

3.2 Foto da microlâmpada . . . . . . . . . . . . . . . . . . . 57

3.3 Máscaras utilizadas na fabricação das microlâmpadas . . . . . . . . . . . 59

3.4 Filamento em ponte da microlâmpada . . . . . . . . . . . . . 60 
3.5 Tipos de filamentos produzidos . . . . . . . . . . . . . . 61

3.6 Arranjo para a energização das microlâmpadas . . . . . . . . . . . . . . 62

3.7 Amostras de a-SiC e AlN produzidas sobre uma região de $\mathrm{Cr}$. . . . . . 65

3.8 Forno tubular utilizado para o tratamento térmico das amostras . . . . 66

4.1 Esquema das medidas de absorção de raios X realizadas com feixe microfoco 70

4.2 Refinamento Rietveld do padrão c-SiC utilizado. . . . . . . . . . . . . 72

4.3 Padrões experimentais utilizados. . . . . . . . . . . . . 73

4.4 Espectro XANES das microlâmpadas com $\mathrm{TiO}_{2} \ldots \ldots \ldots$. . . . . . 75

4.5 Espectro XANES das microlâmpadas com a- $\mathrm{SiO}_{x} \mathrm{~N}_{y} \ldots \ldots \ldots 76$

4.6 Concentração atômica reportada na literatura para o a- $\mathrm{SiO}_{x} \mathrm{~N}_{y}$ depositado por PECVD . . . . . . . . . . . . . . . . 77

4.7 Espectro XANES das microlâmpadas com a-SiC $\ldots \ldots$. . . . . . 78

4.8 Espectros XANES das amostras de filmes finos adicionais de a-SiC . . . 81

4.9 Transformada de Fourier do sinal EXAFS obtido com a borda K do Si das amostras de filmes finos adicionais de a-SiC. . . . . . . . . . . 83

4.10 Foto do Laboratório de Análise de Materiais por Feixes Iônicos (LAMFI) 84

4.11 Espectros RBS e perfil em profundidade obtidos com a amostra SiC/Cr-RT 86

4.12 Arranjo experimental utilizando em GIXRF . . . . . . . . . . . . . 87

4.13 Fluorescência de raios X com incidência rasante das amostras de filmes finos adicionais de $\mathrm{SiC} \ldots \ldots \ldots$. . . . . . . . . . . . . 89

4.14 Espectro XANES nas amostras de a-SiC sobre Cr, medido com incidência rasante . . . . . . . . . . . . . . . . . . . . . 91

4.15 Espectros de absorção calculados com o FDMNES . . . . . . . . . . . . 92

4.16 Vizinhança dos átomos de $\mathrm{Si}$ da estrutura amorfa de $\mathrm{SiC}$ obtida por dinâmica molecular . . . . . . . . . . . . . . . . . . . . . . . 94 
4.17 Espectros XANES do carbeto de silício amorfo obtido por dinâmica molecular . . . . . . . . . . . . . . . . . . 95

4.18 Vizinhança dos átomos de Si da estrutura amorfa de SiC-O obtida por dinâmica molecular . . . . . . . . . . . . . . . . . . . . . . . 97

4.19 Vizinhança dos átomos de Si da estrutura amorfa de SiC-Cr obtida por dinâmica molecular . . . . . . . . . . . . . . . . . . . . . . . 98

4.20 Espectros XANES das estruturas a-SiC-O e a-SiC-C. . . . . . . . . . . 99

4.21 Espectros XANES das estruturas a-SiC-O e a-SiC-C de átomos selecionados101

4.22 Comparação do espectro XANES da microlâmapada ML49-SiC com padrões e os resultados da simulação com o FDMNES . . . . . . . . . 105

4.23 Espectro XANES das microlâmpadas de AlN . . . . . . . . . . . . . 107

4.24 Detalhes dos espectros XANES das microlâmpadas com AlN . . . . . . 108

4.25 Espectros XANES das amostras de filmes finos adicionais de AlN . . . 110

4.26 Espectro RBS da amostra AlN/Cr-RT . . . . . . . . . . . . . . . 112

4.27 Fluorescência de raios X com incidência rasante nas amostras de AlN . . 115

A.1 Interação dos raios X com a matéria . . . . . . . . . . . . . . 137

A.2 Interferência das ondas espalhadas do fotoelétron . . . . . . . . . . 138

A.3 Representação do espalhamento simples e espalhamento múltiplo . . . 139

B.1 Potencial muffin-tin . . . . . . . . . . . . . . . . . . 145

B.2 Representação de alguns tipos de caminhos de espalhamento . . . . . . 146

C.1 Amplitudes dos feixes refletido e refratado em filmes finos sobre um substrato . . . . . . . . . . . . . . . . . 151

D.1 Colisão entre projétil e alvo no RBS . . . . . . . . . . . . . . . . 159

D.2 Perda de energia e espectro RBS . . . . . . . . . . . . . . . 160

D.3 Espectro RBS de um material de composição $A_{m} B_{n} \ldots \ldots$. . . . . 163 


\section{Lista de Tabelas}

3.1 Parâmetros utilizados nas deposições por PECVD e sputtering . . . . . 58

3.2 Parâmetros utilizados na corrosão do a-SiC por RIE . . . . . . . . . . 62

3.3 Condições de energização e identificação das microlâmpadas . . . . . . . 63

3.4 Condutividade térmica dos materiais utilizados como camada de proteção e condições de operação das microlâmpadas . . . . . . . . . . . . . . . 64

3.5 Identificação das amostras de filmes finos adicionais de a-SiC e AlN . 67

4.1 Características dos padrões utilizados . . . . . . . . . . 72

4.2 Espessura e composição dos filmes das amostras de filmes finos adicionais de $\mathrm{SiC} \ldots \ldots \ldots \ldots \ldots \ldots \ldots$

4.3 Estruturas cristalinas simuladas com o FDMNES . . . . . . . . . . . . . 91

4.4 Posições dos átomos vizinhos da estrutura teórica de a-SiC $\quad \ldots$. . . . . 93

4.5 Espessura e composição dos filmes finos das amostras de filmes finos adicionais de AlN . . . . . . . . . . . . . . . . . . 113 


\section{Sumário}

1 Estado da arte e objetivos 1

1.1 MEMS e suas aplicações . . . . . . . . . . . . . . . . . . . . 1

1.1 .1 Objetivos da tese ................... 5

1.1.2 A microlâmpada estudada nesta pesquisa . . . . . . . . . . 6

1.2 Processos de microfabricação de MEMS/MOEMS . . . . . . . . . . . . . 6

1.2.1 Processos de crescimento e deposição de materiais . . . . . . . 7

1.2 .2 Fotolitografia . . . . . . . . . . . . . . . . 10

1.2.3 Técnicas de Corrosão . . . . . . . . . . . . . . . . . . . . . . . . 14

1.3 Propriedades dos materiais empregados como camada de proteção nas microlâmpadas . . . . . . . . . . . . . . . . . 17

1.3.1 Carbeto de silício $-\mathrm{SiC} \ldots \ldots \ldots \ldots$

1.3.2 Nitreto de alumínio - AlN . . . . . . . . . . . . . . 21

1.3.3 Dióxido de titânio $-\mathrm{TiO}_{2} \ldots \ldots \ldots \ldots . \ldots \ldots$

1.3.4 Oxinitreto de silício $-\mathrm{SiO}_{x} \mathrm{~N}_{y} \ldots \ldots \ldots \ldots 22$

2 Técnicas experimentais $\quad 25$

2.1 Espectroscopia de absorção de raios X (XAS) . . . . . . . . . . . 25

2.1.1 Estrutura fina de absorção de raios X (XAFS) . . . . . . . . 26

2.1 .2 Arranjo experimental típico . . . . . . . . . . . . . . 28

2.1.3 Tratamento dos dados de XAS . . . . . . . . . . . . 30 
2.1.4 Remoção do contínuo (background) e normalização . . . . . . . . 31

2.1.5 Normalização . . . . . . . . . . . . . . . . . . . . . . . . 31

2.1.6 Remoção do contínuo . . . . . . . . . . . . . . . . . . . . 32

2.1.7 Análise dos dados de XANES . . . . . . . . . . . . . . . . 34

2.1.8 Análise dos dados de EXAFS . . . . . . . . . . . . . . . . . 37

2.1.9 Cálculos teóricos de XANES e EXAFS . . . . . . . . . . . . . 39

2.2 Fluorescência de raios X com incidência rasante - GIXRF . . . . . . . . 41

2.2.1 Atenuação e deflexão de raios X . . . . . . . . . . . . . . . . 42

2.2.2 Reflexão total externa . . . . . . . . . . . . . . . . . . . 45

2.2.3 Fluorescência em filmes finos sobre um substrato . . . . . . . . . 46

2.2.4 Aspectos experimentais de GIXRF . . . . . . . . . . . . 47

2.3 Espectroscopia de retroespalhamento de Rutherford - RBS . . . . . . . 49

2.3.1 Seção de choque de espalhamento de Rutherford . . . . . . . . 49

2.3.2 Análise de RBS utilizando softwares . . . . . . . . . . . . . 50

2.3.3 Medidas em ressonância . . . . . . . . . . . . . . . . . . 52

3 Fabricação das microlâmpadas e dos filmes finos adicionais $\quad 55$

3.1 Detalhes da fabricação das microlâmpadas . . . . . . . . . . . . . 56

3.1.1 O filamento em forma de ponte . . . . . . . . . . . . . 58

3.1.2 Corrosão por RIE das microlâmpadas com a-SiC . . . . . . . . . 61

3.2 Energização . . . . . . . . . . . . . . . . . . . . . . 62

3.3 Filmes finos adicionais de a-SiC e AlN . . . . . . . . . . . . . . . 64

4 Resultados e discussão $\quad 69$

4.1 Medidas experimentais realizadas nas microlâmpadas . . . . . . . . . . . 69

4.2 Medidas experimentais realizadas nas amostras de filmes finos adicionais 70

4.3 Padrões experimentais utilizados $\ldots \ldots \ldots$. . . . . . . . . 71

4.4 Microlâmpadas com óxido de titânio $-\mathrm{TiO}_{2} \ldots \ldots \ldots$. . . . . . 74 
4.5 Microlâmpadas com oxinitreto de silício amorfo $-\mathrm{a}_{-} \mathrm{SiO}_{x} \mathrm{~N}_{y} \ldots \ldots$. . . 74

4.6 Microlâmpadas com carbeto de silício amorfo - a-SiC . . . . . . . . . 76

4.6.1 Espectros XAS das amostras de filmes finos adicionais de a-SiC . 79

4.6.2 Espectroscopia por retroespalhamento de Rutherford - RBS . . . 82

4.6.3 Fluorescência de raios X com incidência rasante - GIXRF . . . . 86

4.6.4 Espectro de absorção XANES com incidência rasante . . . . . . 90

4.6 .5 Espectros XANES teóricos . . . . . . . . . . . . . 90

4.6.6 Discussão sobre os resultados obtidos com a microlâmpada com

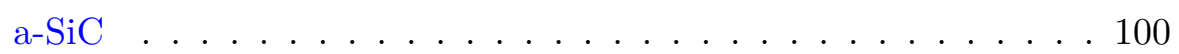

4.7 Microlâmpadas com nitreto de alumínio -AlN . . . . . . . . . . . . . 105

4.7.1 Espectros XAS das amostras de filmes finos adicionais de AlN . 109

4.7.2 Espectroscopia por retroespalhamento de Rutherford - RBS . . . 111

4.7.3 Fluorescência de raios X com incidência rasante - GIXRF . . . . 114

4.7.4 Discussão sobre os resultados obtidos com a microlâmpada com $\mathrm{AlN} \ldots \ldots \ldots \ldots \ldots \ldots \ldots \ldots \ldots$

5 Conclusões

5.1 Perspectivas de investigações futuras . . . . . . . . . . . . . 118

5.2 Trabalhos decorrentes dessa tese . . . . . . . . . . . . . . . 119

Referências Bibliográficas

$\begin{array}{ll}\text { A A física da estrutura fina de absorção de raios X } & 136\end{array}$

A.1 Interação dos raios X com a matéria . . . . . . . . . . . . . . 136

A.2 Introdução à equação EXAFS . . . . . . . . . . . . . . . . . . . 138

B Fundamentos dos cálculos teóricos de XANES e EXAFS 142

B.1 A probabilidade de transição e a regra de ouro de Fermi . . . . . . . . . 142

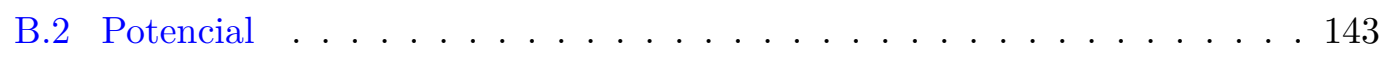


B.2.1 Potencial muffin-tin . . . . . . . . . . . . . . . . . 144

B.3 Espalhamento múltiplo . . . . . . . . . . . . . . . . . . . 145

B.3.1 Expansão do espalhamento múltiplo . . . . . . . . . . . . . . . 147

B.3.2 Espalhamento múltiplo total (Full multiple Scattering) . . . . . . 149

C Intensidade de fluorescência em filmes finos sobre um substrato

D Fundamentos da espectroscopia de retroespalhamento de Rutherford 158

D.1 O fator cinemático . . . . . . . . . . . . . . . . 158

D.2 Poder de freamento . . . . . . . . . . . . . . . . . . 160

E Publicação decorrente deste trabalho 


\section{Capítulo 1}

\section{Estado da arte e objetivos}

\subsection{MEMS e suas aplicações}

MEMS (Microelectromechanical Systems) é o acrônimo utilizado para se referir a um dispositivo de dimensões micrométricas, geralmente com algum tipo de atuação mecânica (partes móveis) e elétrica. Esse termo é empregado de maneira mais generalizada, incluindo também sistemas térmicos, fluídicos, magnéticos, ópticos, e até mesmo sem partes móveis, mas sempre de dimensões micrométricas. Os MEMS são projetados para executar alguma função específica tais como: sensoriamento, monitoramento biomédico, controle de motores, segurança automotiva, chaveamento óptico, atuação mecânica, transporte em sistemas microfluídicos, análises químicas e diversas outras ${ }^{[1-3]}$. A construção dos MEMS é feita aplicando as técnicas de microfabricação utilizadas na microeletrônica, onde os materiais são empregados, geralmente, na forma de filmes finos. Alguns exemplos desses materiais são o silício e seus compostos (óxidos, nitretos e carbetos de silício), metais como o titânio, tungstênio, alumínio, cobre, entre outros ${ }^{[2]}$.

Microfilamentos resistivos podem ser incorporados aos MEMS com o objetivo de utilizar a sua função óptica ou térmica integrada com outras funcionalidades do dispositivo. Essas microlâmpadas encontram diversas aplicações, tais como: fonte de sinal 
$\operatorname{IR}^{[4]}$, espectrofotometria ${ }^{[5]}$, sensores ${ }^{[6]}$, displays $^{[7]}$ e transmissão de sinal por guias de onda ${ }^{[8]}$. Quando percorrido por corrente elétrica, o microfilamento aquece por efeito Joule e emite radiação policromática. Por atingir temperaturas elevadas, o filamento deve ser isolado do ar externo com a aplicação de um filme como camada de proteção. Isso evita a oxidação prematura e consequente redução do tempo de vida do dispositivo.

O desenvolvimento dos MEMS iniciou-se na segunda metade do século XX, sendo uma das primeiras conquistas, a fabricação de sensores de pressão em silício pela HoneyWell em $1962^{[9]}$. Atualmente, é uma área em grande desenvolvimento tecnológico, com inúmeros dispositivos em plena comercialização que alimenta um mercado da ordem de algumas dezenas de bilhões de dólares ${ }^{[10-12]}$. Alguns exemplos interessantes de MEMS são exibidos na figura 1.1. O termo MOEMS (Micro-optoelectromechanical systems) refere-se a MEMS com sistemas ópticos incorporados, tais como: guias de ondas, chaves, microespelhos, microlentes, microlâmpadas e sensores ópticos integrados ${ }^{[8,13,14]}$. A figura 1.2 exibe alguns exemplos de MOEMS. 

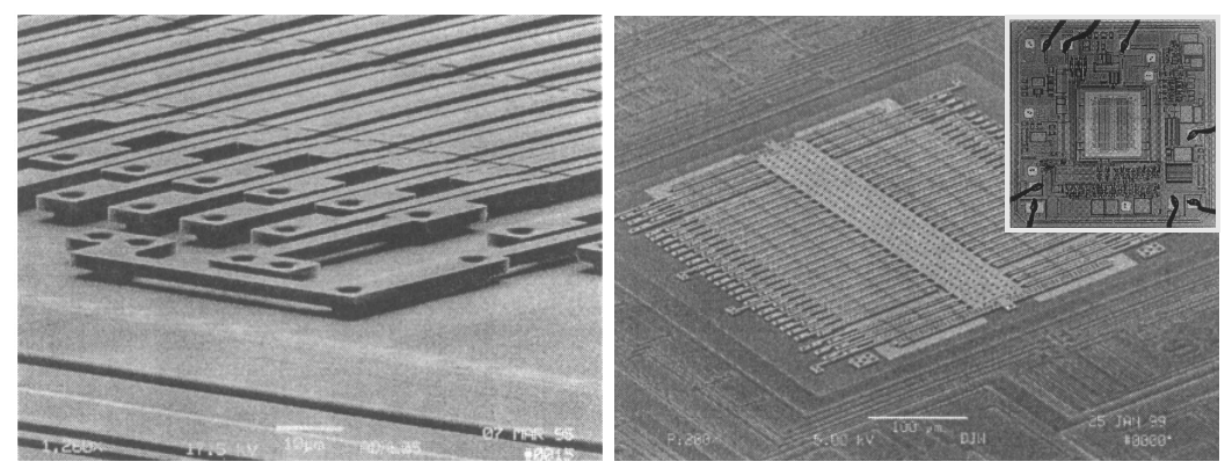

(a)
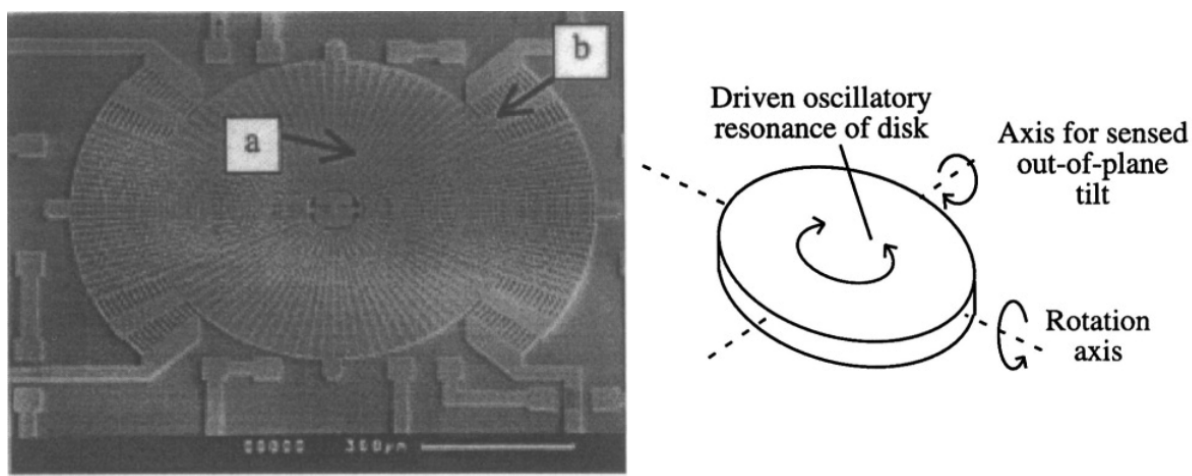

(b)

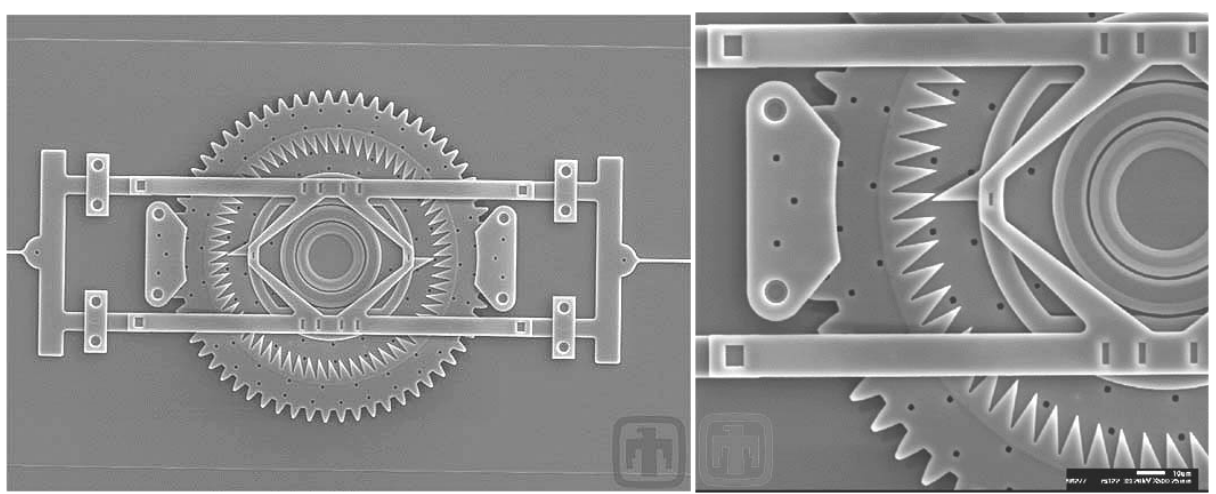

(c)

Figura 1.1: Alguns exemplos de MEMS. Em (a) um acelerômetro ${ }^{[1]}$, em (b) um giroscópio $^{[1]}$, em (c) um motor indexador ${ }^{[15]}$. 


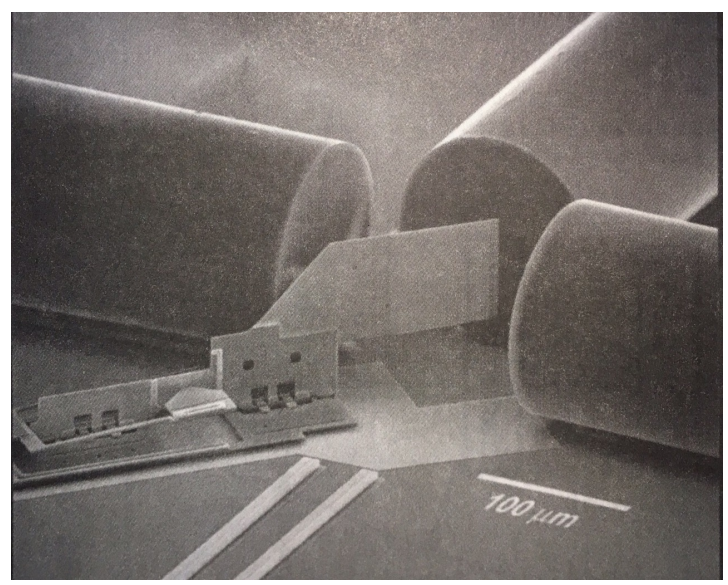

(a)
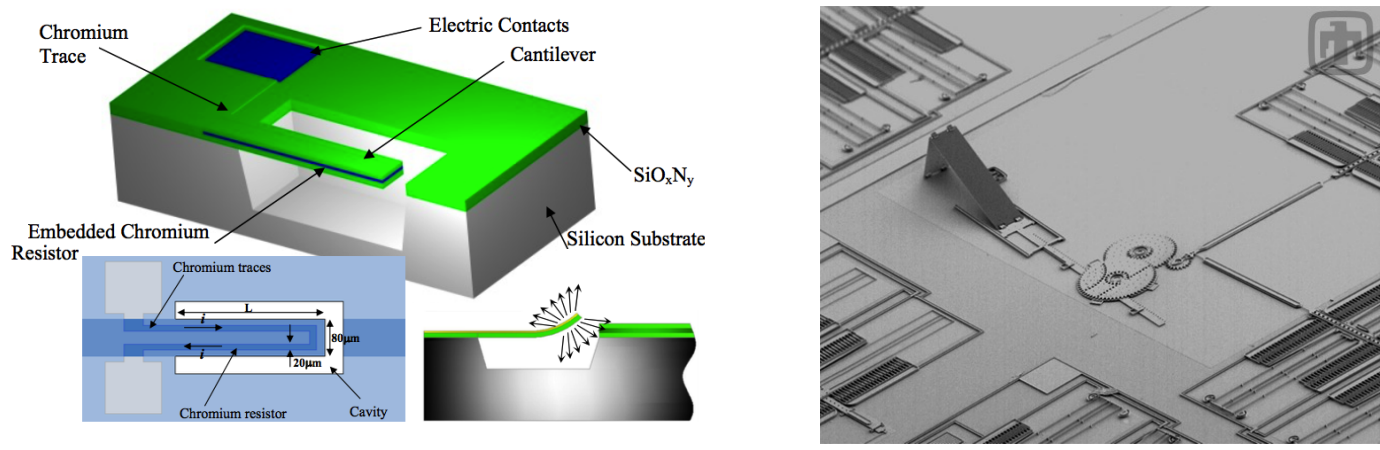

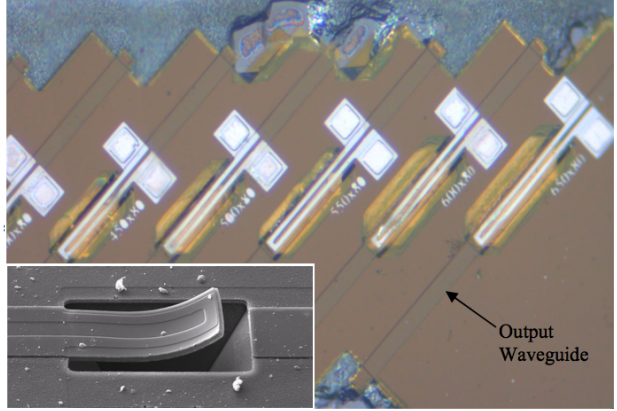

(b)

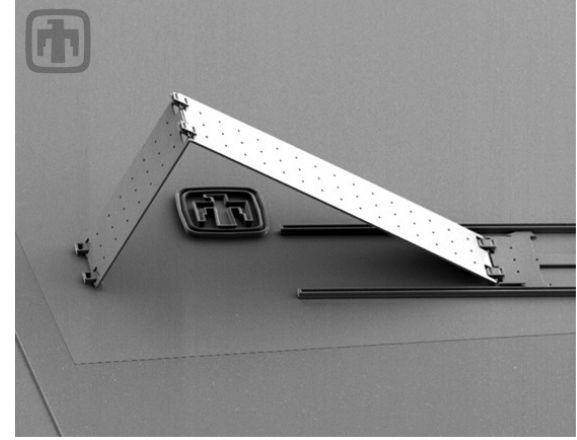

(c)

Figura 1.2: Alguns exemplos de MOEMS. Em (a), uma chave óptica 1x2 ${ }^{[16]}$, em (b), um guia de onda ${ }^{[8]}$ e em (c) um espelho suspenso ${ }^{[15]}$. 


\subsubsection{Objetivos da tese}

O objetivo deste trabalho consiste em estudar eventuais mudanças químicas e estruturais de materiais transparentes, na forma de filmes finos, depositados sobre microlâmpadas de cromo, a fim de protegê-las de oxidação (vide figura 1.3a). Os quatro materiais estudados foram: a-SiC, a- $\mathrm{SiO}_{x} \mathrm{~N}_{y}, \mathrm{AlN}$ e $\mathrm{TiO}_{2}$. Neste trabalho, utilizando-se fonte de luz síncrotron microfoco, foi possível avaliar, por técnicas de absorção de raios X, as propriedades do filme da camada de proteção depositado na própria microlâmpada, bem como, as alterações químicas e estruturais resultantes de sua operação, exatamente na região termicamente afetada pelo filamento (vide figura 1.3b). Até onde é de conhecimento do autor, não há na literatura trabalhos anteriores sobre a análise destes sistemas em escala micrométrica. Geralmente, os estudos dos filmes finos constituintes de sistemas micrométricos são realizados em amostras depositadas separadamente da sua aplicação,

sendo então os resultados extrapolados para os dispositivos. É importante frisar que, para o propósito deste trabalho, não é suficiente apenas avaliar as microlâmpadas energizadas a fim de indicar qual camada protetora é mais adequada, mas também explicar a origem de eventuais mudanças estruturais decorrentes da energização.

Os objetivos específicos desta pesquisa são: dos quatro materiais utilizados na camada de proteção das microlâmpadas, avaliar qual é o mais adequado para a aplicação; comparar os resultados obtidos com os filmes da microlâmpada, depositados sobre o filamento micrométrico de $\mathrm{Cr}$, com filmes depositados, sob as mesmas condições, em substratos convencionais, ou seja, de grandes dimensões e uniformes em toda a extensão (tal análise foi realizada apenas para os materiais a-SiC e AlN pelos motivos que serão descritos posteriormente); discutir a viabilidade de analisar os filmes depositados no próprio dispositivo, com uma técnica de investigação localizada, como a absorção de raios $\mathrm{X}$ com feixe microfoco. 


\subsubsection{A microlâmpada estudada nesta pesquisa}

A microlâmpada estudada foi produzida em colaboração com o Grupo de Novos Materiais e Dispositivos (GNMD) da Escola Politécnica da USP (POLI-USP) cujo projeto baseia-se nos trabalhos anteriores do grupo ${ }^{[8,17,18]}$. A figura 1.3 mostra uma imagem de uma das peças produzidas contendo diversas lâmpadas de dimensões micrométricas. Detalhes da fabricação do dispositivo são descritos no capítulo 3. Dado que o GNMD possui larga experiência na deposição de filmes finos extensos sobre diversos substratos utilizando PECVD e pulverização catódica* (sputtering) ${ }^{[19-28]}$, a microlâmpada analisada neste trabalho foi produzida utilizando tais técnicas, bem como demais processos de microfabricação, conforme descrito a seguir.

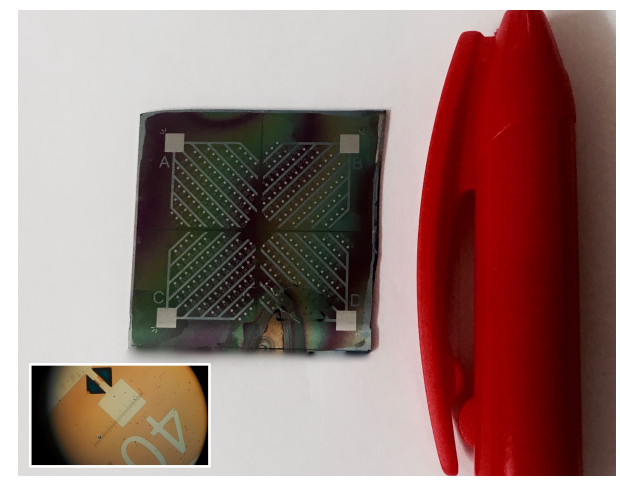

(a)

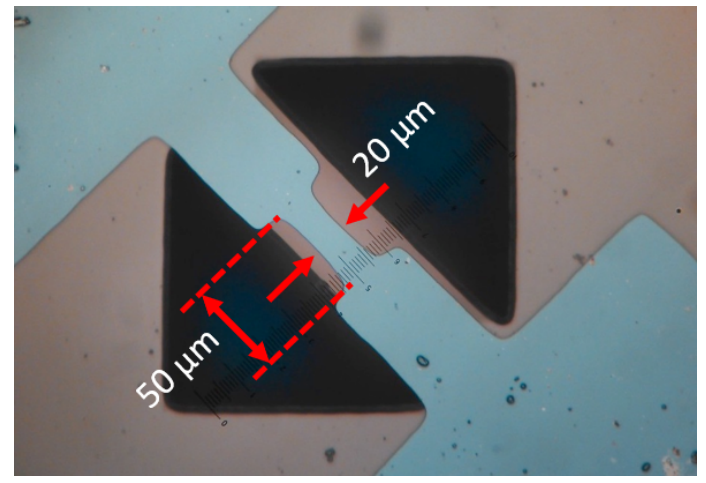

(b)

Figura 1.3: Em (a) uma foto da peça produzida contendo dezenas de microlâmpadas. Em (b) foto obtida com microscópio óptico com detalhe do filamento de uma das microlâmpadas.

\subsection{Processos de microfabricação de MEMS/MOEMS}

Os MEMS/MOEMS herdaram os processos de fabricação já utilizados pela microeletrônica no desenvolvimento dos circuitos integrados, tais como: fotolitografia, corrosão

\footnotetext{
*Para maior clareza, no restante do texto, optou-se por utilizar o termo inglês sputtering, uma vez que é amplamente empregado no meio científico e tecnológico.
} 


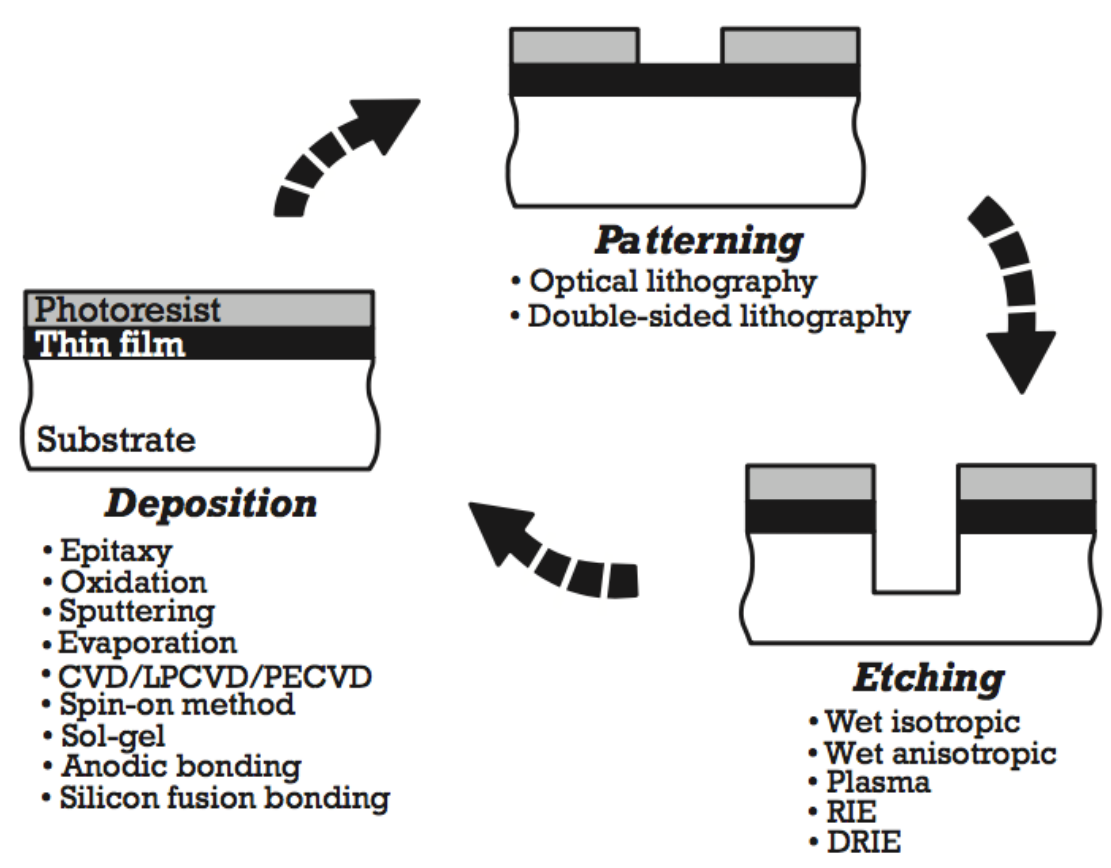

Figura 1.4: Processos de microfabricação utilizados em MEMS ${ }^{[2]}$.

e deposição por CVD (Chemical Vapor Deposition) e sputtering. A figura 1.4 mostra alguns dos principais métodos utilizados.

\subsubsection{Processos de crescimento e deposição de materiais}

Uma breve descrição dos principais processos de crescimento e deposição de materiais é apresentada a seguir. Maiores detalhes podem ser obtidos em diversos textos da literatura ${ }^{[1,2,29-31]}$.

\section{Oxidação}

O dióxido de silício $\left(\mathrm{SiO}_{2}\right)$ é facilmente produzido pela oxidação do silício em atmosfera de oxigênio seco ou em vapor. O mecanismo de oxidação é amplamente conhecido, e gráficos prevendo a espessura do óxido em função dos parâmetros de processo (temperatura, tempo, etc.) estão disponíveis facilmente na literatura ${ }^{[2]}$. A taxa de silício convertido 
em óxido é proporcional às suas respectivas densidades, cujo fator de proporção é 0,46 (figura 1.5) ${ }^{[32]}$.

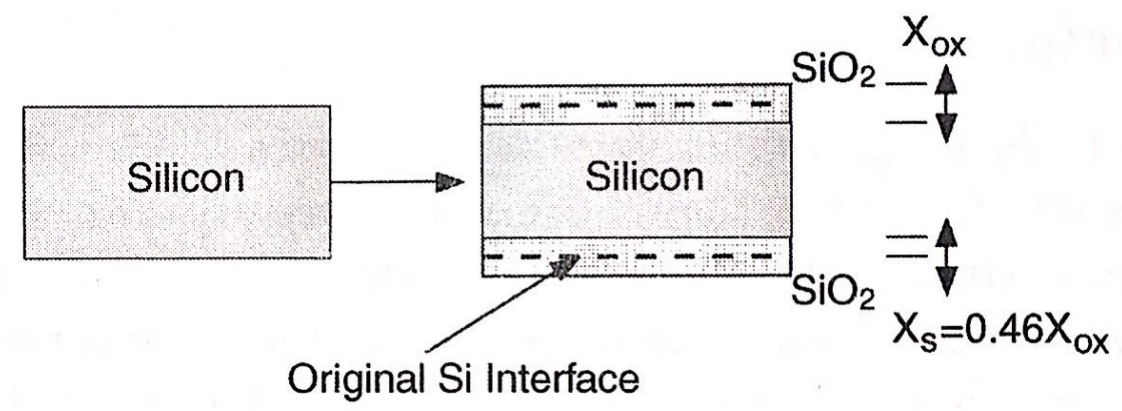

Figura 1.5: Representação esquemática de uma camada de Si submetida à oxidação térmica. $\mathrm{SiO}_{2}$ é formado nas duas superfícies. A diferença de densidade entre os materiais faz com que a espessura da camada de $\mathrm{SiO}_{2}\left(X_{O X}\right)$ gerada no processo seja maior do que a espessura original da camada de $\mathrm{Si}\left(X_{S}\right)$ oxidada ${ }^{[32]}$.

Em razão da diferença do coeficiente de dilatação térmico e do volume molecular, entre o $\mathrm{Si}$ e o $\mathrm{SiO}_{2}$, observam-se tensões de compressão no óxido obtido por esses processos térmicos. $\mathrm{SiO}_{2}$ de melhor qualidade é obtido na oxidação a seco. Em atmosfera de oxigênio puro, com temperaturas elevadas (de 900 a $1150^{\circ} \mathrm{C}$ ), o resultado é um óxido estequiométrico de alta densidade $\left(\approx 2,26 \mathrm{~g} / \mathrm{cm}^{3}\right)$ e com poucos defeitos. A oxidação úmida em vapor é muito mais rápida, porém, produz um óxido menos denso $\left(\approx 2,18 \mathrm{~g} / \mathrm{cm}^{3}\right)$ e mais propício para a difusão de impurezas ${ }^{[32]}$.

\section{Sputtering}

Sputtering é um processo de deposição física do vapor PVD (Physical Vapor Deposition) no qual o material que se deseja depositar (alvo) é bombardeado por íons de argônio (ou de outro gás inerte) produzidos em plasma. Tal bombardeamento faz com que átomos da superfície do alvo sejam ejetados, atingindo e condensando no substrato ${ }^{[2,32]}$, conforme mostra esquematicamente a figura 1.6. Neste processo de baixa temperatura, o alvo é mantido em potencial negativo (catodo), enquanto o substrato é mantido em potencial positivo (anodo). O plasma pode ser produzido por três mecanismos 
principais. Na configuração DC os íons são acelerados por um campo elétrico DC entre o alvo e o substrato. Na configuração RF, o alvo e o substrato formam duas placas paralelas com excitação RF aplicada ao alvo. Uma terceira configuração é a utilização de um campo magnético externo que eleva a densidade dos íons nas proximidades do alvo, aumentando a taxa de deposição ${ }^{[2]}$. Essa técnica é amplamente utilizada em laboratórios e em processos produtivos. Uma de suas características é a capacidade de cobrir muito bem degraus do substrato, uma vez que, devido à ocorrência de diversas colisões do átomo do alvo no caminho até atingir o substrato, a incidência ocorre em ângulos aleatórios. A técnica também resulta em boa aderência ao substrato, uma vez que os átomos são ejetados do alvo tipicamente a 10 - $100 \mathrm{eV}^{[32]}$.

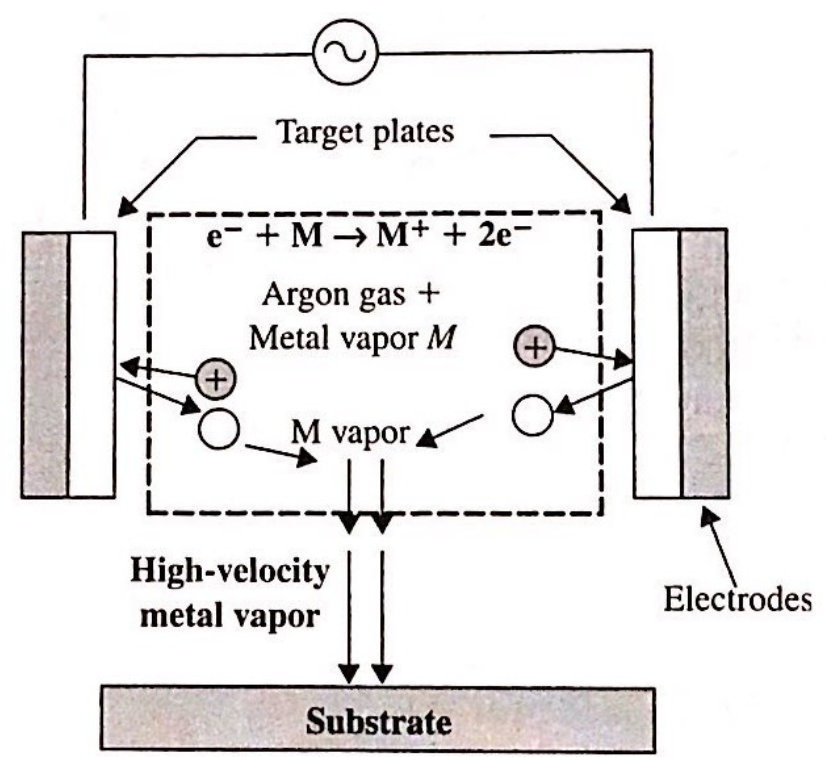

Figura 1.6: Esquema de um reator de sputtering ${ }^{[31]}$.

\section{CVD Chemical Vapor Deposition}

No processo de deposição química de vapor CVD, uma reação química ocorre na superfície do substrato ou nas suas proximidades. Reagentes na forma gasosa são introduzidos no reator e, em temperaturas mais elevadas que no sputtering (acima de $300^{\circ} \mathrm{C}$ ), parti- 
cipam da reação química que proverá a formação do filme sobre o substrato. Diversas configurações foram desenvolvidas para este processo, tais como: APCVD (Atmosferic Pressure Chemical Vapor Deposition), LPCVD (Low Pressure Chemical Vapor Deposition), PECVD (Plasma-Enhanced Chemical Vapor Deposition) e HDPCVD (High Density Plasma Chemical Vapor Deposition) ${ }^{[2,32]}$.

O PECVD apresenta algumas vantagens em relação a outras técnicas. O substrato é mantido em torno de $300-400^{\circ} \mathrm{C}$, temperatura menor em relação ao LPCVD (acima de $500^{\circ} \mathrm{C}$ ), apresenta alta taxa de deposição, boa adesão e boa cobertura de degraus do substrato $^{[32]}$. Na produção do nitreto de silício amorfo não estequiométrico (a-Si ${ }_{x} \mathrm{~N}_{y}$ ) em PECVD pode-se utilizar os gases silano $\left(\mathrm{SiH}_{4}\right)$ e óxido nitroso $\left(\mathrm{N}_{2} \mathrm{O}\right)$ como reagentes. Diversos trabalhos mostraram que a utilização do gás nitrogênio $\left(\mathrm{N}_{2}\right)$ pode melhorar a qualidade do filme obtido ${ }^{[28,33]}$. Na produção do carbeto de silício amorfo pode-se utilizar como reagentes o silano e o metano $\left(\mathrm{CH}_{4}\right)$. Observa-se que a utilização do gás hidrogênio $\left(\mathrm{H}_{2}\right)$ também contribui para uma melhor estequiometria do carbeto produzido $^{[19,20]}$.

\subsubsection{Fotolitografia}

A fotolitografia é a técnica utilizada para transferir uma cópia de um padrão principal para a superfície de um material. Tal técnica é largamente utilizada pela indústria na fabricação de circuitos integrados e seu sucesso foi aplicado também aos MEMS/MOEMS. A figura 1.7 exibe as principais etapas desse processo. Neste exemplo, um substrato de silício com um filme de óxido de silício $\left(\mathrm{SiO}_{2}\right)$ é coberto com uma fina camada de $1 \mu \mathrm{m}$ de fotorresiste (nesse caso do tipo negativo). Com o auxílio de uma máscara contendo o padrão que se deseja transferir, a região da amostra que não estiver coberta pelo padrão recebe radiação, endurecendo o resiste. Após o enxágue com uma solução reveladora, o resiste não atingido pela radiação é removido, deixando na placa o negativo do padrão contido na máscara. O conjunto é colocado em solução adequada para corroer o óxido 
(tipicamente $\mathrm{HF}$ e $\mathrm{NH}_{4} \mathrm{~F}$ ), apenas na região não protegida pelo resiste endurecido. $\mathrm{O}$ resiste é então removido por alguma solução que não ataca o óxido (ácidos, solventes orgânicos, soluções alcalinas ou acetona) ${ }^{[32]}$. O resultado é uma camada de $\mathrm{SiO}_{2}$ com o negativo do padrão da máscara.

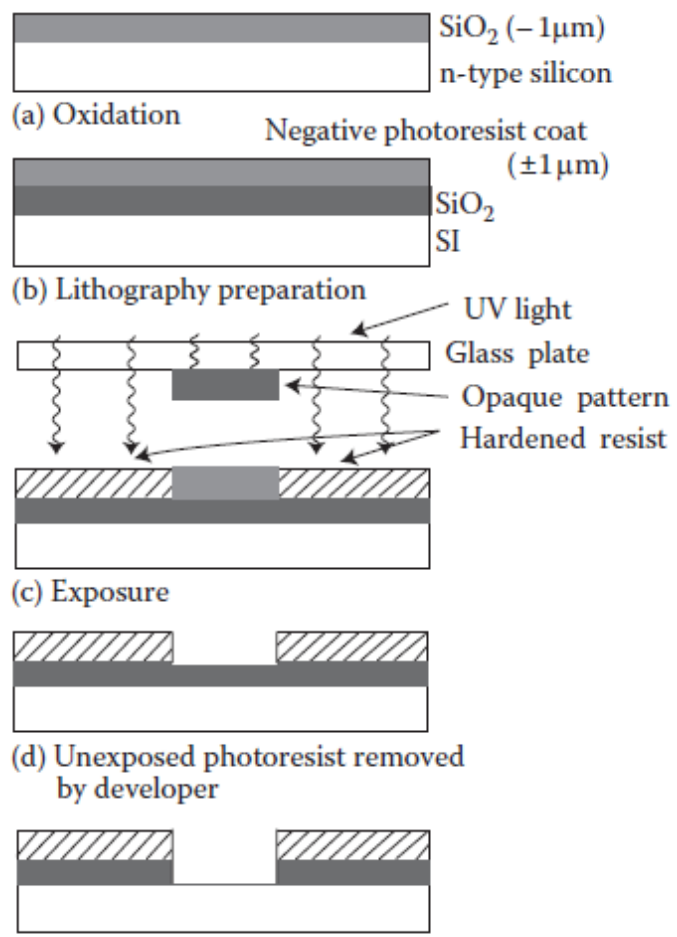

(e) $\mathrm{SiO}_{2}$ etched with $\mathrm{NH}_{4} \mathrm{~F}+\mathrm{HF}$

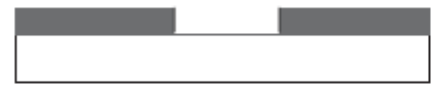

(f) Exposed photoresist removed

Figura 1.7: Principais etapas da fotolitografia (adaptado de ${ }^{[29]}$ ).

Uma etapa de grande importância é a preparação da máscara, pois a sua qualidade reflete no padrão a ser transferido ao filme. Ela é constituída por uma placa transparente à radiação (tipicamente quartzo ou vidro) com o padrão feito de uma fina camada metálica opaca. Ao ser colocada sobre a superfície revestida pelo resiste, a radiação incidente sobre a máscara atravessa apenas a região transparente, modificando a estrutura molecular do resiste logo abaixo dela ${ }^{[32]}$. O processo de impressão pode 
ser por proximidade ou projeção, conforme mostrado na figura 1.8. No processo por proximidade, as máscaras são colocadas em contato direto ou muito próximas (10 a $50 \mu m$ acima) da superfície a ser litografada. Esse método pode produzir defeitos na máscara durante o manuseio, mas é inadequado para aplicações em regiões extensas. No processo por projeção, a máscara permanece longe do filme a ser litografado e uma imagem da máscara é produzida sobre a superfície desejada através de um sistema de lentes de alta resolução. A imagem pode ser reduzida em até dez vezes, de forma que a máscara pode ser fabricada em dimensões maiores que o padrão desejado, facilitando o processo $^{[2,32]}$. É importante mencionar que deve ser previsto um sistema de alinhamento da máscara com o material a ser processado que, em geral, é feito com o auxílio de um microscópio óptico.

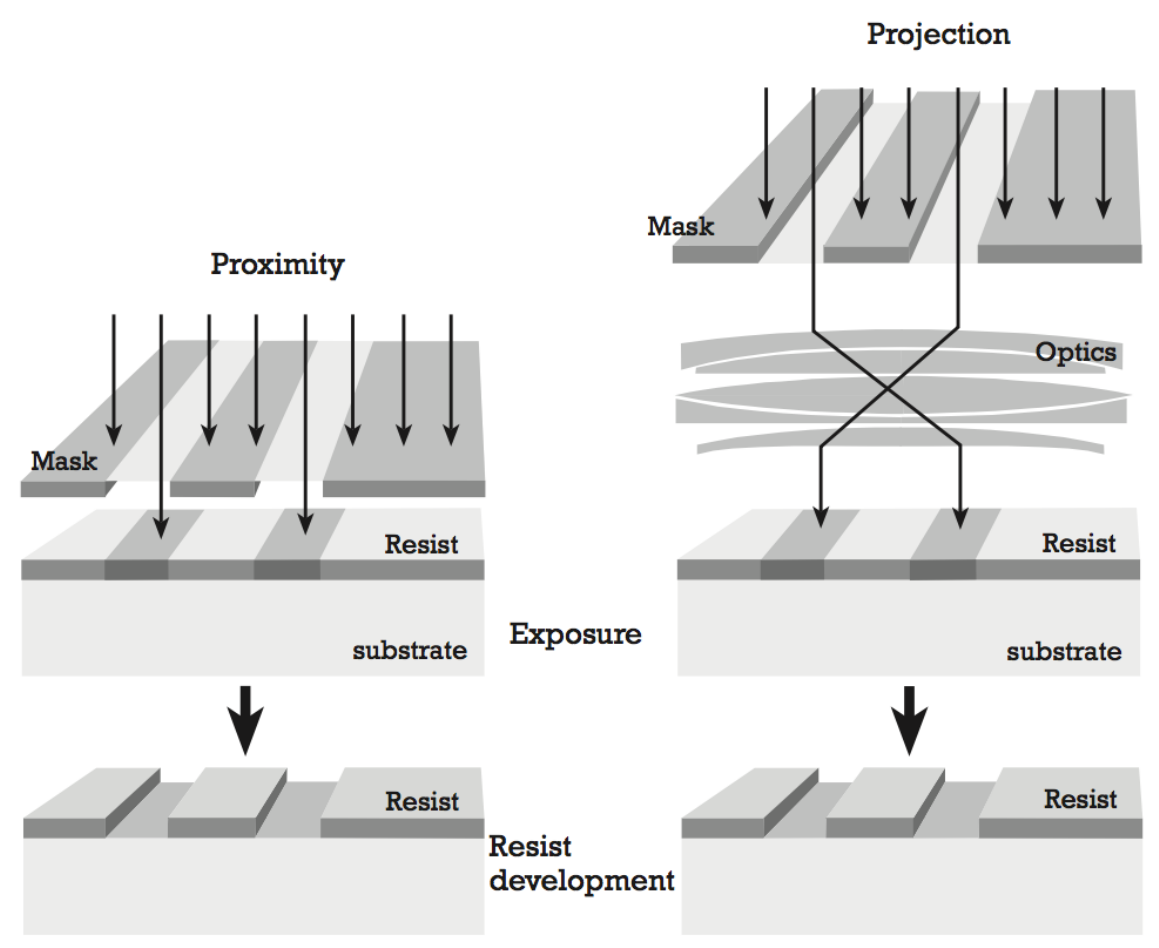

Figura 1.8: Sistemas de impressão da máscara em fotolitografia. Na esquerda a impressão por proximidade e na direita por projeção, utilizando um sistema óptico ${ }^{[2]}$.

O resiste é constituído de um polímero, sensibilizador e solvente. A estrutura do 
polímero é modificada quando em contato com a radiação. O solvente permite aplicar uma fina camada do resiste (da ordem de $\approx 5 \mu \mathrm{m}$ ) sobre o material utilizando uma centrífuga (spin coating) e o sensibilizador controla as reações fotoquímicas. A uniformidade da camada do resiste é essencial para obter um elevado padrão de qualidade. Após essa etapa, o material é aquecido por alguns minutos para remover o solvente residual e promover a adesão do resiste. Os fotorresistes podem ser do tipo positivo ou negativo. O resiste é positivo quando a exposição à radiação o torna mais solúvel ao revelador, enquanto que o resiste negativo torna-se mais resistente. Como mostrado na figura 1.9, o resultado após a corrosão do filme protegido pelo resiste é diferente em cada caso. Para o resiste positivo, o próprio padrão da máscara é obtido. Já, com o resiste negativo, o resultado é o negativo do padrão da máscara ${ }^{[2,32]}$.

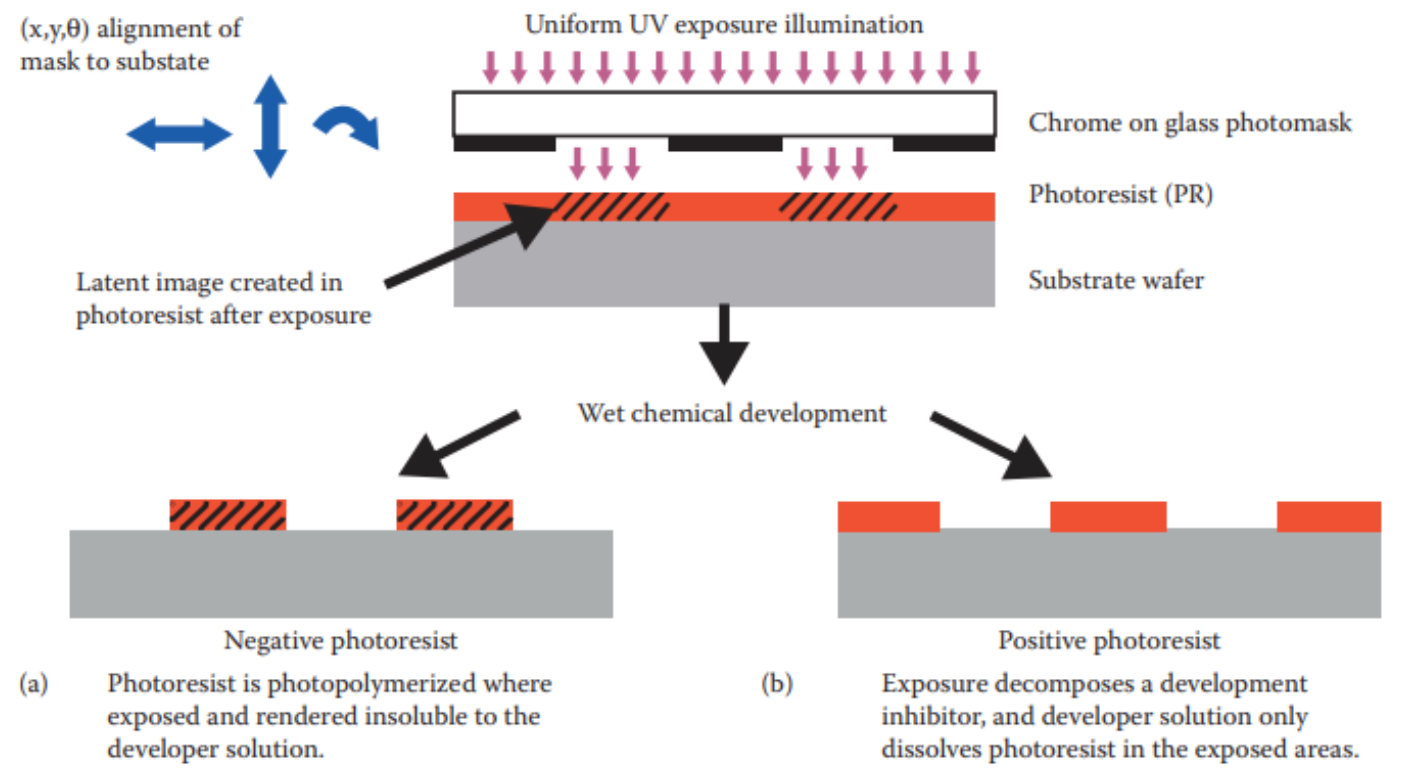

Figura 1.9: Diferença entre os resultados obtidos com o resiste positivo e negativo ${ }^{[29]}$.

Uma etapa que requer atenção é a chamada lift off, representada na figura 1.10. Considere a situação em que se pretende depositar um filme com um padrão relacionado com o desenho da máscara. Após a deposição do material, utiliza-se um solvente para remover o resiste, arrancando também o filme crescido sobre ele. Para que essa etapa de 
lift off seja realizada com sucesso, deve haver descontinuidades no material depositado, de forma que o solvente possa penetrar pelas paredes do resiste, o que é obtido mais facilmente com técnicas de deposição direcionais como a evaporação ${ }^{[29]}$.
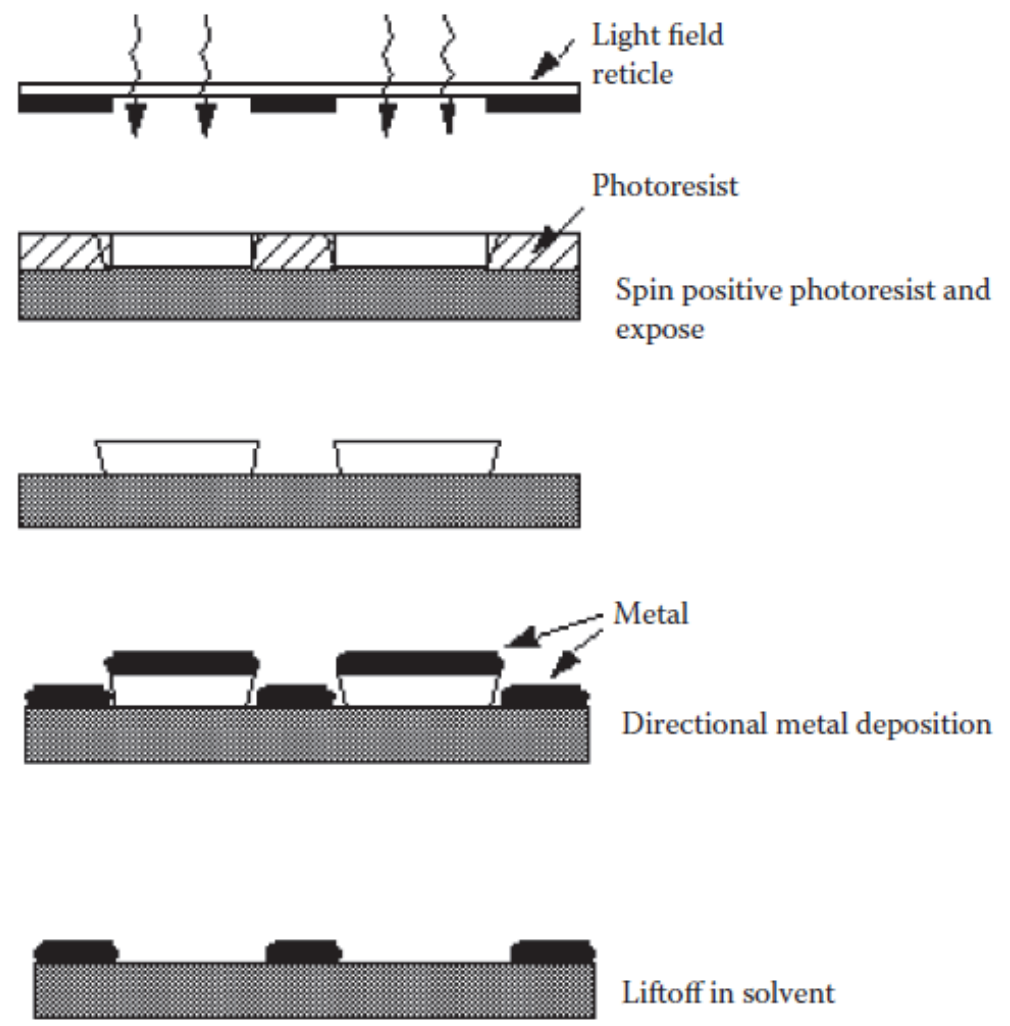

Figura 1.10: Representação da etapa de lift off ${ }^{[29]}$.

\subsubsection{Técnicas de Corrosão}

Após a litografia, os dispositivos, em geral, são submetidos a um processo de corrosão. A corrosão pode ser entendida como a transferência de um padrão por um processo físico ou químico de remoção de material de um filme ou substrato ${ }^{[32]}$. Diversas técnicas de corrosão foram criadas durante o desenvolvimento da microeletrônica nos processos de fabricação de circuitos integrados, bem como na fabricação de MEMS/MOEMS. 
Os processos de corrosão podem ser secos, quando ocorrem em fase gasosa (plasma), ou úmidos, quando ocorrem em fase líquida. Diversos processos foram desenvolvidos para a corrosão do Si com diferentes aplicações e resultados. A corrosão isotrópica ocorre uniformemente em todas as direções, resultando em uma cavidade arredondada. Corrosão anisotrópica atua, preferencialmente, em uma direção cristalográfica do Si, resultando em cavidades definidas por superfícies planas (figura 1.11) ${ }^{[2]}$.

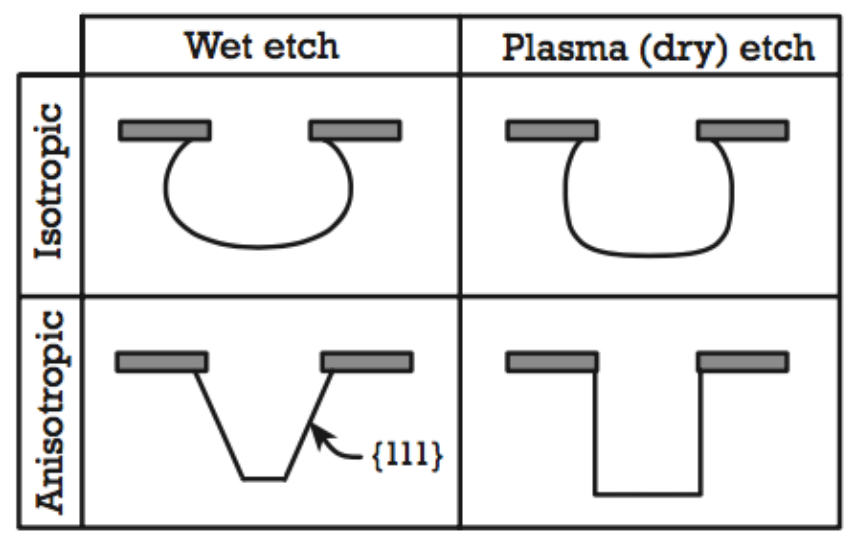

Figura 1.11: Perfis resultantes da corrosão isotrópica e anisotrópica úmida e seca ${ }^{[2]}$.

\section{Corrosão anisotrópica úmida}

Um dos processos de corrosão úmida anisotrópica mais comuns utiliza o hidróxido de potássio $(\mathrm{KOH})$, que corrói planos $\{111\}$ a uma taxa 100 vezes menor que corrói planos $\{100\}$, produzindo cavidades em forma de $\mathrm{V}^{[2,34]}$, conforme mostra a figura 1.12. A taxa de corrosão do Si em KOH é cerca de 0,5 a $2 \mu \mathrm{m} / \mathrm{min}$, enquanto que no nitreto de silício é 1000 vezes menor, podendo este último ser usado como máscara contra a corrosão de $\mathrm{KOH}^{[2]}$. Etilenodiamina-pirocatecol (EDP) e hidróxido de tetrametilamônio (TMAH) são soluções também utilizadas para a corrosão úmida anisotrópica do Si. Maiores detalhes sobre o desempenho e as características desses corrosivos e outros podem ser encontrados na literatura ${ }^{[32,35]}$. 

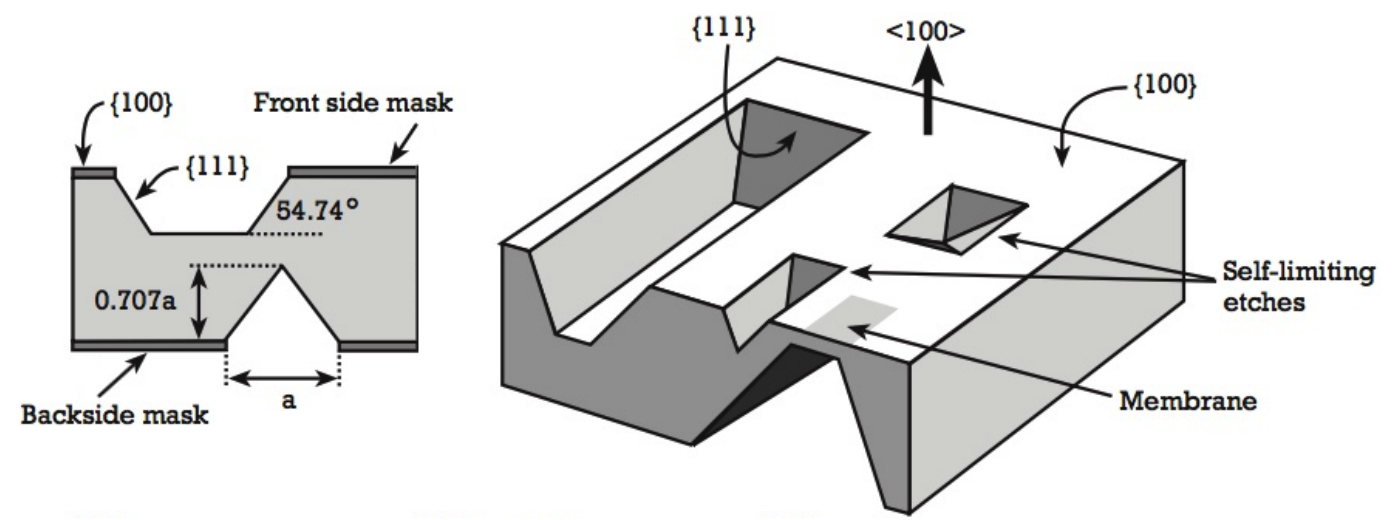

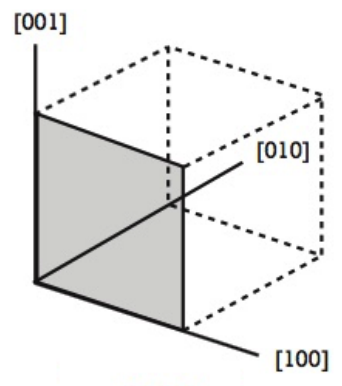

(100)

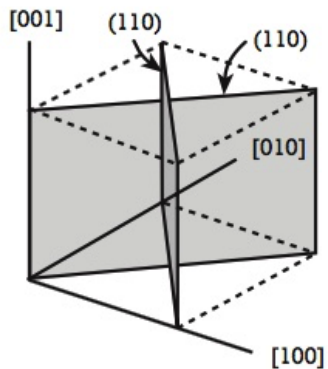

(110)

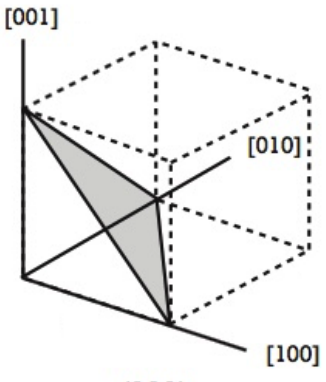

(111)

Figura 1.12: (acima) Alguns formatos obtidos com a corrosão anisotrópica em Si $\{100\}$. (abaixo) Planos (100), (110) e (111) na estrutura cúbica do Si (adaptado de ${ }^{[2]}$ ).

\section{Corrosão seca}

O processo de corrosão seca é aquele em que o material do substrato é removido sem o uso de agentes químicos. Nele, é possível obter elevada anisotropia e menor contaminação no material corroído. A corrosão seca utiliza-se de diferentes métodos para a remoção de material, recebendo as denominações sputtering, corrosão por plasma ou RIE (Reactive Ion Etching) ${ }^{[29]}$. A figura 1.13 mostra o perfil obtido por esses métodos.

Na corrosão por sputtering, íons acelerados do plasma removem átomos da superfície do substrato por transferência de momento durante a colisão. O processo é puramente físico e, portanto, pouco seletivo, ou seja, a taxa de corrosão é semelhante para todos os materiais presentes na camada a ser processada. A corrosão é anisotrópica, pois ocorre na direção do campo elétrico que acelera os íons. O argônio é o íon mais utilizado nos 
1.3. Propriedades dos materiais empregados como camada de proteção nas

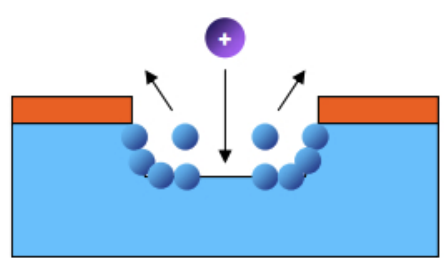

(a) sputtering

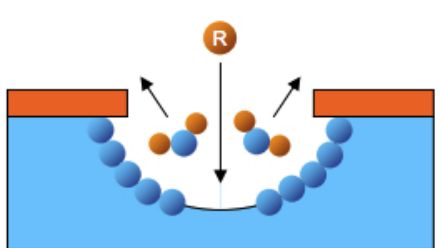

(b) plasma etching

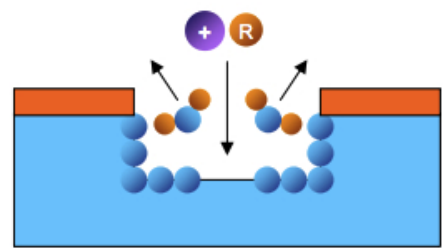

(c) Reactive Ion Etching

(RIE)

Figura 1.13: Perfil obtido com os diferentes tipos de corrosão seca. (a) perfil, preferencialmente anisotrópico, obtido com a colisão dos íons no processo de sputtering. (b) perfil isotrópico, obtido com a corrosão química no processo de corrosão por plasma. (c) Combinação dos processos de sputtering e plasma na corrosão por RIE, produzindo um perfil altamente anisotrópico ${ }^{[36]}$.

plasmas por ser pouco reativo quimicamente. Na corrosão por plasma, reações químicas ocorrem entre os radicais do plasma (geralmente de cloro e flúor) e o substrato, formando produtos voláteis. A corrosão por plasma é seletiva, pois é fortemente influenciada pela reatividade dos materiais presentes no substrato. Por não haver uma direção preferencial a corrosão tem caráter isotrópico. O processo RIE (Reactive Ion Etching) promove a remoção do material, combinando os efeitos da colisão física (sputtering), e as reações químicas na superfície (corrosão por plasma). O resultado é uma corrosão de elevada anisotropia e boa seletividade.

\subsection{Propriedades dos materiais empregados como camada de proteção nas microlâmpadas}

Nesta seção será apresentada uma breve descrição dos materiais empregados como camada de proteção nas microlâmpadas. As informações a seguir não têm o objetivo de fornecer uma descrição detalhada, tampouco completa, das inúmeras propriedades desses materiais amplamente estudados pela comunidade científica. O propósito é dar subsídios às análises descritas nos capítulos posteriores. Maiores detalhes podem ser obtidos nas referências mencionadas ao longo desta seção. 


\subsubsection{Carbeto de silício - SiC}

As primeiras utilizações industriais do $\mathrm{SiC}$, devido às suas propriedades mecânicas, foram como material para corte e polimento. Hoje, o carbeto de silício é um material que encontra aplicações em dispositivos microeletrônicos, células solares, guias de onda, sensores e em sistemas de potência ${ }^{[21,37]}$. O SiC é conhecido pelas suas excelentes propriedades. Tem elevada dureza, é quimicamente inerte, possui boa estabilidade térmica e qualidades interessantes como material semicondutor. Tais propriedades fazem com que seja um material promissor para utilização na eletrônica de alta potência e alta temperatura.

\section{Carbeto de silício cristalino}

O carbeto de silício pode cristalizar em diversas fases diferentes. Os átomos de $\mathrm{Si}$ e C são tetravalentes e formam ligações covalentes. No cristal, cada átomo de Si tem 4 átomos de $\mathrm{C}$ vizinhos e vice-versa. Já o comprimento das ligações é sempre em torno de $1,89 \AA^{[38]}$. A diferença entre as fases do SiC está na forma como os átomos da estrutura hexagonal close-packed são empilhados ao longo do eixo c. A figura 1.14 apresenta alguns dos tipos mais comuns, juntamente com seus parâmetros de rede. As fases mais estáveis e, consequentemente mais estudadas, são o 4H-SiC e o 6H-SiC. As fases 3C-SiC e 15R-SiC também encontram destaque nas pesquisas científicas.

\section{Filmes de carbeto de silício amorfo hidrogenado}

As principais técnicas de produção de filmes de carbeto de silício são sputtering e PECVD. Diversos estudos têm sido realizados buscando correlacionar a estrutura obtida com as condições de deposição e tratamento térmico. Choi relata resultados contraditórios na literatura quanto às estruturas obtidas ${ }^{[39]}$. No PECVD, por exemplo, é comum utilizar os gases silano $\left(\mathrm{SiH}_{4}\right)$, metano $\left(\mathrm{CH}_{4}\right)$ e hidrogênio $\left(\mathrm{H}_{2}\right)$ para obter filmes densos de a-Si ${ }_{1-x} \mathrm{C}_{x}: \mathrm{H}$ com boas propriedades ópticas e mecânicas ${ }^{[19,20]}$. A figura 1.15 mostra 


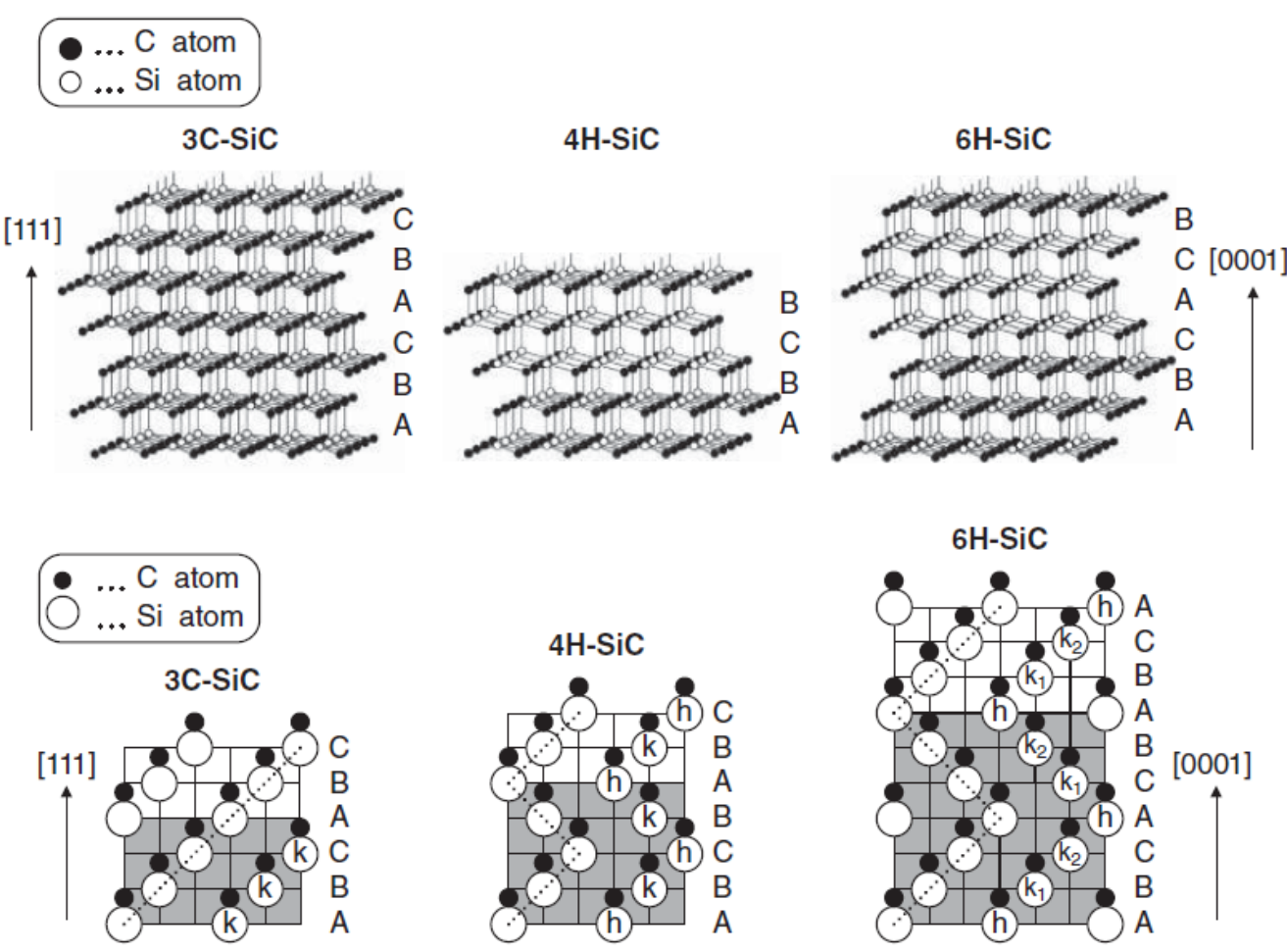

\begin{tabular}{lll}
\hline Polytype & $a(\AA)$ & $c(\AA)$ \\
\hline $3 \mathrm{C}$ & 4.3596 & - \\
$4 \mathrm{H}$ & 3.0798 & 10.0820 \\
$6 \mathrm{H}$ & 3.0805 & 15.1151 \\
\hline
\end{tabular}

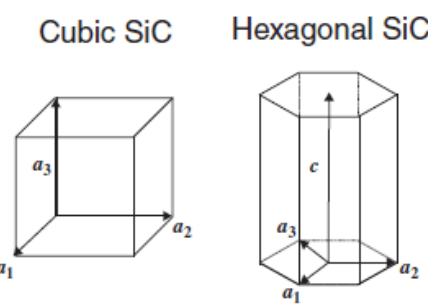

Figura 1.14: Algumas das principais estruturas cristalinas do SiC. As diferentes formas de empilhamento dos sítios A, B e C da estrutura hexagonal close-packed correspondem aos vários politipos: $3 \mathrm{C}-\mathrm{SiC}$ (repetição dos planos $\mathrm{ABC}$ ), $4 \mathrm{H}-\mathrm{SiC}$ (repetição dos planos $\mathrm{ABCB}$ ) e $6 \mathrm{H}-\mathrm{SiC}$ (repetição dos planos $\mathrm{ABCACB}$ ) (adaptado de ${ }^{[38]}$ ). 
alguns dos inúmeros resultados da literatura sobre a estrutura do a-Si $\mathrm{Si}_{1-x} \mathrm{C}_{x}: \mathrm{H}$. Medidas de FTIR e deslocamento Raman mostram como materiais com quantidades diferentes de ligações Si-Si, Si-C e Si-H, podem ser obtidos.

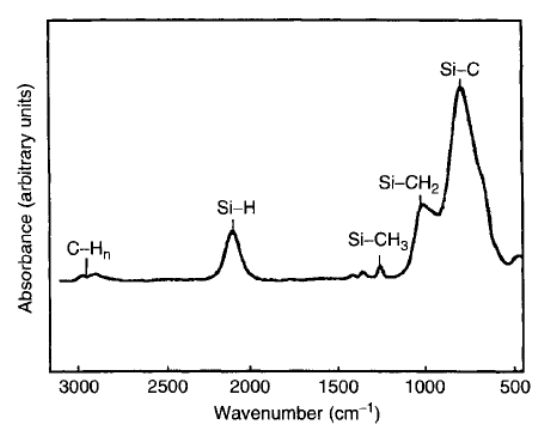

(a)

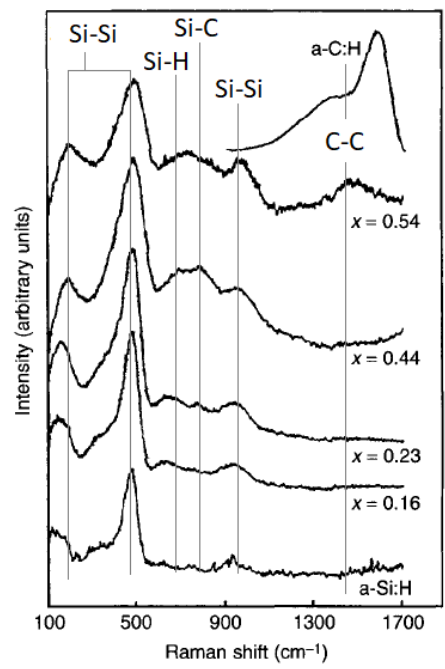

(c)

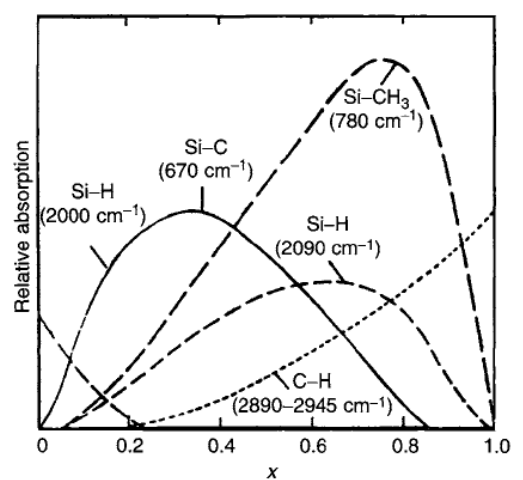

(b)
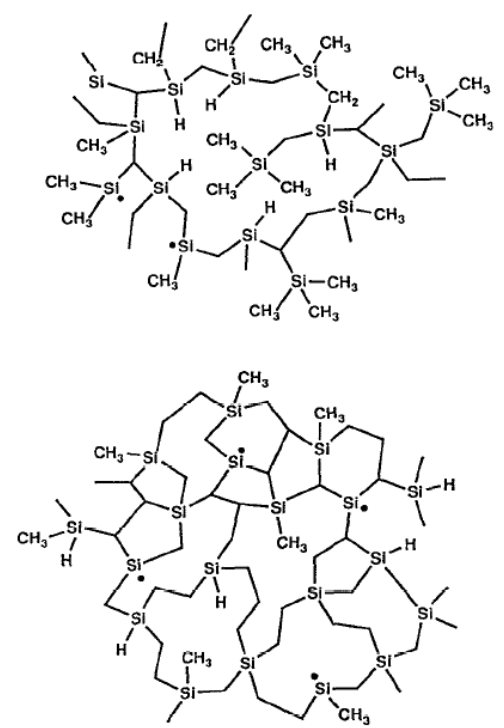

(d)

Figura 1.15: Alguns resultados da literatura do a-Si ${ }_{1-x} \mathrm{C}_{x}: \mathrm{H}$. Em (a) um espectro FTIR típico ${ }^{[22]}$, em (b) as intensidades relativas das bandas de absorção IR em função de $x^{[40]}$, em (c) medidas de deslocamento Raman ${ }^{[41]}$ e em (d) dois modelos de estrutura propostos para condições específicas de deposição ${ }^{[42]}$.

A condutividade térmica de filmes de $\mathrm{SiC}$ amorfo é consideravelmente menor que 
1.3. Propriedades dos materiais empregados como camada de proteção nas

a do material cristalino em volume. Em temperatura ambiente, a condutividade do material cristalino foi reportada em $330-490 \mathrm{~W} / \mathrm{m} . \mathrm{K}$, enquanto que, para os filmes amorfos foi de $1,7-160 \mathrm{~W} / \mathrm{m} \cdot \mathrm{K}^{[38,43]}$.

\subsubsection{Nitreto de alumínio - AIN}

O nitreto de alumínio é um semicondutor de grande interesse científico por apresentar características adequadas para diversas aplicações tecnológicas. As suas propriedades optoeletrônicas permitem o emprego em LEDs, sensores, atuadores e MEMS ${ }^{[44]}$. O AlN possui condutividade térmica na faixa de $180-260 \mathrm{~W} / \mathrm{m} . \mathrm{K}$ e apresenta também elevada dureza, alta estabilidade térmica, e sua oxidação em ar se inicia apenas a $1200 \mathrm{~K}^{[45-47]}$. Nano estruturas de AlN também têm sido objeto de diversos estudos científicos ${ }^{[48]}$. O nitreto de alumínio cristaliza em três fases (figura 1.16). A fase estável é a hexagonal wurtzita, enquanto que a fase cúbica zinc blende é meta-estável. A transição para a fase rock salt, quando em materiais em volume, ocorre em altas pressões, permanecendo até a pressão atmosférica, quando esta é removida ${ }^{[45,49,50]}$. A fase rock salt foi reportada também em nanoestruturas ${ }^{[51,52]}$. Diversos estudos sobre filmes de AlN estão disponíveis na literatura. Nas deposições por sputtering, dependendo das condições, a estrutura obtida pode ser amorfa ou wurtzita ${ }^{[23,53]}$. A fase zinc blende estável foi obtida em filmes muito finos $(1,5-2,0 \mathrm{~nm})^{[45]}$, e a rock salt foi estabilizada em filmes crescidos epitaxialmente em condições especiais ${ }^{[54]}$.

\subsubsection{Dióxido de titânio $-\mathrm{TiO}_{2}$}

O dióxido de titânio é um material que apresenta interessantes propriedades elétricas, magnéticas, catalíticas e eletroquímicas. Elas possibilitam aplicações nas áreas de fotocatálise, sensores, guias de ondas e células solares. Estudos revelam que a condutividade térmica do material é relativamente baixa, com valores de 5,0 a $15 \mathrm{~W} / \mathrm{m} . K$, dependendo da fase e da temperatura ${ }^{[55,56]}$. O $\mathrm{TiO}_{2}$ possui também elevado índice de refração, boa 


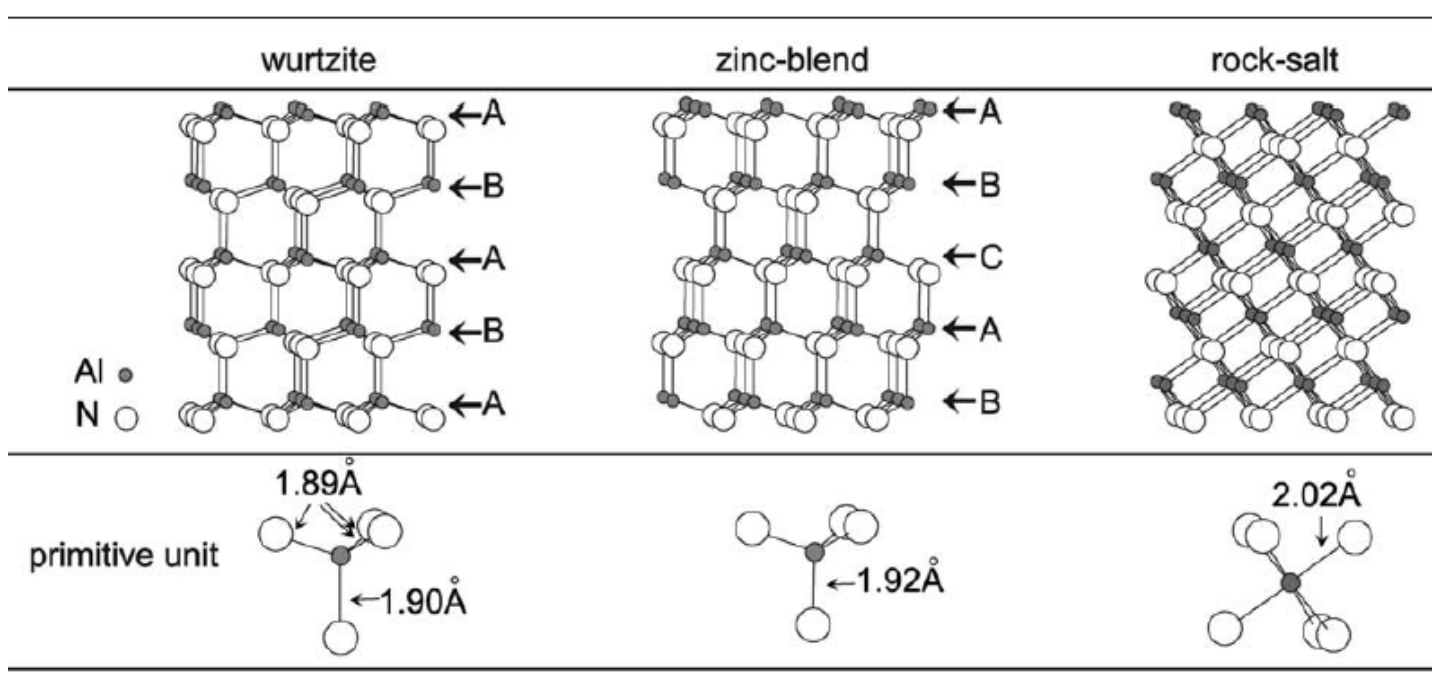

Figura 1.16: As fases do nitreto de alumínio ${ }^{[49]}$.

estabilidade química e é resistente à corrosão ${ }^{[21,24,25,57,58]}$. As três fases mais comuns do dióxido de titânio são rutilo, anatase e brookite (figura 1.17). Rutilo é estável e é a estrutura geralmente obtida no crescimento de cristais e de filmes ${ }^{[59]}$. As fases anatase e brookite são meta-estáveis ${ }^{[60]}$.

O processo de deposição por sputtering é bastante eficaz para a produção de filmes de $\mathrm{TiO}_{2}$. Apresenta alta reprodutibilidade e pode ser aplicado a substratos de grandes áreas com elevadas taxas de deposição. Os filmes produzidos podem ser amorfos ou cristalinos (rutilo ou anatase), dependendo das condições de deposição e de um eventual tratamento térmico ${ }^{[26,61-63]}$. As propriedades ópticas, resistividade, band gap e índice de refração dependem da estrutura obtida. Filmes, onde ambas as fases coexistem, podem também ser obtidos, condição esta que favorece aplicações em fotocatálise ${ }^{[61]}$.

\subsubsection{Oxinitreto de silício - $\mathrm{SiO}_{x} \mathrm{~N}_{y}$}

O oxinitreto de silício é um material com importantes propriedades eletrônicas e mecânicas. Apresenta fotoluminescência, alta durabilidade em elevadas temperaturas, alta resistência térmica e à oxidação. Por esse motivo encontra diversas aplicações, tais como 


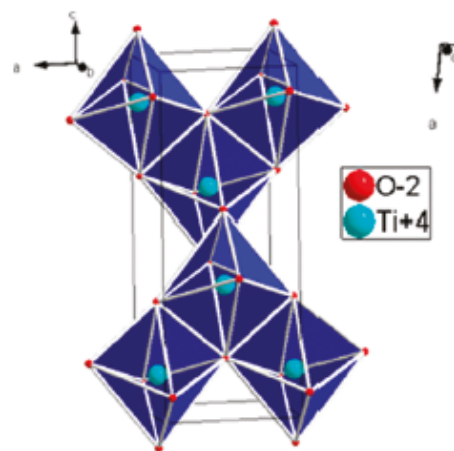

Anatase

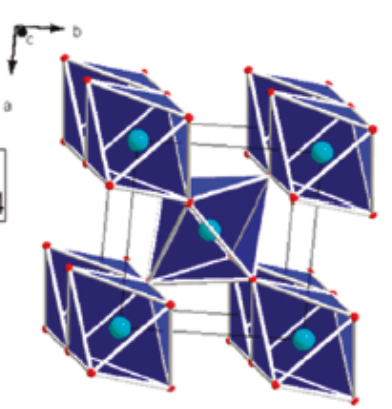

Rutile

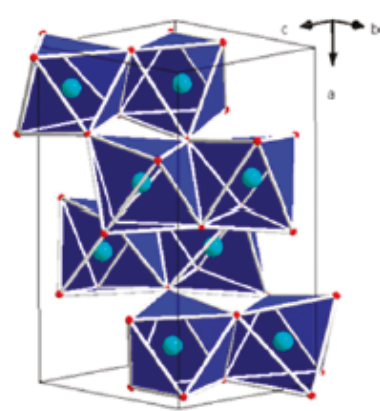

Brookite

\begin{tabular}{lccc}
\hline \multicolumn{4}{c}{ Crystal structure data of $\mathrm{TiO}_{2}}$. \\
\hline & Rutile & Anatase & Brookite \\
\hline Crystal structure & tetragonal & tetragonal & orthorhombic \\
Lattice constants $(\AA)$ & $a=4.5936$ & $a=3.784$ & $a=9.184$ \\
& $c=2.9587$ & $c=9.515$ & $b=5.447$ \\
& & & $c=5.145$ \\
Space group & $P 4_{2} / m n m$ & $I 4_{1} /$ amd & $P b c a$ \\
Molecule/cell & 2 & 4 & 8 \\
Volume/molecule $\left(\AA^{3}\right)$ & 31.2160 & 34.061 & 32.172 \\
Density $\left(\mathrm{g} / \mathrm{cm}^{3}\right)$ & 4.13 & 3.79 & 3.99 \\
$\mathrm{Ti}-\mathrm{O}$ bond length & $1.949(4)$ & $1.937(4)$ & $1.87 \sim 2.04$ \\
$(\AA)$ & $1.980(2)$ & $1.965(2)$ & \\
$\mathrm{O}-\mathrm{Ti}-\mathrm{O}$ bond angle & $81.2^{\circ}$ & $77.7^{\circ}$ & $77.0^{\circ} \sim 105^{\circ}$ \\
& $90.0^{\circ}$ & $92.6^{\circ}$ & \\
\hline \hline
\end{tabular}

Figura 1.17: As fases do óxido de titânio (adaptado das referências ${ }^{[59,60]}$ ).

circuitos integrados, guias de ondas e LEDs ${ }^{[21,64]}$.

$\mathrm{O} \mathrm{SiO}_{x} \mathrm{~N}_{y}$ pode ser interpretado como um material intermediário entre o $\mathrm{SiO}_{2}$ e $\mathrm{Si}_{3} \mathrm{~N}_{4}$, de forma que, modificando a sua composição química (fração de oxigênio e nitrogênio), é possível obter um material com as propriedades mais adequadas para cada aplicação (figura 1.18), tais como o índice de refração e a constante dielétrica. A condutividade térmica do material também está relacionada com a composição, ficando entre o valor atribuído ao $\mathrm{SiO}_{2}\left(0,8\right.$ a $\left.1,4 \mathrm{~W} / m \cdot K^{[65]}\right)$ e ao $\mathrm{Si}_{3} \mathrm{~N}_{4}\left(\right.$ de 25 a $\left.36 \mathrm{~W} / m \cdot K^{[66]}\right)$. Um dos métodos de crescimento de filmes de oxinitreto de silício é a deposição por 
PECVD $^{[33]}$. Alterando os parâmetros da deposição, bem como as condições de um eventual tratamento térmico, é possível ajustar a estequiometria do material e suas propriedades ópticas ${ }^{[27,28,67]}$ (figura 1.18).
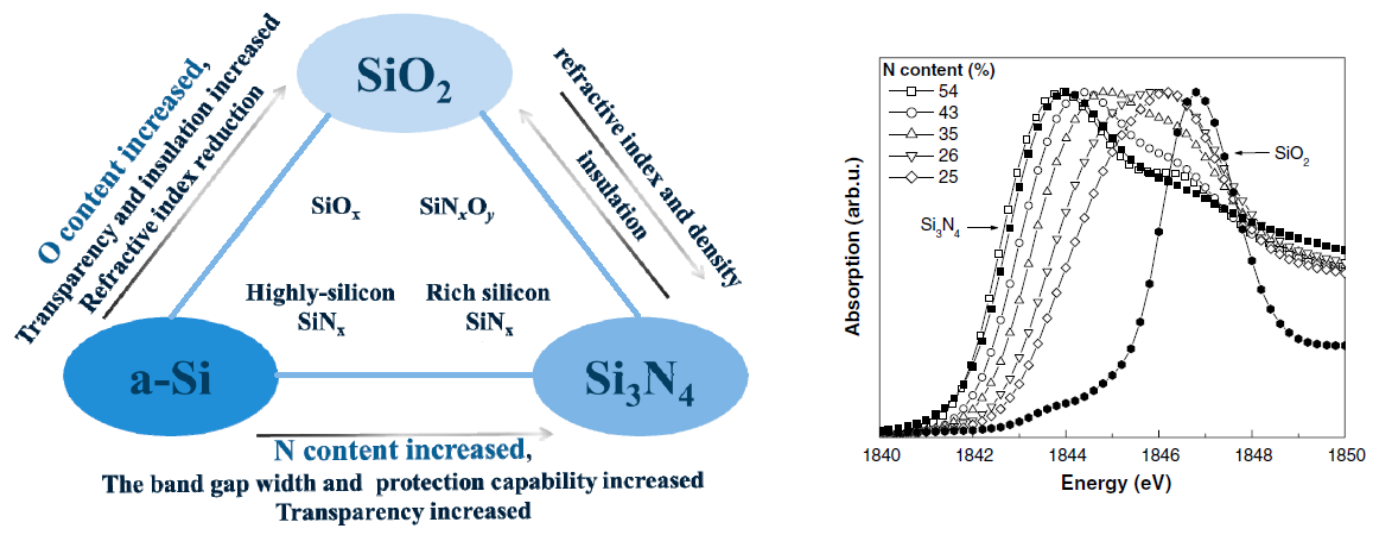

Figura 1.18: (esquerda) Diagrama esquemático da influência da composição química nas propriedades do $\mathrm{SiO}_{x} \mathrm{~N}_{y}{ }^{[64]}$. (direita) XANES da borda $\mathrm{K}$ do $\mathrm{Si}$ em função da composição, em comparação com padrões de $\mathrm{Si}_{3} \mathrm{~N}_{4}$ e $\mathrm{SiO}_{2}{ }^{[28]}$. Para maiores detalhes, vide referências indicadas. 


\section{Capítulo 2}

\section{Técnicas experimentais}

Esta tese foi baseada em análises por três técnicas experimentais: espectroscopia de absorção de raios X (XAS), fluorescência de raios X com incidência rasante (GIXRF) e espectroscopia por retroespalhamento de Rutherford (RBS). Esse capítulo apresenta uma introdução aos conceitos principais dessas técnicas.

\subsection{Espectroscopia de absorção de raios X (XAS)}

A espectroscopia de absorção de raios X (XAS) é uma técnica amplamente utilizada na análise de materiais. O espectro obtido experimentalmente é uma assinatura da amostra em estudo, pois é sensível à estrutura atômica e às propriedades eletrônicas e vibracionais do material ${ }^{[68,69]}$. A técnica pode ser aplicada a materiais cristalinos e amorfos, em filmes ou pó, sólidos ou em solução, condutores ou isolantes. Quando um feixe de raios X, de intensidade $I_{0}$, incide sobre uma amostra, parte do feixe é absorvido pelos átomos do material, de forma que o feixe transmitido tem sua intensidade reduzida para $I_{t}$ (figura 2.1). Segundo a lei de Beer-Lambert, a intensidade transmitida depende da espessura $t$ da amostra e do coeficiente de absorção linear $\mu(E)$ conforme a expressão,

$$
I_{t}(t)=I_{0} e^{-\mu(E) t}
$$



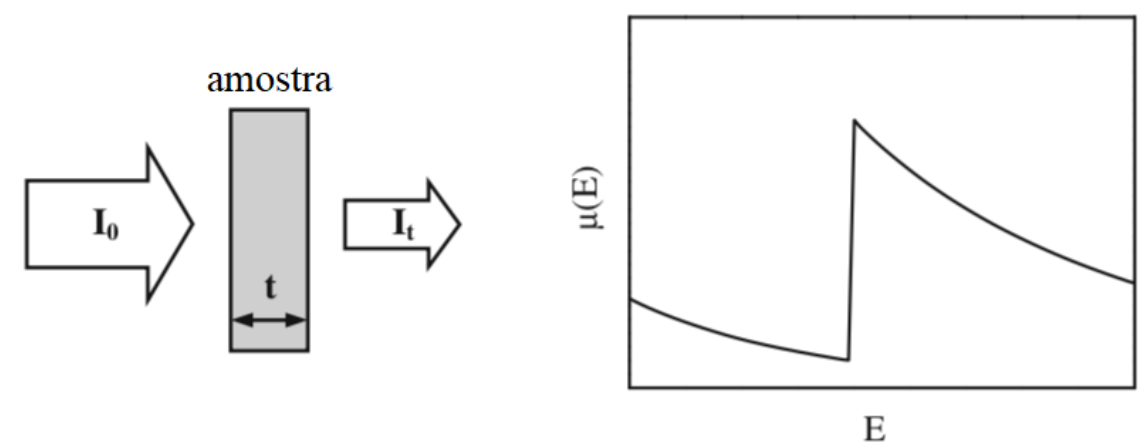

Figura 2.1: (esquerda) Esquema da absorção de raios X pela matéria. (direita) A variação do coeficiente de absorção $\mu(E)$ em função da energia do feixe incidente (adaptado de $\left.{ }^{[70]}\right)$.

Num experimento de absorção de raios X, a grandeza medida é, basicamente, o coeficiente de absorção $\mu(E)$ em função da energia $E$ dos fótons incidentes, resultando no espectro de absorção. De uma forma geral, conforme pode ser visto na figura 2.2 , a absorção dos fótons decresce com $E^{3}$. Quando a energia é suficiente para excitar um dos elétrons das camadas internas do átomo (figura interior de 2.2), o número de fótons absorvido aumenta significativamente, produzindo bordas acentuadas no espectro. Neste caso, o fóton é absorvido e um fotoelétron é ejetado, deixando uma vacância (buraco de caroço). Cerca de $10^{-15} s$ depois, um dos elétrons de camadas superiores decai, preenchendo a vacância. Tal processo resulta na emissão de um fóton (fluorescência) ou de um elétron (efeito Auger).

\subsubsection{Estrutura fina de absorção de raios X (XAFS)}

A figura 2.3 mostra um espectro de absorção típico obtido em um experimento de XAS. Se um elétron do orbital $n=1$ absorve um fóton, o salto no espectro é denominado borda K. O lado direito da figura 2.3 mostra a nomenclatura da borda quando o elétron inicialmente está nos demais níveis de energia. O conjunto de oscilações, que se iniciam imediatamente antes da borda (pré-borda) e vão até algumas centenas de eV após a borda, é denominado estrutura fina e está relacionado com a estrutura do material da 


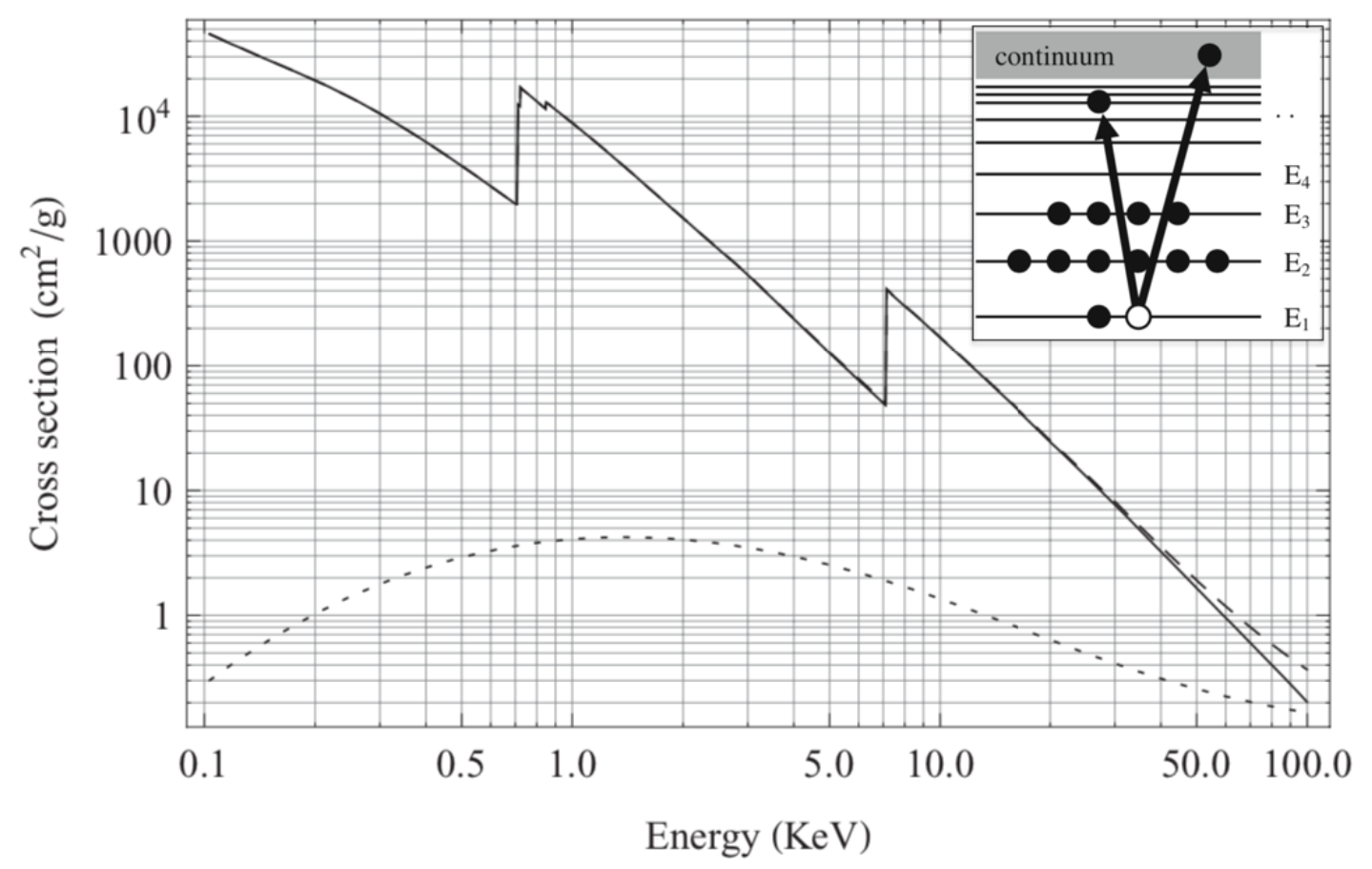

Figura 2.2: Seção de choque de absorção do Fe. As diferentes linhas representam: efeito fotoelétrico (contínua), espalhamento elástico e inelástico (pontilhada), total (tracejada) ${ }^{[69]}$. A figura interna mostra os níveis de energia da transição do elétron na absorção fotoelétrica.

amostra.

As regiões do espectro são apresentadas na figura 2.3. A região que vai da pré-borda até aproximadamente $50 \mathrm{eV}$ acima da borda é chamada de XANES (X-Ray Absorption Near-Edge Structure) ou NEXAFS (Near-Edge X-ray Absorption Fine Structure). Nela observam-se diversos picos de intensidade e largura variadas. A região que vai de $50 \mathrm{eV}$ acima da borda em diante é chamada de EXAFS (Extended X-Ray Absorption Fine Structure). Nela observam-se oscilações periódicas, cujo espaçamento, aumenta com a energia. Os principais aspectos físicos relacionados com o espectro de absorção de raios X estão apresentados no apêndice A. 

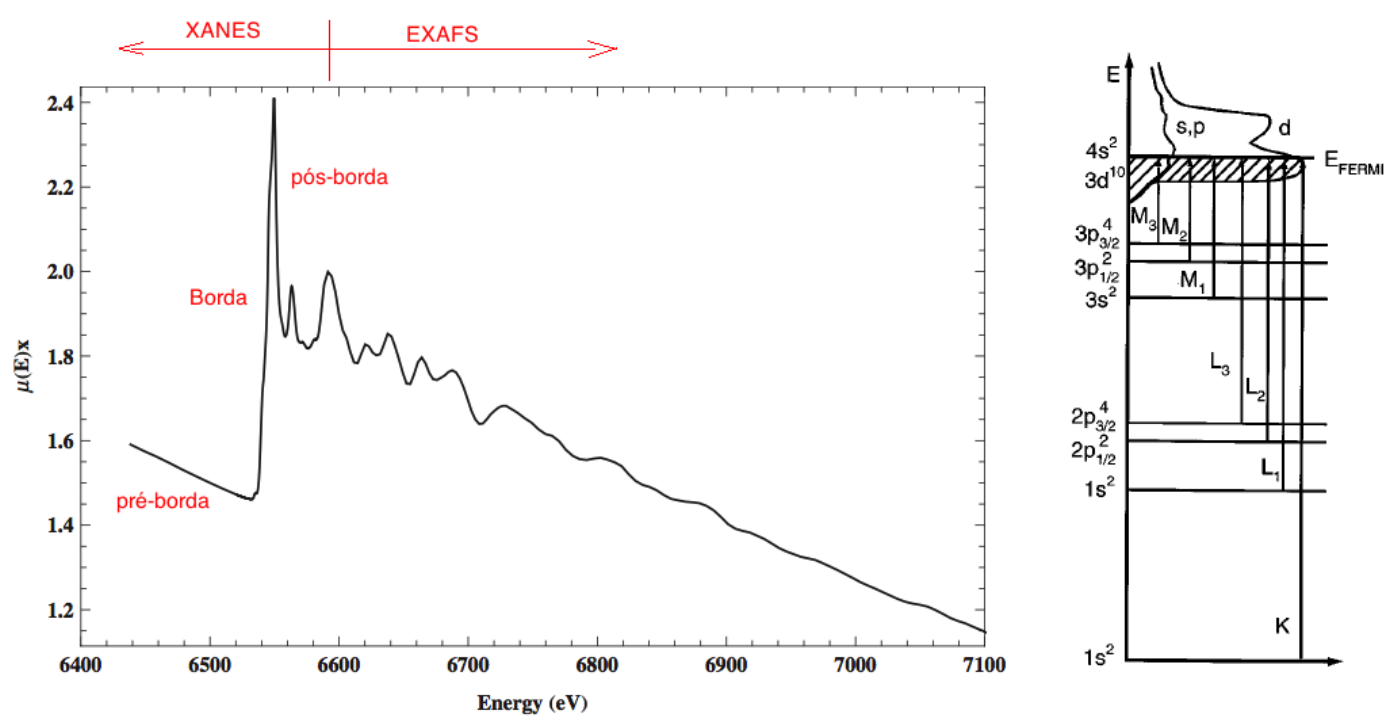

Figura 2.3: À esquerda, um espectro de absorção da borda K do MnO. As oscilações após a borda de absorção formam a chamada estrutura fina ${ }^{[69]}$. À direita, a nomenclatura adotada para as bordas de absorção e a relação com os níveis de energia ${ }^{[68]}$.

\subsubsection{Arranjo experimental típico}

Medidas de XAS são realizadas de forma eficiente em fontes de luz síncrotron, onde o feixe incidente é de alto brilho, para que as medidas possuam boa qualidade e resolução, e a energia dos fótons incidentes é continuamente aumentada, de modo a obter um espectro de absorção. Durante o experimento, a intensidade do feixe incidente sobre a amostra, $I_{0}$, é medida em câmaras de ionização. A absorção pode ser obtida de três modos diferentes (figura 2.4).

\section{Modo transmissão}

No modo transmissão, a grandeza medida é a intensidade do feixe de fótons que atravessam a amostra $I_{t}$. Para que o feixe não seja todo absorvido, medidas por transmissão devem ser realizadas em filmes finos, soluções ou gases. As amostras devem ser uniformes. Os fótons que não atravessam a amostra podem ter passado por diversos processos. 


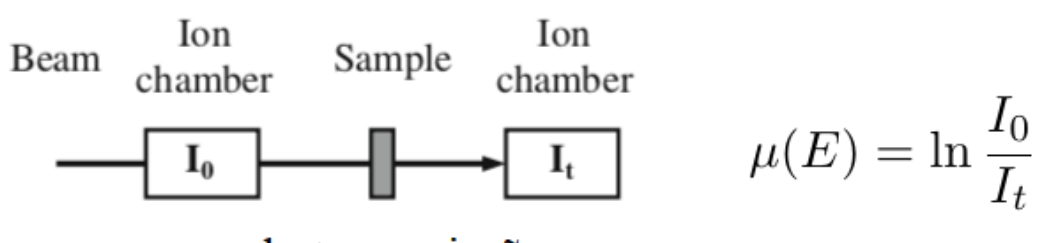

modo transmissão
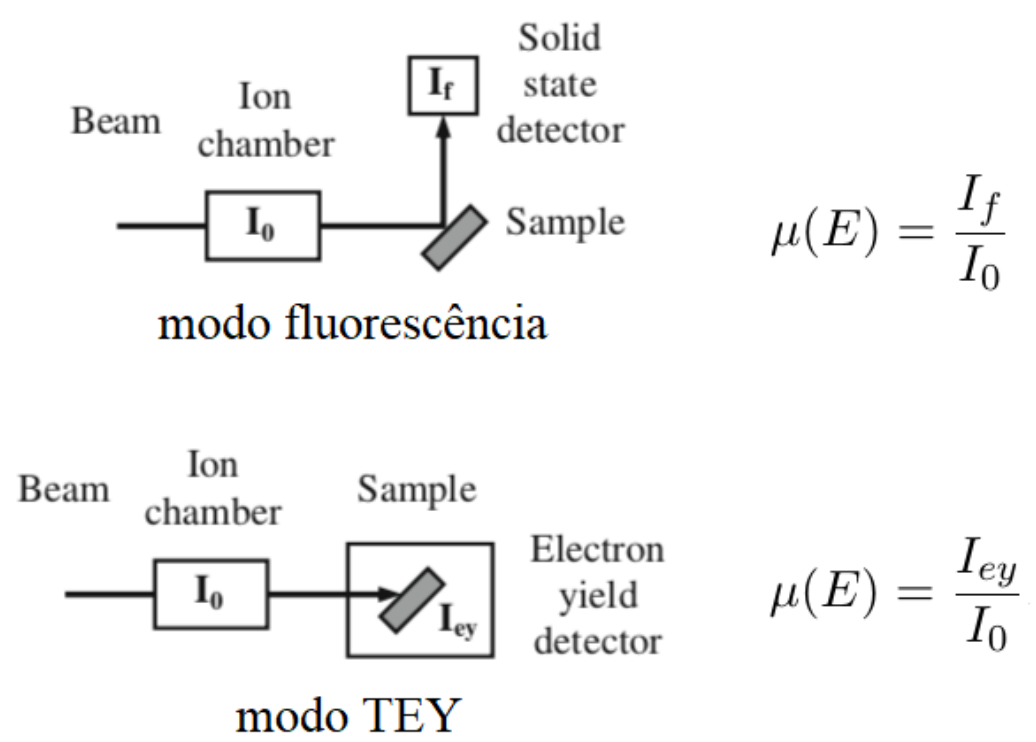

Figura 2.4: Diferentes formas de tomada de dados de absorção (adaptado de ${ }^{[70]}$ ).

Podem ter sofrido espalhamento elástico, inelástico, serem absorvidos por algum elemento que não seja de interesse ou até, ter sido espalhado pelo ar ao longo da trajetória. Tais processos podem prejudicar a medida, uma vez que o sinal desejado é apenas da absorção pelo elemento de interesse.

\section{Modo fluorescência}

Nos experimentos realizados no modo fluorescência, é medido o número de fótons emitidos quando a vacância é preenchida por um elétron do átomo absorvedor. Em amostras de elevada espessura e concentração, os problemas decorrentes dos efeitos de auto-absorção devem ser considerados. A vantagem de utilizar o modo fluorescência 
é a capacidade de avaliar amostras não homogêneas e diluídas. Em geral, este modo é indicado quando o elemento que deseja-se estudar está presente em concentrações atômicas menores que $\approx 1 \%$ na amostra.

\section{Modo TEY (Total Electron Yield)}

No modo TEY são medidos os elétrons Auger emitidos pela amostra. Na prática, quando o material não é isolante, utiliza-se um pico-amperímetro conectado entre a amostra e o terra, para medir a quantidade de elétrons que é reconduzida ao material quando o efeito Auger ocorre. O fato do livre caminho médio dos elétrons Auger ser da ordem de algumas dezenas de $n m^{[71,72]}$ faz com que esse modo de detecção seja sensível apenas à região superficial do material. Por exemplo, medidas na borda K do Si têm limite de detecção reportado em $70 \mathrm{~nm}$ no $\mathrm{SiO}_{2}{ }^{[72]}$. Medidas por TEY não são muito influenciadas pela inomogeneidade da amostra ou pela auto-absorção. Entretanto, efeitos de superfície, como oxidação, podem influenciar os resultados da medida $^{[73]}$. Esse método é especialmente interessante para filmes finos não isolantes, uma vez que a espessura do substrato impede a medição por transmissão.

\subsubsection{Tratamento dos dados de XAS}

As informações importantes no espectro de absorção são as oscilações presentes nas regiões da pré e pós-borda (incluindo a própria borda). Para que essas informações possam ser utilizadas, os dados brutos devem ser tratados. Alguns softwares estão disponíveis para auxiliar no processo de normalização e também na análise dos dados. Neste trabalho foram utilizados os programas ATHENA ${ }^{[74]}$ e WinXAS ${ }^{[75]}$.

Inicialmente, o espectro de absorção (ainda não normalizado) deve ser obtido fazendo

$\ln \frac{I_{0}}{I_{t}}$, quando as medidas foram tomadas por transmissão, ou simplesmente $\frac{I_{f}}{I_{0}}$ ou $\frac{I_{e y}}{I_{0}}$, quando foram tomadas por fluorescência ou TEY (figura 2.4). Para obter uma boa relação sinal ruído, frequentemente, várias tomadas de dados são realizadas para a 
mesma amostra. Após o alinhamento e a remoção de eventuais pontos descontínuos (glitches), é tomada a média das diferentes medidas, resultando num espectro semelhante ao exibido no lado esquerdo da figura 2.3.

\subsubsection{Remoção do contínuo (background) e normalização}

Abaixo segue uma descrição resumida do procedimento de normalização de um espectro XAS. Uma descrição mais detalhada pode ser encontrada no livro de Scott Calvin ${ }^{[73]}$ e no manual do ATHENA.

\section{Determinação experimental de $E_{0}$}

Primeiramente, a energia correspondente à borda de absorção, $E_{0}$, deve ser determinada. Valores tabelados estão disponíveis na literatura para substâncias puras. Entretanto, como $E_{0}$ depende da vizinhança do átomo absorvedor, é conveniente obtê-lo experimentalmente. $E_{0}$ corresponde à energia no ponto em que o espectro de absorção apresenta um aumento súbito. Logo, pode ser determinada pelo ponto de inflexão da borda, o que corresponde ao máximo da primeira derivada de $\mu(E)$ (figura 2.5).

\subsubsection{Normalização}

O espectro de absorção não normalizado depende de diversos fatores experimentais, tais como, concentração e espessura da amostra, ângulo sólido subtendido pelo detector e a configuração de filtros e colimadores. Para que os resultados possam ser comparados com outros trabalhos, o espectro deve ser normalizado. A figura 2.6 mostra um exemplo do procedimento de normalização. Uma reta é ajustada aos dados antes da borda (préborda) e um polinômio é ajustado com os dados após a borda (pós-borda). O salto da borda é a diferença entre a pós-borda e a pré-borda, exatamente sobre a borda $\left(E_{0}\right)$. Os dados do espectro não normalizado são divididos pelo valor do salto da borda e, posteriormente, os ajustes da pré-borda e pós-borda são subtraídos, resultando no 

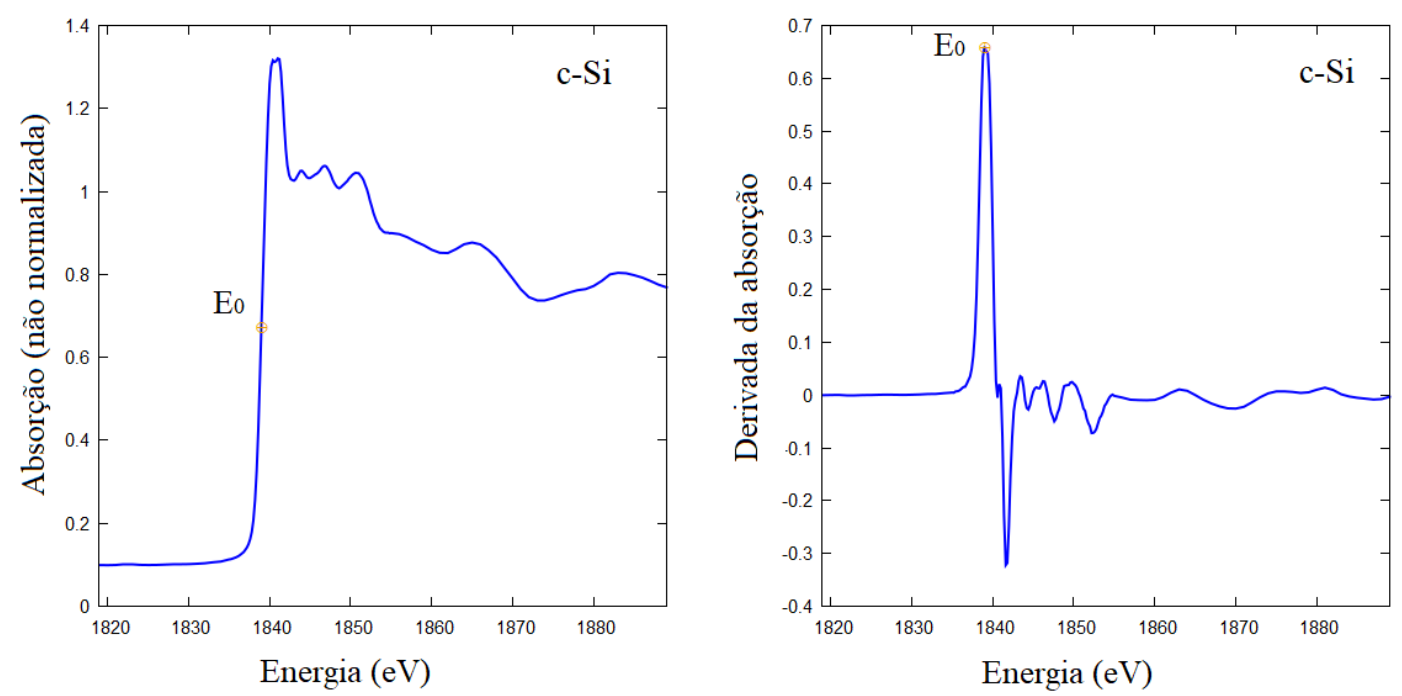

Figura 2.5: Exemplo da determinação experimental de $E_{0}$ pela primeira derivada de $\mu(E)$, para uma amostra de c-Si.

espectro normalizado. Se o objeto de estudo for a região XANES, os dados já estão prontos para análise.

\subsubsection{Remoção do contínuo}

Para a análise de EXAFS, os dados de interesse são apenas os da estrutura fina do espectro, ou seja, as rápidas oscilações do coeficiente de absorção $\mu(E)$ com a energia. $\mu(E)$ pode ser interpretado como a absorção do átomo isolado, $\mu_{0}(E)$, somada a um termo envolvendo $\chi(E)$ devido à presença dos átomos vizinhos,

$$
\mu(E)=\mu_{0}(E)[1+\chi(E)]
$$

Desta forma, o sinal EXAFS, $\chi(E)$, é definido por ${ }^{[76]}$ :

$$
\chi(E)=\frac{\mu(E)-\mu_{0}(E)}{\mu_{0}(E)}
$$



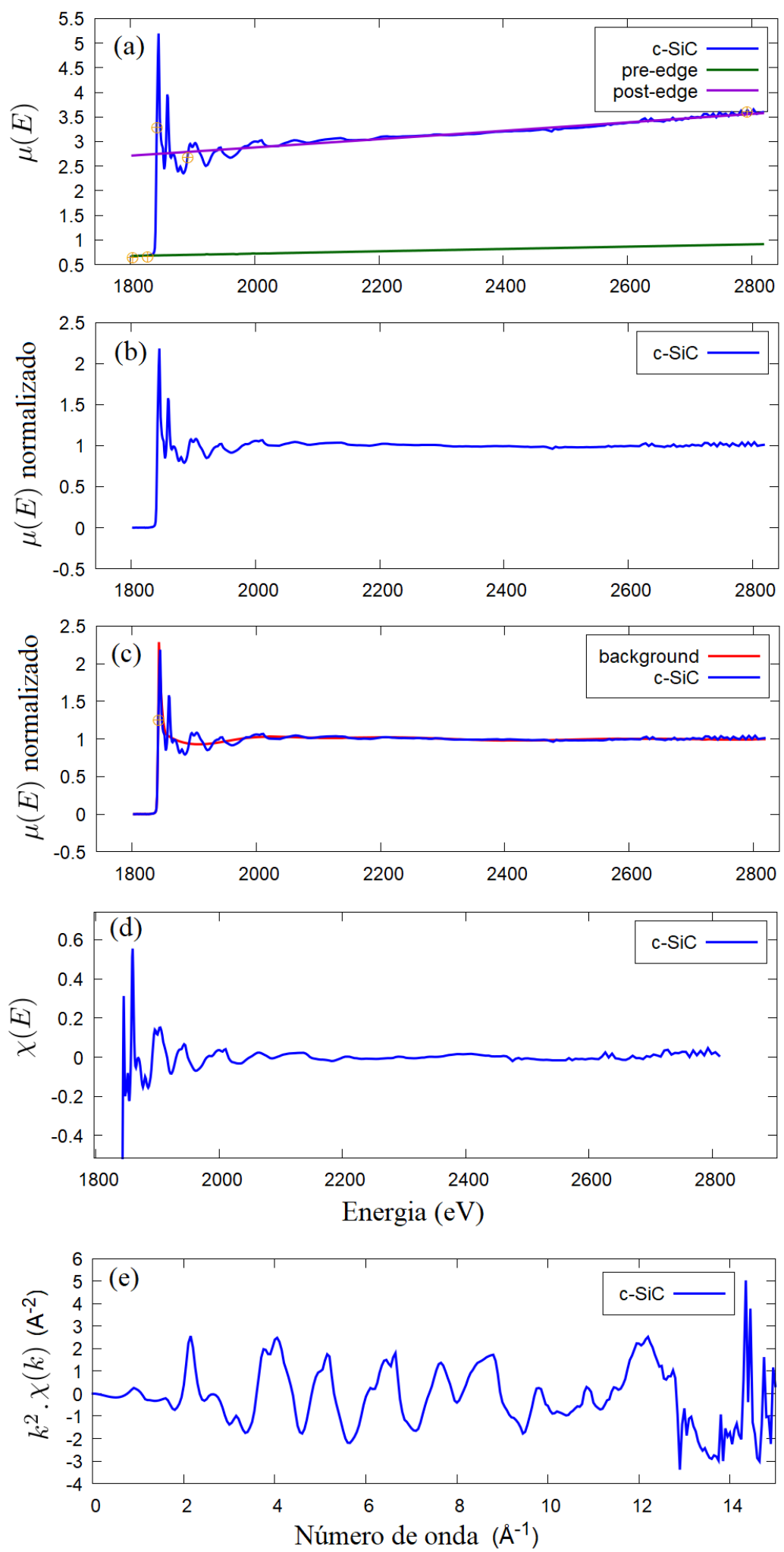

Figura 2.6: Etapas do processo de normalização e remoção do contínuo de uma amostra de c-SiC. (a) espectro não normalizado e o ajuste da pré-borda e pós-borda, (b) espectro normalizado, (c) ajuste do contínuo (background) realizado pelo algorítimo do ATHENA, (d) sinal EXAFS $\chi(E)$ e (e) sinal EXAFS $k^{2} \cdot \chi(k)$. 
onde os dados de fundo (background), $\mu_{0}(E)$, corresponde à influência da borda e da parte do espectro que varia lentamente com a energia. Tal influência deve ser removida dos dados normalizados. Para obter os dados de fundo a serem removidos, pode-se utilizar os softwares já mencionados. A parte (c) da figura 2.6 mostra o o ajuste do contínuo (background) obtido com o algorítimo do ATHENA. O manual do programa pode ser consultado para obter detalhes do procedimento realizado. Observa-se que o ajuste do contínuo segue a variação lenta do espectro, na região da pós-borda, a partir de uns $100 \mathrm{eV}$ em diante. Na região próxima à borda, entretanto, a curva ajustada é mais difícil de determinar. Isso não é um problema, pois essa região do espectro tem pequena influência na análise dos dados de EXAFS, uma vez que será descartada ao fazer a transformada de Fourier. Removidos os dados de fundo dos dados normalizados, obtém-se $\chi(E)$. A conversão para $\chi(k)$ é obtida facilmente utilizando a relação:

$$
k=\frac{2 \pi}{\lambda}=\frac{1}{\hbar} \sqrt{2 m_{e}\left(E-E_{0}\right)},
$$

onde $\hbar=\frac{h}{2 \pi}$, com $h$ sendo a constante de Planck, $m_{e}$ a masa do elétron e $k$ o número de onda do fotoelétron ejetado no processo de absorção. $\chi(k)$ geralmente decresce com $k$. Para facilitar a análise do sinal EXAFS é comum apresentar os dados multiplicados por $k, k^{2}$ ou $k^{3}$, como é mostrado na parte (e) da figura 2.6.

\subsubsection{Análise dos dados de XANES}

Com os dados devidamente normalizados, é possível realizar diversas análises da região de XANES.

\section{Comparação direta com padrões e ajustes de picos}

Uma análise simples, frequentemente empregada, é uma comparação direta do espectro com algum padrão experimental ou teórico. A figura 2.7 mostra um espectro da borda 
$\mathrm{K}$ de uma amostra de $\mathrm{TiO}_{2}$. Comparando com padrões experimentais do mesmo óxido nas fases rutilo e anatase pode-se concluir que a amostra é constituída majoritariamente da fase rutilo.
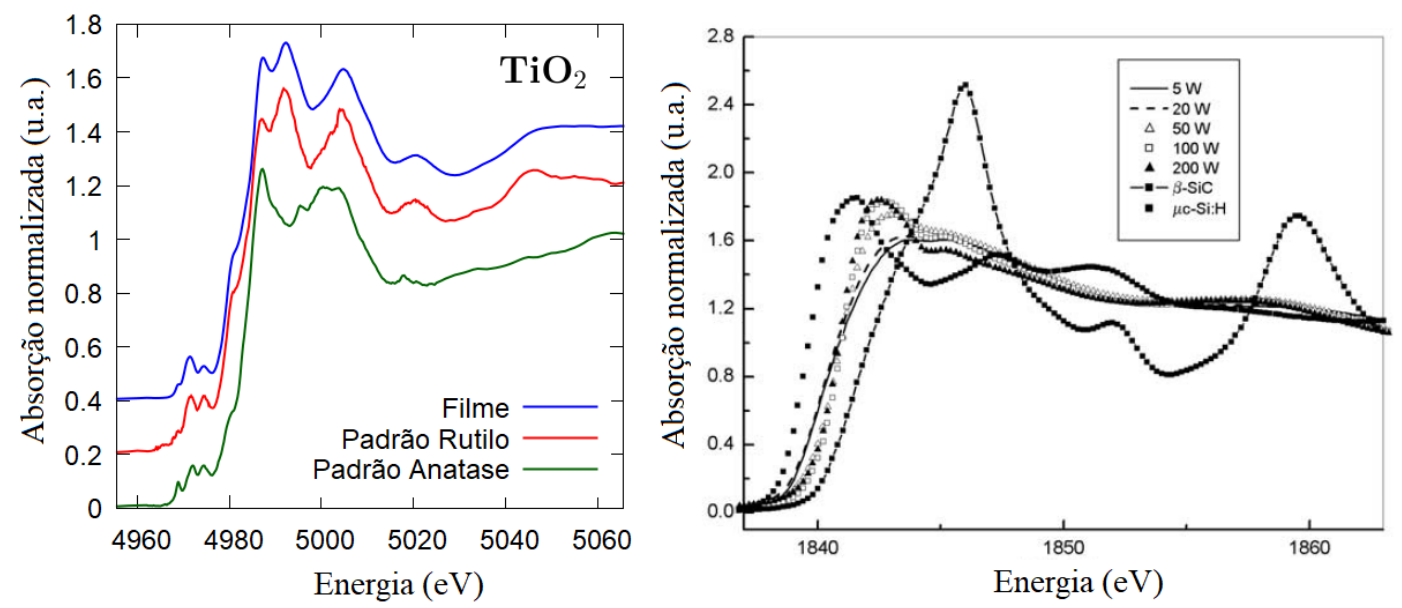

Figura 2.7: Exemplo da análise de XANES pela comparação de padrões conhecidos. (esquerda) Um filme de $\mathrm{TiO}_{2}$ comparado com padrões de rutilo e anatase. Qualitativamente é possível concluir que o filme é predominantemente constituído da fase rutilo. (direita) Comparação do espectro XANES de filmes de carbeto de silício, depositados por PECVD com diferentes potências rf, com padrões $\beta$-SiC e c-Si:H ${ }^{[19]}$.

Outra análise simples é ajustar os picos do espectro XANES com funções gaussianas, lorentzianas ou pseudo-Voigt de forma a separar as contribuições de cada pico e comparálas com as de amostras diferentes. A borda pode ser ajustada com uma função arcotangente ou função erro. A figura 2.8 mostra um exemplo dessa análise feita com o auxílio do ATHENA. Nem sempre é fácil encontrar um sentido físico para cada pico do ajuste, entretanto, o procedimento pode ser aplicado para comparar amostras e padrões quando ajustados da mesma forma ${ }^{[73]}$.

\section{Combinação linear}

Se a amostra em estudo é composta por mais de uma fase, o espectro de absorção obtido é uma combinação linear dos espectros de cada fase, proporcionalmente à quantidade de 


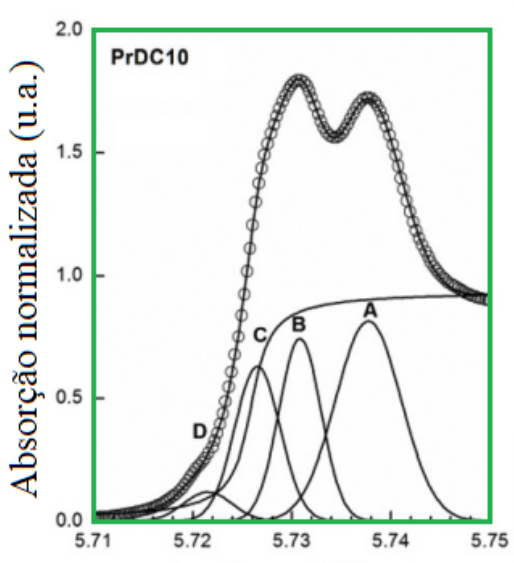

Energia (keV)

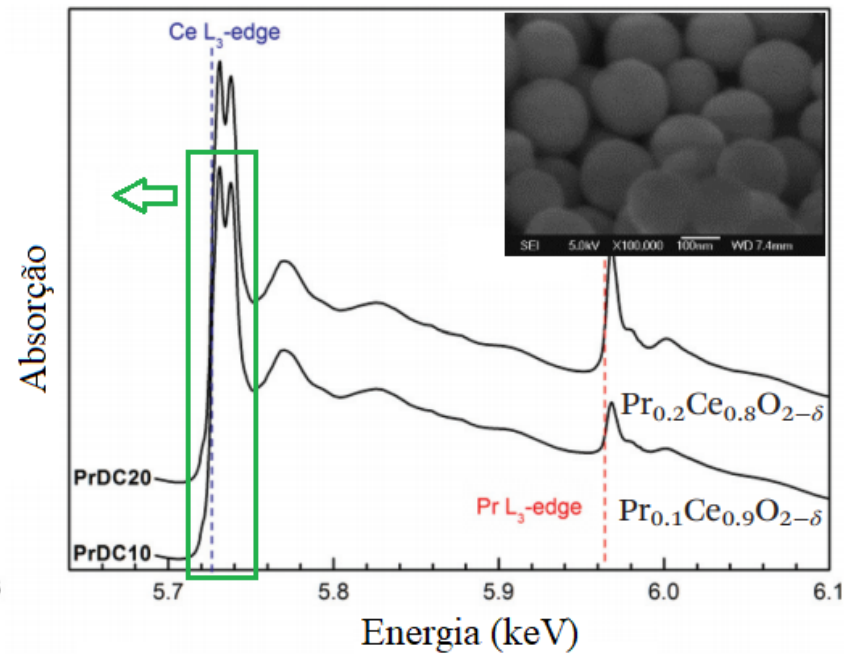

Energia $(\mathrm{keV})$

Figura 2.8: Exemplo da análise de XANES pelo método do ajuste de picos. O espectro de nano-esferas de $\operatorname{Pr}_{0,1} \mathrm{Ce}_{0,9} \mathrm{O}_{2-\delta}$, submetida a condições redutoras, foi decomposto em 4 funções gaussianas e uma função arco-tangente (adaptado de ${ }^{[77]}$ ).

átomos envolvidos no processo de absorção ${ }^{[73]}$. Se os espectros das fases constituintes estão disponíveis, podem ser usados como padrões para obter a composição da amostra em estudo. Deve-se portanto calcular qual combinação linear dos padrões, melhor reproduz o espectro da amostra. Novamente, esse procedimento de ajuste é facilitado utilizando o ATHENA. A figura 2.9 mostra um exemplo dessa análise aplicada a uma amostra de $\mathrm{TiO}_{2}$ com diferentes fases, que se deseja avaliar. Observa-se que o espectro da borda $\mathrm{K}$ do Ti da amostra é bem reproduzido quando combina-se 75,7\% do espectro do padrão anatase e 24,3\% do padrão rutilo. Como já mencionado, o espectro resultante da combinação linear é proporcional à quantidade de átomos envolvidos no processo de absorção. O valor percentual pode ser convertido na composição em massa ou volume da amostra, conforme desejado ${ }^{[73]}$. 


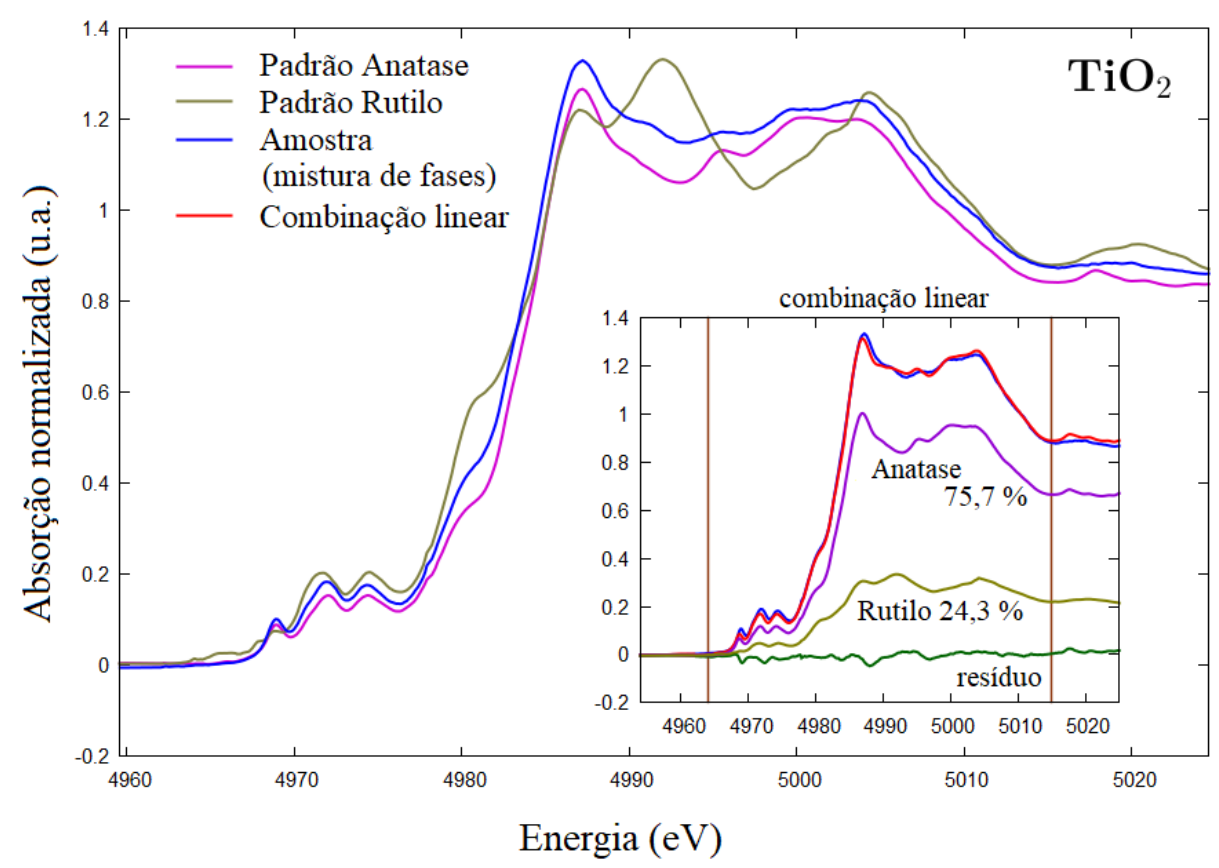

Figura 2.9: Exemplo da análise de XANES pela combinação linear de padrões. O espectro da amostra de $\mathrm{TiO}_{2}$ corresponde a $75,7 \%$ do espectro do padrão anatase e $24,3 \%$ do rutilo.

\subsubsection{Análise dos dados de EXAFS}

Como é descrito no apêndice A, o sinal XAS está relacionado com o efeito de interferência entre as ondas dos fotoelétrons espalhadas nos átomos vizinhos do absorvedor. Nesta seção, será apresentada também a equação de EXAFS (A.1) que descreve $\chi(k)$ como uma superposição de ondas senoidais. No momento, de forma simplificada, pode-se dizer que:

$$
\chi(k) \propto \sum_{i} A_{i} \operatorname{sen}\left[2 k D_{i}+\delta_{i}(k)\right],
$$

onde $i$ representa os diferentes caminhos que a onda do fotoelétron espalhada pode percorrer, $D_{i}$ é a metade da distância total percorrida pela onda, $\delta_{i}$ a mudança de fase devido ao espalhamento e $A_{i}$ é uma amplitude que depende de diversos fatores, tais 
como: a probabilidade de espalhamento (fator de forma), número de coordenação, $k$, $D$ e a desordem térmica ou estrutural do material (maiores detalhes na seção A.2). Desta forma, EXAFS é uma técnica capaz de obter informações da microestrutura local dos materiais. Note que, na figura 2.6(e), $\chi(k)$ é compatível com a soma de funções senoidais de diferentes amplitudes, frequências e fases.

\section{Transformada de Fourier de $\chi(k)$}

O sinal EXAFS pode ser analisado separando as contribuições das senoides correspondentes aos diferentes caminhos $i$. Isso é facilmente obtido realizando a transformada de Fourier de $\chi(k)^{[73]}$. Como exemplo, a figura 2.10 mostra a transformada de Fourier do sinal EXAFS do c-SiC da figura 2.6(e), assim como de outras amostras de c-Si e a-Si. As curvas foram obtidas com o auxílio do software ATHENA, que facilita muito o processo. O pico principal em $\approx 2,0 \AA$, dos materiais c-Si e a-Si, corresponde ao espalhamento do fotoelétron com os primeiros vizinhos (átomos de Si situados a $\approx 2,35 \AA$ ). A diferença entre a posição do pico na transformada de Fourier e a distância dos átomos vizinhos correspondente deve-se à fase $\delta(k)$ da expressão 2.5. Como o material amorfo não apresenta ordem local além dos primeiros vizinhos, não há picos adicionais. Para o material cristalino, no entanto, é possível observar picos em $\approx 3,5 \AA$ e $\approx 4,1 \AA$, que podem ser atribuídos aos segundos e terceiros vizinhos (átomos de Si situados a $\approx 3,84$ e 4,50 $\AA$ ). Para o c-SiC, os picos da primeira $(\approx 1,5 \AA)$ e segunda $(\approx 2,6 \AA)$ esferas de coordenação estão presentes (4 átomos de $\mathrm{C}$ situados a $\approx 1,89 \AA$ e 12 átomos de Si situados $\mathrm{a} \approx 3,08 \AA$ ). A intensidade dos picos está relacionada com o número de coordenação, a espécie envolvida no espalhamento, e o fator Debye-Waller.

É importante notar que $R$ (às vezes denominada distância aparente) não corresponde à distância real dos átomos vizinhos ao absorvedor. Simulações e ajustes do sinal EXAFS podem ser realizados para obter essa informação, assim como os demais dados estruturais do material presentes na equação A.1. 


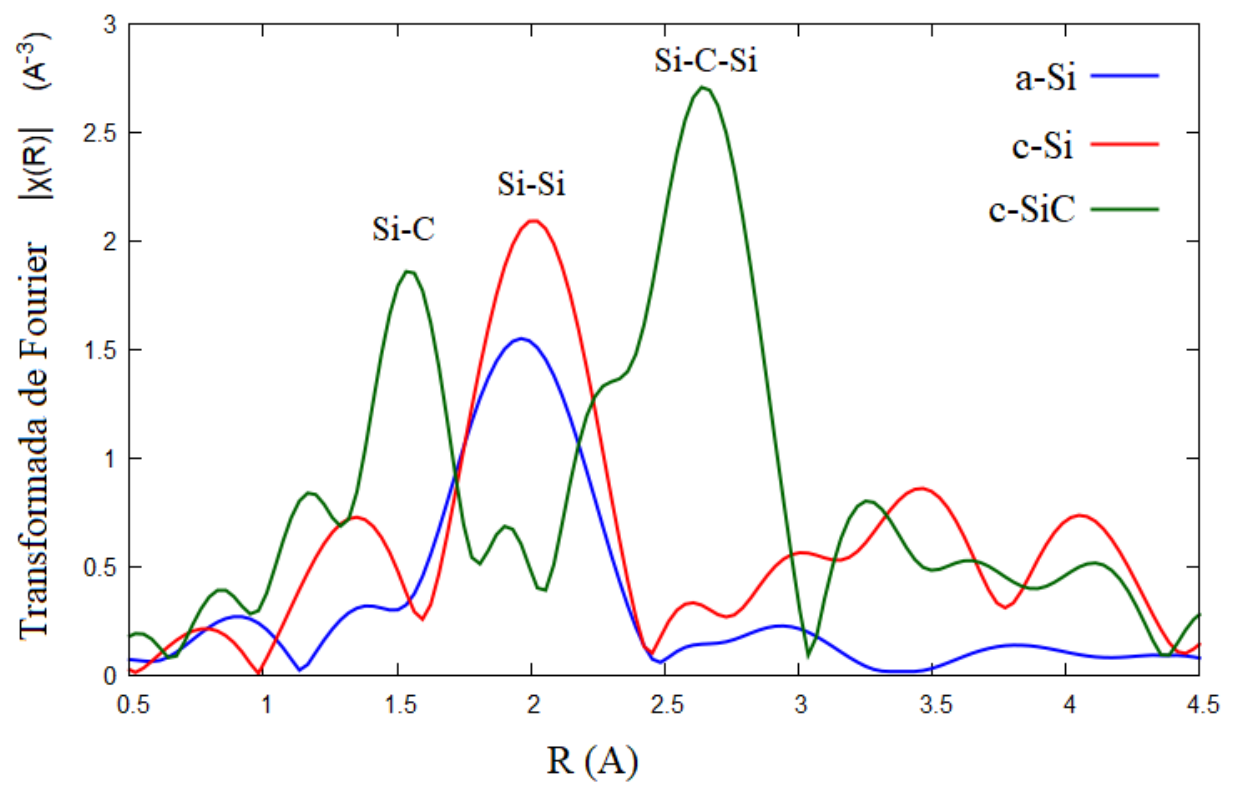

Figura 2.10: Exemplo da transformada de Fourier do sinal EXAFS de três materiais diferentes. A curva do c-SiC corresponde à transformada de $k^{2} \cdot \chi(k)$ da figura 2.6(e).

\subsubsection{Cálculos teóricos de XANES e EXAFS}

Avanços teóricos significativos sobre o entendimento dos fenômenos envolvendo XAS foram obtidos nas últimas décadas. Tais progressos são, não por acaso, concomitantes com o aumento do desempenho dos computadores, bem como das linhas de luz síncrotron. Atualmente, diversos códigos estão disponíveis para simular os espectros XANES e EXAFS. Uma lista de softwares pode ser obtida na referência ${ }^{[78]}$. Entre eles destacam-se o FEFF ${ }^{[79]}$ e o FDMNES ${ }^{[80]}$. O apêndice B apresenta algumas das principais abordagens e aproximações utilizadas nas simulações realizadas por esses códigos.

\section{Método das diferenças finitas (FDM) e o FDMNES}

Os cálculos baseados no formalismo da expansão do espalhamento múltiplo (MS) geralmente utilizam a aproximação muffin-tin do potencial para expandir as funções de 
onda (vide apêndice B). Tal aproximação pode tornar-se insatisfatória na região de XANES, quando o potencial na região intersticial é próximo da energia cinética do fotoelétron ${ }^{[80]}$. Um dos métodos desenvolvidos para evitar a aproximação muffin-tin nos cálculos de XANES e de estrutura de bandas é a utilização do método das diferenças finitas (finite-diffrence method - FDM) ${ }^{[81]}$. O método FDM discretiza a equação de Schrödinger numa malha de pontos, convertendo-a em um sistema de equações lineares, com o objetivo de calcular os estados quânticos finais do processo (equação B.1) ${ }^{[80]}$. O código FDMNES ${ }^{[80]}$ foi desenvolvido para efetuar simulações ab initio do espectro XANES pelo método FDM. Atualmente, o código está bastante otimizado, permitindo chegar ao resultado final em tempo computacional comparável com cálculos por expansão MS ${ }^{[82]}$. A figura 2.11 representa o procedimento adotado no FDMNES. O método FDM é aplicado na região esférica, em torno do átomo absorvedor, de extensão suficientemente grande, além da qual, o espalhamento do fotoelétron não mais contribui significativamente (zona 2). Fora dela (zona 3), o potencial é considerado aproximadamente constante e uma expansão em ondas esféricas é realizada. Além de operações de simetria, para aumentar a velocidade do cálculo, excluem-se os pontos na região esférica (de 0,5 a $0,7 \AA$ ) bem próxima aos átomos (zona 1), onde o potencial é considerado de simetria esférica e a expansão de ondas esféricas pode novamente ser realizada. Um procedimento foi desenvolvido para conectar as três diferentes regiões de cálculo ${ }^{[80]}$.

No FDMNES, o potencial é calculado por aproximação da densidade local (local density approximation - LDA), e o método FDM não demanda aproximações quanto a sua forma, como é feito na abordagem muffin-tin, obtendo melhores resultados que o MS. O FDMNES pode também realizar o cálculo auto consistente da estrutura eletrônica (vide seção B.2.1) para determinar o estado inicial e a energia de Fermi, antes de obter o espectro de absorção XANES ${ }^{[83]}$. 


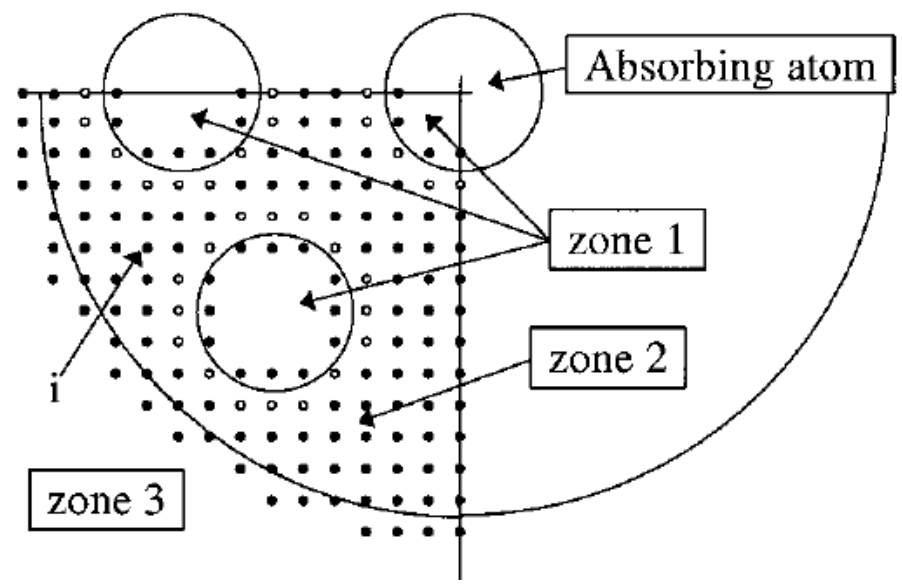

Figura 2.11: Representação esquemática do procedimento adotado no FDMNES. O método FDM é aplicado na malha de pontos representado na região 2 da figura. Nas regiões 1 e 3 , o potencial é considerado de simetria esférica ${ }^{[80]}$.

\subsection{Fluorescência de raios X com incidência rasante - GIXRF}

Fluorescência de raios X (XRF) é a técnica em que é possível identificar a composição elementar de uma amostra na qual se incide um feixe de raios $\mathrm{X}$ (figura 2.12). Os átomos excitados emitem raios X secundários que são como uma assinatura de cada elemento presente de forma que, analisando o espectro de emissão, pode-se identificar a composição do material. A técnica pode ser aplicada a uma ampla gama de materiais e, com os equipamentos disponíveis atualmente, elementos de $Z>11$ podem ser identificados com boa precisão ${ }^{[84]}$.

Num arranjo de Fluorescência de Raios X em Reflexão Total (Total Reflection Xray Fluorescence - TXFR), o feixe de raios X é colocado em incidência rasante sobre a amostra, tipicamente menor que $0,1^{\circ}$. Quando abaixo do ângulo de reflexão total, o feixe é totalmente refletido, o que permite a análise de constituintes em pequena concentração. No caso de filmes finos, o espectro obtido por TXRF possui uma dependência com o ângulo rasante de incidência. Variando o ângulo de incidência de 0 até o limite de reflexão total, é possível obter o sinal de fluorescência do elemento e analisar a 
composição em função da profundidade. Essa técnica é chamada de fluorescência de raios X por incidência rasante (Grazing Incidence X-Ray Fluorescence - GIXRF), conforme apresentado na figura 2.12 .

(a)

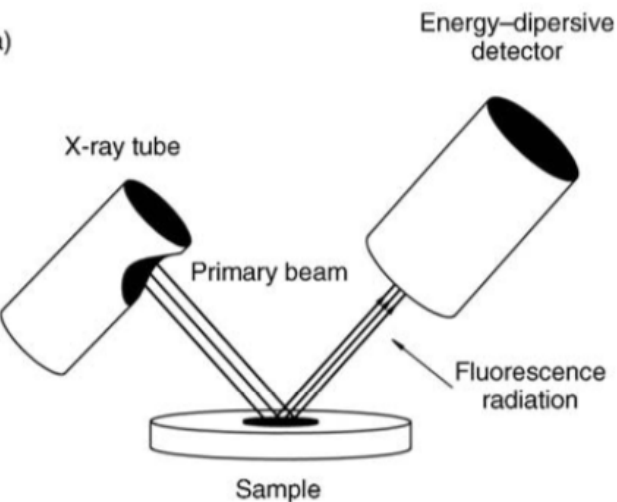

(b)

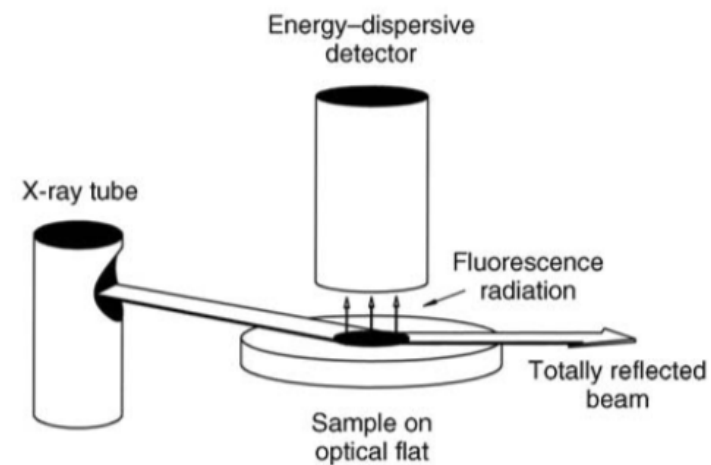

Figura 2.12: Arranjo experimental utilizado em medidas de fluorescência de raios X. Em (a) o método convencional. Em (b) o arranjo em reflexão total (adaptado de ${ }^{[84]}$ ).

\subsubsection{Atenuação e deflexão de raios $\mathrm{X}$}

Conforme já foi mencionado na seção 2.1, a intensidade do feixe de raios X, ao atingir um material de densidade $\rho$ e espessura $t$, é reduzida, conforme a equação 2.1 reproduzida abaixo:

$$
\begin{aligned}
& I_{t}(t)=I_{0} e^{-\mu t} \\
& I_{t}(t)=I_{0} e^{-\left(\frac{\mu}{\rho}\right) \rho t}
\end{aligned}
$$

onde $\mu$ é o coeficiente de atenuação linear e $\frac{\mu}{\rho}$ é o coeficiente de atenuação de massa, que depende da energia. Para materiais comuns, fora da borda de absorção, os coeficientes podem ser obtidos em tabelas disponíveis na literatura ${ }^{[85]}$ e, para materiais compostos, o coeficiente de absorção de massa é obtido a partir das frações em massa $c_{i}$ dos 
constituintes, fazendo:

$$
\left(\frac{\mu}{\rho}\right)_{\text {total }}=\sum c_{i}\left(\frac{\mu}{\rho}\right)_{i} .
$$

A figura 2.13 mostra um feixe de raios $\mathrm{X}$ que se propaga de um meio 1 até o meio 2 . Ao atingir a interface, parte do feixe é refletido e parte refratado. O ângulo de incidência dos feixes incidente e refletido são iguais, $\alpha_{1}=\alpha_{1}^{*}$, e a relação entre os ângulos do feixe incidente e refratados, segundo a lei de Snell, é

$$
n_{1} \cos \alpha_{1}=n_{2} \cos \alpha_{2},
$$

onde $n$ corresponde ao índice de refração absoluto do meio, definido como a razão entre a velocidade da luz no vácuo, e a velocidade de fase do feixe no meio.

(a)

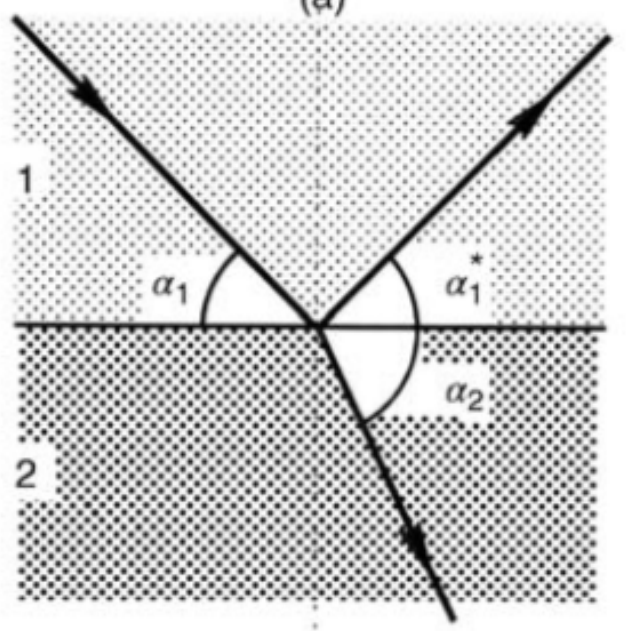

(b)

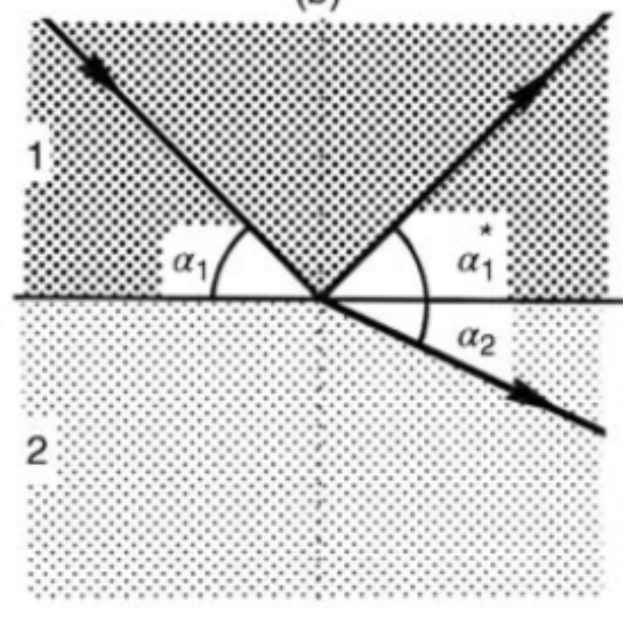

Figura 2.13: Representação dos feixes incidente, refletido e refratado numa superfície entre dois meios de índices de refração $n$ diferentes. Em (a) $n_{2}>n_{1}$ e (b) $n_{2}<n_{1}$. Note que os ângulos são medidos a partir da superfície, e não da direção normal à superfície, como é costume na óptica da luz visível ${ }^{[84]}$. 
O índice de refração pode ser representado pelo número complexo ${ }^{[86]}$

$$
n=1-\delta-i \beta,
$$

onde o decremento $\delta$ corresponde ao desvio da componente real em relação ao vácuo $\left(n_{\text {vácuo }}=1\right)$ e $\beta$ é a componente imaginária associada à absorção do feixe ao penetrar no meio e está relacionada com a atenuação por ${ }^{[84,87]}$ :

$$
\beta=\frac{\lambda}{4 \pi}\left(\frac{\mu}{\rho}\right) \rho
$$

Para energias longe da borda de absorção, o decremento pode ser obtido aproximadamente por ${ }^{[84,87]}$ :

$$
\delta=C_{m} \lambda^{2}
$$

onde a constante do material, $C_{m}$, é dada por:

$$
C_{m}=\frac{N_{A}}{2 \pi} r_{e l} \frac{Z}{A} \rho
$$

com $r_{e l}$ sendo o raio clássico do elétron, $N_{A}$ o número de Avogadro e $\mathrm{Z}$ e A o número e a massa atômica do elemento constituinte do material. Para materiais compostos, o índice de refração é obtido pela fração em massa de cada componente, fazendo:

$$
\delta_{\text {total }}=\sum c_{i} \delta_{i} \quad, \quad \beta_{\text {total }}=\sum c_{i} \beta_{i}
$$

Os valores de $\delta$ e $\beta$ são bem pequenos para raios X. A tabela da figura 2.14 apresenta alguns valores típicos. 


\begin{tabular}{lccc}
\hline Medium & $\rho\left(\mathrm{g} / \mathrm{cm}^{3}\right)$ & $\delta\left(10^{-6}\right)$ & $\beta\left(10^{-8}\right)$ \\
\hline Plexiglas & 1.16 & 0.9 & 0.055 \\
Glassy carbon & 1.41 & 1.0 & 0.049 \\
Boron nitride & 2.29 & 1.5 & 0.090 \\
Quartz glass & 2.20 & 1.5 & 0.46 \\
Aluminum & 2.70 & 1.8 & 0.79 \\
Silicon & 2.33 & 1.6 & 0.84 \\
Cobalt & 8.92 & 5.6 & 19.8 \\
Nickel & 8.91 & 5.8 & 21.9 \\
Copper & 8.94 & 5.6 & 24.1 \\
Germanium & 5.32 & 3.2 & 18.7 \\
Gallium arsenide & 5.31 & 3.2 & 18.7 \\
Tantalum & 16.6 & 9.1 & 87.5 \\
Platinum & 21.45 & 11.7 & 138.2 \\
Gold & 19.3 & 10.5 & 129.5 \\
\hline
\end{tabular}

Figura 2.14: Parte real e imaginária do índice de refração de alguns meios, calculados para a radiação Mo $K_{\alpha}$, de $\lambda=0,071 \mathrm{~nm}$ (tabela da referência ${ }^{[84]}$ ).

\subsubsection{Reflexão total externa}

Voltando para a figura 2.13 , se $n_{2}<n_{1}$ o feixe transmitido para o meio 2 é desviado para a interface (parte (b) da figura). Quando o ângulo de incidência for menor que um valor crítico $\left(\alpha_{1}<\alpha_{\text {crit }}\right)$ ocorrerá reflexão total, ou seja, $\alpha_{2}=0$. Para os raios $\mathrm{X}$, em contraste com o que ocorre com a luz visível, qualquer sólido é opticamente menos denso do que o ar. Analisando a equação 2.9 pode-se concluir que, quando o feixe incide a partir do vácuo ou ar $(n \approx 1)$, reflexão externa total ocorrerá se:

$$
\cos \alpha_{c r i t}=n_{2},
$$

ou seja, não haverá feixe transmitido e a superfície se comporta como um espelho ideal.

O ângulo crítico de reflexão total pode ser calculado utilizando a expansão do cosseno,

$$
\cos \alpha_{c r i t} \approx 1-\frac{\alpha_{c r i t}^{2}}{2}
$$


Com a expressão 2.10 obtém-se:

$$
\alpha_{c r i t}^{2} \approx 2(\delta-i \beta)
$$

o que resulta em $\alpha_{\text {crit }} \approx \sqrt{2 \delta}$, que pode ser escrito por:

$$
\alpha_{c r i t} \approx \lambda \sqrt{2 C_{m}}
$$

longe da borda de absorção.

\subsubsection{Fluorescência em filmes finos sobre um substrato}

Ao incidir sobre um material composto por camadas de filmes finos sobre um substrato, os raios X são refletidos e refratados pelas diversas interfaces.
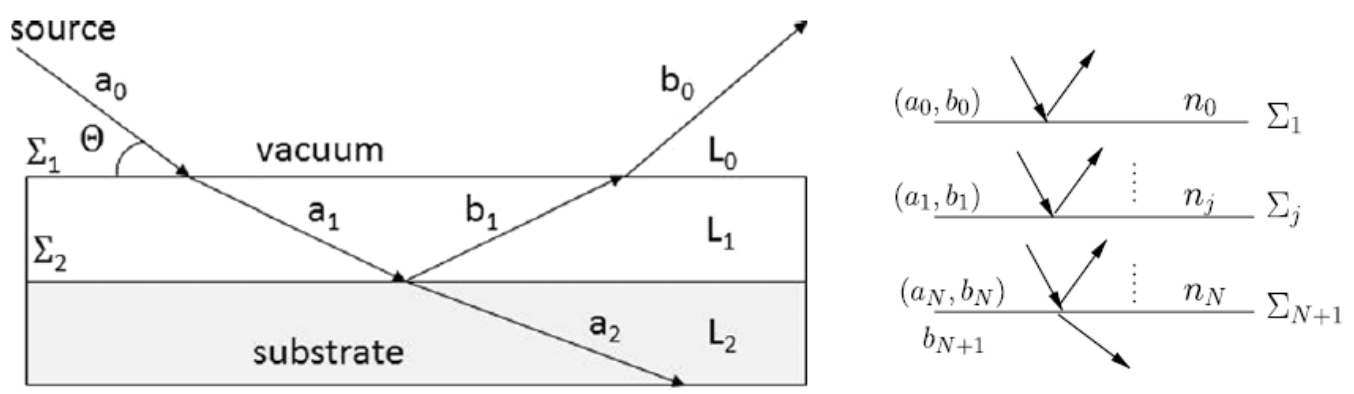

Figura 2.15: Amplitudes do campo elétrico dos feixes refletido e refratado em filmes finos sobre um substrato ${ }^{[88]}$.

A intensidade do sinal de fluorescência de um elemento $m$, proveniente de camadas de filmes sobre um substrato, como representado na figura 2.15, é dada por

$$
F_{m}(\theta)=\sum_{j=1}^{N+1} F_{m}(j, \theta),
$$


onde $F_{m}(j, \theta)$ corresponde à contribuição de cada camada $j$ dada por ${ }^{[87]}$ :

$$
F_{m}(j, \theta)=K \rho_{j} Q_{m, \lambda}^{j} \exp \left(\sum_{s=1}^{j-1} \mu_{s \lambda_{m}} \rho_{s} h_{s}\right) \int_{0}^{h_{j}} I\left(\theta, z_{j}\right) \exp \left(-\mu_{j \lambda_{m}} \rho_{j} z_{j}\right) d z_{j}
$$

$\operatorname{com} Q_{m, \lambda}^{j}=W_{m}^{j} J_{m} \omega_{m} g_{m} \tau_{m, \lambda}$.

Nessa expressão, o termo $I\left(\theta, z_{j}\right)$ corresponde a intensidade do raio X, na profundidade $z$ no interior da camada $j$ e é dada pela expressão ${ }^{[87,88]}$ :

$$
I\left(\theta, z_{j}\right)=\left|a_{j} e^{i k z p_{j}}+b_{j} e^{i k z p_{j}}\right|^{2}
$$

onde os coeficientes de transmissão, $a_{j}$, e reflexão, $b_{j}$, podem ser calculados utilizando o formalismo apresentado no apêndice C. Os demais termos da expressão 2.20 são:

- $K$ - fator instrumental que depende da geometria do arranjo experimental;

- $\rho_{j}$ - densidade da camada $j$;

- $\mu_{j, \lambda}$ - coeficiente de atenuação (de massa) da camada $j$, para raios $\mathrm{X}$ de comprimento de onda $\lambda$;

- $\lambda_{m}$ - comprimento de onda característico da fluorescência do elemento $m$;

- $h_{j}$ - espessura da camada $j$;

- $W_{m}^{j}$ - concentração do elemento $m$ na camada $j$;

- $J_{m}$ - salto de absorção do elemento $m$;

- $\omega_{m}$ - taxa de fluorescência do elemento $m$ (fluorescence yield);

- $g_{m}$ - probabilidade de emissão de fluorescência do elemento $m$;

- $\tau_{m, \lambda}$ - coeficiente de absorção (de massa) do elemento $m$, para raios $\mathrm{X}$ de comprimento de onda $\lambda$.

\subsubsection{Aspectos experimentais de GIXRF}

Num experimento de GIXRF, o ângulo de incidência dos raios X é variado, desde 0 , até pouco mais do que o ângulo crítico, enquanto o sinal de fluorescência é obtido. A 
intensidade do sinal obtido é relacionada com o espectro de emissão característico de cada elemento, de forma que é possível obter o sinal para cada elemento. A figura 2.16 mostra a curva obtida por essa técnica para um filme fino de Cr depositado sobre um substrato de Si. A partir de $\approx 0,2^{\circ}$, a fluorescência do $\mathrm{Cr}$, que está na primeira camada, é detectada. O substrato de silício só é atingido pelos raios $\mathrm{X}$ a partir de $\approx 0,65^{\circ}$. O sinal do Cr aumenta até aproximadamente $1,2^{\circ}$, valor que pode ser relacionado à espessura do filme. O sinal do Si cresce continuamente pois trata-se de um substrato de espessura infinita.

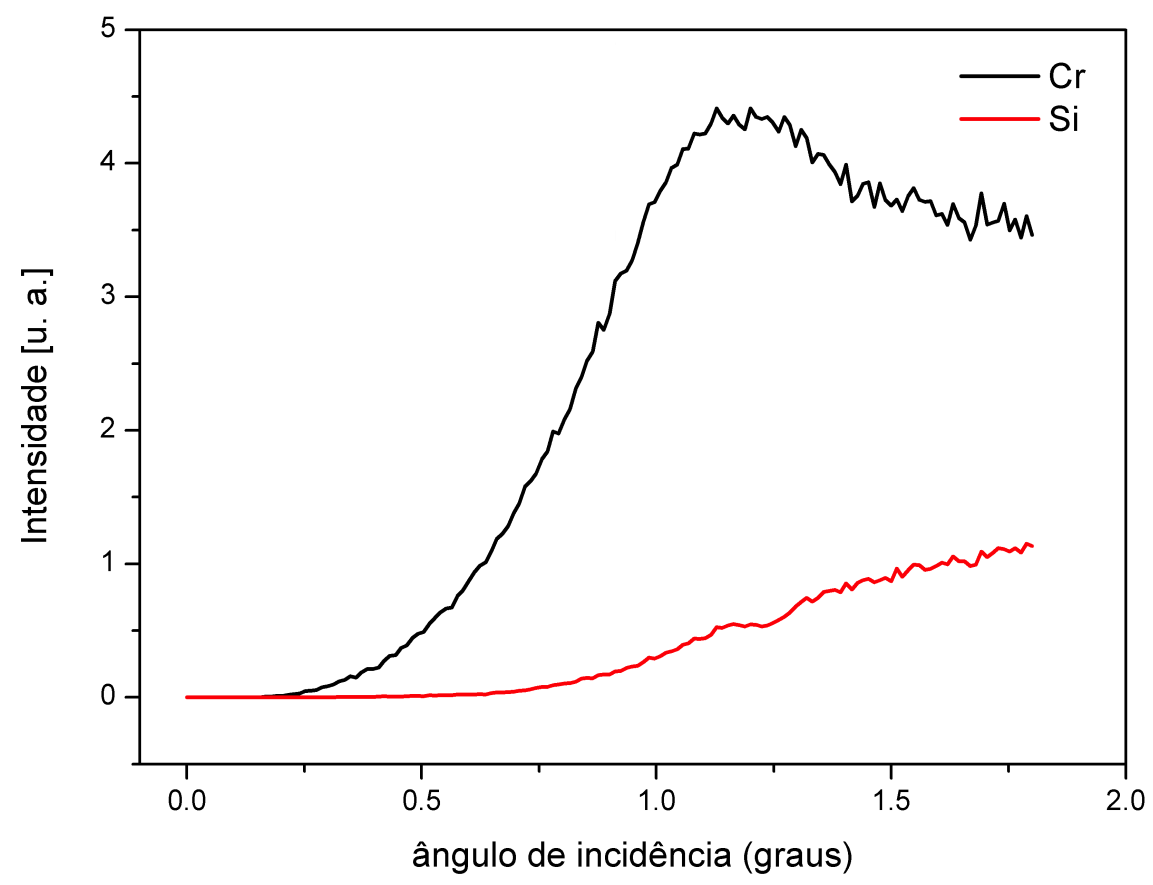

Figura 2.16: Exemplo da curva obtida por GIXRF a partir de um filme de Cr sobre um substrato de Si. 


\subsection{Espectroscopia de retroespalhamento de Rutherford - RBS}

A espectroscopia de retroespalhamento de Rutherford (Rutherford Backscattering Spectrometry - RBS) é uma técnica muito utilizada para obter a composição de filmes finos em função da profundidade. Os dados são coletados de forma não destrutiva e os resultados não são sensíveis às ligações químicas e à cristalinidade do material. A técnica é limitada à região superficial do filme, tipicamente de 2,0 $\mu m$, e é menos sensível aos elementos mais leves ${ }^{[89,90]}$. Num experimento de RBS típico, um feixe monoenergético de íons, geralmente $\mathrm{He}^{+}$e, com energia de 0,5 a 2,5 $\mathrm{MeV}$, atinge a amostra a ser analisada. Os íons retroespalhados são contados por um detector, com resolução em energia, posicionado em um ângulo $\theta$ em relação ao feixe incidente (figura 2.17).

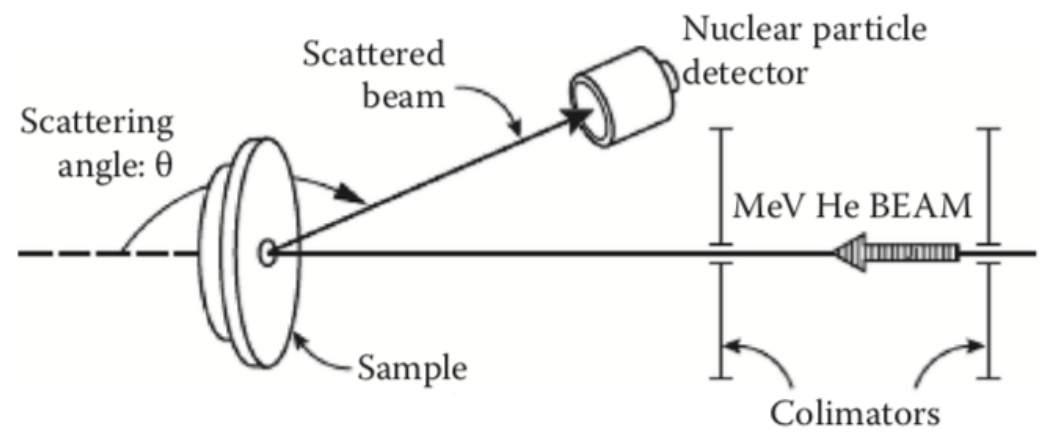

Figura 2.17: Arranjo experimental típico de um experimento de RBS ${ }^{[90]}$.

\subsubsection{Seção de choque de espalhamento de Rutherford}

O espectro RBS depende da probabilidade de colisão entre o íon do feixe incidente e os núcleos do material analisado. Tal probabilidade é expressa em termos da seção de choque de colisão. Quando a interação entre os núcleos do feixe e do alvo é coulombiana, o espalhamento é chamado de Rutherford e a seção de choque, $\sigma(\theta)$, é expressa por ${ }^{[89]}$ : 


$$
\frac{\mathrm{d} \sigma(\theta)}{\mathrm{d} \Omega}=\left(\frac{Z_{1} Z_{2} e^{2}}{4 E}\right)^{2} \frac{4}{\operatorname{sen}^{4} \theta} \frac{\left\{\left[1-\left(\left(M_{1} / M_{2}\right) \operatorname{sen} \theta\right)^{2}\right]^{1 / 2}+\cos \theta\right\}^{2}}{\left[1-\left(\left(M_{1} / M_{2}\right) \operatorname{sen} \theta\right)^{2}\right]^{1 / 2}}
$$

onde $\theta$ é a direção de espalhamento, $\Omega$ é o ângulo sólido subtendido pelo detector, $Z \mathrm{e}$ $M$ são o número atômico e a massa do átomo (1 para o projétil incidente e 2 para o alvo) e $E$ a energia do projétil antes da colisão.O número de contagens de íons espalhados em uma fina camada $\Delta t$ do material será:

$$
Y=\sigma(\theta) \Omega Q N \frac{\Delta t}{\cos \theta_{1}}
$$

onde $Q$ é o número de partículas incidentes e $N$ a densidade atômica do material.

A figura 2.18 exibe um exemplo do espectro RBS onde um feixe de $\mathrm{He}^{+}$é espalhado, $\operatorname{com} \theta_{1}=170^{\circ}$, num filme de Ni sobre um substrato de Si. O primeiro pico corresponde aos íons espalhados pelo $\mathrm{Ni}$ e inicia-se com energia $K_{N i} E_{0}$, onde $K_{N i}$ corresponde ao fator cinemático do elemento, conforme descrito no apêndice D. Ao penetrar na amostra, o feixe de íons perde energia, causando um alargamento no pico, de forma que a espessura do filme pode ser relacionada com a largura $\Delta E$. O sinal relativo ao substrato de silício inicia-se em uma região de menor energia, pois o fator cinemático do $\mathrm{Si}, K_{\mathrm{Si}}$, é menor que do $\mathrm{Ni}$ e, por ter espessura infinita, aparece no espectro como um patamar.

\subsubsection{Análise de RBS utilizando softwares}

Diversas características podem tornar o espectro mais difícil de analisar. Além da possibilidade de sobreposição dos picos e os efeitos decorrentes da resolução do detector, o chamado straggling, que corresponde à dispersão da energia do feixe enquanto penetra na amostra, também afeta o espectro. No mais, para aumentar a precisão dos resultado, 


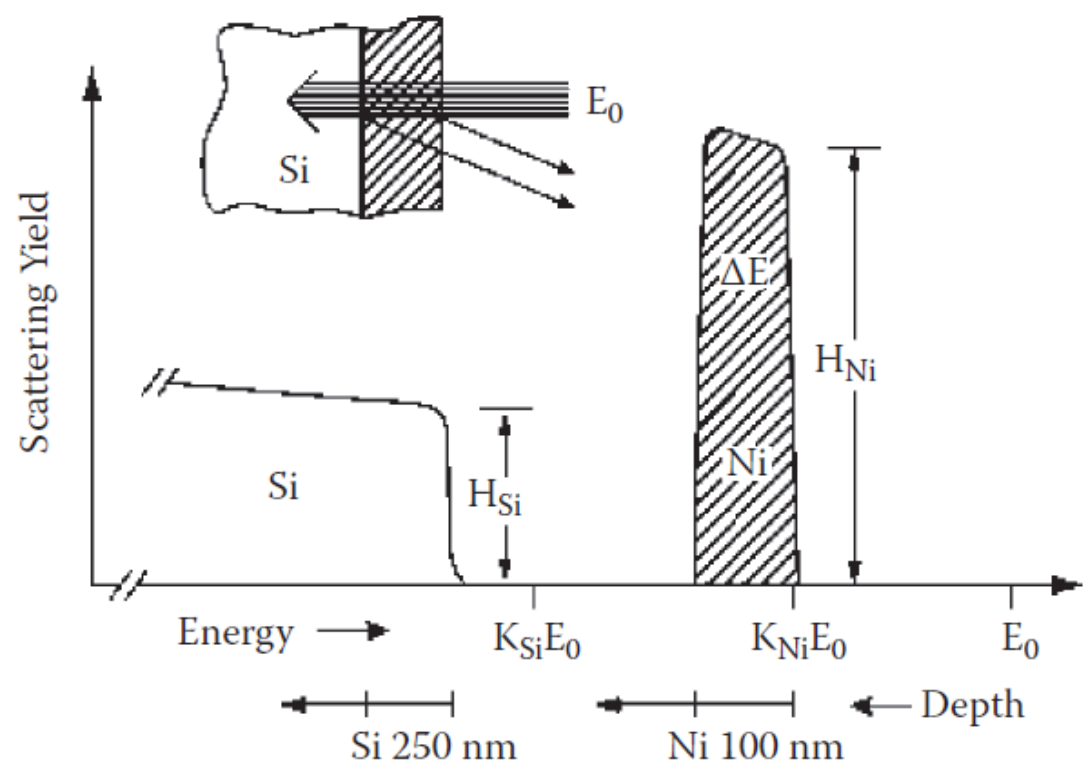

Figura 2.18: Exemplo do espectro RBS de um feixe de $\mathrm{He}^{+}$espalhado num filme de $\mathrm{Ni}$ sobre um substrato de $\mathrm{Si}^{[91]}$.

é comum obter diversos espectros da mesma amostra, tomados em ângulos de incidência e espalhamento diferentes. Neste cenário, a utilização de softwares facilita bastante a análise. O SIMNRA ${ }^{[92]}$ e MultiSIMNRA ${ }^{[93]}$ permitem simular os resultados experimentais e obter o perfil em profundidade dos filmes. A figura 2.19 exibe um exemplo do ajuste realizado no MultiSIMNRA, onde quatro espectros de um filme de AlN sobre $\mathrm{Si}$ são simultaneamente considerados.

A concentração atômica da amostra em função da espessura é melhor estimada em unidades de TFU (Thin Film Unit) que equivale a $10^{15}$ átomos $/ \mathrm{cm}^{2}$. A conversão de TFU em $\mathrm{cm}$ é feita por:

$$
t[\mathrm{~cm}]=t[T F U] \frac{M}{\rho N_{A}} \times 10^{15}
$$

onde $\rho$ e $M$ são a densidade e a massa molar do filme e $N_{A}$ o número de Avogadro. A espessura em $\mathrm{cm}$ é um valor aproximado pois, geralmente, a densidade não é conhecida 
com precisão.
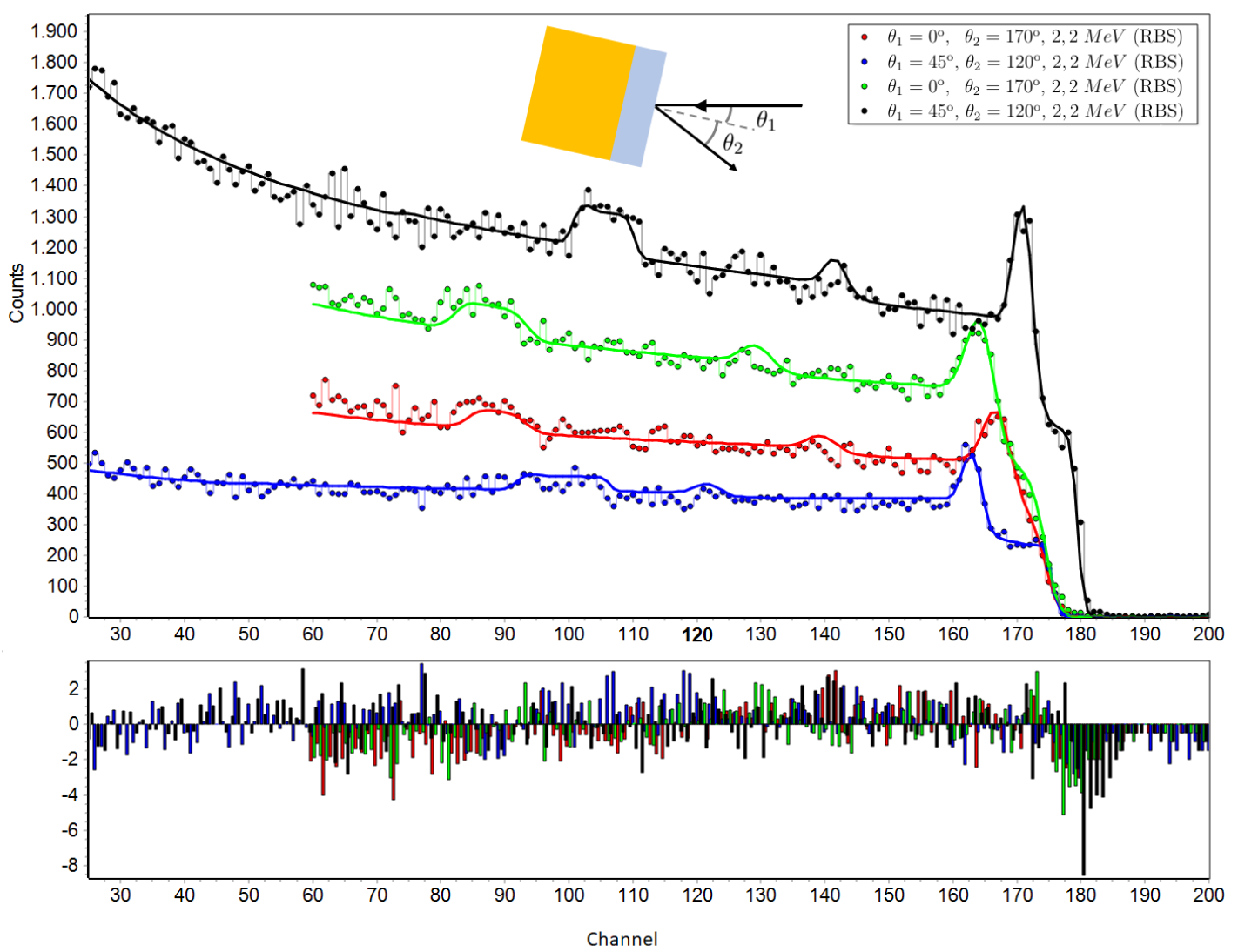

Figura 2.19: Exemplo da analise de um filmes de AlN depositado sobre Si realizado pelo MultiSIMNRA. Quatro espectros, tomados com diferentes ângulos $\theta_{1}$ e $\theta_{2}$, foram simulados simultaneamente. A parte inferior exibe a diferença entre a simulação os espectros experimentais.

\subsubsection{Medidas em ressonância}

Para valores da energia do feixe maiores, interações nucleares entre o projétil e o núcleo do alvo podem ocorrer durante a colisão. Assim, o espalhamento não será Rutherford, pois o processo não pode ser bem descrito por um potencial coulombiano ${ }^{[90]}$. Essa efeito pode ser usado para melhorar a precisão na quantificação de elementos leves, difíceis de obter por RBS. A técnica é chamada de EBS (Elastic Backscattering Spectrometry), 
quando a energia do feixe é ajustada para um valor no qual ocorre ressonância com o elemento desejado. Nessas condições, a seção de choque aumenta significativamente. A figura 2.20 mostra um exemplo da utilização da ressonância do oxigênio, que ocorre em 3,037 MeV. Novamente, a análise pode ser feita no SIMNRA.
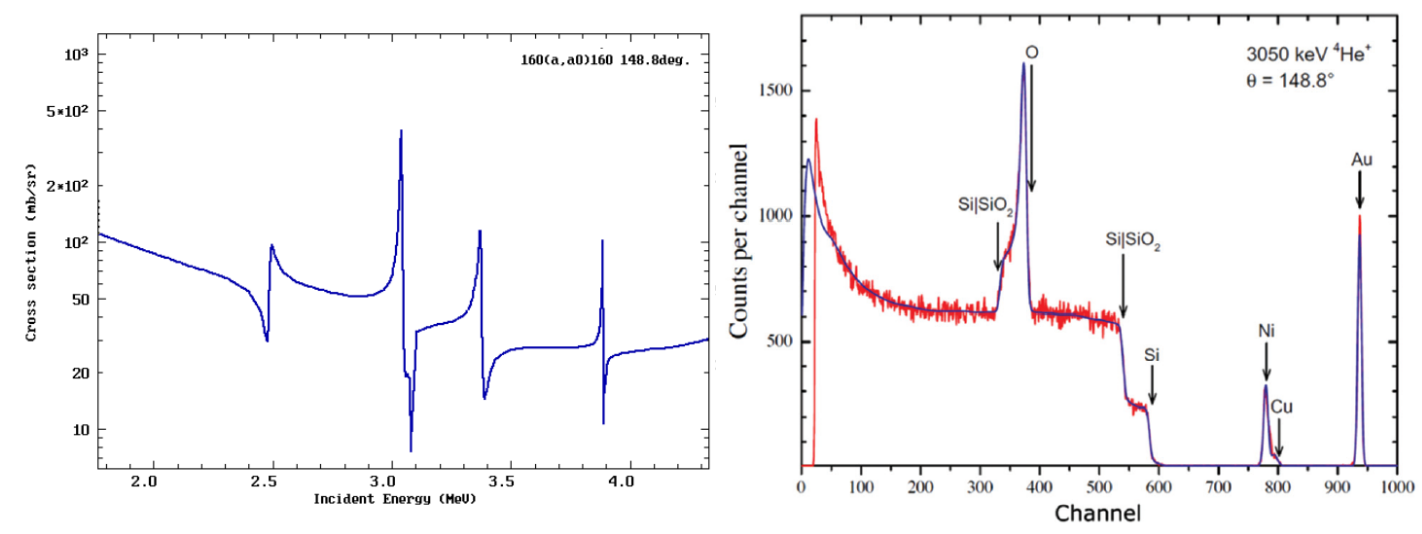

Figura 2.20: (esquerda) seção de choque do espalhamento de partículas $\alpha$ em ${ }^{16} \mathrm{O}$ com $\theta=148,8^{\circ}$, exibindo a ressonância em 3,037 $\mathrm{MeV}^{[94]}$. (direita) Exemplo de um espectro tomado na ressonância do $\mathrm{O}$ de uma amostra de $\mathrm{Au} / \mathrm{NiCu} / \mathrm{SiO}_{2}$ sobre um substrato de Si. Os sinais dos demais elementos são Rutherford, apenas o oxigênio exibe a ressonância nessa energia ${ }^{[95]}$. 
Capítulo 2. Técnicas experimentais 


\section{Capítulo 3}

\section{Fabricação das microlâmpadas e}

\section{dos filmes finos adicionais}

As microlâmpadas utilizadas nesta tese são constituídas de filamentos resistivos de $\mathrm{Cr}$ em forma de ponte e protegidos do ambiente por filmes isolantes. Quando energizados, os filamentos aquecem por efeito Joule e emitem luz. A figura 3.1 mostra esquematicamente a microlâmpada, e uma foto do dispositivo produzido é exibida na figura 3.2. Sobre um substrato de $\mathrm{Si}<100>$ é depositada uma camada isolante de $\mathrm{SiO}_{x} \mathrm{~N}_{y}$ com $\approx 2,43 \mu \mathrm{m}$ de espessura, sobre a qual é depositado o filme de $\mathrm{Cr}$, com espessura de $\approx 240 \mathrm{~nm}$, formando as trilhas, contatos e o filamento. A figura 3.1 (c) mostra uma imagem de microscópio com o detalhe do filamento. Para impedir a oxidação prematura durante o aquecimento, uma última camada de proteção é depositada sobre o filamento, com aproximadamente $120 \mathrm{~nm}$, sendo ela constituída por um dos quatro materiais a seguir: a-SiC, a-SiO $\mathrm{N}_{y}, \mathrm{AlN}$ ou $\mathrm{TiO}_{2}$. Esta última camada protetora é o objeto de estudo desta tese. 


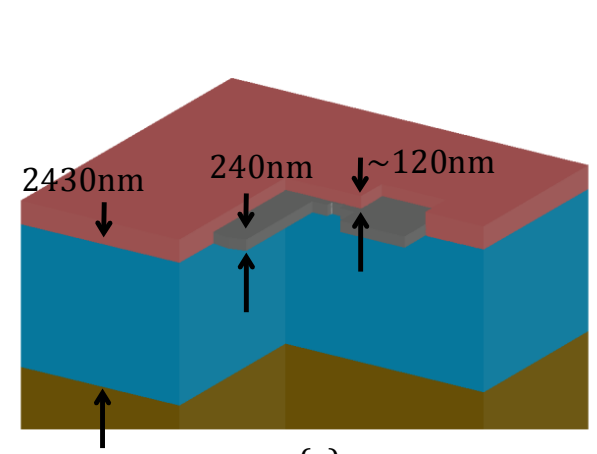

(a)

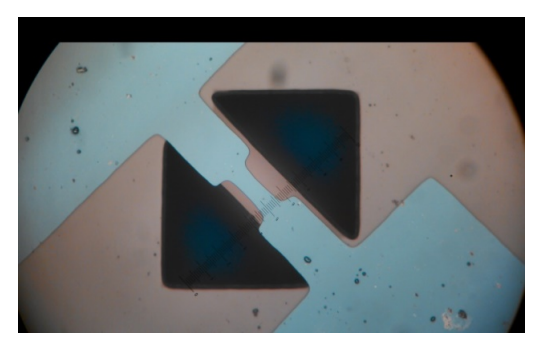

(c)

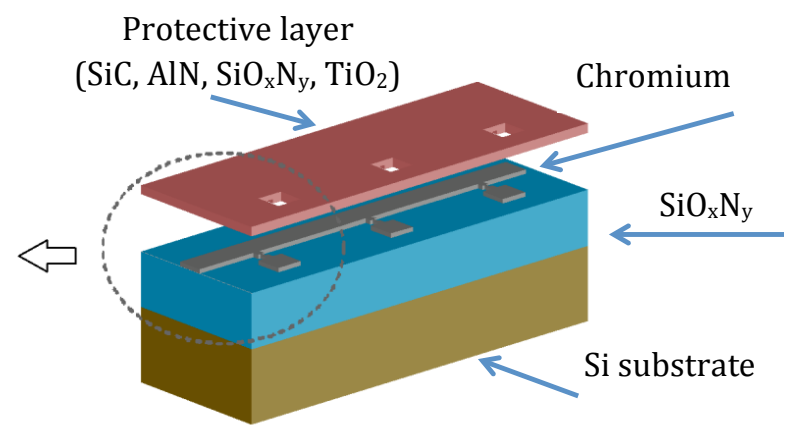

(b)

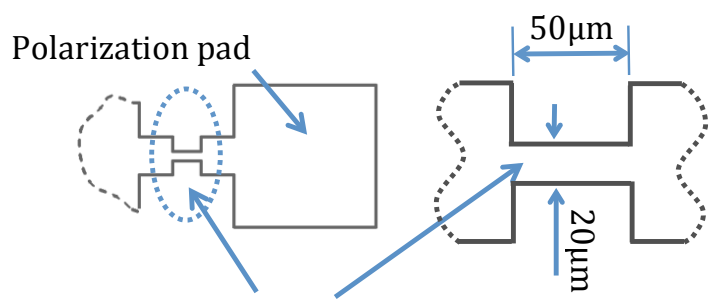

Chromium filament

(d)

Figura 3.1: Representação esquemática da microlâmpada. Em (a) a espessura dos filmes, em (b) os materiais utilizados, em (c) uma foto do filamento de $\mathrm{Cr}$ ampliada no microscópio e em (d) as dimensões do filamento.

\subsection{Detalhes da fabricação das microlâmpadas}

As microlâmpadas estudadas foram fabricadas no Grupo de Novos Materiais e Dispositivos (GNMD) da Escola Politécnica da USP (POLI-USP) seguindo procedimentos já desenvolvidos anteriormente pelo mesmo grupo ${ }^{[8,17]}$. As principais etapas de fabricação foram:

a) Limpeza padrão do substrato $\mathrm{Si}<100>$;

b) Oxidação térmica;

c) Corte de lâminas nas dimensões de 1 pol x 1 pol;

d) Nova etapa de limpeza padrão; 
e) Deposição de a-SiO $\mathrm{N}_{y}$ por PECVD, conforme parâmetros da tabela 3.1;

f) Fotogravação da $1^{\text {a }}$ máscara (figura $3.3 \mathrm{a}$ ), com a revelação do fotorresiste, para produção dos contatos, trilhas e filamento de $\mathrm{Cr}$;

g) Remoção do fotorresiste excedente deixando o padrão da $1^{\mathrm{a}}$ máscara sobre a superfície do material;

h) Deposição de Cr por sputtering, conforme parâmetros da tabela 3.1;

i) Remoção do resiste (lift off);

j) Fotogravação da $2^{\mathrm{a}}$ máscara (figura $3.3 \mathrm{~b}$ ), com a revelação do fotorresiste, para produzir as cavidades ao lado do filamento;

k) Remoção do fotorresiste excedente deixando o padrão da $2^{\mathrm{a}}$ máscara sobre a superfície do material;

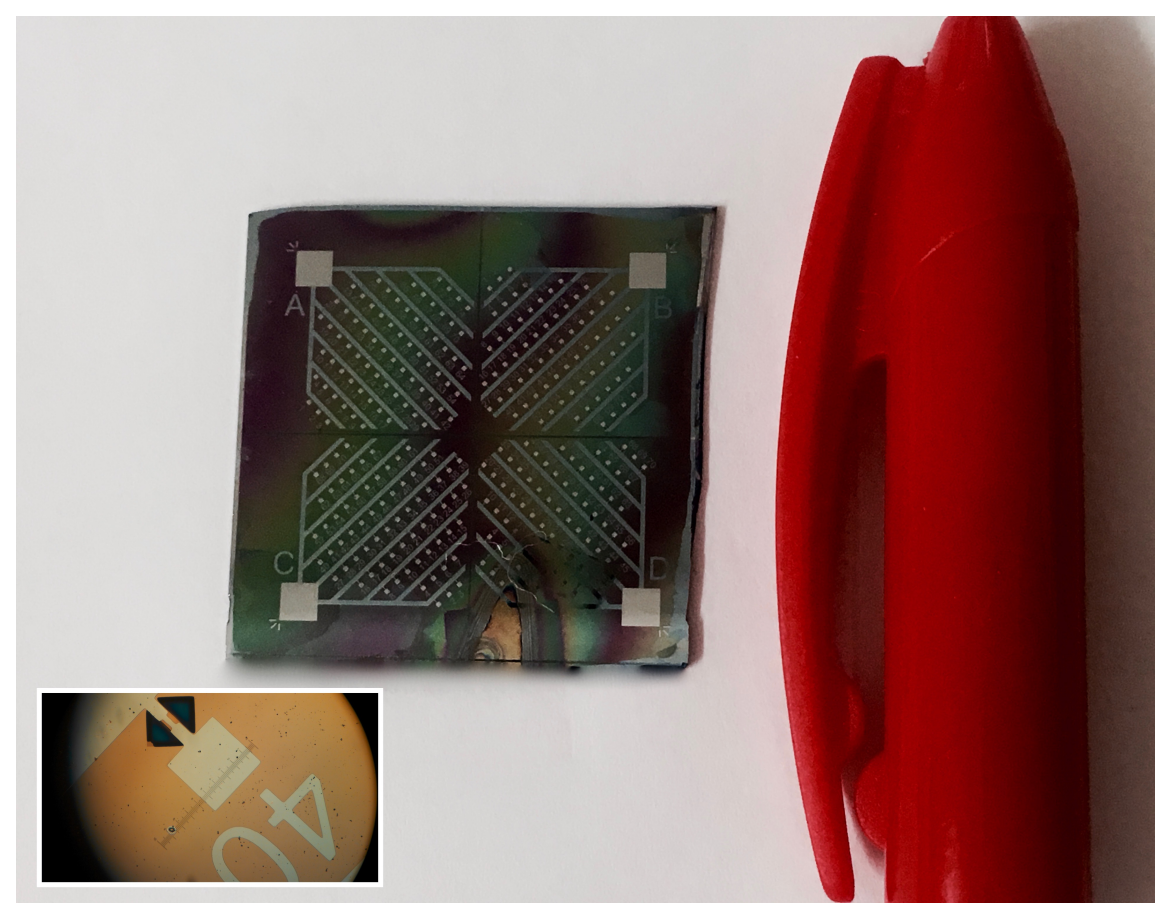

Figura 3.2: Foto da peça produzida contendo dezenas de microlâmpadas, ao lado de uma tampa de caneta. No detalhe a microlâmpada $\mathrm{n}^{\circ} 40$ do quadrante $\mathrm{D}$. 
1) Remoção do $a-\mathrm{SiO}_{x} \mathrm{~N}_{y}$ com solução DLV (decapante lento de vidro) segundo o padrão da $2^{\circ}$ máscara;

m) Remoção total do resiste;

n) Corrosão de $\mathrm{Si}$ em $\mathrm{KOH}$ a $80^{\circ} \mathrm{C}$ por 50-60 min, para a obtenção das cavidades em V, conforme descrito na seção 1.2.3;

o) Deposição da última camada de a-SiC, a- $\mathrm{SiO}_{x} \mathrm{~N}_{y}, \mathrm{AlN}$ ou $\mathrm{TiO}_{2}$, com os contornos definidos pela $2^{\mathrm{a}}$ máscara, conforme parâmetros da tabela 3.1 ;

p) Raspagem dos contatos;

q) Energização, conforme tabela 3.3.

Tabela 3.1: Parâmetros utilizados nos processos de deposição por PECVD e sputtering. As funções de cada camada são: IS (camada isolante), FM (filamento da microlâmpada), CP (camada de proteção).

\begin{tabular}{|c|c|c|c|c|c|c|c|c|c|c|}
\hline \multirow{2}{*}{$\begin{array}{l}\text { Material } \\
\mathrm{a}-\mathrm{SiO}_{x} \mathrm{~N}_{y}\end{array}$} & \multirow{2}{*}{$\begin{array}{c}\text { Função } \\
\text { IS }\end{array}$} & \multirow{2}{*}{$\begin{array}{c}\begin{array}{c}\text { Processo } \\
\text { Deposição }\end{array} \\
\text { PECVD }\end{array}$} & \multicolumn{3}{|c|}{ Fluxo $(\mathrm{sccm})$} & \multirow{2}{*}{$\begin{array}{c}\begin{array}{l}\text { Temp. } \\
\left({ }^{\circ} \mathrm{C}\right)\end{array} \\
320\end{array}$} & \multirow{2}{*}{$\begin{array}{c}\begin{array}{c}\text { Pressão } \\
\text { (mTorr) }\end{array} \\
38\end{array}$} & \multirow{2}{*}{$\begin{array}{c}\text { Potência } \\
\text { R.F.(W) } \\
200\end{array}$} & \multirow{2}{*}{$\begin{array}{c}\begin{array}{l}\text { Tempo } \\
(\text { min })\end{array} \\
150\end{array}$} & \multirow{2}{*}{$\begin{array}{l}\begin{array}{l}\text { Esp.* } \\
(n m)\end{array} \\
2430\end{array}$} \\
\hline & & & $\mathrm{N}_{2} \mathrm{O}: 45$ & $\mathrm{~N}_{2}: 30$ & $\mathrm{SiH}_{4}: 30$ & & & & & \\
\hline $\mathrm{Cr}$ & $\mathrm{FM}$ & sputtering & & Ar: 10 & & - & 2 & 70 & 20 & 240 \\
\hline $\mathrm{a}-\mathrm{SiC}$ & $\mathrm{CP}$ & PECVD & $\mathrm{H}_{2}: 200$ & $\mathrm{CH}_{4}: 32.4$ & $\mathrm{SiH}_{4}: 3.6$ & 320 & 46 & 100 & 25 & 125 \\
\hline $\mathrm{a}-\mathrm{SiO}_{x} \mathrm{~N}_{y}$ & $\mathrm{CP}$ & PECVD & $\mathrm{N}_{2} \mathrm{O}: 45$ & $\mathrm{~N}_{2}: 30$ & $\mathrm{SiH}_{4}: 30$ & 320 & 38 & 200 & 8 & 114 \\
\hline $\mathrm{AlN}$ & $\mathrm{CP}$ & sputtering & $\mathrm{Ar}$ & $\mathrm{N}_{2}:$ & & - & 2 & 100 & 30 & 115 \\
\hline $\mathrm{TiO}_{2}$ & $\mathrm{CP}$ & sputtering & & $\mathrm{O}_{2}:$ & & - & 1 & 150 & 83 & 136 \\
\hline
\end{tabular}

* valor esperado em condições ideais

\subsubsection{O filamento em forma de ponte}

A etapa $\mathrm{k}$ produz cavidades em $\mathrm{V}$ para que o filamento $\mathrm{Cr}$ fique na forma de ponte, intensificando a emissão de luz pelo dispositivo, uma vez que parte dela será refletida 


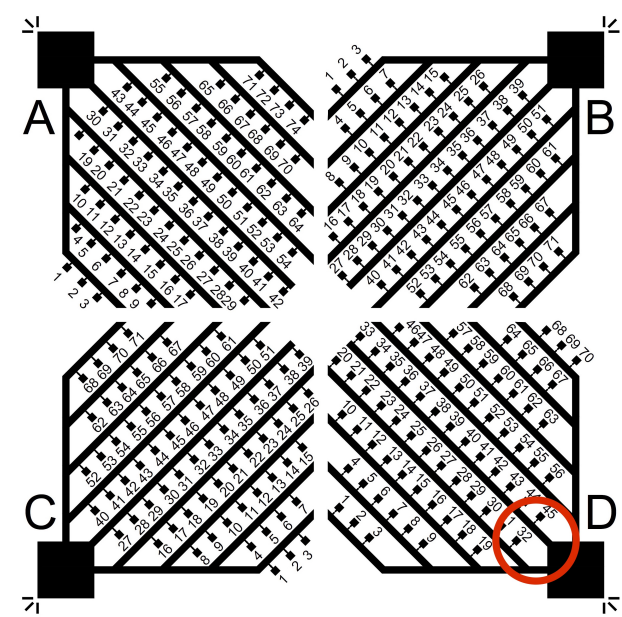

(a)

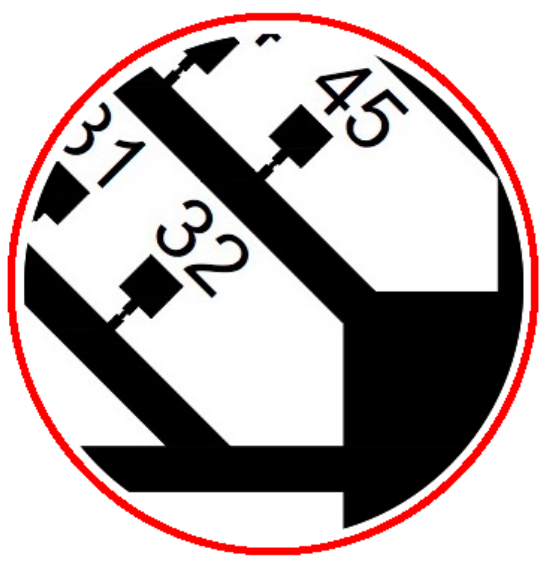

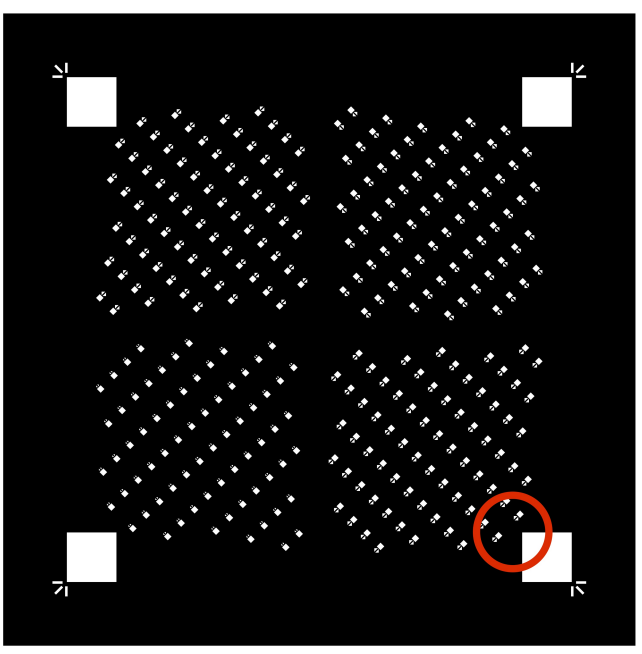

(b)

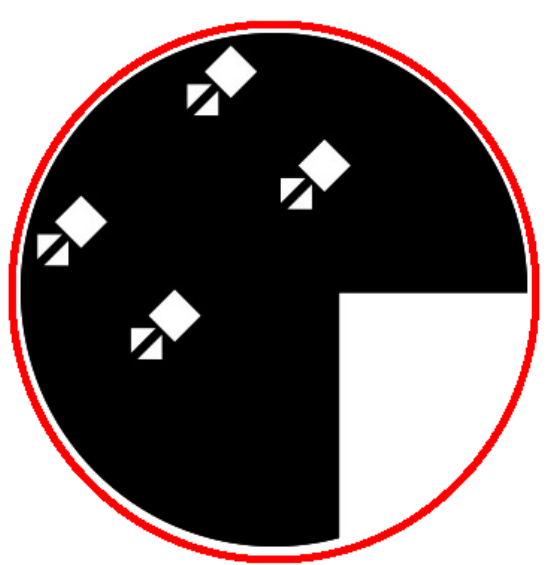

(c)

Figura 3.3: Máscaras utilizadas no processo de litografia aplicado às microlâmpadas. (a) $1^{\mathrm{a}}$ máscara, utilizada para produzir os contatos de cromo, as trilhas e os filamentos. Nela é possível observar os quadrantes A-D, bem como a numeração de cada microlâmpada. (b) $2^{a}$ máscara, utilizada para definir as regiões onde não o a- $\mathrm{SiO}_{x} \mathrm{~N}_{y}$ será removido com solução DLV para, posteriormente, produzir as cavidades. (c) Detalhes das regiões demarcadas das máscaras. 
pelo substrato. Para ilustrar o resultado, a figura 3.4 mostra a cavidade sob o filamento de uma outra microlâmpada, também produzida pelo GNMD ${ }^{[96]}$.

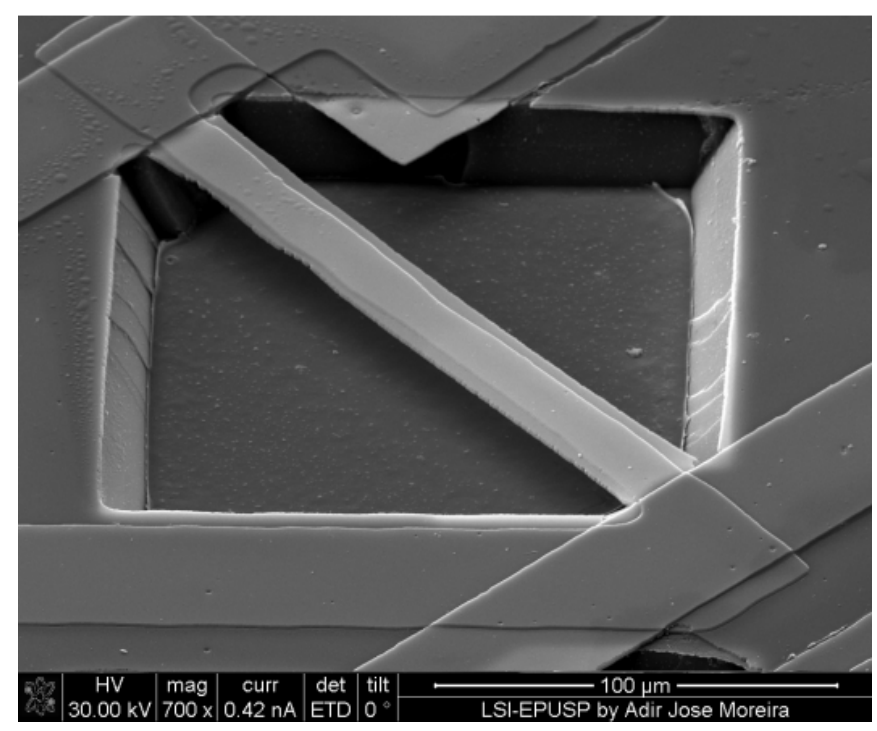

Figura 3.4: Imagem do filamento de Cr em ponte de uma microlâmpada produzida pelo GNMD $^{[96]}$. A imagem não é do mesmo dispositivo estudado nessa tese, mas tem forma construtiva semelhante. A camada de proteção ainda não tinha sido depositada.

O dispositivo foi dividido em quatro quadrantes, nos quais foram preparados filamentos de formatos diferentes. A figura 3.5 mostra fotografias tiradas com microscópio ótico de cada tipo de filamento. Entretanto, por limitações experimentais, apenas o filamento do quadrante D foi analisado nesta tese. 


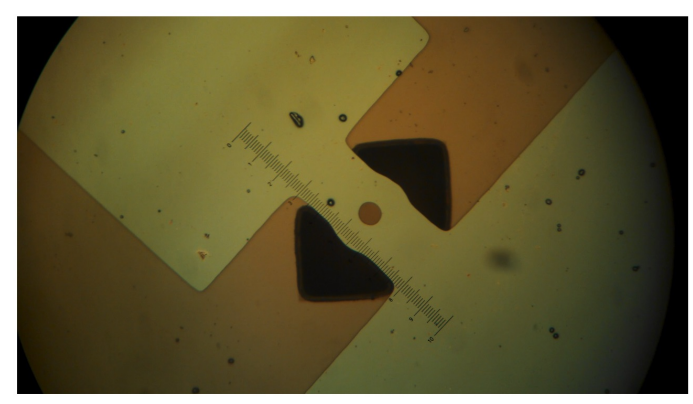

Quadrante A

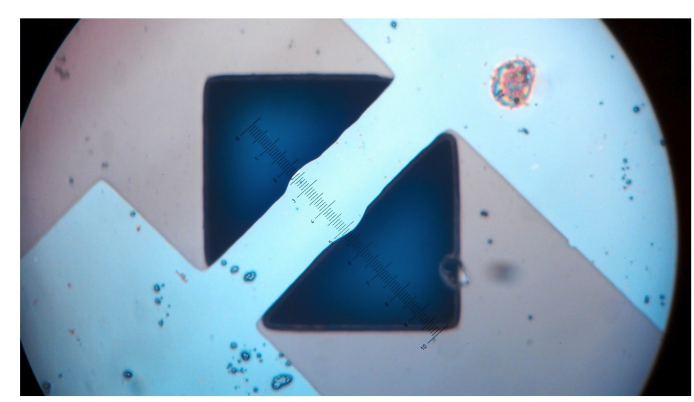

Quadrante C

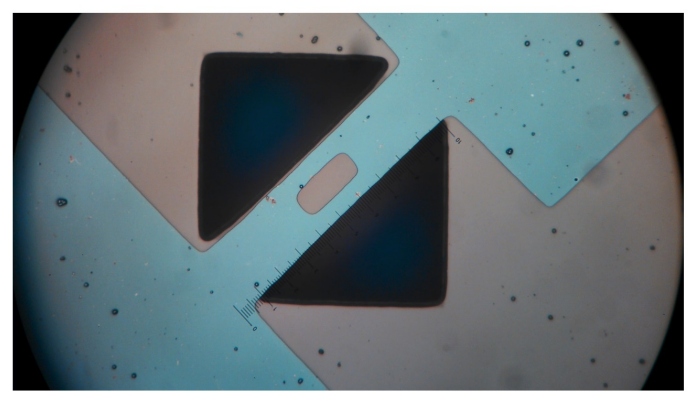

Quadrante B

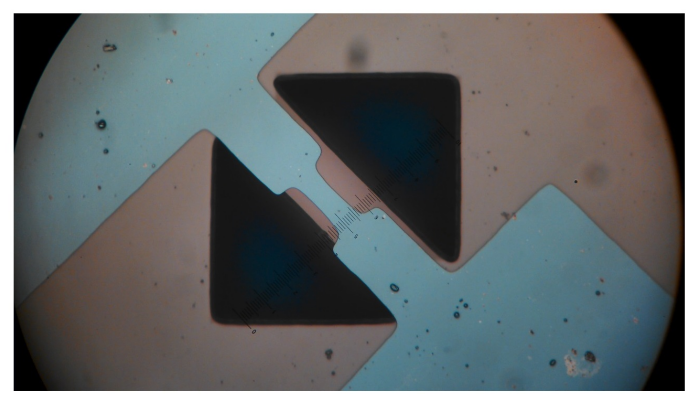

Quadrante D

Figura 3.5: Imagem ampliada dos diferentes filamentos produzidos nos quadrantes A, B, C e D da microlâmpada. Apenas o filamento do quadrante D foi estudado nesta tese.

\subsubsection{Corrosão por RIE das microlâmpadas com a-SiC}

$\mathrm{Na}$ fabricação da microlâmpada com camada protetora de a-SiC, a raspagem dos contatos (etapa p) não foi feita com sucesso, devido à elevada resistência mecânica do material. O material sobre os contatos foi então corroído pelo processo RIE (Reactive Ion Etching), conforme descrito na seção 1.2.3. As etapas adicionadas ao processo foram então:

p1) Fotogravação novamente da $2^{\mathrm{a}}$ máscara (figura 3.3b), com a revelação do fotorresiste;

p2) Revelação do fotorresiste e posterior remoção do resiste excedente deixando o padrão da máscara sobre a superfície do material;

p3) Corrosão por RIE em $\mathrm{CHF}_{3}$ e $\mathrm{O}_{2}$, conforme parâmetros da tabela 3.2. 
Tabela 3.2: Parâmetros utilizados na corrosão do a-SiC por RIE

\begin{tabular}{lcccccc}
\hline $\begin{array}{l}\text { Material } \\
\text { corroído }\end{array}$ & Fluxo $($ sccm $)$ & $\begin{array}{l}\text { Temp. } \\
\left({ }^{\circ} \mathrm{C}\right)\end{array}$ & $\begin{array}{c}\text { Pressão } \\
(\text { mTorr })\end{array}$ & $\begin{array}{c}\text { Potência } \\
\text { R.F. }(W)\end{array}$ & $\begin{array}{l}\text { Tempo } \\
(\text { min })\end{array}$ \\
\hline a-SiC & $\mathrm{CHF}_{3}: 40$ & $\mathrm{O}_{2}: 40$ & - & 100 & 100 & 7 \\
\hline
\end{tabular}

\subsection{Energização}

Para estudar o efeito do aquecimento do filamento na estrutura do material da camada protetora, as microlâmpadas foram energizadas ex situ (ver figura 3.6), nas regiões metálicas expostas ( $p a d s$ ) onde a camada protetora foi removida, com correntes e tempos diferentes. A tabela 3.3 exibe tais condições e a identificação de cada microlâmpada.

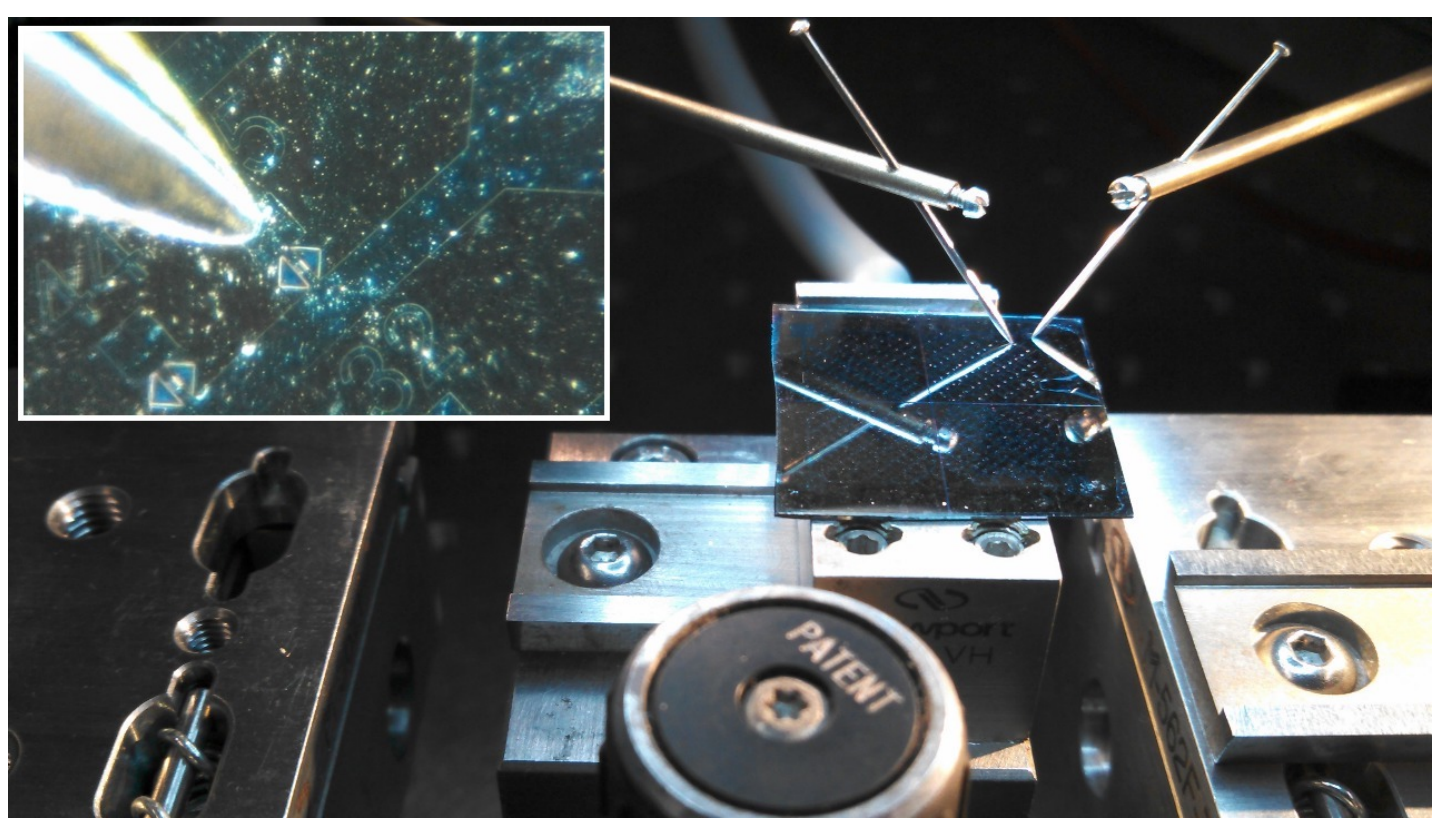

Figura 3.6: Arranjo com agulhas utilizado para a energização das microlâmpadas. No detalhe, foto durante a energização da microlâmpada 45 do quadrante D.

A tabela 3.4 reproduz a faixa de valores da condutividade térmica para os referidos materiais que foi apresentada na seção 1.3. Os valores devem ser tomados apenas como uma ordem de grandeza, pois dependem das condições de deposição, fase e temperatura. Como as espessuras dos quatro filmes são semelhantes (de 114 a $136 \mathrm{~nm}$ ), é razoável 
Tabela 3.3: Condições de energização e identificação das microlâmpadas

\begin{tabular}{lcc||lcc}
\hline \multicolumn{3}{c}{ a-SiC } & \multicolumn{5}{c}{$\mathrm{a}-\mathrm{SiO}_{x} \mathrm{~N}_{y}$} \\
\hline TAG & $\begin{array}{c}\text { Corrente } \\
(\mathrm{mA})\end{array}$ & Tempo (s) & TAG & $\begin{array}{c}\text { Corrente } \\
(\mathrm{mA})\end{array}$ & Tempo (s) \\
\hline ML49-SiC & 0 & 0 & ML59-SiON & 0 & 0 \\
ML41-SiC & 30 & 1800 & ML62-SiON & 30 & 3600 \\
ML52-SiC & 30 & 3600 & ML49-SiON & 44 & 10 \\
ML37-SiC & 45 & 1800 & ML51-SiON & 44 & 20 \\
ML39-SiC & 45 & 3600 & ML55-SiON & 45 & queimada \\
ML20-SiC & 48 & 20 & & & \\
ML34-SiC & 48 & 60 & & & \\
ML27-SiC & 50 & 10 & & & \\
ML24-SiC & 50 & 20 & & & \\
ML23-SiC & 51 & queimada & & & \\
emite luz visível a partir de $47 \mathrm{~mA}$ & emite luz visível a partir de $41 \mathrm{~mA}$ \\
\hline
\end{tabular}

\begin{tabular}{|c|c|c|c|c|c|}
\hline \multicolumn{3}{|c|}{$\mathrm{AlN}$} & \multicolumn{3}{|c|}{$\mathrm{TiO}_{2}$} \\
\hline TAG & $\begin{array}{c}\text { Corrente } \\
(\mathrm{mA})\end{array}$ & Tempo (s) & TAG & $\begin{array}{c}\text { Corrente } \\
(\mathrm{mA})\end{array}$ & Tempo (s) \\
\hline ML53-AlN & 0 & 0 & ML49- $\mathrm{TiO}_{2}$ & 0 & 0 \\
\hline ML17-AlN & 30 & 1800 & ML09- $\mathrm{TiO}_{2}$ & 30 & 1800 \\
\hline ML32-AlN & 30 & 3600 & ML11- $\mathrm{TiO}_{2}$ & 30 & 3600 \\
\hline ML31-AlN & 40 & 1800 & $\mathrm{ML}_{42}-\mathrm{TiO}_{2}$ & 38 & 1800 \\
\hline ML28-AlN & 40 & 3600 & ML19- $\mathrm{TiO}_{2}$ & 38 & 3600 \\
\hline ML70-AlN & 43 & 20 & ML39- $\mathrm{TiO}_{2}$ & 40 & 20 \\
\hline ML54-AlN & 43 & 60 & ML30- $\mathrm{TiO}_{2}$ & 40 & 60 \\
\hline ML62-AlN & 45 & 10 & ML28- $\mathrm{TiO}_{2}$ & 41 & 10 \\
\hline ML59-AlN & 45 & 20 & ML26- $\mathrm{TiO}_{2}$ & 41 & 20 \\
\hline ML37-AlN & 46 & queimada & ML13- $\mathrm{TiO}_{2}$ & 42 & queimada \\
\hline \multicolumn{6}{|c|}{ emite luz visível a partir de $43 \mathrm{~mA} \quad$ emite luz visível a partir de $40 \mathrm{~mA}$} \\
\hline
\end{tabular}


supor que a perda de calor pela superfície seja menor no $\mathrm{TiO}_{2}$ e $\mathrm{SiO}_{x} \mathrm{~N}_{y}$ (quando rico em oxigênio), pois apresentam os menores valores de condutividade térmica, condição compatível com o desempenho das microlâmpadas reproduzido aqui na mesma tabela.

Tabela 3.4: (esquerda) Faixa de valores, reportados na literatura, da condutividade térmica dos filmes utilizados como camada de proteção nas microlâmpadas. (direita) corrente necessária para emissão de luz visível e queima do filamento das microlâmpadas (repetição dos valores apresentados no capítulo 1.3 e na secção 3.2 ).

\begin{tabular}{|c|c|c|c|c|c|c|}
\hline \multicolumn{4}{|c|}{ Condutividade térmica $(W / m . K)$} & \multicolumn{3}{|c|}{ Corrente de energização $(m A)$} \\
\hline Material & & $\min$ & $\max$ & Material da $\mathrm{CP}$ & luz visível & queima \\
\hline $\mathrm{AlN}$ & & 180 & 260 & $\mathrm{AlN}$ & 43 & 46 \\
\hline $\mathrm{SiC}$ & & 1,7 & 160 & $\mathrm{SiC}$ & 47 & 51 \\
\hline $\mathrm{TiO}_{2}$ & & 5,0 & 15 & $\mathrm{TiO}_{2}$ & 40 & 42 \\
\hline \multirow{2}{*}{$\mathrm{SiO}_{x} \mathrm{~N}_{y} \searrow$} & $\mathrm{SiO}_{2}$ & 0,8 & 1,4 & \multirow{2}{*}{$\mathrm{SiO}_{x} \mathrm{~N}_{y}$} & \multirow{2}{*}{41} & \multirow{2}{*}{45} \\
\hline & $\mathrm{Si}_{3} \mathrm{~N}_{4}$ & 25 & 36 & & & \\
\hline
\end{tabular}

\subsection{Filmes finos adicionais de a-SiC e AlN}

Os resultados que serão exibidos nas seções 4.6 e 4.7 mostram modificações nos espectros XANES, obtidos a partir das microlâmpadas com a-SiC e AlN, em função da energização. Com o objetivo de aprofundar o estudo desses materiais e entender o motivo de tais modificações, amostras de filmes finos adicionais, crescidos sobre substratos extensos, foram produzidas em condições similares às das microlâmpadas, conforme a descrição a seguir. Sobre um substrato de $\mathrm{Si}<100>$ foram depositadas uma camada de $\mathrm{Cr}$ e uma camada do material de proteção (a-SiC ou $\mathrm{AlN}$ ). As deposições foram feitas com as mesmas condições da tabela 3.1, de forma a obter um sistema que simule as microlâmpadas. No total foram produzidos dois conjuntos — cinco amostras de a-SiC sobre $\mathrm{Cr}$ e cinco de AlN sobre $\mathrm{Cr}$ - cada conjunto fabricado na mesma batelada. Para estudar a influência do Cr no sistema, ele foi depositado apenas sobre uma região parcial do substrato. Desta forma, obteve-se amostras do material de proteção (a-SiC ou AlN) 
com e sem o filme de Cr sobre o substrato de $\mathrm{Si}$, conforme mostra a figura 3.7. As amostras produzidas não são de dimensões micrométricas, o que permite analisá-las por espectroscopia de absorção de raios X (XAS) com feixes convencionais de dimensões milimétricas.

Para simular o efeito térmico decorrente da energização das microlâmpadas, as amostras foram submetidas a tratamento térmico em forno tubular, em ar, nas temperaturas de $500,700,900$ e $1100^{\circ} \mathrm{C}$. A tabela 3.5 apresenta a identificação das amostras produzidas. As mesmas não permaneceram nestas temperaturas por muito tempo. O forno foi desligado assim que a temperatura desejada foi atingida e as amostras foram deixadas resfriar dentro do forno. Essa condição se assemelha um pouco ao aquecimento obtido durante a operação das microlâmpadas, apesar dessa última atingir altas temperaturas muito mais rapidamente. As imagens do lado direito da figura 3.8 exibem como as amostras tratadas a 900 e $1100^{\circ} \mathrm{C}$ ficaram deterioradas agressivamente na região onde o cromo estava presente.

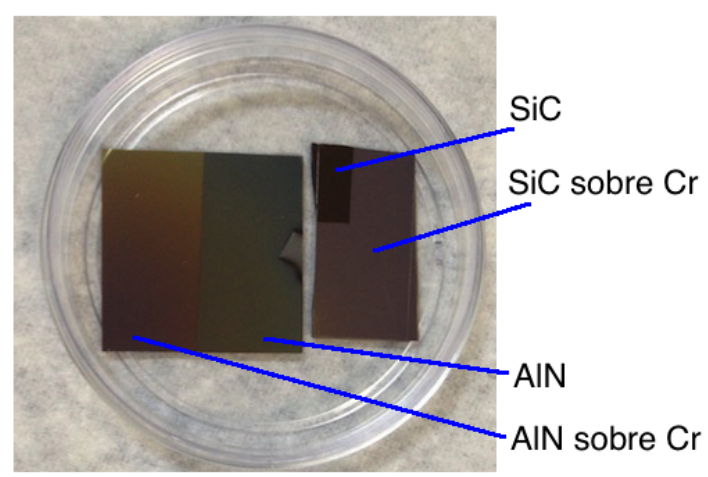

(a)

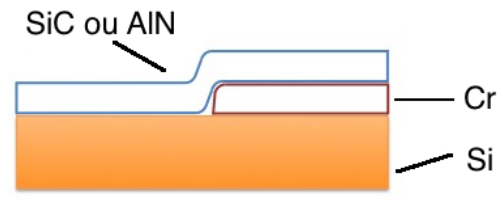

(b)

Figura 3.7: Amostras de a-SiC e AlN produzidas sobre uma região de Cr. Em (a), uma foto das amostras onde é possível observar a região com e sem Cr. Em (b) uma representação esquemática das camadas depositadas. 

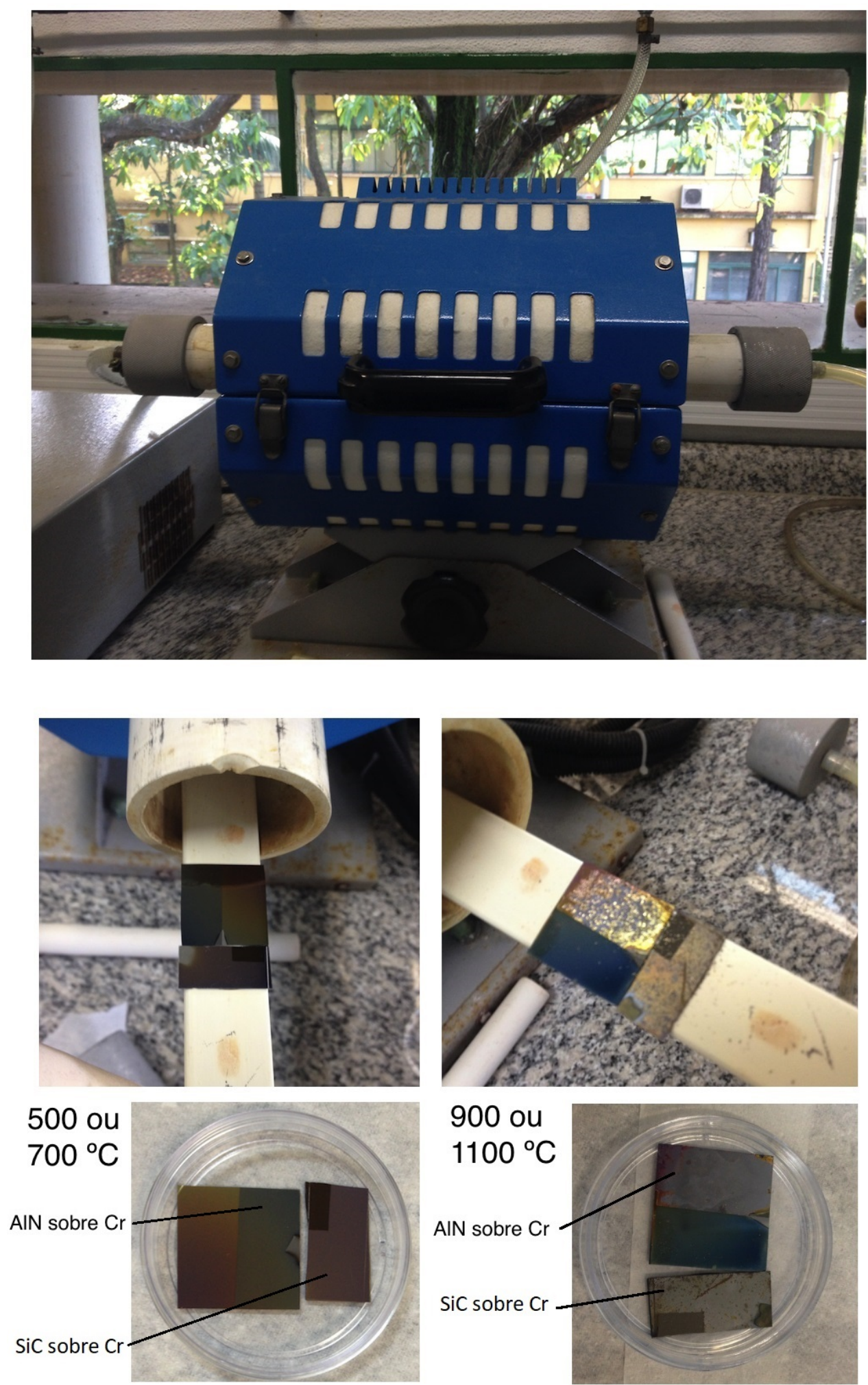

Figura 3.8: (acima) Forno tubular utilizado para o tratamento térmico. (abaixo) Foto de algumas amostras após o tratamento térmico. As que foram submetidas a temperaturas de 900 ou $1100^{\circ} \mathrm{C}$ apresentaram deterioração acentuada, apenas na região depositada sobre Cr. 
Tabela 3.5: Identificação das amostras de filmes finos adicionais de a-SiC e AlN

\begin{tabular}{lcc||lcc}
\hline Identif. & Composição* & $\begin{array}{c}\text { Tratamento } \\
\text { Term. }\left({ }^{\circ} \mathrm{C}\right)\end{array}$ & Identif. & Composição* & $\begin{array}{c}\text { Tratamento } \\
\text { Term. }\left({ }^{\circ} \mathrm{C}\right)\end{array}$ \\
\hline $\mathrm{SiC}-\mathrm{RT}$ & $\mathrm{a}-\mathrm{SiC}$ & - & AlN-RT & AlN & - \\
$\mathrm{SiC}-500$ & a-SiC & 500 & AlN-500 & AlN & 500 \\
$\mathrm{SiC}-700$ & a-SiC & 700 & AlN-700 & AlN & 700 \\
$\mathrm{SiC}-900$ & a-SiC & 900 & AlN-900 & AlN & 900 \\
$\mathrm{SiC}-1100$ & a-SiC & 1100 & AlN-1100 & AlN & 1100 \\
$\mathrm{SiC} / \mathrm{Cr}-\mathrm{RT}$ & a-SiC sobre Cr & - & AlN/Cr-RT & AlN sobre Cr & - \\
$\mathrm{SiC} / \mathrm{Cr}-500$ & a-SiC sobre Cr & 500 & AlN/Cr-500 & AlN sobre Cr & 500 \\
$\mathrm{SiC} / \mathrm{Cr}-700$ & a-SiC sobre Cr & 700 & AlN/Cr-700 & AlN sobre Cr & 700 \\
$\mathrm{SiC} / \mathrm{Cr}-900$ & a-SiC sobre Cr & 900 & AlN/Cr-900 & AlN sobre Cr & 900 \\
$\mathrm{SiC} / \mathrm{Cr}-1100$ & a-SiC sobre Cr & 1100 & AlN/Cr-1100 & AlN sobre Cr & 1100 \\
\hline
\end{tabular}

* todas amostras crescidas sobre $\mathrm{Si}<100>$ 
Capítulo 3. Fabricação das microlâmpadas e dos filmes finos adicionais 


\section{Capítulo 4}

\section{Resultados e discussão}

Com o objetivo de estudar as propriedades estruturais das camadas protetoras das microlâmpadas, bem como as modificações induzidas durante a sua operação, foram realizadas medidas de Espectroscopia de Absorção de Raios X (XAS) nos dispositivos. Nas amostras de filmes finos adicionais, além de XAS, medidas de Fluorescência de raios X com incidência rasante (GIXRF) e de Espectroscopia por Retroespalhamento de Rutherford (RBS) foram realizadas.

\subsection{Medidas experimentais realizadas nas microlâmpadas}

Nas microlâmpadas, após a energização ex-situ, foram efetuadas medidas de absorção na região XANES, utilizando radiação de luz síncrotron microfoco da linha LUCIA disponível no SOLEIL ${ }^{[97]}$. O feixe de dimensões micrométricas $\left(3 \times 3 \mu \mathrm{m}^{2}\right)$ foi focalizado, com o auxílio de um microscópio óptico, diretamente na região do filamento, atingindo a área termicamente afetada da camada protetora. O sinal foi obtido por TEY (Total Electron Yield), como mostra a figura 4.1. Para efeito de comparação, algumas amostras de materiais padrão foram medidas na mesma linha, assim como foram utilizados espectros de padrões obtidos em trabalhos anteriores realizados pelo 


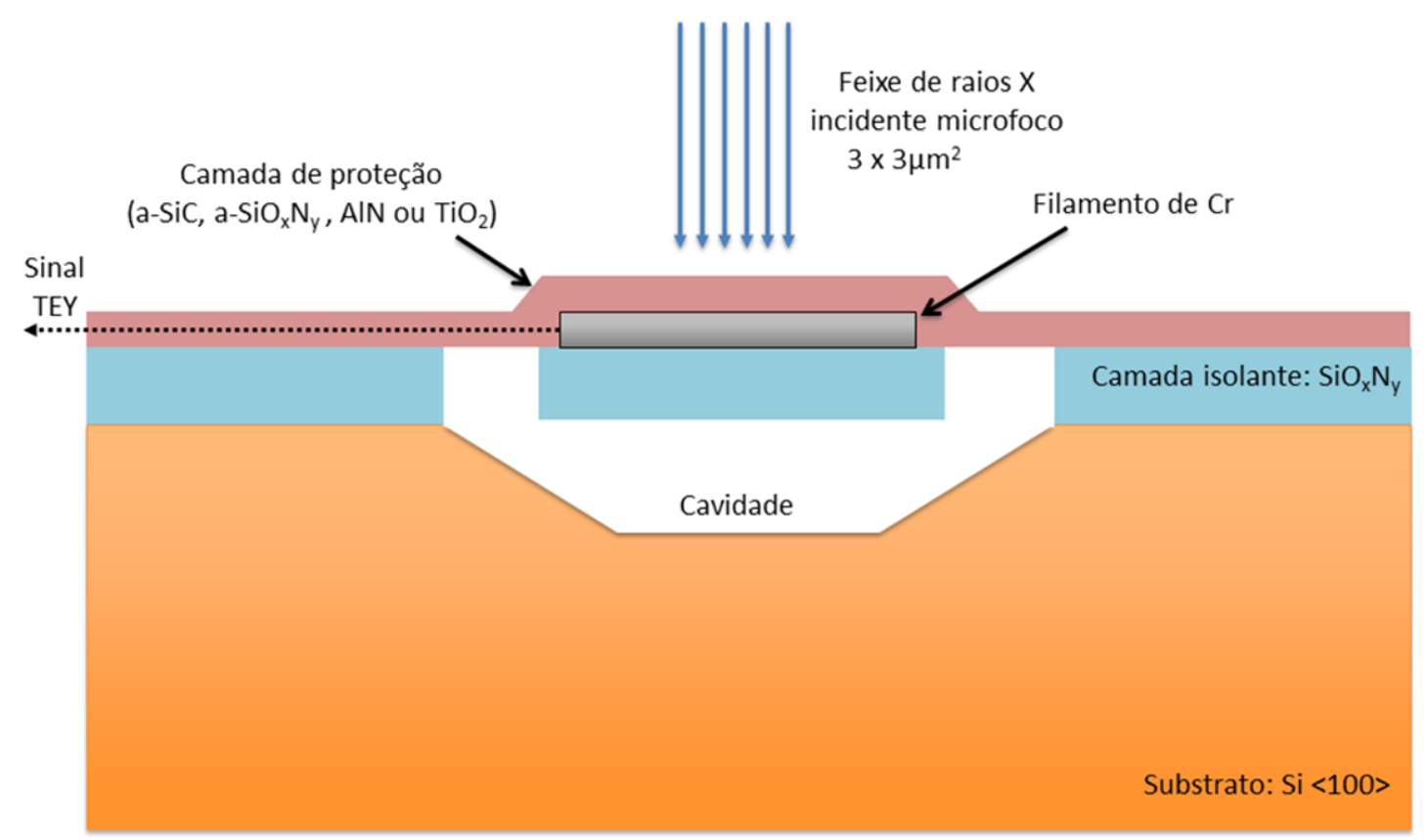

Figura 4.1: Esquema das medidas de absorção de raios $\mathrm{X}$ realizadas com o feixe microfoco nas microlâmpadas. As medidas foram obtidas por TEY (Total Electron Yield) a partir do próprio circuito do filamento.

mesmo grupo de pesquisa ${ }^{[28,33]}$.

\subsection{Medidas experimentais realizadas nas amostras de fil- mes finos adicionais}

Com o objetivo de melhor entender os resultados obtidos com as microlâmpadas de a-SiC e AlN, amostras de filmes finos adicionais, depositados sobre substratos extensos, foram crescidos com os mesmos parâmetros no PECVD e sputtering, respectivamente, utilizados nas microlâmpadas. Todas foram crescidas sobre dois substratos: o material da camada protetora (a-SiC ou AlN) depositado sobre Si e sobre Cr (vide seção 3.3), de forma a verificar a influência do Cr no filme. As amostras foram submetidas a um tratamento térmico nas temperaturas de $500,700,900$ e $1100^{\circ} \mathrm{C}$ e uma permaneceu à temperatura ambiente (RT). A identificação das amostras é exibida na tabela 3.5. 
Ainda outras amostras de a-SiC depositadas sobre Cr e corroídas por RIE foram também produzidas. A corrosão em diferentes profundidades permitiu avaliar a possível influência desse processo no carbeto de silício.

O fato dos filmes finos adicionais não serem de dimensões micrométricas, permitiu medi-las no feixe de luz síncrotron das linhas SXS ${ }^{[98]}$ (XANES e EXAFS) e XRF ${ }^{[99]}$ (GIXRF), disponíveis no Laboratório Nacional de Luz Síncrotron (LNLS) ${ }^{[100]}$. Adicionalmente, medidas de RBS foram realizadas nessas amostras no Laboratório de Análises de Materiais por Feixes Iônicos (LAMFI) do Instituto de Física da USP (IF-USP).

\subsection{Padrões experimentais utilizados}

As análises que serão apresentadas nas seções seguintes utilizam espectros de padrões experimentais para comparação. A tabela 4.1 resume as suas principais características e a figura 4.3 exibe os seus espectros. A amostra padrão de c-SiC foi caracterizada por difração de raios X e analisada pelo método de Rietveld ${ }^{[101]}$. O difratograma foi obtido no difratômetro D8-Discovery Bruker, disponível no Laboratório de Cristalografia do Instituto de Física da USP (LCr-IF-USP), em geometria $\theta-\theta$, e radiação $\mathrm{CuK}_{\alpha}$. Uma mistura de c-SiC(pó) e c-Si(pó) foi medida para melhorar a precisão da localização dos picos. A figura 4.2 exibe o resultado do refinamento, onde foi identificada a presença

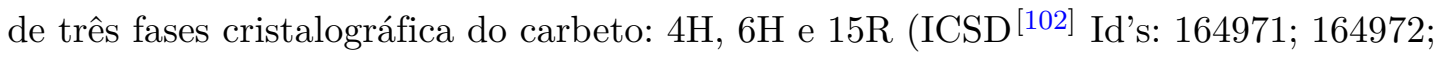
24168 , respectivamente). 
Tabela 4.1: Características dos padrões experimentais utilizados.

\begin{tabular}{|c|c|c|c|}
\hline Identificação & Descrição & Apresentação & Fonte \\
\hline c-Si & Silício monocristalino $<100>$ & lâmina & comercial \\
\hline $\mathrm{a}-\mathrm{Si}$ & Silício amorfo & filme & $\begin{array}{l}\text { depositado } \\
\text { PECVD }\end{array}$ \\
\hline $\mathrm{c}-\mathrm{SiC}$ & $\begin{array}{l}\text { Carbeto de silício cristalino } \\
6 \mathrm{H} / 4 \mathrm{H} / 15 \mathrm{R}\end{array}$ & pó & comercial \\
\hline $\mathrm{a}-\mathrm{SiC}$ & $\begin{array}{l}\text { Carbeto de silício amorfo a- } \\
\mathrm{Si}_{x} \mathrm{C}_{1-x}: \mathrm{H}\end{array}$ & filme & $\begin{array}{l}\text { depositado } \\
\text { PECVD* }\end{array}$ \\
\hline $\mathrm{a}-\mathrm{SiO}_{2}$ & Óxido de silício amorfo & filme & $\begin{array}{l}\text { óxido térmico so- } \\
\text { bre um substrato } \\
\text { de } \mathrm{Si}\end{array}$ \\
\hline $\mathrm{a}-\mathrm{Si}_{3} \mathrm{~N}_{4}$ & Nitreto de silício amorfo & filme & $\begin{array}{l}\text { depositado por } \\
\text { PECVD }\end{array}$ \\
\hline anatase & $\begin{array}{l}\text { Dióxido de titânio na fase ana- } \\
\text { tase }\end{array}$ & pó & comercial \\
\hline rutilo & Dióxido de titânio na fase rutilo & pó & comercial \\
\hline $\mathrm{Al}$ & Alumínio metálico & lâmina & $\begin{array}{l}\text { comercial (dispo- } \\
\text { nível no LNLS) }\end{array}$ \\
\hline AlN & Nitreto de alumínio amorfo & filme & $\begin{array}{l}\text { depositado } \\
\text { sputtering* }\end{array}$ \\
\hline $\mathrm{Al}_{2} \mathrm{O}_{3}$ & Óxido de alumínio (corundum) & pó & comercial \\
\hline
\end{tabular}

* crescido sobre $\mathrm{Si}$, juntamente com a camada de proteção da microlâmpada correspondente

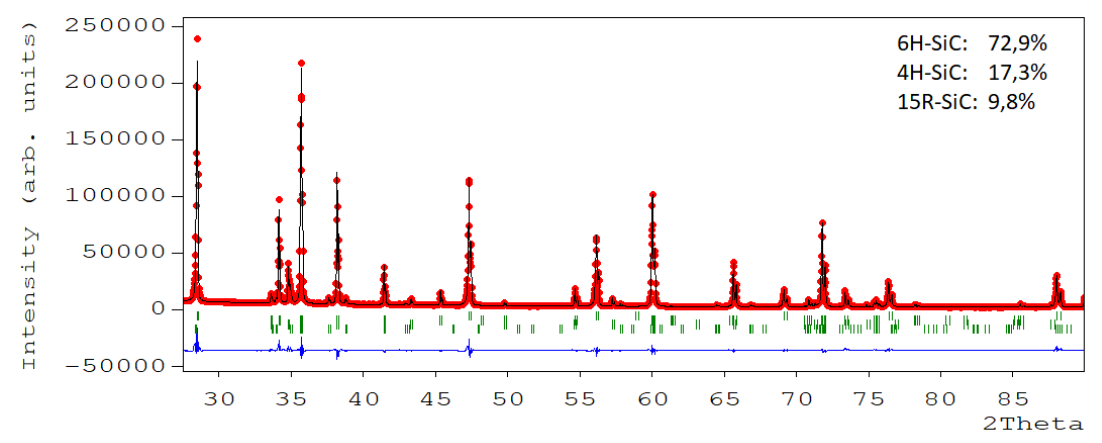

Figura 4.2: Refinamento Rietveld do padrão c-SiC utilizado. O difratograma foi obtido com uma mistura de c-SiC(pó) e c-Si(pó). O refinamento foi realizado com o software FullProf ${ }^{[103]}$. 


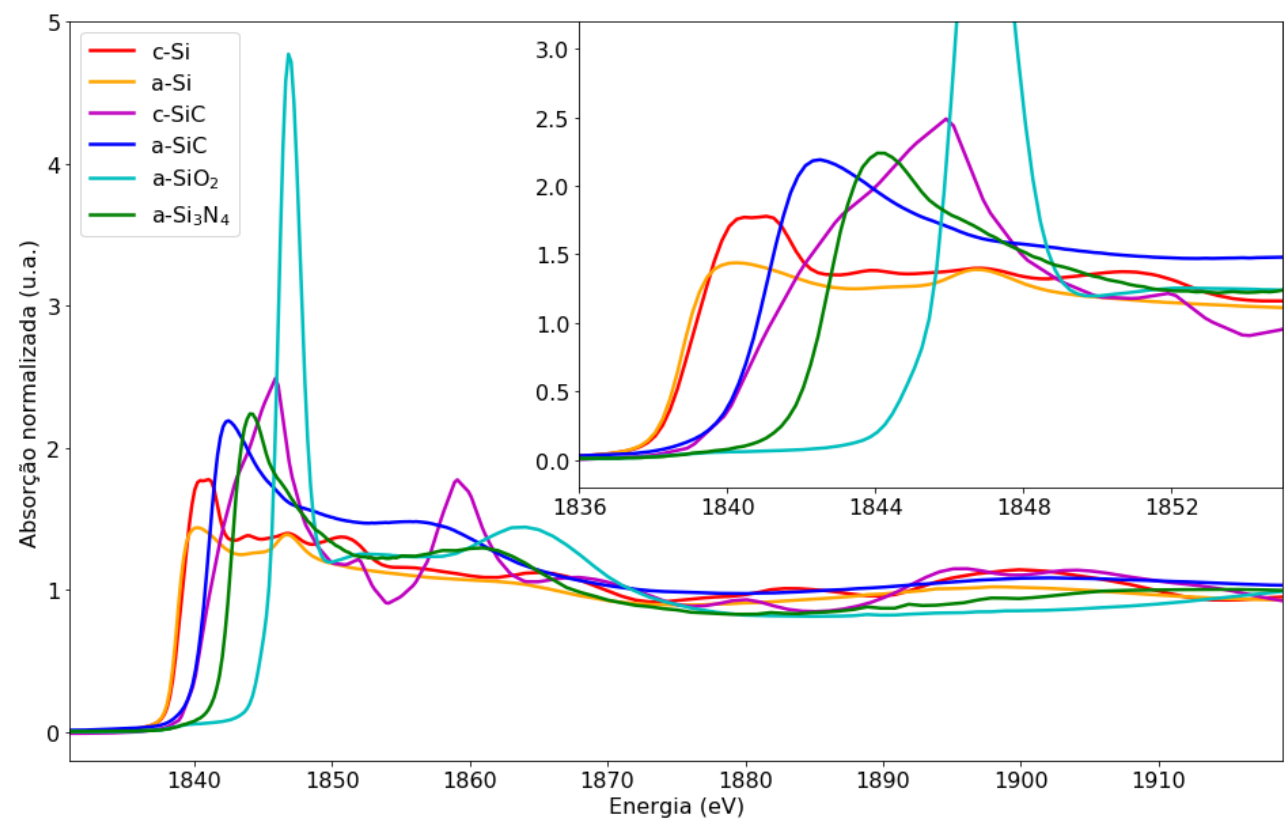

(a)

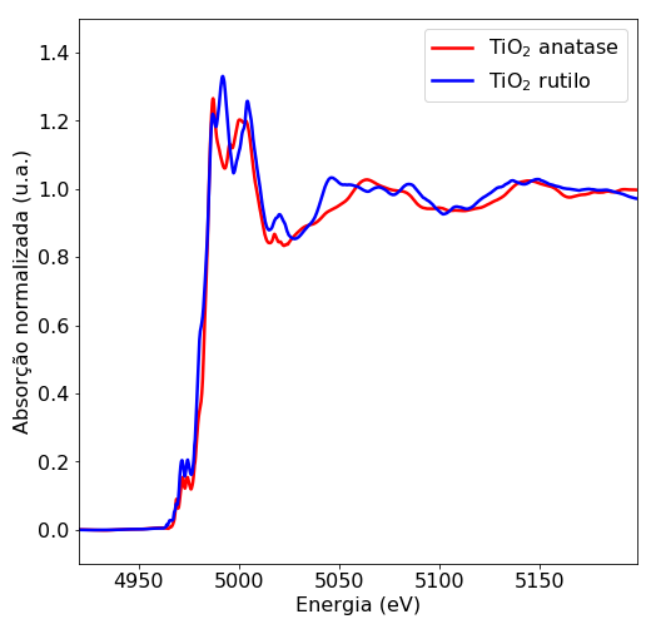

(b)

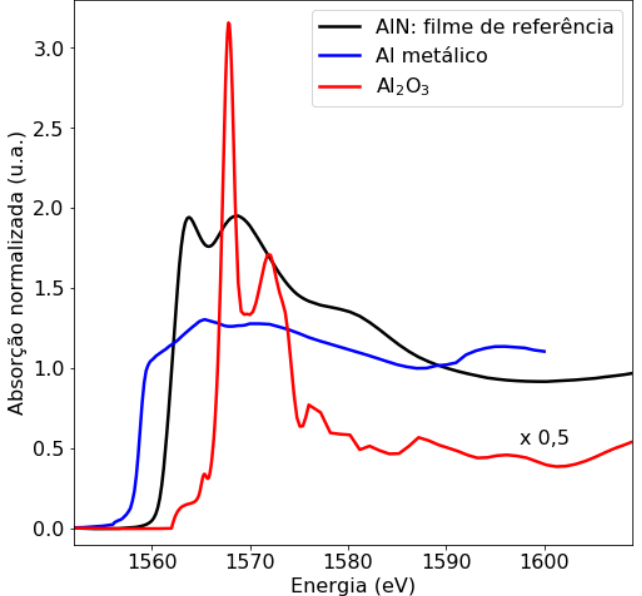

(c)

Figura 4.3: Espectro XANES dos padrões experimentais utilizados. Em (a) borda K do Si de alguns materiais com Si na composição. Em (b) a borda K do Ti dos padrões rutilo e anatase e em (c) borda $\mathrm{K}$ do $\mathrm{Al}$ de materiais com $\mathrm{Al}$ na composição. 


\subsection{Microlâmpadas com óxido de titânio $-\mathrm{TiO}_{2}$}

A figura 4.4 mostra os espectros XANES da borda K do Ti obtidos nas microlâmpadas com camada protetora de $\mathrm{TiO}_{2}$, juntamente com as amostras padrão de $\mathrm{TiO}_{2}$ nas fases rutilo e anatase. Uma análise qualitativa dos espectros indica que o material é termicamente estável nas condições de energização empregadas, uma vez que não sofreu alterações significativas com o aumento da temperatura decorrente da operação das microlâmpadas. Comparando qualitativamente os espectros com os padrões, notase que a fase de $\mathrm{TiO}_{2}$ obtida com a deposição por sputtering nas microlâmpadas é predominantemente rutilo. Não foi possível quantificar, pela combinação linear dos espectros, o percentual do material na fase anatase (ou em estado amorfo), uma vez que tal quantidade é pequena e está fora do limite da análise quantitativa por esse método.

\subsection{Microlâmpadas com oxinitreto de silício amorfo - a- $\mathrm{SiO}_{x} \mathbf{N}_{y}$}

Os espectros XANES da borda $\mathrm{K}$ do $\mathrm{Si}$, obtidos com as microlâmpadas de a- $\mathrm{SiO}_{x} \mathrm{~N}_{y}$ são exibidos na figura 4.5, juntamente com os padrões a-Si, a-SiO $\mathrm{Si}_{2}$ e a- $\mathrm{Si}_{3} \mathrm{~N}_{4}$. Observa-se que o material também apresenta excelente estabilidade térmica durante a operação das microlâmpadas, uma vez que não há modificações nos espectros. As curvas indicam que os materiais são ricos em oxigênio, exibindo poucos aspectos do a- $\mathrm{Si}_{3} \mathrm{~N}_{4}$. O gráfico interno da figura 4.5 mostra que a borda de absorção indica a presença também, em pequena quantidade, do a-Si. Estudos anteriores sobre a- $\mathrm{SiO}_{x} \mathrm{~N}_{y}$ depositado por PECVD ${ }^{[28]}$ demostraram que, com os fluxos de $\mathrm{N}_{2} \mathrm{O}: 45$ sccm, $\mathrm{N}_{2}: 30$ sccm e $\mathrm{SiH}_{4}$ em 3 ou $15 \mathrm{sccm}$, o material resultante é rico em oxigênio (vide figura 4.6). Na microlâmpada, a deposição foi feita com fluxo de silano superior, mas com os mesmos valores para os demais gases $\left(\mathrm{N}_{2} \mathrm{O}: 45, \mathrm{~N}_{2}: 30\right.$ e $\left.\mathrm{SiH}_{4}: 30 \mathrm{sccm}\right)$, de forma que a abundância em oxigênio é esperada. Tal composição é desejada para a camada de proteção da microlâmpada, 


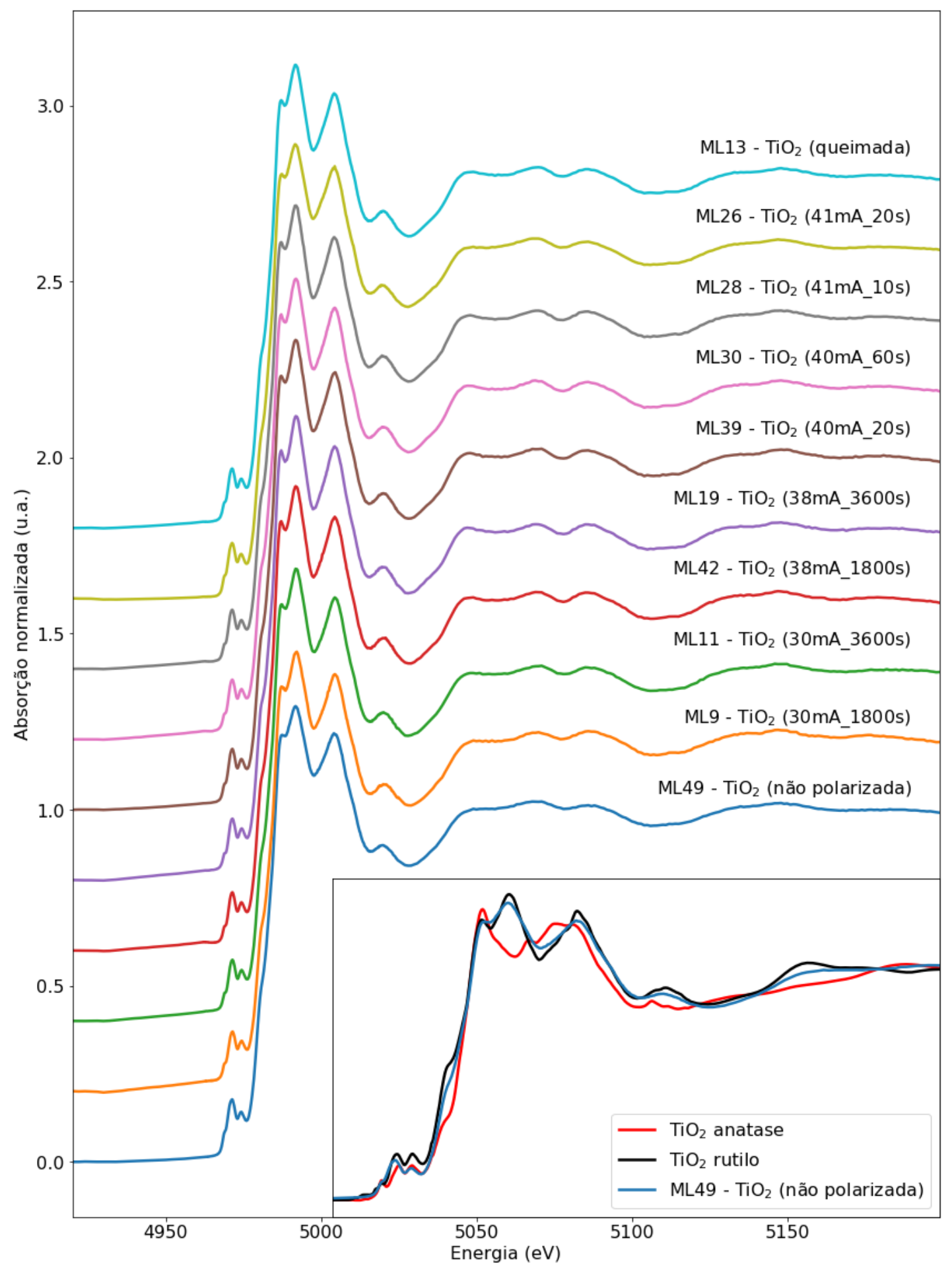

Figura 4.4: Espectro XANES da borda $\mathrm{K}$ do Ti das microlâmpadas com $\mathrm{TiO}_{2}$. No gráfico principal as curvas estão deslocadas para melhor visualização, e as condições de energização estão indicadas. No gráfico interno a $\mathrm{ML}_{4} 4-\mathrm{TiO}_{2}$ é comparada com os padrões rutilo e anatase. 
pois, o material rico em oxigênio apresenta maior transparência e menor condutividade térmica ${ }^{[64]}$.

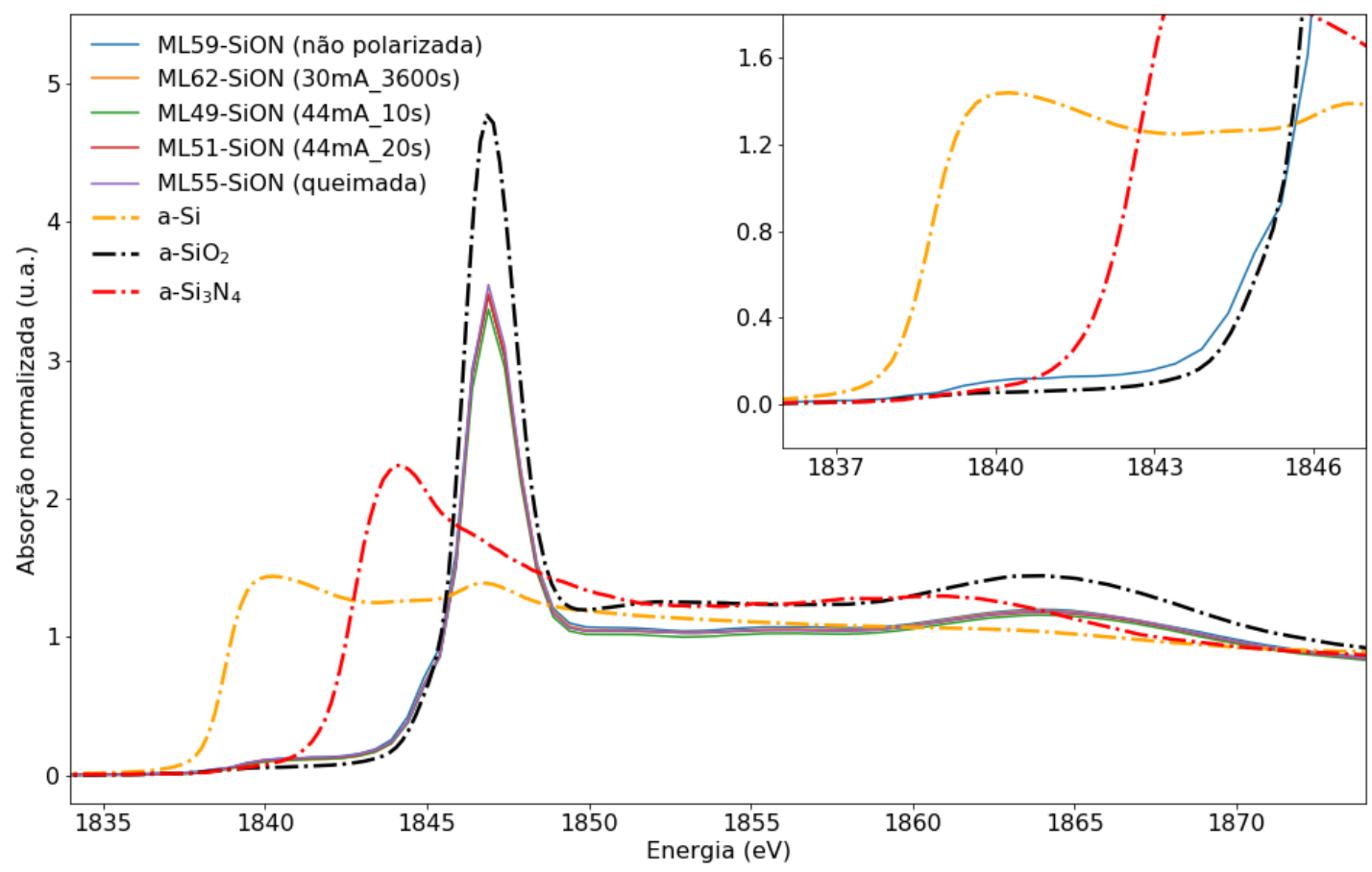

Figura 4.5: Espectro XANES da borda $\mathrm{K}$ do $\mathrm{Si}$ das microlâmpadas com a- $\mathrm{SiO}_{x} \mathrm{~N}_{y}$ e dos padrões a-Si, a- $\mathrm{SiO}_{2}$ e a- $\mathrm{Si}_{3} \mathrm{~N}_{4}$. Os espectros das microlâmpadas são muito semelhantes, de forma que aparecem sobrepostos na figura. O gráfico interno mostra o detalhe da borda da ML59 indicando a presença de a-Si e a- $\mathrm{SiO}_{3} \mathrm{~N}_{4}$ em baixa quantidade.

\subsection{Microlâmpadas com carbeto de silício amorfo - a-SiC}

A figura 4.7 exibe os espectros XANES da borda $\mathrm{K}$ do Si das microlâmpadas de a-SiC. Para auxiliar a análise, os espectros dos padrões de a-SiC e a-SiO $\mathrm{S}_{2}$ são apresentados na figura. Observa-se facilmente que, com o aumento da corrente e/ou tempo de energização, o pico em $\approx 1843 \mathrm{eV}$, característico do a-SiC, se reduz, enquanto que o pico em $\approx 1847 \mathrm{eV}$, característico do a- $\mathrm{SiO}_{2}$, aumenta. Tal fato indica que a camada protetora apresenta um processo gradativo de oxidação do Si com o aquecimento decorrente da energização. A detecção da oxidação, mesmo com antes da energização (ML49-SiC), 

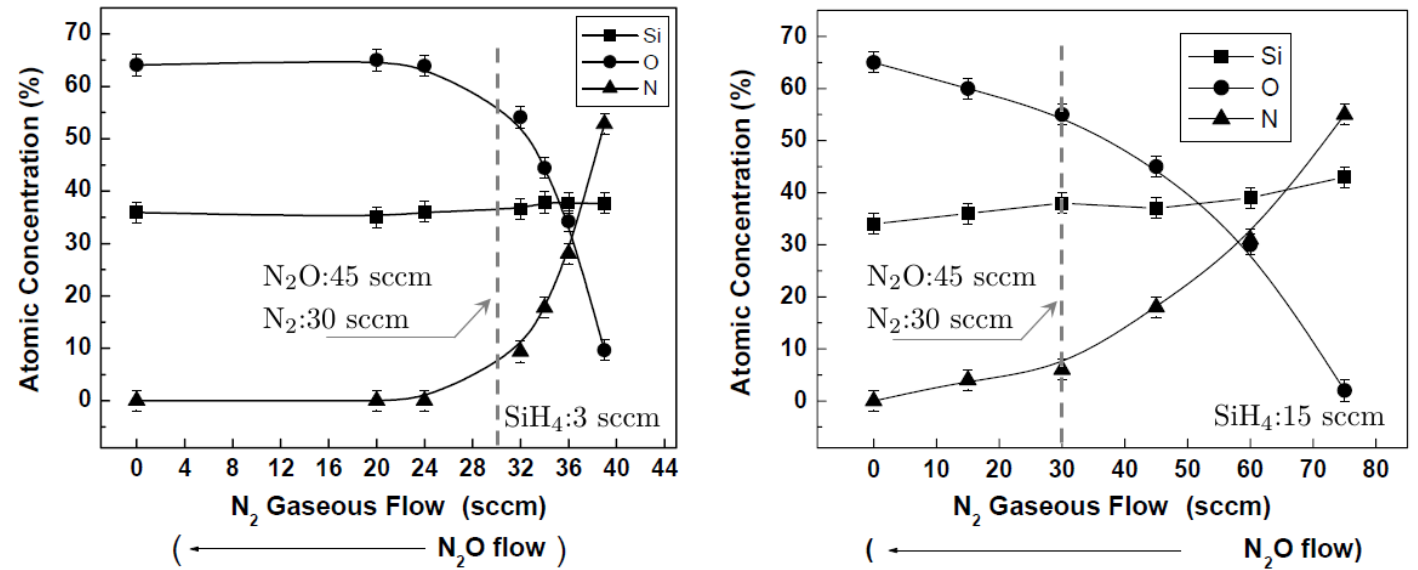

Figura 4.6: Percentual de concentração atômica, reportado na literatura, para a- $\mathrm{SiO}_{x} \mathrm{~N}_{y}$ depositado por PECVD, em função do fluxo dos gases $\mathrm{N}_{2} \mathrm{O}$ e $\mathrm{N}_{2}{ }^{[28]}$. O fluxo dos gases $\mathrm{N}_{2} \mathrm{O}$ e $\mathrm{N}_{2}$ foram variados, mas sempre com a soma contante em $75 \mathrm{sccm}$. O fluxo de silano foi $3 \mathrm{sccm}$ (esquerda) ou $15 \mathrm{sccm}$ (direita). As retas indicam os resultados para $\mathrm{N}_{2} \mathrm{O}: 45$ e $\mathrm{N}_{2}: 30$ sccm. Para maiores detalhes das condições de deposição, vide referência.

sugere que ela ocorre na interface com o ar, uma vez que as medidas de XANES foram todas por TEY, método sensível à região superficial da amostra.

Outro aspecto importante, é revelado no gráfico interior da figura 4.7, onde a curva da microlâmpada não energizada ML49-SiC é comparada com o padrão a-SiC. Esperava-se que as curvas fossem muito semelhantes, uma vez que a camada protetora da ML49SiC, por não ter sido energizada, deveria ser essencialmente carbeto de silício amorfo. Entretanto, pelo menos duas diferenças são perceptíveis em seu espectro: (1) a borda inicia-se, aproximadamente, com energia $2,0 \mathrm{eV}$ menor e $(2)$ o pico em $\approx 1843 \mathrm{eV}$ é bem mais largo e intenso. As hipóteses levantadas para tentar justificar as diferenças entre os espectros foram:

- A presença do filme de cromo sob o carbeto de silício poderia induzir a alguma modificação no filme de a-SiC, eventualmente por um processo de difusão ou por reações químicas na superfície de contato entre os filmes;

- O processo de corrosão do a-SiC por RIE com $\mathrm{CHF}_{3}$ e $\mathrm{O}_{2}$, conforme descrito na 


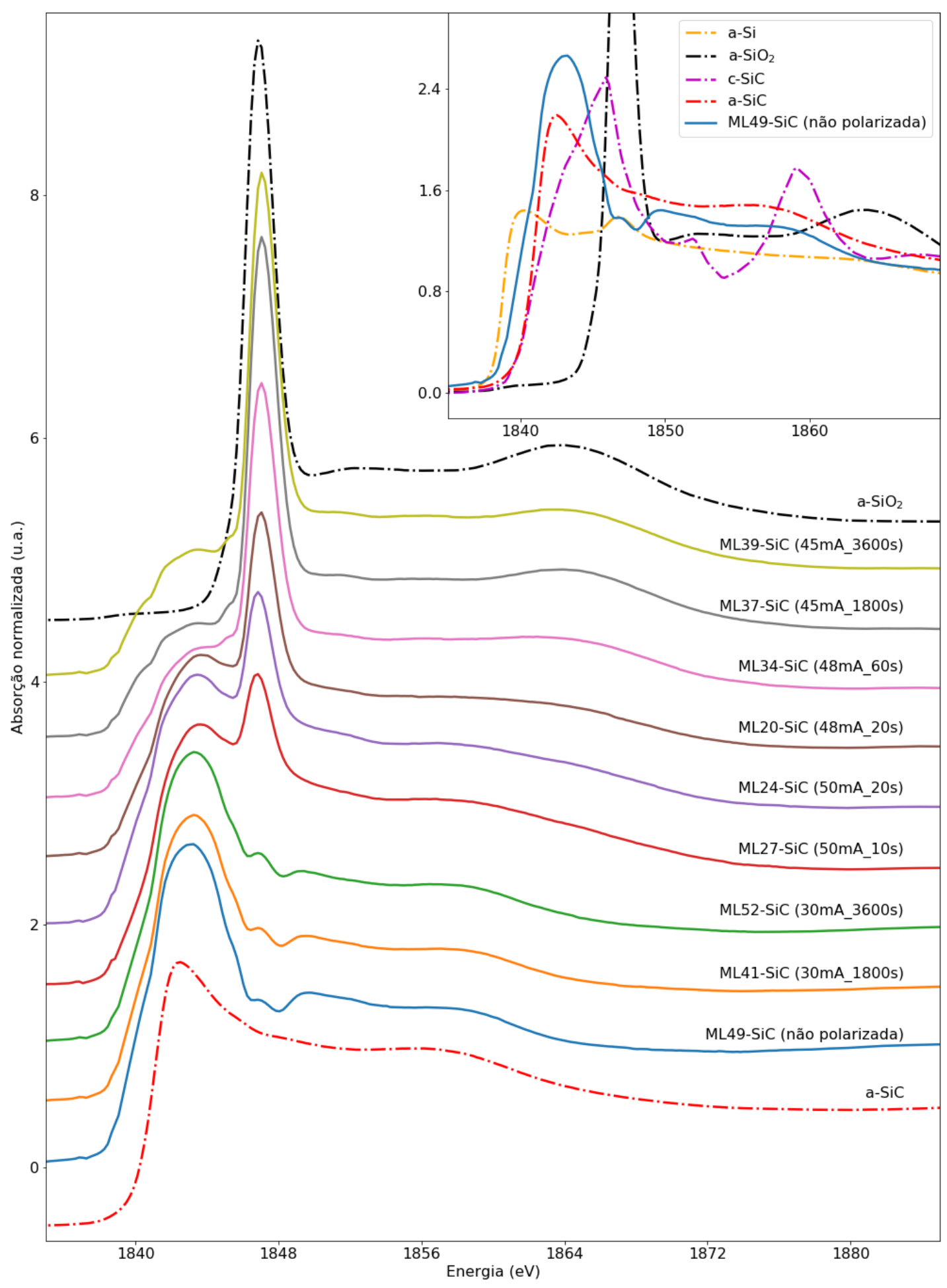

Figura 4.7: Espectro XANES da borda K do Si das microlâmpadas com a-SiC e dos padrões a-SiC e $\mathrm{SiO}_{2}$. No gráfico principal as curvas estão deslocadas para melhor visualização e as condições de energização estão indicadas na figura. No gráfico interno o espectro da microlâmpada ML49-SiC (não energizada) é comparada com os padrões. 
seção 3.1.2, poderia resultar em alguma contaminação ou mudança estrutural no filme;

- A cavidade presente sob o filamento do dispositivo (vide figura 4.1) poderia ter afetado a deposição do carbeto na área, de dimensões micrométricas, exatamente sobre ela. Uma vez que, no reator de PECVD, o aquecimento da superfície de deposição é feito por condução de calor através do substrato, a região acima da cavidade poderia não atingir a temperatura de deposição esperada, o que modificaria a estrutura do carbeto crescido no local.

Para melhor avaliar as hipóteses acima, as amostras de filmes finos adicionais de a-SiC foram também analisadas.

\subsubsection{Espectros XAS das amostras de filmes finos adicionais de a-SiC}

As figuras 4.8 e 4.9 mostram os resultados obtidos com as medidas de absorção XANES e EXAFS da borda K do Si das amostras de filmes finos adicionais de a-SiC. O sinal foi obtido por TEY (Total Electron Yield). Detalhes técnicos da linha de luz podem ser obtidos em ${ }^{[104]}$.

\section{Análise dos espectros XANES dos filmes finos adicionais de a-SiC}

As características que mais se destacam nos espectros XANES da figura 4.8 são:

- Os espectros das amostras SiC-RT SiC/Cr-RT (temperatura ambiente) são semelhantes ao padrão de carbeto de silício amorfo e não apresentam as características encontradas na microlâmpada não energizada ML49-SiC. Nota-se que as amostras de filmes finos adicionais são microcristalinas, exibindo uma inclinação da borda de absorção que é característica do c-SiC;

- De maneira semelhante às microlâmpadas, observa-se o comportamento indicativo da oxidação do Si (aumento do pico em $\approx 1847 \mathrm{eV}$ ) decorrente da elevação 
da temperatura. Entretanto, a amostra SiC/Cr-1100 perdeu completamente as características do espectro do carbeto de silício, sendo ela apenas uma mistura de c-Si e a-SiO $\mathrm{S}_{2}$. Tal fato deve-se à presença do $\mathrm{Cr}$ que, com a elevada temperatura, provocou o descolamento da camada de a-SiC e destruiu a amostra (ver figura 3.8);

- As amostras com e sem $\mathrm{Cr}$ (exceto a aquecida a $1100^{\circ} \mathrm{C}$ ) apresentaram espectros muito semelhantes quando submetidas à mesma temperatura. Tal fato demonstra que não foi possível observar modificações induzidas pela presença do cromo.

\section{Análise da influência do processo de corrosão do a-SiC por RIE}

O gráfico da figura 4.8b mostra os espectros de três amostras de a-SiC submetidas ao mesmo processo de corrosão por RIE que as microlâmpadas de carbeto de silício. Tais amostras foram identificadas como SiC-RIE e tiveram um percentual de sua espessura corroído (não corroído, 20\% e 50\%). Percebe-se que os espectros sem corrosão e com $20 \%$ corroído são muito semelhantes, diferenciando apenas por um ombro em $\approx 1846 \mathrm{eV}$. Encontram-se diferenças maiores, apenas, quando a espessura do carbeto já foi reduzida pela metade, que devem-se ao fato da medida por TEY já ser capaz de enxergar o substrato de Si abaixo do a-SiC. Esse resultado indica que o processo de corrosão por RIE não é o responsável pelas características observadas nos espectros das microlâmpadas de a-SiC. 


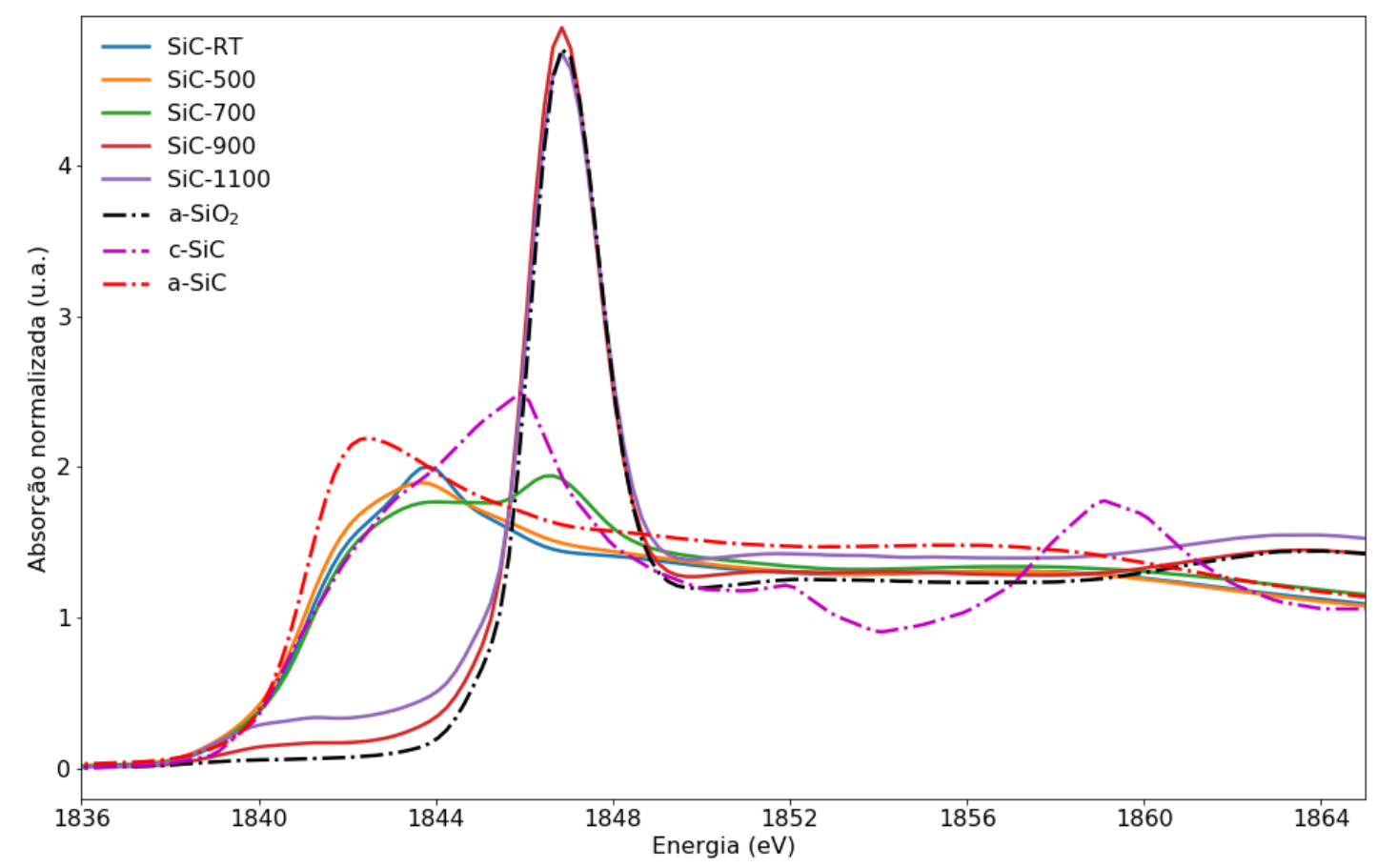

(a)

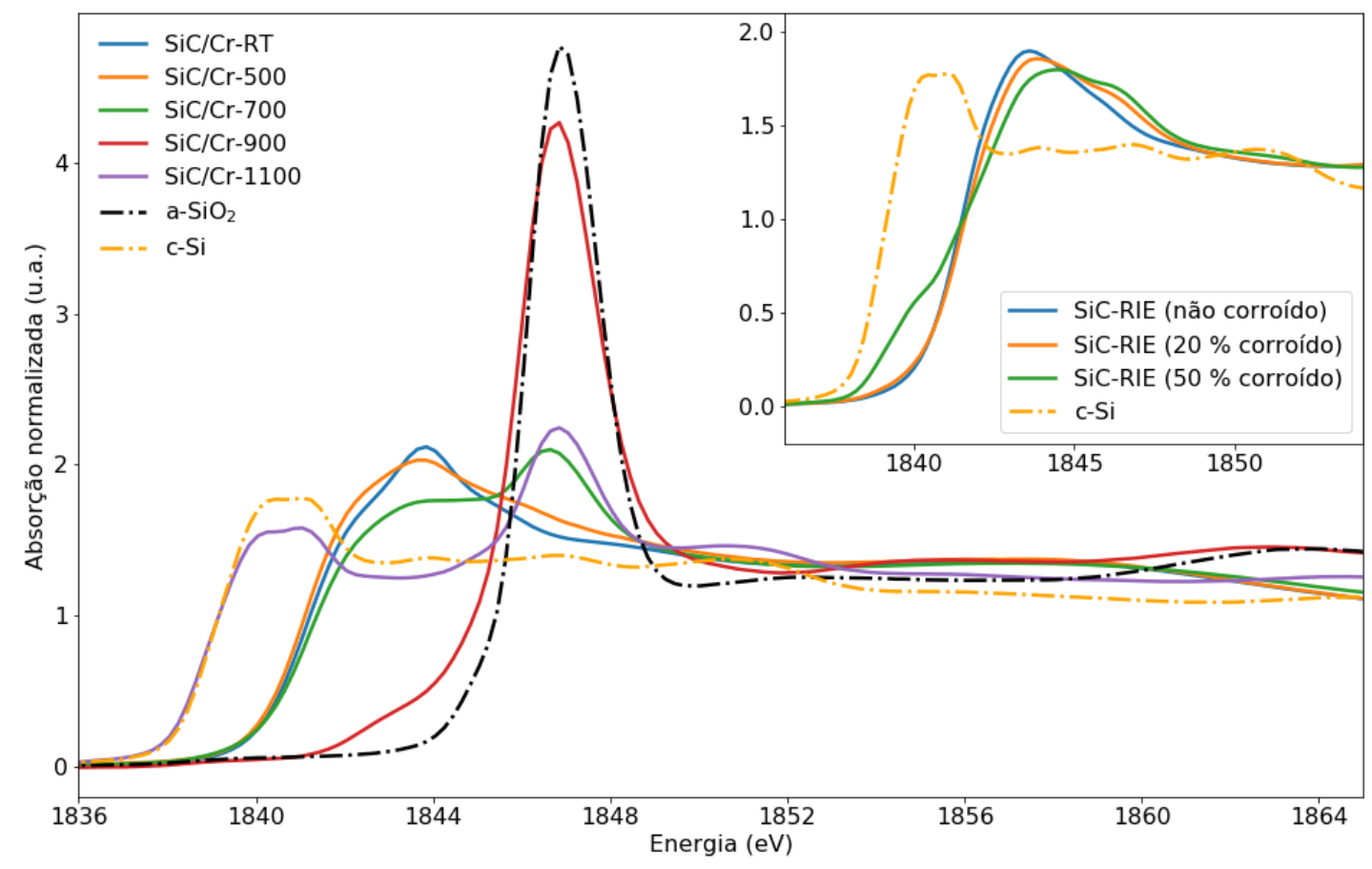

(b)

Figura 4.8: Espectros XANES da borda K do Si das amostras de filmes finos adicionais de a-SiC submetidas a tratamento térmico. Em (a), amostras depositadas sobre Si e em (b), sobre Cr. No gráfico internos de (b) os espectros das amostras corroídas por RIE. Alguns padrões são exibidos para comparação. 


\section{Análise dos espectros EXAFS dos filmes finos adicionais de a-SiC}

A parte superior da figura 4.9 apresenta a magnitude da transformada de Fourier do sinal EXAFS dos filmes finos adicionais de a-SiC, bem como as posições correspondentes das primeiras esferas de coordenação de amostras padrão (c-SiC, c-Si e a-SiO ${ }_{2}$. A parte inferior da mesma figura mostra a parte imaginária da transformada de Fourier de algumas amostras selecionadas, juntamente com o sinal de alguns padrões. Apesar do aspecto amorfo dos materiais, é possível identificar os primeiros vizinhos dos átomos de Si absorvedor. Observa-se que as amostras que não foram submetidas a elevadas temperaturas $\left(900^{\circ} \mathrm{C}\right.$ e $\left.1100^{\circ} \mathrm{C}\right)$ apresentam ordem de curto alcance correspondente às ligações Si-O e Si-C, o que é compatível com o carbeto de silício oxidado. Quando submetidas às temperaturas de $900^{\circ} \mathrm{C}$ ou mais, a característica da ligação Si-C, presente no carbeto, fica bastante reduzida, enquanto aumenta o pico correspondente da ligação Si-O. Exceção se faz para a amostra $\mathrm{SiC} / \mathrm{Cr}-1100$, cujo resultado é nitidamente correspondente ao padrão c-Si. Os resultados mencionados são compatíveis com os obtidos por XANES.

\subsubsection{Espectroscopia por retroespalhamento de Rutherford - RBS}

As dimensões milimétricas (grandes comparadas com às das microlâmpadas) das amostras de filmes finos adicionais de a-SiC permitem analisá-las também por RBS. Os dados foram coletados no LAMFI-USP (fig. 4.10) com feixe de $\mathrm{He}^{+}$de $2,2 \mathrm{MeV}$, e com a amostra em duas posições: normal ao feixe e com inclinação de $45^{\circ}\left(\theta_{1}\right)$. Em cada posição, as medidas foram tomadas com os detectores posicionados em ângulos de espalhamento de $120^{\circ}$ e $170^{\circ}\left(\theta_{2}\right)$. Para obter maior sensibilidade, foram coletados também espectros com as ressonâncias do oxigênio e do carbono. Nesses casos, a energia do feixe foi 3,037 MeV (para o O) e 4,262 $\mathrm{MeV}$ (para o C), com a amostra inclinada a $7^{\circ}$ e, novamente, com os detectores a $120^{\circ}$ e $170^{\circ}$. Desta forma, foram obtidos oito espectros por amostra. 

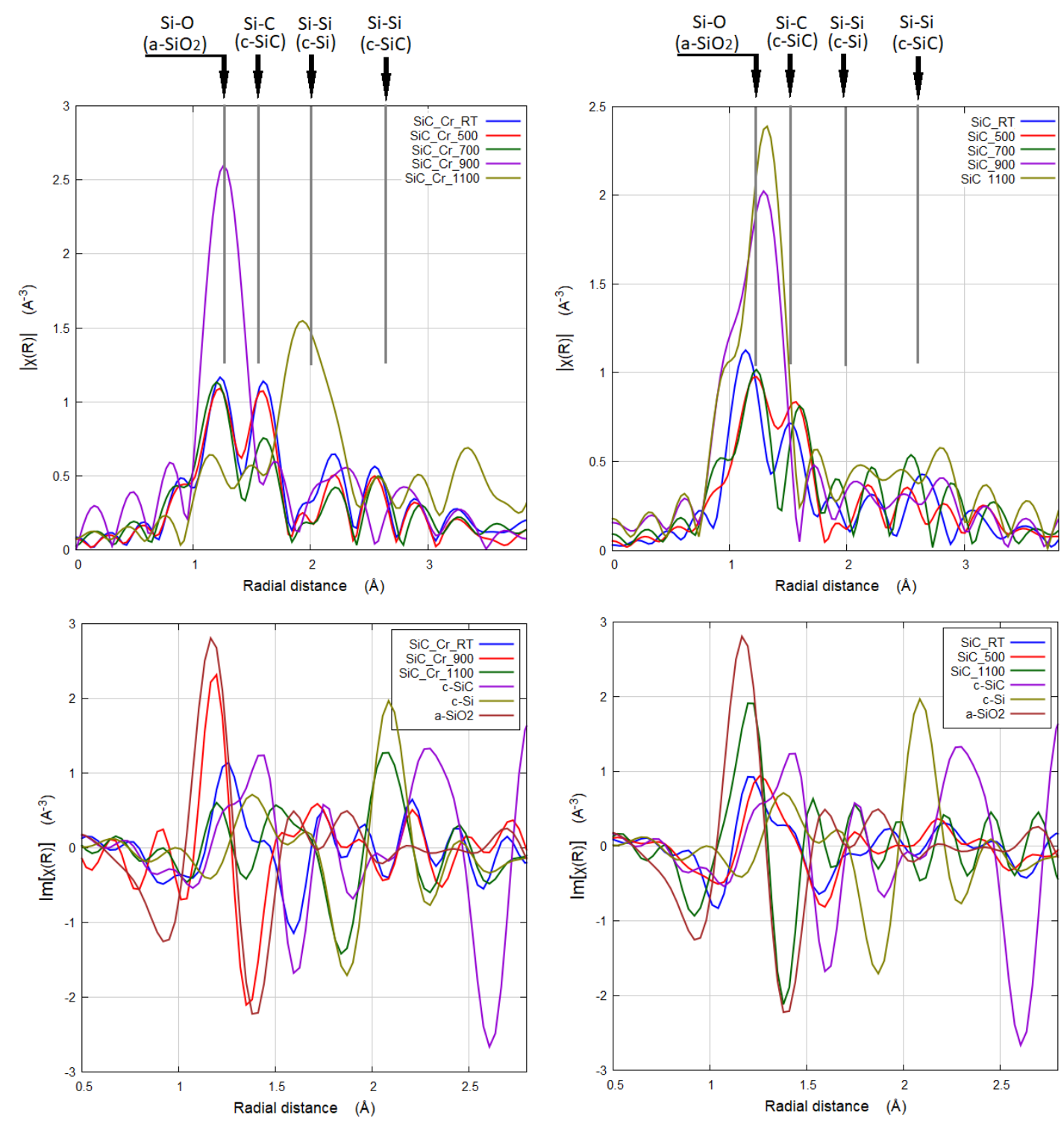

Figura 4.9: Magnitude (superior) e parte imaginária (inferior) da transformada de Fourier do sinal EXAFS obtido com a borda $\mathrm{K}$ do Si das amostras de filmes finos adicionais de a-SiC. As linhas verticais em destaque indicam as posições dos picos correspondentes às esferas de coordenação de amostras padrões (c-SiC, c-Si e a-SiO${ }_{2}$ ). 

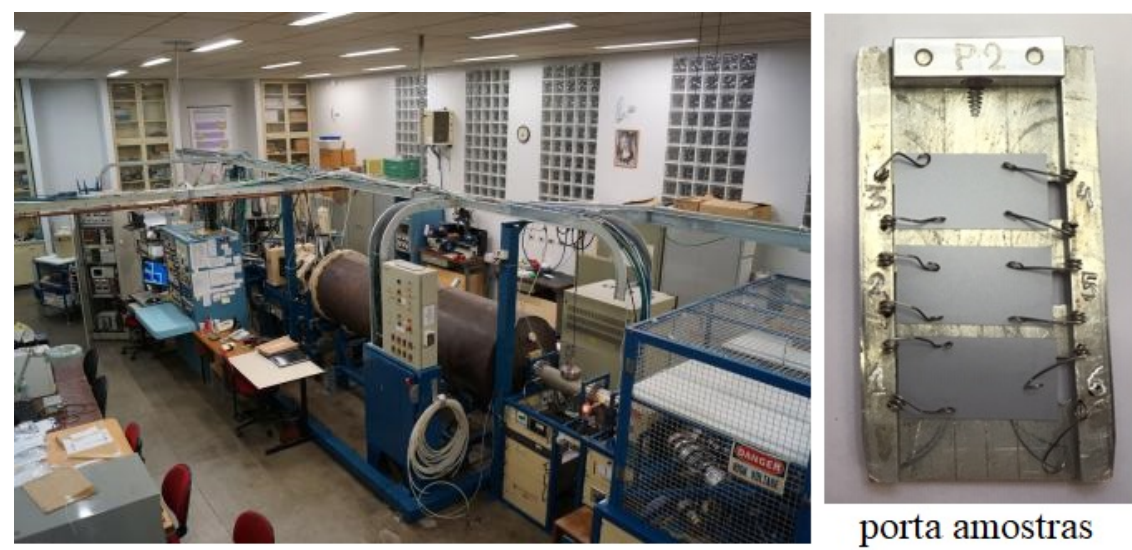

porta amostras

Figura 4.10: Foto do Laboratório de Análise de Materiais por feixes Iônicos $(\mathrm{LAMFI})^{[105]}$, onde foram coletados os dados de RBS.

A parte superior da figura 4.11 exibe os espectros para a amostra SiC/Cr-RT. A parte inferior mostra o perfil em profundidade da concentração de $\mathrm{C}, \mathrm{O}, \mathrm{Si}$ e $\mathrm{Cr}$, resultante do ajuste realizado com os softwares SIMNRA ${ }^{[92]}$ e MultiSIMNRA ${ }^{[93]}$. A região colorida corresponde à incerteza atribuída pelo MultiSIMNRA na concentração do elemento correspondente. A tabela 4.2 apresenta os resultados dos ajustes obtidos para as amostras $\mathrm{SiC} / \mathrm{Cr}-\mathrm{RT}, \mathrm{SiC} / \mathrm{Cr}-500$ e $\mathrm{SiC} / \mathrm{Cr}-700$. Nos dois primeiros casos, há uma região (de $\approx 45 \mathrm{~nm}$ ) de carbeto de silício (rico em $\mathrm{C}$ ) e óxido, seguida por uma camada (de $\approx 40-45 \mathrm{~nm}$ ) em que o Cr está difundido no carbeto. Em maior profundidade encontra-se a camada de $\mathrm{Cr}(\mathrm{de} \approx 145-160 \mathrm{~nm})$ depositada por sputtering que simula o filamento. Percebe-se também a difusão do Cr na interface com o substrato de Si. No caso da amostra $\mathrm{SiC} / \mathrm{Cr}-700$, a concentração de Cr é maior, fato que indica o aumento da difusão do Cr no carbeto com a elevação da temperatura. A figura 4.11c representa a diferença entre as espessuras esperadas dos filmes (vide tabela 3.1) e os valores obtidos experimentalmente para a amostra $\mathrm{SiC} / \mathrm{Cr}-\mathrm{RT}$. É importante lembrar que as espessuras em $n m$ são estimadas, pois foram calculadas com valores de densidade típicos para esses materiais. 
Tabela 4.2: Espessura e composição dos filmes das amostras de filmes finos adicionais de $\mathrm{SiC}$ obtidos por RBS (esquerda) e GIXRF (direita).

Amostra: $\mathrm{SiC} / \mathrm{Cr}-\mathrm{RT}$

\begin{tabular}{|c|c|c|c|c|c|c|c|c|c|c|c|}
\hline \multicolumn{6}{|c|}{ Resultados do RBS } & \multicolumn{6}{|c|}{ Resultados do ajuste - GIXRF } \\
\hline \multicolumn{2}{|c|}{ Espessura } & \multicolumn{4}{|c|}{ Composição (\%) } & \multicolumn{2}{|c|}{ Espessura } & \multicolumn{4}{|c|}{ Composição (\%) } \\
\hline$\left(\mathrm{TFU}^{*}\right)$ & $\left(\mathrm{nm}^{*}\right)$ & $\mathrm{C}$ & $\mathrm{O}$ & $\mathrm{Si}$ & $\mathrm{Cr}$ & $\left(\mathrm{TFU}^{*}\right)$ & $\left(\mathrm{nm}^{*}\right)$ & $\mathrm{C}$ & $\mathrm{O}$ & $\mathrm{Si}$ & $\mathrm{Cr}$ \\
\hline 126,6 & 14,4 & 61,4 & 7,8 & 30,8 & - & \multirow{2}{*}{374,2} & \multirow{2}{*}{42,1} & \multirow{2}{*}{64,0} & \multirow{2}{*}{5,2} & \multirow{2}{*}{30,8} & \multirow{2}{*}{ - } \\
\hline 258,9 & 31,1 & 35,5 & 40,5 & 24,0 & - & & & & & & \\
\hline 338,0 & 39,1 & 4,0 & 2,3 & 3,5 & 90,2 & \multirow{2}{*}{436,6} & \multirow{2}{*}{51,8} & \multirow{2}{*}{1,0} & \multirow{2}{*}{1,0} & \multirow{2}{*}{2,0} & \multirow{2}{*}{96,0} \\
\hline 130,4 & 15,4 & 2,3 & & 1,1 & 96,6 & & & & & & \\
\hline 1314,6 & 158,1 & - & - & - & 100 & 1367,0 & 164,5 & - & - & - & 100 \\
\hline 198,8 & 30,7 & - & - & 87,5 & 12,5 & 199,0 & 30,7 & - & - & 87,5 & 12,5 \\
\hline \multicolumn{2}{|c|}{ substrato } & - & - & 100 & - & \multicolumn{2}{|c|}{ substrato } & - & - & 100 & - \\
\hline
\end{tabular}

Amostra: $\mathrm{SiC} / \mathrm{Cr}-500$

\begin{tabular}{|c|c|c|c|c|c|c|c|c|c|c|c|}
\hline \multicolumn{6}{|c|}{ Resultados do RBS } & \multicolumn{6}{|c|}{ Resultados do ajuste - GIXRF } \\
\hline \multicolumn{2}{|c|}{ Espessura } & \multicolumn{4}{|c|}{ Composição (\%) } & \multicolumn{2}{|c|}{ Espessura } & \multicolumn{4}{|c|}{ Composição (\%) } \\
\hline$\left(\mathrm{TFU}^{*}\right)$ & $\left(\mathrm{nm}^{*}\right)$ & $\mathrm{C}$ & $\mathrm{O}$ & $\mathrm{Si}$ & $\mathrm{Cr}$ & $\left(\mathrm{TFU}^{*}\right)$ & $\left(\mathrm{nm}^{*}\right)$ & $\mathrm{C}$ & $\mathrm{O}$ & $\mathrm{Si}$ & $\mathrm{Cr}$ \\
\hline 190,2 & 21,5 & 50,3 & 22,9 & 26,8 & - & \multirow{2}{*}{377,6} & \multirow{2}{*}{44,1} & \multirow{2}{*}{56,8} & \multirow{2}{*}{11,4} & \multirow{2}{*}{31,8} & \multirow{2}{*}{ - } \\
\hline 193,8 & 24,6 & 35,4 & 29,8 & 34,7 & 0,1 & & & & & & \\
\hline 163,2 & 19,4 & 9,3 & 0,4 & 1,6 & 88,7 & \multirow{2}{*}{331,1} & \multirow{2}{*}{39,5} & \multirow{2}{*}{0,7} & \multirow{2}{*}{0,7} & \multirow{2}{*}{0,6} & \multirow{2}{*}{98,0} \\
\hline 168,6 & 20,3 & 5,2 & 2,0 & 3,6 & 89,2 & & & & & & \\
\hline 1220,1 & 146,8 & - & - & - & 100 & 1253,8 & 150,8 & - & - & - & 100 \\
\hline 358,7 & 69,8 & - & - & 97,6 & 2,4 & 358,8 & 70,8 & - & - & 99,5 & 0,5 \\
\hline \multicolumn{2}{|c|}{ substrato } & - & - & 100 & - & \multicolumn{2}{|c|}{ substrato } & - & - & 100 & - \\
\hline
\end{tabular}

Amostra: SiC/Cr-700

\begin{tabular}{|c|c|c|c|c|c|c|c|c|c|c|c|}
\hline \multicolumn{6}{|c|}{ Resultados do RBS } & \multicolumn{6}{|c|}{ Resultados do ajuste - GIXRF } \\
\hline \multicolumn{2}{|c|}{ Espessura } & \multicolumn{4}{|c|}{ Composição (\%) } & \multicolumn{2}{|c|}{ Espessura } & \multicolumn{4}{|c|}{ Composição (\%) } \\
\hline$\left(\mathrm{TFU}^{*}\right)$ & $\left(\mathrm{nm}^{*}\right)$ & $\mathrm{C}$ & $\mathrm{O}$ & $\mathrm{Si}$ & $\mathrm{Cr}$ & $\left(\mathrm{TFU}^{*}\right)$ & $\left(\mathrm{nm}^{*}\right)$ & $\mathrm{C}$ & $\mathrm{O}$ & $\mathrm{Si}$ & $\mathrm{Cr}$ \\
\hline 84,2 & 9,5 & 58,5 & 9,4 & 31,8 & 0,3 & \multirow{2}{*}{366,6} & \multirow{2}{*}{44,7} & \multirow{2}{*}{51,4} & \multirow{2}{*}{13,7} & \multirow{2}{*}{34,9} & \multirow{2}{*}{ - } \\
\hline 324,7 & 38,3 & 38,0 & 37,0 & 24,7 & 0,3 & & & & & & \\
\hline 150,4 & 18,2 & 6,6 & 5,9 & 6,6 & 80,9 & \multirow{2}{*}{586,3} & \multirow{2}{*}{70,1} & \multirow{2}{*}{0,5} & \multirow{2}{*}{0,5} & \multirow{2}{*}{0,0} & \multirow{2}{*}{99,0} \\
\hline 381,9 & 46,0 & 1,7 & 0,1 & 1,7 & 96,5 & & & & & & \\
\hline 1107,7 & 133,3 & - & - & - & 100 & 1108,7 & 133,4 & - & - & - & 100 \\
\hline 158,3 & 22,1 & - & - & 49,1 & 50,9 & 158,0 & 21,7 & - & - & 76,8 & 23,2 \\
\hline subst & ato & - & - & 100 & - & subs & cato & - & - & 100 & - \\
\hline
\end{tabular}

*Espessura em $\mathrm{nm}$ estimada $\left(\mathrm{TFU}=10^{15}\right.$ átomos $\left./ \mathrm{cm}^{2}\right)$. 


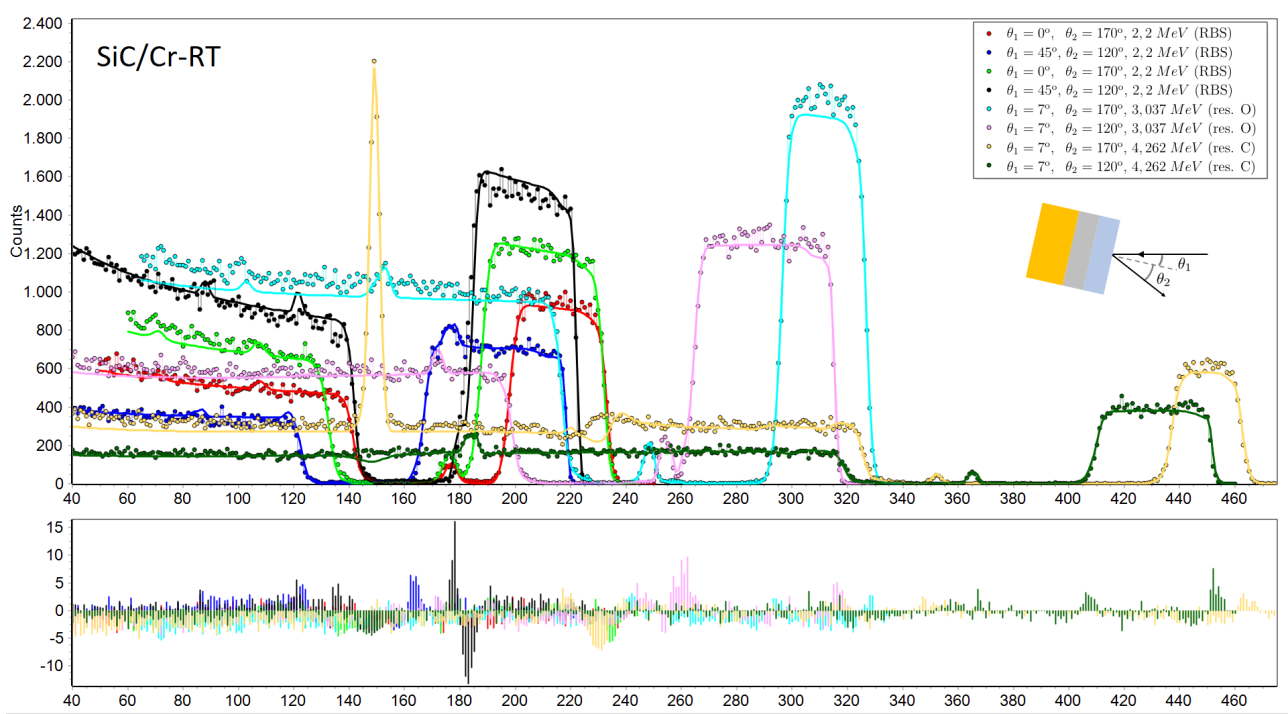

(a)

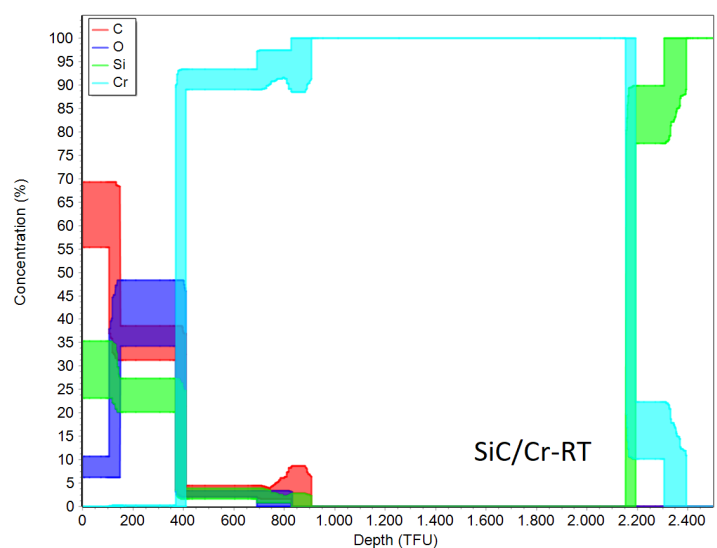

(b)

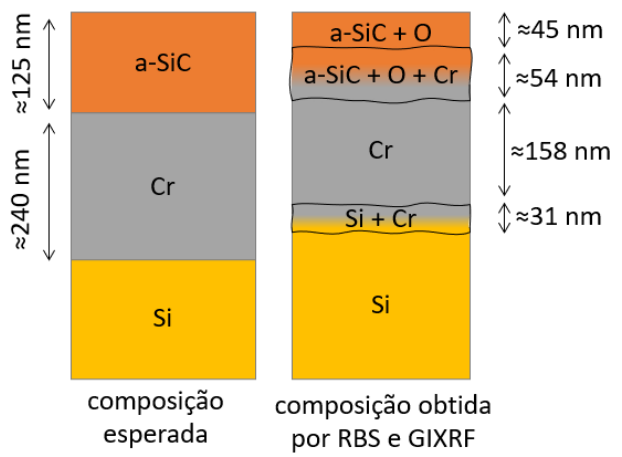

(c)

Figura 4.11: (a) Espectros RBS obtidos para a amostra SiC/Cr-RT. (b) Perfil em profundidade resultante do ajuste realizado com os softwares SIMNRA ${ }^{[92]}$ e MultiSIMNRA ${ }^{[93]}$. A região colorida corresponde à incerteza atribuída pelo MultiSIMNRA na concentração do elemento correspondente. (c) Comparação entre as espessuras esperadas e as obtidas experimentalmente para a amostra $\mathrm{SiC} / \mathrm{Cr}-\mathrm{RT}$.

\subsubsection{Fluorescência de raios $\mathrm{X}$ com incidência rasante - GIXRF}

Com o objetivo de analisar a composição em função da profundidade, por mais uma técnica, em complemento ao RBS, as amostras de filmes finos adicionais de a-SiC foram medidas por GIXRF na linha XRF (LNLS) (fig. 4.12). Detalhes técnicos da linha de luz 
podem ser obtidos em ${ }^{[106]}$. A figura 4.13 exibe os resultados obtidos com as amostras $\mathrm{SiC} / \mathrm{Cr}-\mathrm{RT}, \mathrm{SiC} / \mathrm{Cr}-500, \mathrm{SiC} / \mathrm{Cr}-700$ e SiC-RT. Foi possível obter um bom número de contagens para a fluorescência do Cr, entretanto, a detecção do Si foi mais difícil, pois a sua fluorescência estava próxima do limite de detecção experimental da linha. A redução na intensidade do sinal de Si, por volta de 10,5 mrad, na amostra SiC-RT, está relacionada com a interface entre as camadas de a-SiC e o substrato de $\mathrm{Si}$. Tal aspecto não é observado nas demais amostras, devido à presença do Cr. As oscilações nas curvas das demais amostras são resultado do fenômeno de interferência entre os raios $\mathrm{X}$ refletidos e transmitidos, conforme descrito na seção 2.2.3.

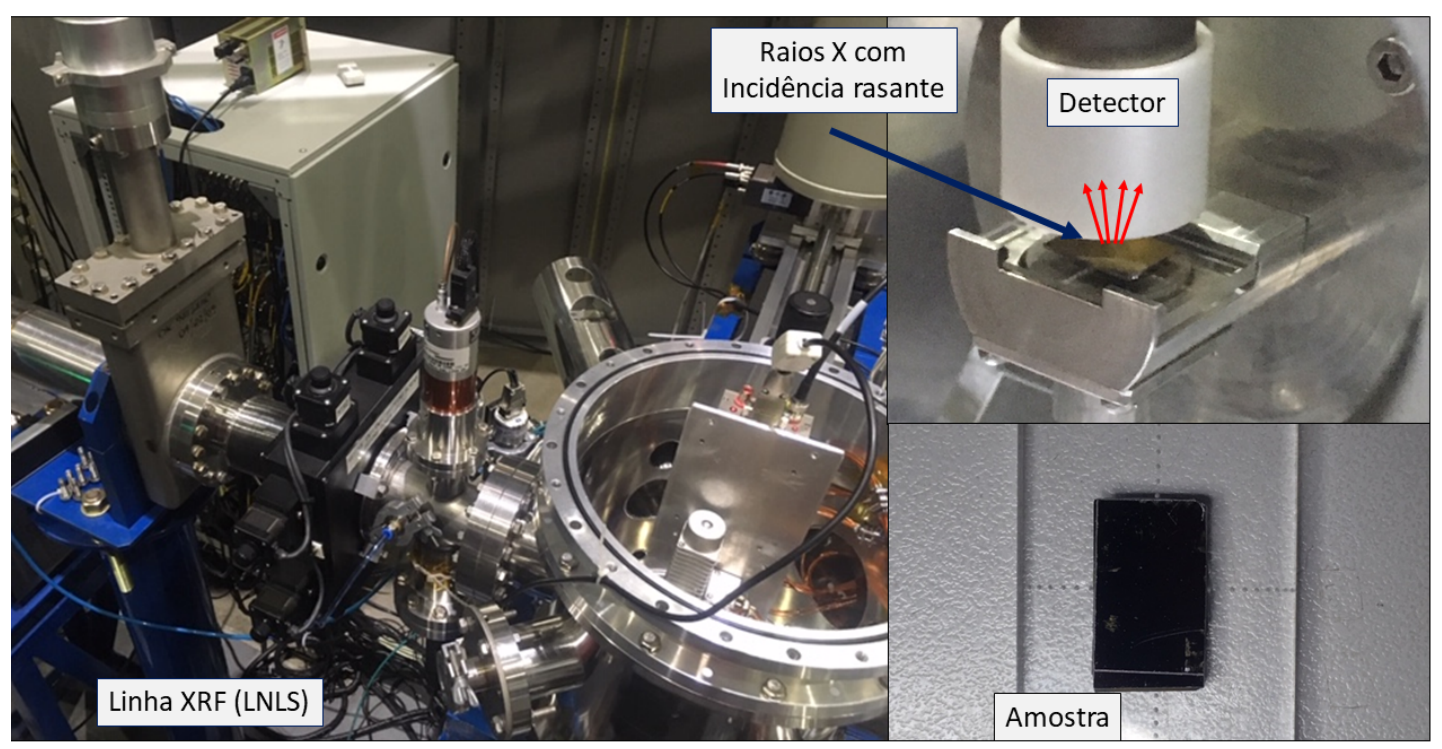

Figura 4.12: Arranjo experimental utilizando nas medidas de GIXRF na linha XRF (LNLS).

O sinal de fluorescência obtido por GIXRF foi calculado utilizando o procedimento apresentado na seção 2.2.3. Os cálculos foram feitos utilizando um código em Python*. Partindo dos dados experimentais provenientes do RBS (tabela 4.2), construiu-se um modelo inicial de filme para obter os resultados teóricos de GIXRF e compará-los com os obtidos experimentalmente. Utilizando um procedimento de ajuste implementado

\footnotetext{
${ }^{*}$ Gentilmente cedido pelo Dr. Carlos Alberto Perez, pesquisador do LNLS.
} 
no código Python, foi possível variar as composições e espessuras do modelo de filme inicial para encontrar o resultado que melhor se aproxima do experimental. As linhas contínuas da parte superior da figura 4.13 mostra os resultados da simulação feita com os dados iniciais (RBS) e com os do ajuste. O lado direito da tabela 4.2 apresenta os melhores resultados obtidos da composição dos filmes. Os resultados obtidos com as duas técnicas independentes são compatíveis com as incertezas experimentais. 

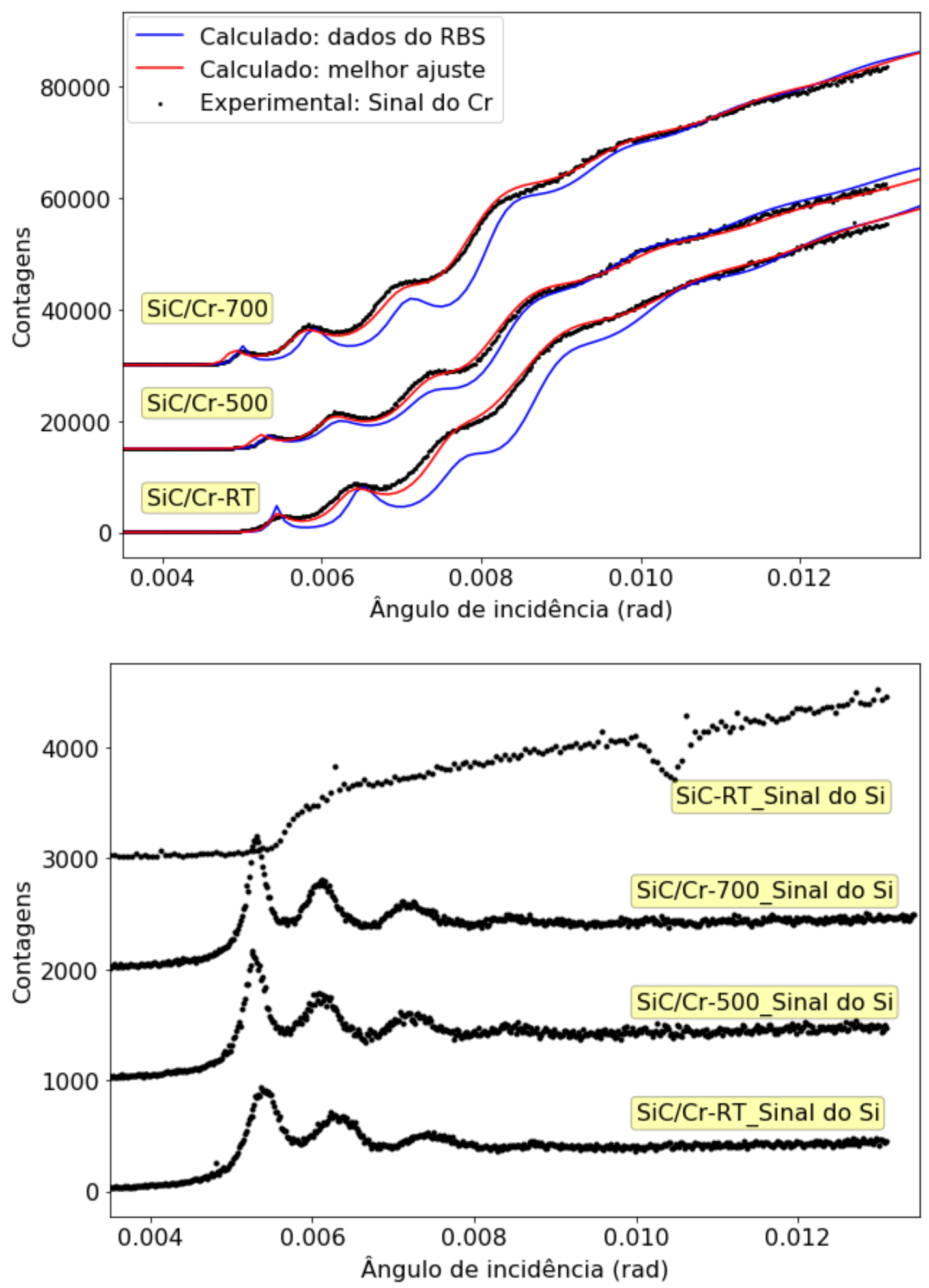

Figura 4.13: Fluorescência de raios X com incidência rasante das amostras de filmes finos adicionais de SiC. Os sinais de Cr (acima) e Si (abaixo) foram detectados. As linhas contínuas na figura superior representam o resultado proveniente da simulação. 


\subsubsection{Espectro de absorção XANES com incidência rasante}

Com o arranjo experimental disponível na linha XRF foi possível medir o espectro de absorção XANES quando incide sobre a amostra um feixe de raios X de maneira rasante. O sinal foi obtido por fluorescência. A figura 4.14 exibe os espectros XANES da borda $\mathrm{K}$ do $\mathrm{Cr}$ medido em diferentes ângulos de incidência. Na análise dessas curvas deve-se levar em conta o efeito da auto absorção, que vai ficando bastante significativo, nesse tipo de experimento, com o aumento do ângulo. No mesmo arranjo experimental, foi medido um padrão de Cr metálico, cujo espectro está também presente na figura. Nas três amostras, com ângulos de incidência de até 7,0 mrad, é possível identificar as características do espectro do Cr metálico (picos em $\approx 6010,6020,6070$ e $6095 \mathrm{eV}$ ). Entretanto, não se observam as absorções na região de $\approx 6030-6040 \mathrm{eV}$, fato que indica que o Cr não está na fase metálica pura, e pode haver parte do cromo ligado ao silício e/ou ao carbono, possivelmente de forma amorfa, resultado que é compatível com a tabela 4.2. Essa estrutura permanece inalterada com o aumento do ângulo de incidência. A ausência de picos nos espectros obtidos em ângulos acima de 7,0 mrad deve-se, provavelmente, ao efeito da auto absorção, pois, conforme a figura 4.13, há sinal de fluorescência do Cr nessa profundidade.

\subsubsection{Espectros XANES teóricos}

Para auxiliar no estudo da microlâmpada, em especial da ML49-SiC (não energizada), espectros XANES teóricos foram simulados utilizando o FDMNES. Em todos os casos apresentados a seguir, os cálculos foram realizados utilizando o método das diferenças finitas (modo FDM), com espalhamento múltiplo total, numa região esférica de raio $7,4 \AA$ em torno do átomo de Si absorvedor. O potencial foi calculado de maneira autoconsistente (modo $\mathrm{SCF}$ ), sob a região esférica de raio 6,0 $\AA$ em torno do absorvedor. Estudos foram realizados indicando que tais regiões são suficientemente grandes para atingir a convergência nos resultados. 

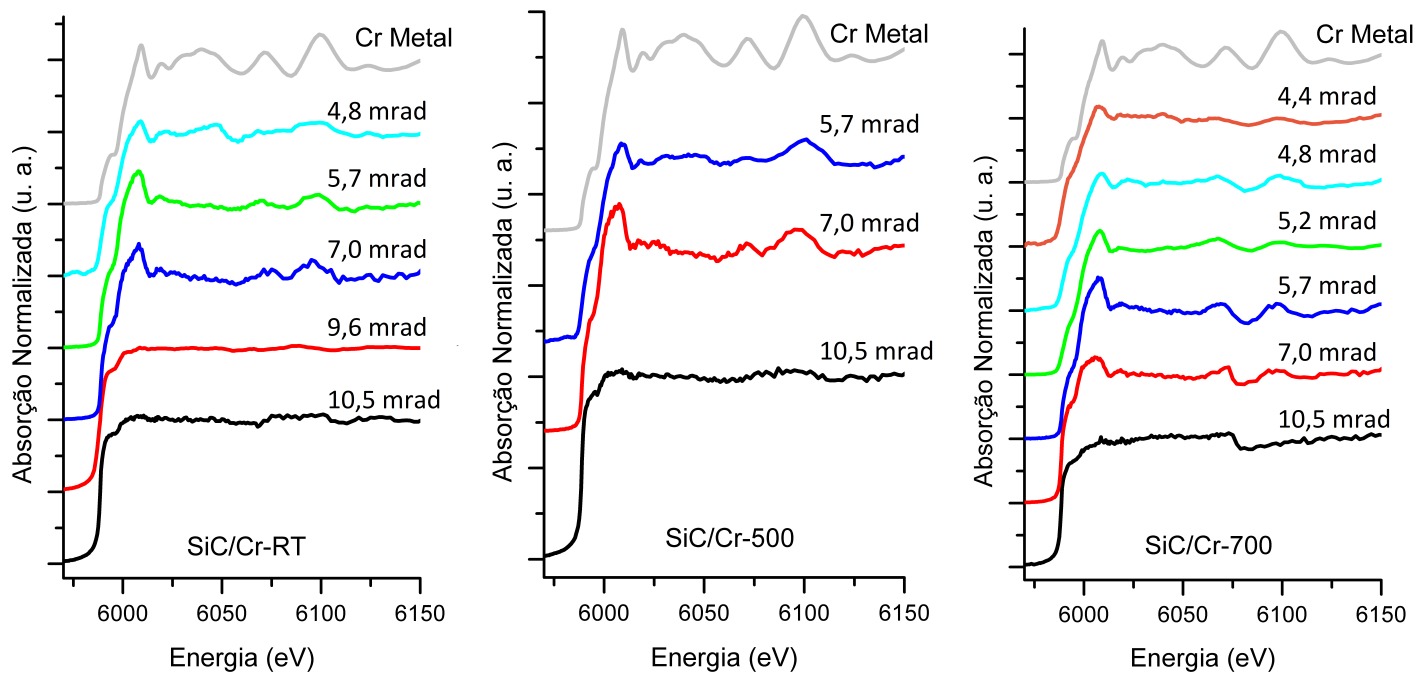

Figura 4.14: Espectros XANES da borda K do Cr nas amostras SiC/Cr-RT, SiC/Cr-500 e $\mathrm{SiC} / \mathrm{Cr}-700$, medido com incidência rasante em diversos ângulos. Em todos os gráficos é exibido o espectro de um padrão de Cr metálico, medido na mesma linha.

Primeiramente, para avaliar o desempenho do software, foram simulados os espectros de c-SiC-6H, c-Si, c-SiO ${ }_{2}$ e c- $\mathrm{Si}_{3} \mathrm{~N}_{4}$, utilizando como dados de entrada os parâmetros de rede e as posições atômicas de estruturas cristalinas disponíveis na Crystallography Open Database (COD) ${ }^{[107]}$, conforme destacado na tabela 4.6.5. A figura 4.15 exibe os resultados, em conjunto com os espectros experimentais correspondentes. Observa-se que o FDMNES foi capaz de obter boa concordância com os dados experimentais. É importante ressaltar que os espectros experimentais de $\mathrm{SiO}_{2}$ e $\mathrm{Si}_{3} \mathrm{~N}_{4}$ (figs. 4.15c e 4.15d) são de materiais amorfos e os cálculos são de estruturas cristalinas.

Tabela 4.3: Estruturas cristalinas simuladas com o FDMNES.

\begin{tabular}{|c|c|c|c|}
\hline Estrutura & $\operatorname{COD} n^{\circ}$ & Estrutura & $\operatorname{COD} n^{\circ}$ \\
\hline $\mathrm{SiC}-6 \mathrm{H}$ & 1011053 & c-Si & 2104737 \\
\hline$\alpha$-quartz $\mathrm{SiO}_{2}$ & 1011097 & $\beta-\mathrm{Si}_{3} \mathrm{~N}_{4}$ & 1001244 \\
\hline
\end{tabular}




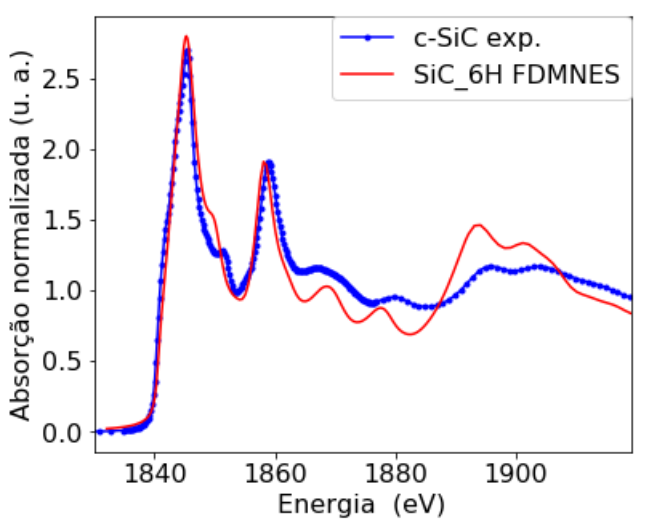

(a)

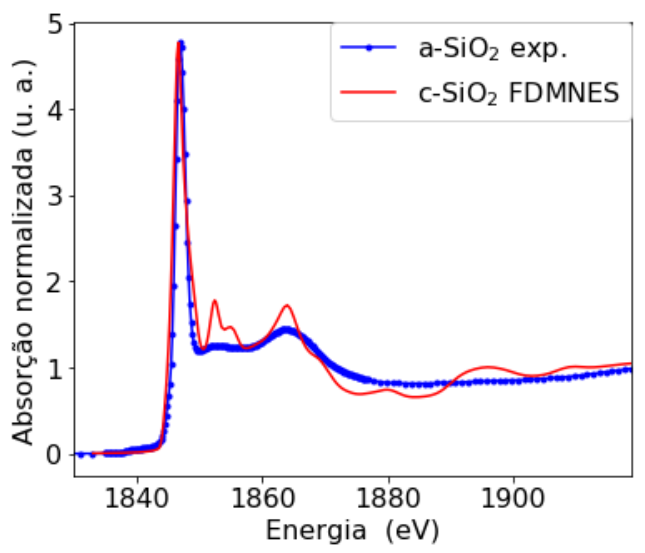

(c)

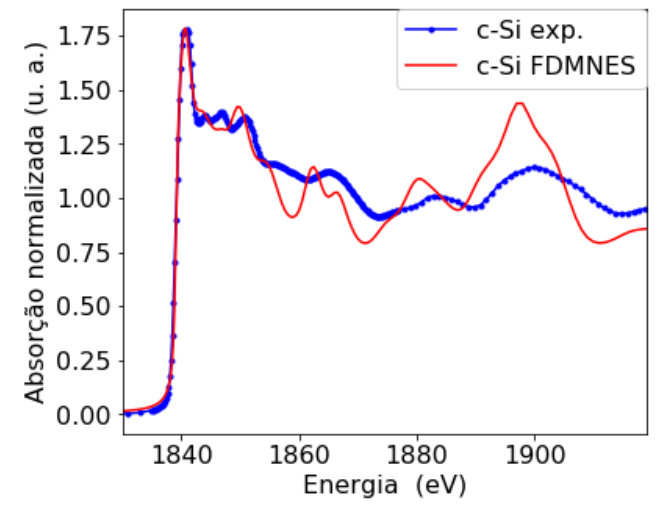

(b)

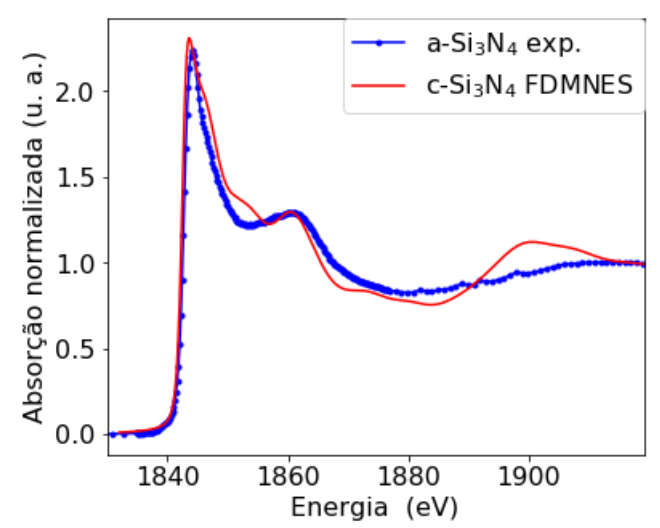

(d)

Figura 4.15: Espectros de absorção calculados com o FDMNES em comparação com medidas experimentais de amostras de $\mathrm{SiC}-6 \mathrm{H}, \mathrm{c}-\mathrm{Si}$, a-SiO${ }_{2}$ e a-Si $\mathrm{N}_{4}$.

\section{Simulação do carbeto de silício amorfo}

Estruturas de carbeto de silício amorfo foram obtidas por dinâmica molecular. O procedimento foi realizado ${ }^{\dagger}$ com o software VASP (Vienna ab-initio simulation package) ${ }^{[108]}$ onde, a partir das posições atômicas do cristal SiC-6H (COD n 1011053) ${ }^{[109]}$, um agregado (cluster) com 192 átomos (96 Si e $96 \mathrm{C}$ ) foi aquecido gradativamente até $5500 \mathrm{~K}$ e, após o relaxamento da estrutura, resfriado lentamente. Detalhes do procedimento de

\footnotetext{
${ }^{\dagger}$ O processo de dinâmica molecular foi realizado em colaboração com o Prof. Dr. Wanderlã Luis Scopel (UFES).
} 
amorfização podem ser encontrados na referência ${ }^{[110]}$.

A estrutura amorfa obtida contém 96 átomos de Si em posições não equivalentes. O seu aspecto amorfo é facilmente observado com o auxílio da figura 4.16. Uma avaliação qualitativa revela que a estrutura obtida está compatível com o esperado, pois os primeiros vizinhos de carbono estão em posições que flutuam levemente em torno da distância de 1,89 A, correspondente ao material cristalino. Já os segundos vizinhos de Si apresentam uma flutuação maior em torno do valor para a estrutura cristalina de 3,07 Å. A função distribuição radial, $g(r)$, no gráfico interno da figura 4.16 auxilia nessa análise. Como exemplo, a tabela 4.4 apresenta as posições atômicas de alguns vizinhos de dois Si absorvedores escolhidos.

Tabela 4.4: Vizinhança de dois Si absorvedores da estrutura teórica a-SiC. Compare as distâncias da tabela com os pontos da figura 4.16. Os valores estão em $\AA$.

\begin{tabular}{|c|c|c|c|c|c|c|c|c|c|}
\hline \multicolumn{5}{|c|}{ Si absorvedor $n^{\circ} 41$} & \multicolumn{5}{|c|}{ Si absorvedor $n^{\circ} 91$} \\
\hline Elem. & $\mathrm{x}$ & $\mathrm{y}$ & $\mathrm{z}$ & Dist. & Elem. & $\mathrm{x}$ & $\mathrm{y}$ & $\mathrm{z}$ & Dist. \\
\hline $\mathrm{Si}$ & 0.0 & 0.0 & 0.0 & 0.0 & $\mathrm{Si}$ & 0.0 & 0.0 & 0.0 & 0.0 \\
\hline $\mathrm{C}$ & 0.745 & -1.290 & -1.106 & 1.855 & $\mathrm{C}$ & 0.919 & 0.759 & 1.405 & 1.842 \\
\hline $\mathrm{C}$ & -1.736 & 0.471 & -0.457 & 1.855 & $\mathrm{C}$ & -0.118 & -1.859 & 0.0438 & 1.863 \\
\hline $\mathrm{C}$ & -0.543 & -1.142 & 1.430 & 1.909 & $\mathrm{C}$ & -1.671 & 0.804 & -0.243 & 1.870 \\
\hline $\mathrm{C}$ & 0.900 & 1.674 & -0.346 & 1.931 & $\mathrm{C}$ & 0.982 & 0.406 & -1.625 & 1.941 \\
\hline $\mathrm{C}$ & -2.174 & 1.190 & 0.811 & 2.607 & $\mathrm{C}$ & -0.367 & 0.789 & 2.226 & 2.390 \\
\hline $\mathrm{C}$ & 2.118 & -0.129 & 1.521 & 2.611 & $\mathrm{Si}$ & -0.0264 & -1.952 & -1.840 & 2.682 \\
\hline $\mathrm{Si}$ & 2.592 & 0.807 & -0.070 & 2.716 & $\mathrm{Si}$ & -1.544 & 0.870 & -2.060 & 2.717 \\
\hline $\mathrm{C}$ & 0.212 & 2.152 & -1.667 & 2.730 & $\mathrm{C}$ & 0.197 & 1.575 & -2.347 & 2.834 \\
\hline $\mathrm{Si}$ & -2.391 & -1.198 & -0.636 & 2.749 & $\mathrm{C}$ & 1.446 & -0.965 & -2.312 & 2.893 \\
\hline $\mathrm{Si}$ & 1.073 & -1.862 & 1.780 & 2.790 & $\mathrm{Si}$ & 2.695 & 0.802 & -1.060 & 3.005 \\
\hline
\end{tabular}




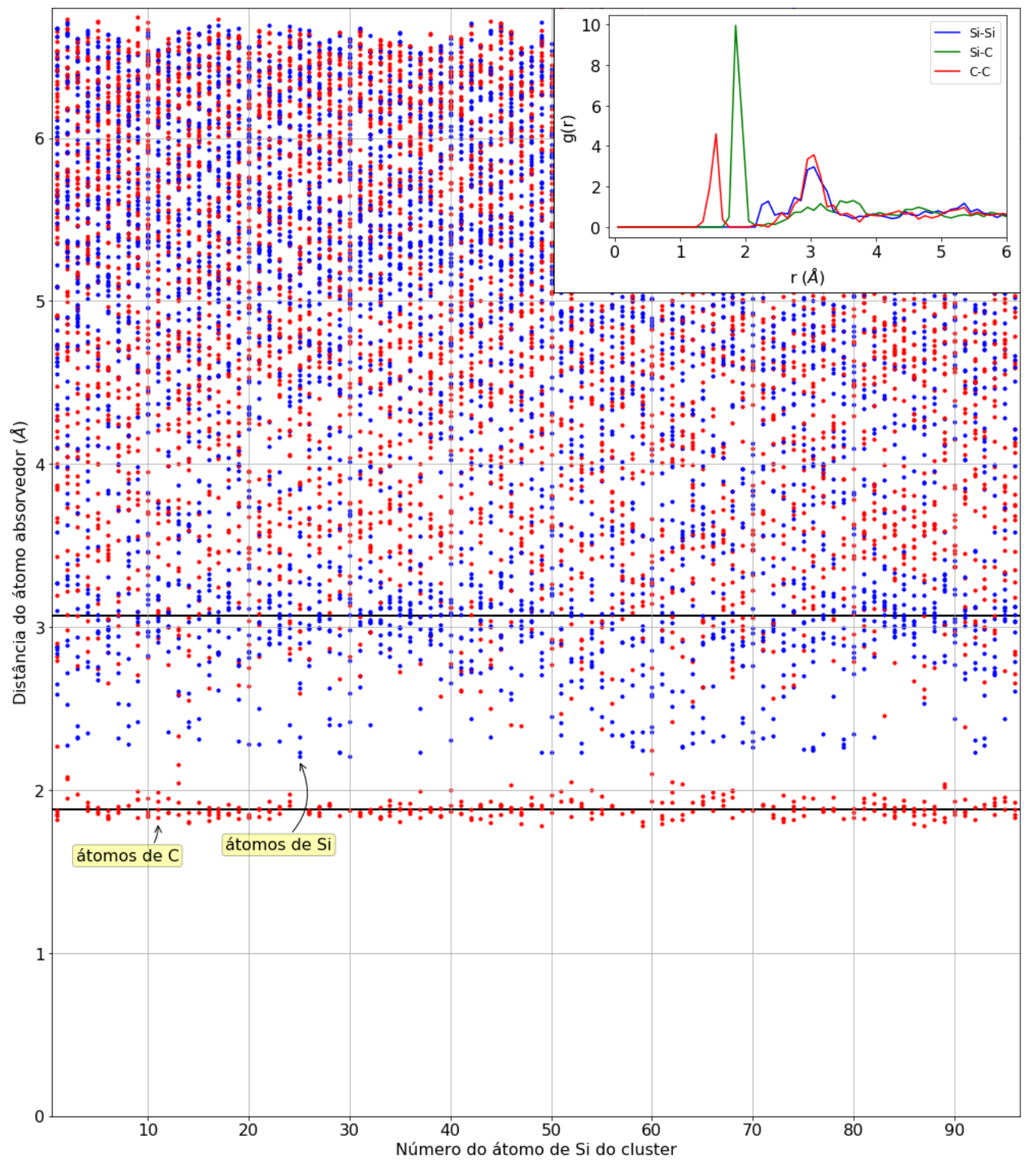

Figura 4.16: Vizinhança dos átomos de $\mathrm{Si}$ da estrutura amorfa de $\mathrm{SiC}$ obtida por dinâmica molecular. Os 96 átomos de Si absorvedores do agregado foram numerados arbitrariamente e correspondem aos valores da abcissa. Os pontos vermelhos correspondem aos vizinhos de $\mathrm{C}$ e os azuis aos vizinhos de Si. As linhas horizontais indicam a distância dos primeiros $(\mathrm{C})$ e segundos $(\mathrm{Si})$ vizinhos da estrutura cristalina do SiC-6H. A distribuição de pares, g(r), é apresentada no gráfico interno. 


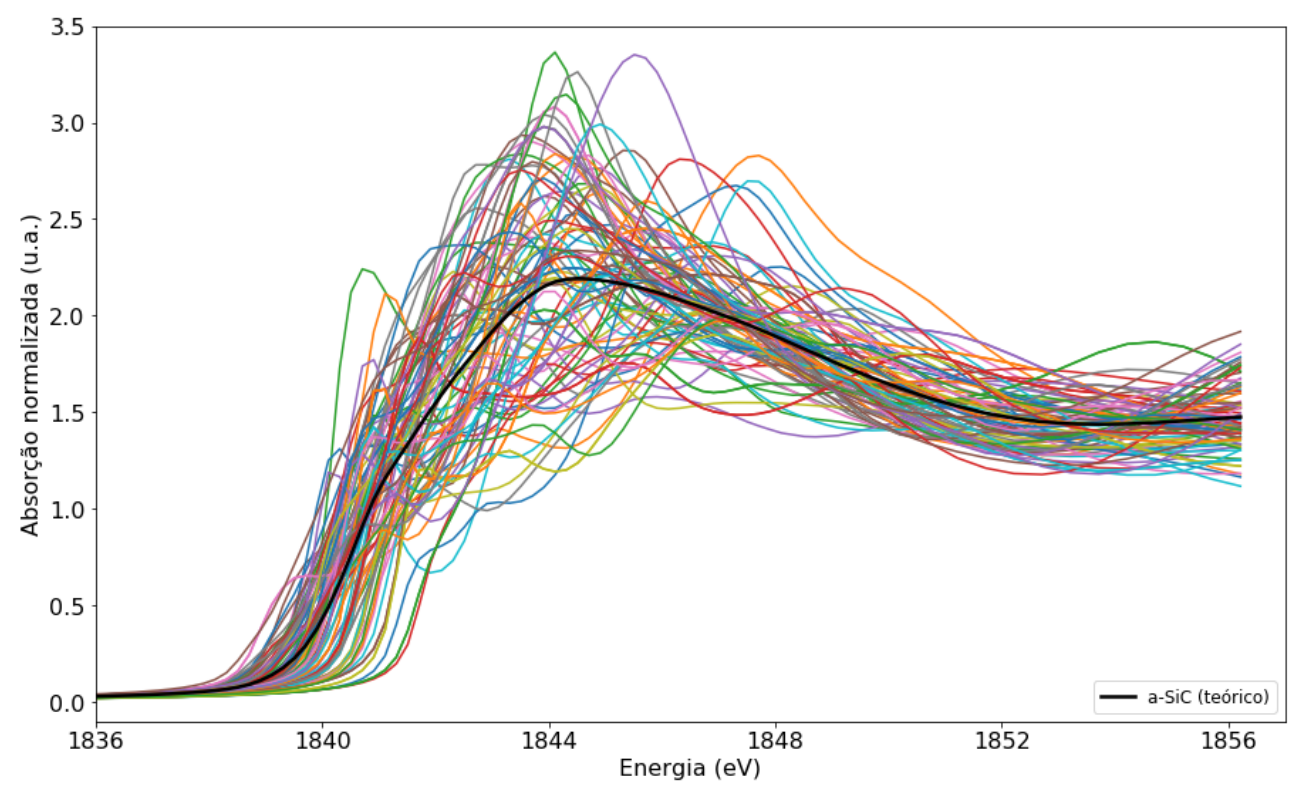

(a)

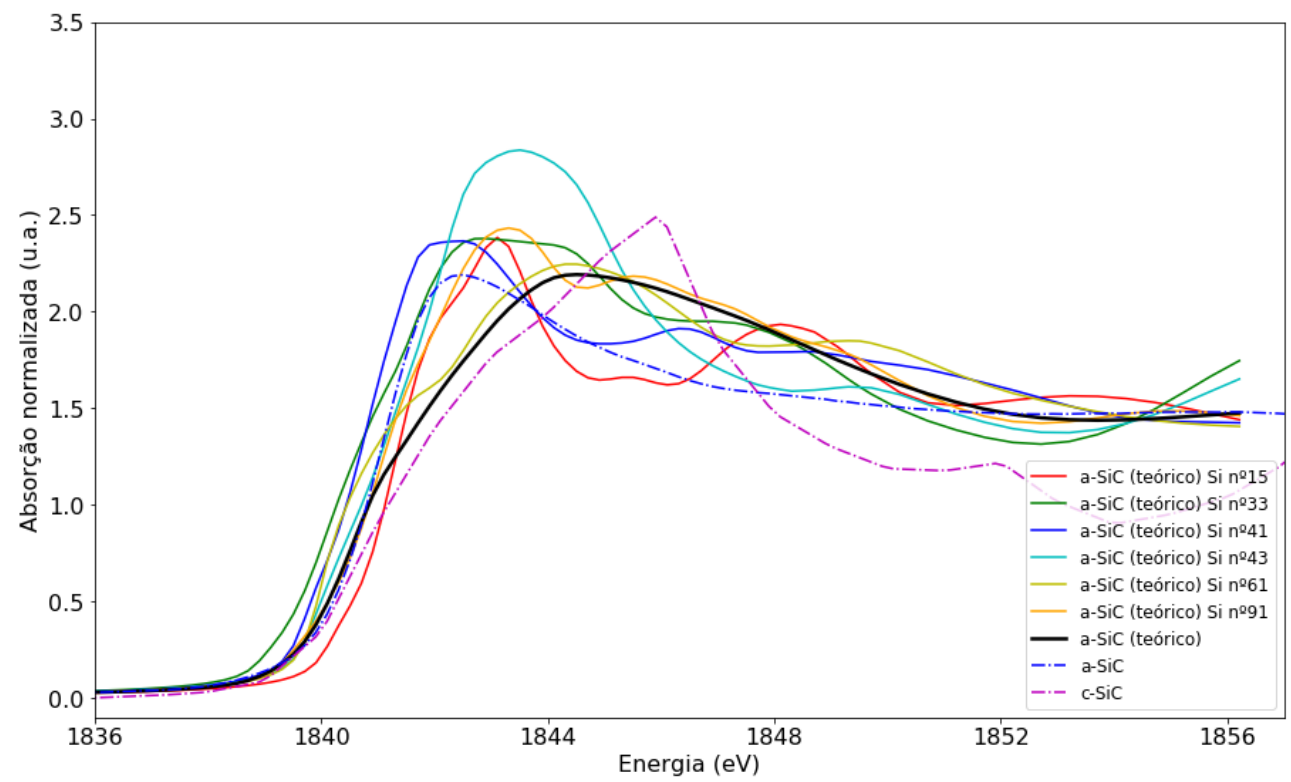

(b)

Figura 4.17: Espectros XANES da borda K do Si do carbeto de silício amorfo da estrutura da figura 4.16, obtida por dinâmica molecular (vermelho). Em (a), os espectros de todos os 96 átomos de Si absorvedores da estrutura são exibidos e em (b), os espectros de apenas alguns átomos selecionados, juntamente com os padrões experimentais a-SiC e c-SiC, para comparação. 
O espectro XANES desses 96 átomos foram simulados com o FDMNES onde o resultado é mostrado na figura 4.17. Pode-se observar que as diferentes vizinhanças dos absorvedores produzem espectros bem distintos entre si, mas que resultam numa média que apresenta os contornos do padrão a-SiC experimental, porém, com a inclinação da borda semelhante à que ocorre no padrão c-SiC. Tal resultado é consistente porque a estrutura possui uma distribuição de distâncias com certa semelhança com o material cristalino inicial. Alguns espectros de absorvedores selecionados estão presentes na figura 4.17b. É possível identificar que alguns se assemelham ao padrão de a-SiC (vide Si n41 e 91), entretanto, é precipitado afirmar que a vizinhança desses absorvedores corresponde ao que ocorre no material, pois, seu espectro corresponde à média das contribuições de diferentes vizinhanças.

\section{Simulações da difusão do oxigênio e cromo no carbeto de silício amorfo}

Com o objetivo de avaliar a influência de uma eventual difusão de $\mathrm{O}$ ou Cr no carbeto de silício da microlâmpada, duas outras estruturas foram construídas. Partindo da estrutura já relaxada da figura 4.16, 10 átomos de $\mathrm{Si}$, escolhidos ao acaso, foram substituídos pelo contaminante $(\mathrm{O}$ ou $\mathrm{Cr})$. A estrutura foi colocada para relaxar, por dinâmica molecular, resultando nos materiais denominados a-SiC-O (figura 4.18) e a-SiC-Cr (figura 4.19). Com o auxílio das figuras, nota-se que o processo manteve a matriz amorfa do carbeto de silício original, modificando um pouco as posições originais dos átomos de Si e C, mas mantendo distâncias compatíveis com as ligações Si-C. Cinco dos dez átomos de oxigênio da estrutura a-SiC-O possuem distância de 1,6 a $1,8 \AA$ com vizinhos de Si, valor compatível com a distância de ligação Si-O. Os demais parecem estar ligados aos átomos de $\mathrm{C}$ (vide, por exemplo, $\mathrm{Si}^{\circ} 5$ ). Os átomos de $\mathrm{Cr}$ da estrutura a-SiC-Cr permaneceram em posições distantes, aproximadamente, 2,3 a

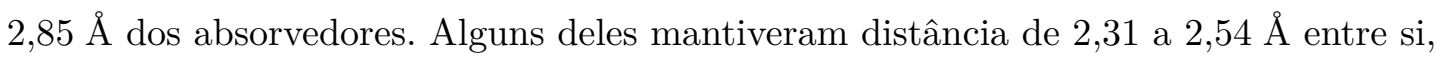
indicando possível ligação Cr-Cr (por exemplo, os dois Cr na vizinhança do Si nº60). 


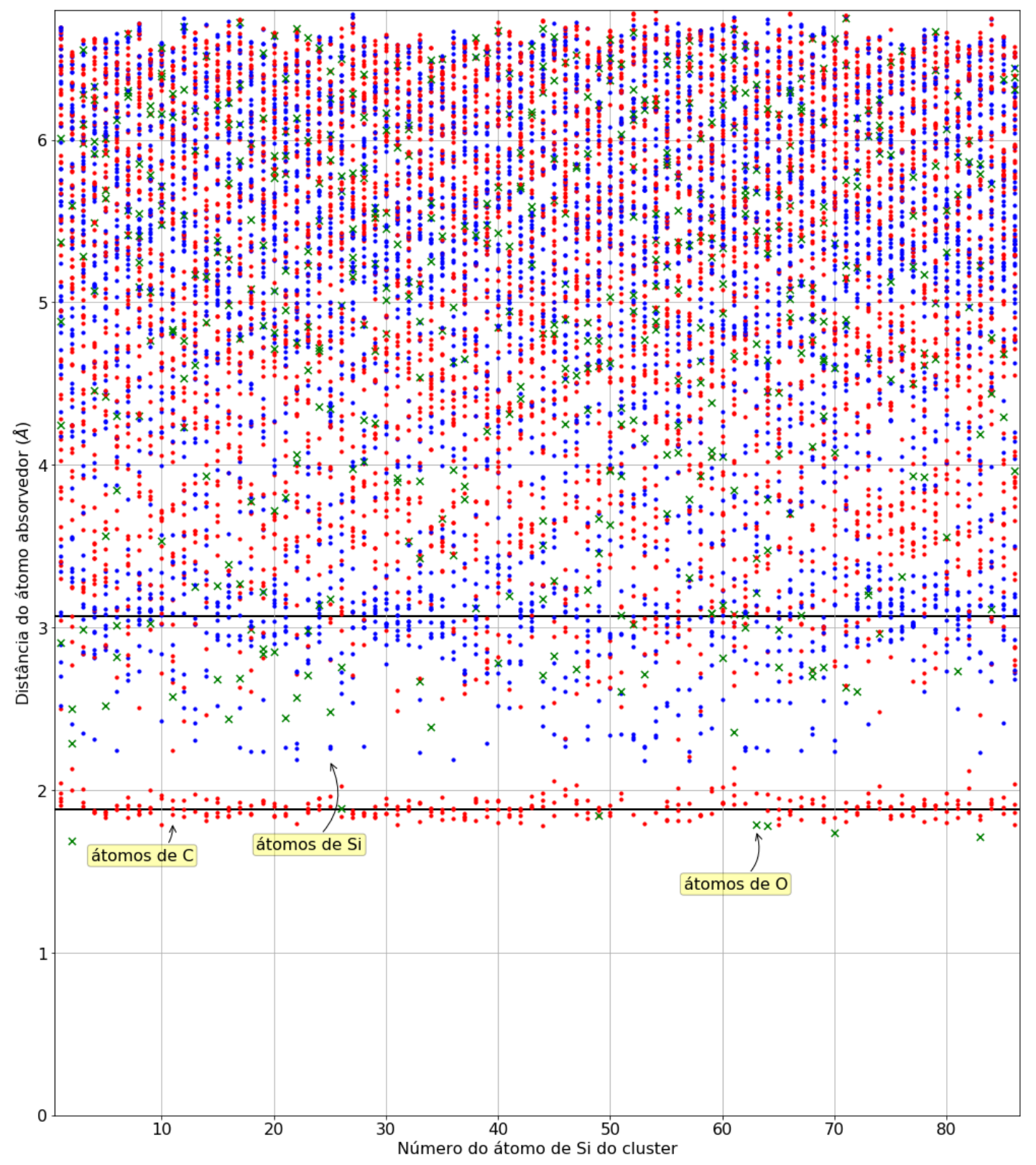

Figura 4.18: Vizinhança dos átomos de Si da estrutura amorfa de SiC-O obtida por dinâmica molecular. Nessa estrutura, 10 dos 96 átomos de Si da figura 4.16 foram substituídos por $\mathrm{O}$, e então o sistema foi colocado para relaxar. Os 86 átomos de $\mathrm{Si}$ restantes correspondem aos valores da abcissa. $(\bullet)$ vermelhos correspondem aos vizinhos de $\mathrm{C},(\bullet)$ azuis aos vizinhos de $\mathrm{Si}$ e (x) verdes aos vizinhos de O. As linhas horizontais indicam a distância dos primeiros $(\mathrm{C})$ e segundos $(\mathrm{Si})$ vizinhos da estrutura cristalina do $\mathrm{SiC}-6 \mathrm{H}$. 


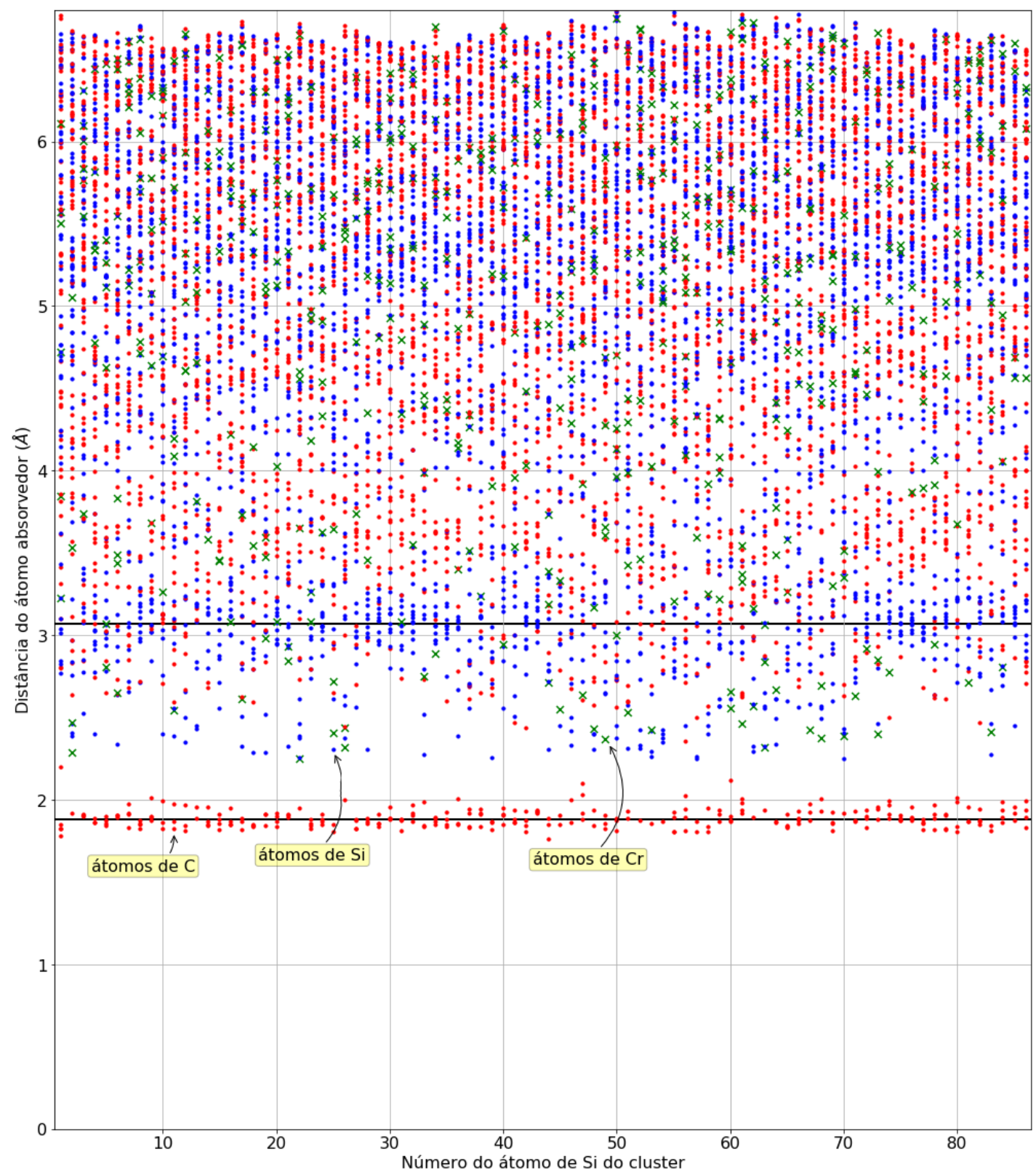

Figura 4.19: Vizinhança dos átomos de Si da estrutura amorfa de SiC-Cr obtida por dinâmica molecular. Nessa estrutura, 10 dos 96 átomos de Si da figura 4.16 foram substituídos por Cr, e então o sistema foi colocado para relaxar. Os 86 átomos de $\mathrm{Si}$ restantes correspondem aos valores da abcissa. $(\bullet)$ vermelhos correspondem aos vizinhos de $\mathrm{C},(\bullet)$ azuis aos vizinhos de Si e (x) verdes aos vizinhos de Cr. As linhas horizontais indicam a distância dos primeiros $(\mathrm{C})$ e segundos $(\mathrm{Si})$ vizinhos da estrutura cristalina do $\mathrm{SiC}-6 \mathrm{H}$. 
O espectro XANES médio dos 86 átomos absorvedores das duas estruturas é apresentado na figura 4.20, juntamente com a curva do material sem os contaminantes $\mathrm{O}$ e Cr. As principais características observadas são:

- A presença do cromo produz um deslocamento do espectro para energias maiores, em torno de $0,5 \mathrm{eV}$, o que resulta em um alargamento do pico;

- A influência do oxigênio, na quantidade presente, causou alteração muito pequena no espectro, sendo ela um leve alargamento do pico;

- Nos dois casos, as modificações induzidas pelos contaminantes são pequenas, indicando que a quantidade de 10 átomos $(\mathrm{O}$ ou $\mathrm{Cr})$ em $86(\mathrm{Si})$ foi uma escolha conservadora e poderia ser majorada. Em especial, para o oxigênio, as alterações no espectro são realmente pequenas a ponto de poderem ser confundidas com simplificações do modelo presente no FDMNES.

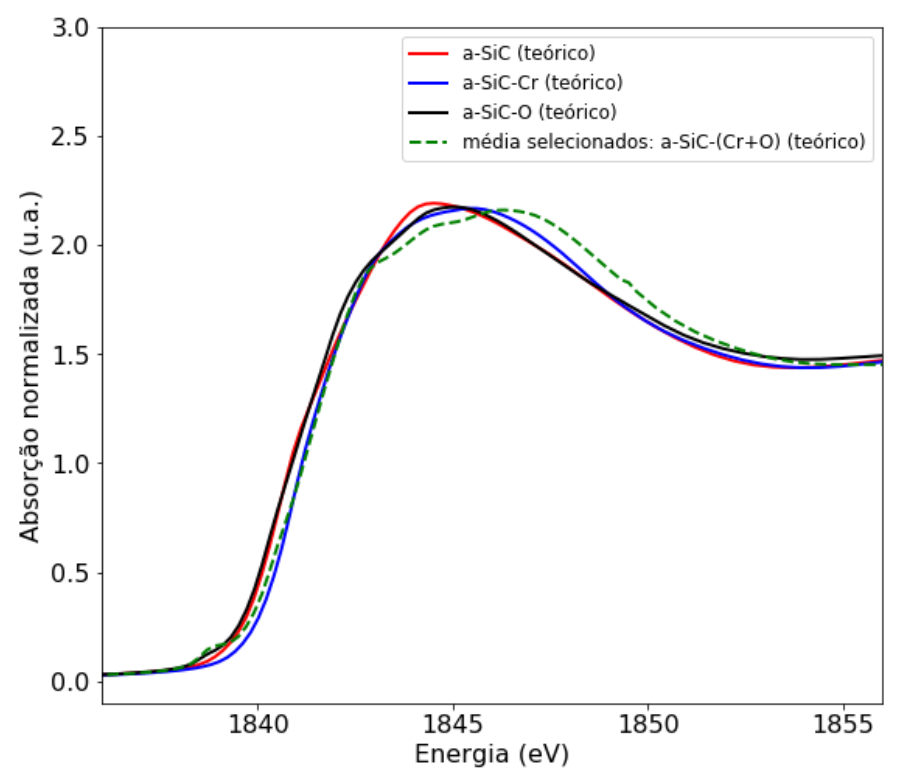

Figura 4.20: Espectros XANES da borda K do Si calculado com o FDMNES para as estruturas a-SiC-O e a-SiC-C. Observa-se que o $\mathrm{Cr}$ induz um leve deslocamento para energias maiores (curva azul). A curva em verde representa o espectro médio dos absorvedores selecionados da figura 4.21 . 
A figura 4.21 apresenta uma tentativa de ampliar as influências induzidas pelos contaminantes. A parte superior da figura indica a quantidade de $\mathrm{O}$ (ou $\mathrm{Cr}$ ) presente numa esfera de raio $6,5 \AA$ em torno de cada absorvedor. A parte inferior apresenta os espectros médios tomando apenas os absorvedores selecionados com a maior quantidade de $\mathrm{O}$ (ou $\mathrm{Cr}$ ) na vizinhança (verde), bem como a média tomando os demais absorvedores não selecionados (laranja). A intenção é minimizar a influência da absorção dos átomos de Si da estrutura cuja vizinhança contém poucos contaminantes, com o propósito de avaliar a tendência caso a concentração de $\mathrm{O}$ (ou $\mathrm{Cr}$ ) fosse maior. Nos dois casos,

obtém-se um alargamento do pico para energias maiores. É interessante notar como a média dos absorvedores com menor quantidade de contaminantes (não selecionados) ficou bem próxima da média de toda a estrutura (preto ou azul). A curva verde da figura 4.20 corresponde à média dos espectros selecionados das duas estruturas, ou seja, a média das curvas verdes de $4.21 \mathrm{a}$ e $4.21 \mathrm{~b}$. Pode-se concluir que a presença dos contaminantes na estrutura, induz um alargamento do pico, juntamente com o leve deslocamento da borda para maiores energias.

\subsubsection{Discussão sobre os resultados obtidos com a microlâmpada com $\mathrm{a}-\mathrm{SiC}$}

O espectro XANES obtido com o carbeto de silício da microlâmpada ML49-SiC (não energizada) possui diferenças significativas em relação ao filme de a-SiC de referência, depositado sobre Si, juntamente com a microlâmpada, o que revela diferenças estruturais entre os dois filmes. Apesar do material obtido não se apresentar como o melhor para a aplicação como camada de proteção na microlâmpada, é de interesse aprofundar o estudo das suas características e no entendimento do motivo das diferenças estruturais. Isto porque, além de já ter sido reportada condutividade térmica semelhante ao AlN e $\mathrm{TiO}_{2}$, o carbeto de silício apresenta propriedades mecânicas que são interessantes quando se pensa em MEMS/MOEMS integrados com outras funcionalidades. 

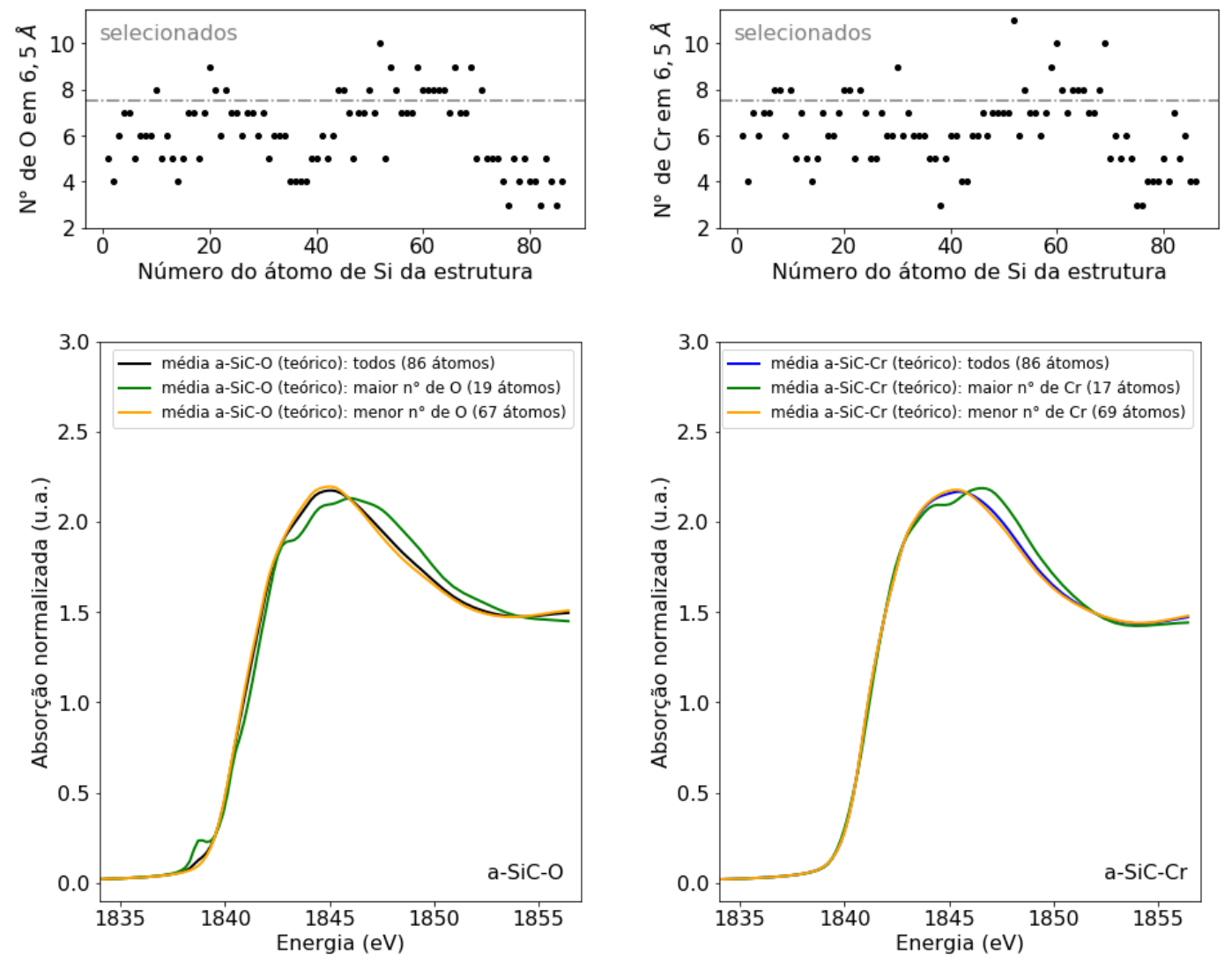

(a)

(b)

Figura 4.21: Espectros XANES da borda K do Si, obtido por simulação com o FDMNES, para as estruturas a-SiC-O e a-SiC-Cr. As curvas em preto apresentam o resultado médio dos 86 átomos de cada estrutura. As curvas em verde correspondem à média dos espectros dos absorvedores que contêm a maior quantidade de $\mathrm{O}$ (ou $\mathrm{Cr}$ ) em sua volta (compreendidos em uma esfera de raio $6,5 \AA$ ). A curva laranja corresponde à média dos espectros dos demais átomos. A parte superior da figura mostra os átomos selecionados em função da quantidade de $\mathrm{O}$ (ou Cr). 
Diversas medidas foram realizadas para tentar entender as diferenças estruturais observadas por XANES. Primeiramente foi descartada a hipótese de que a corrosão por RIE pudesse produzir alterações no espectro pois, conforme indica a figura 4.8, não há grandes alterações estruturais em decorrência da corrosão antes que as medidas de absorção (modo TEY) possam detectar o substrato de Si.

\section{Difusão do cromo}

A hipótese de que a difusão do cromo é responsável pelas alterações no espectro XANES da microlâmpada com carbeto de silício foi investigada. O processo de difusão entre $\mathrm{Cr}$ e $\mathrm{SiC}$ e entre $\mathrm{Cr}$ e Si já foi reportado na literatura ${ }^{[111-114]}$ e, apesar de se intensificar quando os materiais são submetidos a tratamento térmico, ocorre também nos materiais que não foram tratados termicamente.

As medidas de RBS e GIXRF, realizadas nas amostras de filmes finos adicionais, mostram a difusão nas duas interfaces ( $\mathrm{Cr} / \mathrm{a}-\mathrm{SiC}$ e $\mathrm{Cr} /$ substrato de $\mathrm{Si}$ ) de maneira apreciável, mesmo antes do tratamento térmico. Com o aumento da temperatura a difusão parece se intensificar, especialmente a partir $700^{\circ} \mathrm{C}$, em direção ao substrato. Não há grandes diferenças entre a espessura da camada de carbeto, isenta de Cr, nas amostras submetidas a diferentes temperaturas de tratamento térmico. Convém lembrar que a deposição do Cr foi feita por sputtering e o a-SiC por PECVD a $320^{\circ} \mathrm{C}$. Ou seja, essa temperatura pode induzir a difusão do Cr nas interfaces. Tal efeito pode ocorrer mesmo para amostras sem tratamento térmico e microlâmpadas não energizadas.

Espera-se que haja ligações $\mathrm{Si}-\mathrm{Cr}$ na região interfacial entre o a-SiC e o $\mathrm{Cr}$, pois ele não difunde totalmente na forma metálica (ver fig. 4.14). Sendo assim, deveria ser possível detectar alterações na borda do Si devido à sua presença. Entretanto, como revela a figura 4.8, tais alterações não estão presentes no espectro XANES das amostras de filmes finos adicionais. Possivelmente, o modo de detecção TEY, por ser sensível apenas à região superficial da amostra (algumas dezenas de $n m$ ), não atingiu o local 
modificado pelo Cr. Estudos revelaram que a espessura detectável, na borda $\mathrm{K}$ do $\mathrm{Si}$, por TEY no $\mathrm{SiO}_{2}$ é da ordem de $70 \mathrm{~nm}^{[72]}$. No carbeto o valor pode ser ainda menor. É importante mencionar que a espessura da camada isenta de $\mathrm{Cr}$, medida por RBS e GIXRF, aproximadamente $42-48 \mathrm{~nm}$, foi obtida convertendo os valores em TFU (thin film unit) usando as densidades reportadas na literatura. Como os materiais são amorfos, a densidade real deve ser menor, de forma que a espessura tende a ser superior ao valor estimado. Desta forma, a não deteç̧ão do Cr difundido nas amostras de filmes finos adicionais é compatível com as condições experimentais. As simulações XANES das estruturas obtidas por dinâmica molecular indicam que a presença do $\mathrm{Cr}$ na estrutura amorfa do SiC produz um alargamento do pico de absorção na direção de maiores energias, comportamento que é semelhante ao observado na microlâmpada ML49-SiC. A concentração simulada foi de $10 \mathrm{Cr} / 86 \mathrm{Si} \approx 11,6 \%$, que é bem menor do que a difusão observada em RBS/GIXRF nos filmes adicionais.

Voltando para a microlâmpada, é importante lembrar que há uma cavidade logo abaixo do filamento (vide figura 3.4) e, conforme já mencionado, como o aquecimento da região onde o a-SiC é depositado no PECVD é feito por transmissão de calor através do substrato, é razoável supor que a temperatura, imediatamente acima do filamento, não atinja o valor desejado resultando num material com a estrutura modificada nesta região. Tal fato deve ser a razão das alterações no espectro das microlâmpadas, pois a região coincide com o local onde o feixe de raios X microfoco foi direcionado. Além disso, o espectro do filme de referência de a-SiC, depositado sobre Si juntamente com a microlâmpada, não apresenta tais características. No mais, o carbeto de silício modificado na microrregião sobre a cavidade pode ter densidade diferente e ser mais susceptível à difusão do Cr. 


\section{Difusão do oxigênio}

A presença do oxigênio nas amostras de filmes finos adicionais de a-SiC é bastante significativa. Mesmo para a amostra não submetida ao tratamento térmico observa-se uma primeira camada de a-SiC rica em carbono e com $\approx 5-8 \%$ de $\mathrm{O}$. O ajuste com os dados de RBS indica, logo abaixo, uma camada com $\approx 40 \%$ de $\mathrm{O}$ (vide tabela 4.2 ) antes da região com $\mathrm{Cr}$ e a-SiC difundidos. Tal resultado indica que parte do oxigênio é proveniente da oxidação do $\mathrm{Cr}$, presente antes da deposição do carbeto, o que é compatível com o fato de que a amostra foi retirada do sputtering e levada até o PECVD, permanecendo com o cromo algum tempo exposto ao ar. Com a intensificação do tratamento térmico, o ajuste dos dados de GIXRF indica um aumento da oxidação da superfície externa, resultado compatível com XANES. Os dados de RBS sugerem maior difusão do oxigênio na interface intermediária entre o $\mathrm{Cr}$ e o a-SiC.

A microlâmpada não energizada, ML49-SiC, apresenta um pequeno pico em $\approx$ $1847 \mathrm{eV}$ correspondente ao $\mathrm{SiO}_{2}$, o que é compatível com a oxidação superficial encontrada nos filmes finos adicionais. O efeito da presença do oxigênio na estrutura construída por dinâmica molecular foi menos intenso que o caso do $\mathrm{Cr}$ (vide figura 4.20). Um alargamento do pico do espectro para maiores energias só é observado quando algumas vizinhanças mais ricas em O são selecionadas (vide figura 4.21). Provavelmente, a presença do oxigênio na superfície externa do a-SiC da microlâmpada não é responsável pelas modificações do espectro XANES, pois, se fosse, elas deveriam ser observadas também nos espectros dos filmes adicionais, já que seriam detectáveis por TEY.

\section{Estrutura sugerida para o a-SiC das microlâmpadas}

A razão mais provável para a as modificações estruturais da microlâmpada de a-SiC, observadas no espectro XANES, é a deposição por PECVD fora das condições ideais devido à cavidade, juntamente com a presença do $\mathrm{Cr}$ difundido no material. Observando o espectro da microlâmpada ML49-SiC, juntamente com o de amostras padrão da 
figura 4.22, observa-se que a borda de absorção tem boa concordância com a borda do a-Si, logo, conclui-se que a estrutura mais provável do material da camada de proteção da microlâmpada ML49-SiC (não energizada), na microrregião sobre o filamento, é um a-Si $i_{x} \mathrm{C}_{1-x}$, rico em carbono, com agregados de $\mathrm{Si}$ amorfo, uma camada superficial de $\mathrm{a}_{-} \mathrm{SiO}_{2}$ e com átomos de $\mathrm{Cr}$ e/ou $\mathrm{O}$ difundidos. Com o processo de energização o material vai se convertendo em a- $\mathrm{SiO}_{2}$, possivelmente, a partir da superfície externa, mantendo o restante pouco alterado.

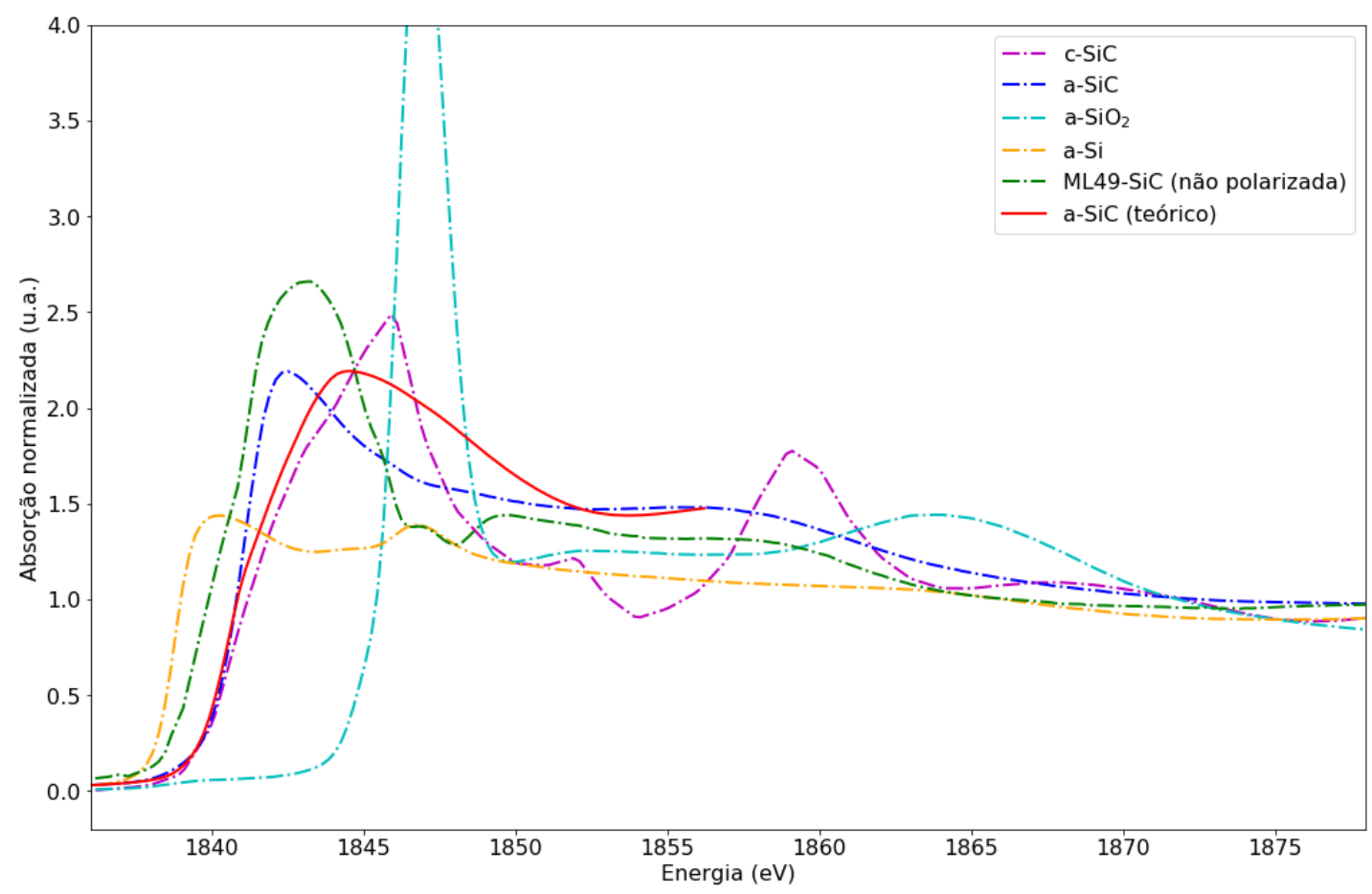

Figura 4.22: Comparação do espectro XANES da borda K do Si da microlâmapada não energizada (ML49-SiC) com padrões experimentais e os resultados da simulação com o FDMNES.

\subsection{Microlâmpadas com nitreto de alumínio -AlN}

A figura 4.23 mostra os espectros XANES da borda $\mathrm{K}$ do Al obtidos com as microlâmpadas com camada de proteção de AlN, juntamente com o espectro de uma amostra de 
AlN padrão, depositada por sputtering em condições semelhantes. Uma análise qualitativa revela que os espectros são muito similares, mesmo com o aumento das condições de energização (corrente e tempo). As principais características dos espectros podem ser observadas na figura 4.24. São elas:

- As microlâmpadas ML53, ML-17 e ML-32-AlN, por não terem sido energizadas ou energizadas com baixa corrente $(30 \mathrm{~mA})$, apresentam espectro muito semelhante ao filme padrão de AlN. As microlâmpadas ML28 e ML31-AlN foram energizadas a $40 \mathrm{~mA}$ e possuem espectros também muito semelhantes às anteriores. Entretanto, observa-se um deslocamento da borda em $\approx 1 \mathrm{eV}$, característica de um processo de oxidação (vide figura 4.24a);

- Quando a energização é superior a $40 \mathrm{~mA}$, o espectro mostra diferenças em relação à microlâmpada não energizada, mesmo se a corrente é aplicada por pouco tempo. As microlâmpadas ML70, ML59 e ML62-AlN apresentam espectros semelhantes, exibindo um aumento relativo do pico em $\approx 1569 \mathrm{eV}$, em comparação ao pico em $\approx 1564 \mathrm{eV}$. A borda de absorção está deslocada em $\approx 0,5 \mathrm{eV}$ (vide figura 4.24b);

- A ML54-AlN foi energizada com a mesma corrente, mas por um tempo maior, que a ML70. Seu espectro também apresenta deslocamento da borda de $\approx 0,5 \mathrm{eV}$, mas, com o par de picos mencionados anteriormente de intensidades semelhantes, mostrando não seguir o padrão de comportamento observado nas microlâmpadas anteriores. Tal fato não invalida a análise, uma vez que as diferenças observadas são muito pequenas e qualquer variação local na condição de deposição ou energização pode acarretar tais mudanças (vide figura 4.24c);

- A microlâmpada ML37-AlN foi energizada a $46 m A$ e teve o seu filamento queimado. O espectro apresenta diferenças nítidas, tendo até picos adicionais em aproximadamente $1567 \mathrm{eV}$ e $1574 \mathrm{eV}$, bem como deslocamento da borda de absorção. Tal fato pode indicar o início de um processo de cristalização (vide 
figura 4.24c. Estudos anteriores do AlN, depositado em condições semelhantes, indicam a presença da fase wurtzita ${ }^{[23]}$.

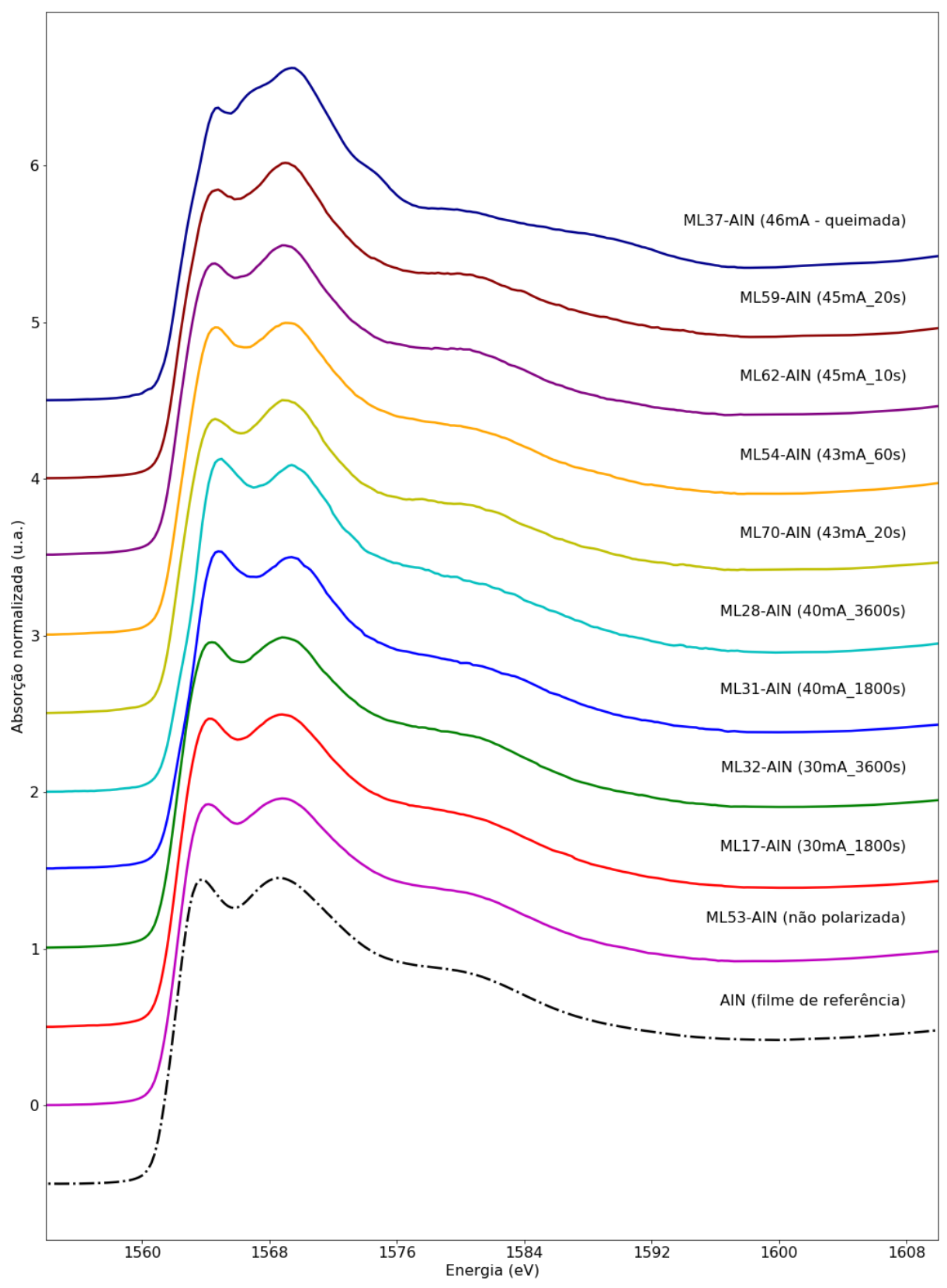

Figura 4.23: Espectro XANES da borda K do Al das microlâmpadas de AlN, juntamente com uma amostra padrão. As curvas estão deslocadas para melhor visualização e as condições de energização estão indicadas. 


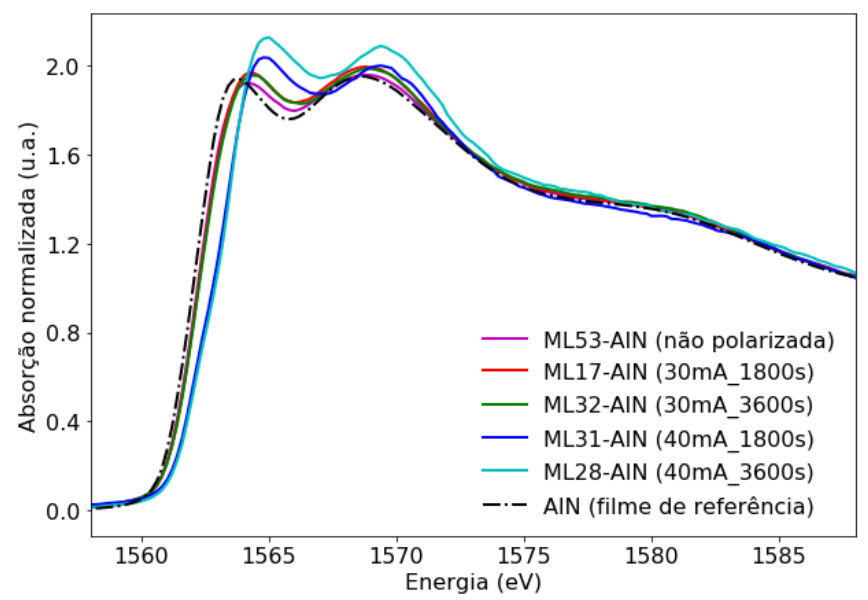

(a)

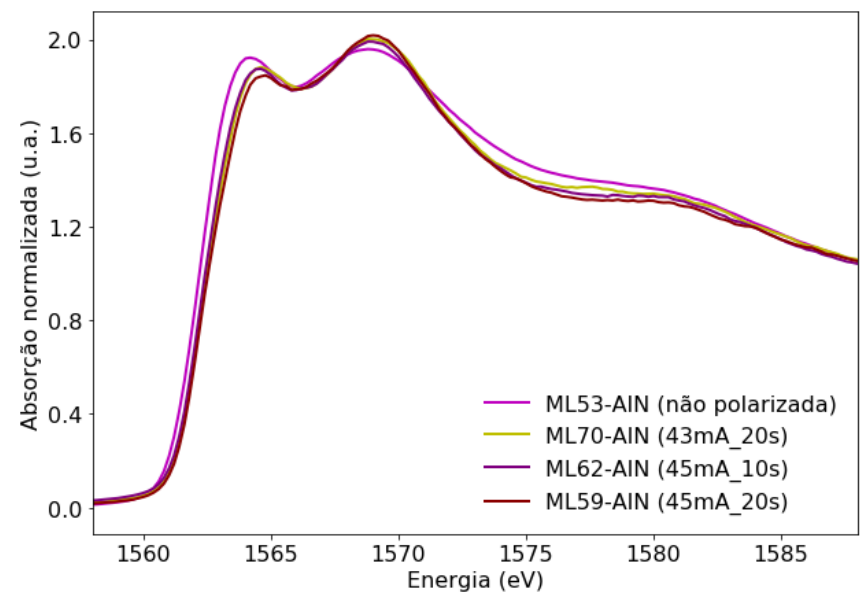

(b)

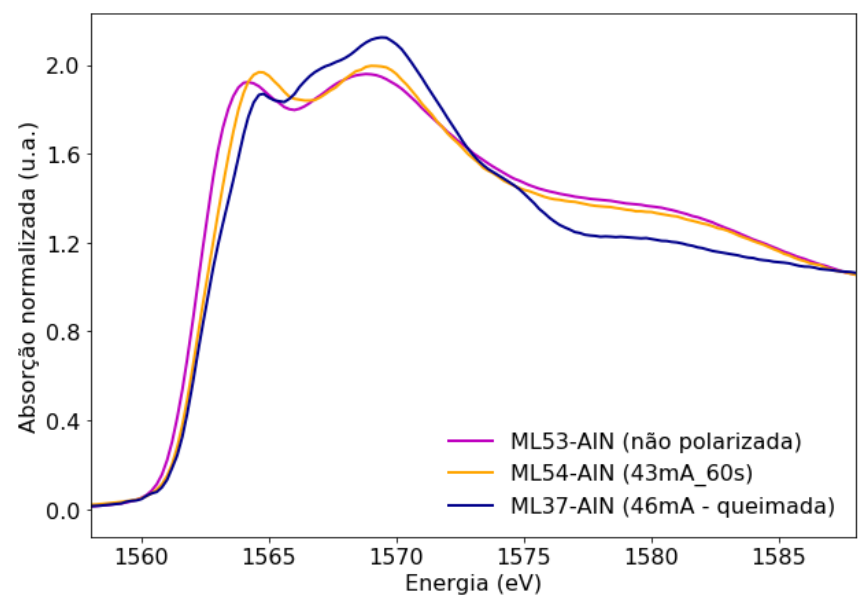

(c)

Figura 4.24: Detalhes dos espectros XANES da borda K do Al das microlâmpadas com AlN. As figuras (a), (b) e (c) comparam as características mencionadas no texto com a ML53-AlN (não energizada). 


\subsubsection{Espectros XAS das amostras de filmes finos adicionais de AlN}

Os espectros XANES da borda $\mathrm{K}$ do $\mathrm{Al}$ obtidos com as amostras de filmes finos adicionais de AlN são exibidos na figura 4.25. Uma análise qualitativa dos gráficos permite identificar os seguintes aspectos principais:

- As bordas de absorção se iniciam em energias menores $(\approx 3,0 \mathrm{eV})$ que a do AlN (referência), indicando a presença de $\mathrm{Al}$ metálico. Essa característica não é das amostras, mas sim de uma contaminação na linha do SXS do LNLS, identificada no dia da realização das medidas. Apesar da contaminação afetar os espectros, ainda foi possível utilizá-los;

- Os espectros mostram o pico característico do $\mathrm{AlN}, \mathrm{em} \approx 1564 \mathrm{eV}$, muito reduzido. Esse aspecto pode ser decorrente da presença do Al metálico, cuja intensidade de absorção é reduzida nessa região.

- Comparando as figuras 4.25a e 4.25b, observa-se que não há diferenças significativas induzidas pela presença do Cr. Exceção se faz para a amostra AlN/Cr-1100 (ausente na figura) que não apresentou borda de absorção do Al. Tal fato devese, possivelmente, à degradação produzida pela elevada temperatura quando da presença do Cr (vide figura 3.8);

- Com o aumento da temperatura de tratamento térmico, as bordas apresentam deslocamento para energias maiores. Tal resultado indica um processo de oxidação;

- Quando submetido a $1100^{\circ} \mathrm{C}$, o material apresenta grande deslocamento da borda de absorção, característica que indica a formação de $\mathrm{Al}_{2} \mathrm{O}_{3}$;

- As amostras submetidas a tratamento térmico de $700^{\circ} \mathrm{C}$ e $900^{\circ} \mathrm{C}$ apresentam pico mais pronunciado em $\approx 1569 \mathrm{eV}$, comportamento semelhante ao apresentado na figura 4.24b. Adicionalmente, o pico em $\approx 1581 \mathrm{eV}$ e os ombros em $\approx 1567 \mathrm{eV}$ 
$\mathrm{e} \approx 1573 \mathrm{eV}$, indicam o processo de cristalização, semelhante ao que ocorre na microlâmpada ML37-AlN (vide figura 4.24c). Comparando com o padrão da figura $4.25 \mathrm{c}$, obtido da referência ${ }^{[15]}$, o material apresenta as características da fase cristalográfica wurtzita, compatível com o resultado obtido anteriormente em estudos realizados pelo GNMD ${ }^{[23]}$.

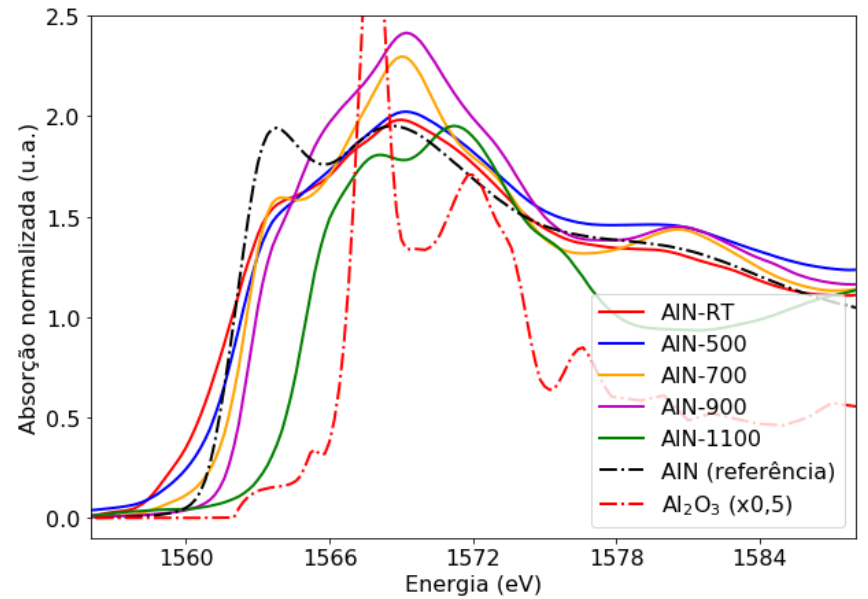

(a)

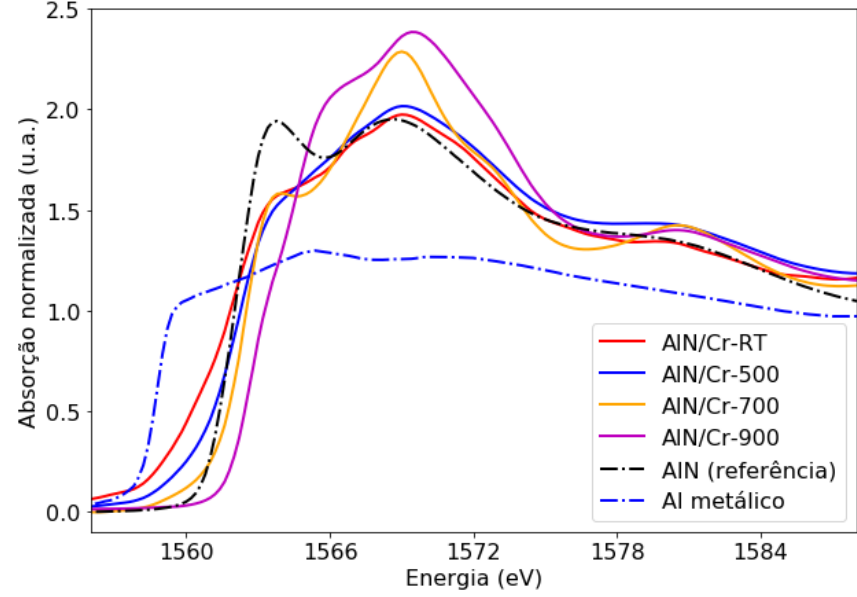

(b)

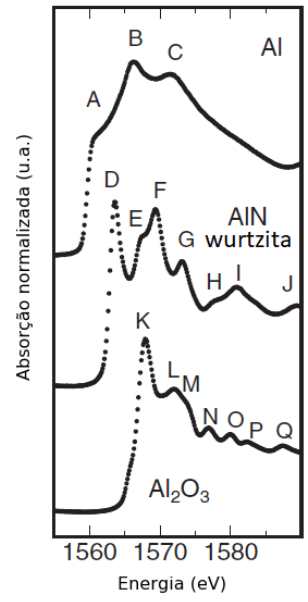

(c)

Figura 4.25: Espectros XANES da borda $\mathrm{K}$ do $\mathrm{Al}$ das amostras de filmes finos adicionais de AlN crescidas (a) sobre Si e (b) sobre Cr. Em (c) espectros experimentais adaptado da padrões da referência ${ }^{[115]}$ 


\subsubsection{Espectroscopia por retroespalhamento de Rutherford - RBS}

Algumas amostras de filmes finos adicionais de AlN foram analisadas também por RBS. Os dados foram coletados com feixe de $\mathrm{He}^{+}$de 2,2 $\mathrm{MeV}$, e com a amostra em duas posições: normal ao feixe e com inclinação de $45^{\circ}\left(\theta_{1}\right)$. Em cada posição, as medidas foram tomadas com o ângulo de espalhamento a $120^{\circ}$ e $170^{\circ}\left(\theta_{2}\right)$, totalizando 4 espectros RBS. Nesse caso, por limitações experimentais, não foram realizadas medidas na ressonância do oxigênio, para quantificar melhor o elemento. A parte superior da figura 4.26 exibe os espectros obtidos para a amostra AlN/Cr-RT. A parte inferior mostra o perfil em profundidade da concentração de N, Al, Si e Cr, resultante da simulação realizado com os softwares SIMNRA ${ }^{[92]}$ e MultiSIMNRA ${ }^{[93]}$. A região colorida corresponde à incerteza atribuída pelo MultiSIMNRA na concentração do elemento correspondente. A tabela 4.5 apresenta os resultados obtidos para as amostras $\mathrm{AlN} / \mathrm{Cr}-$ RT, AlN/Cr-500 e AlN/Cr-700. 

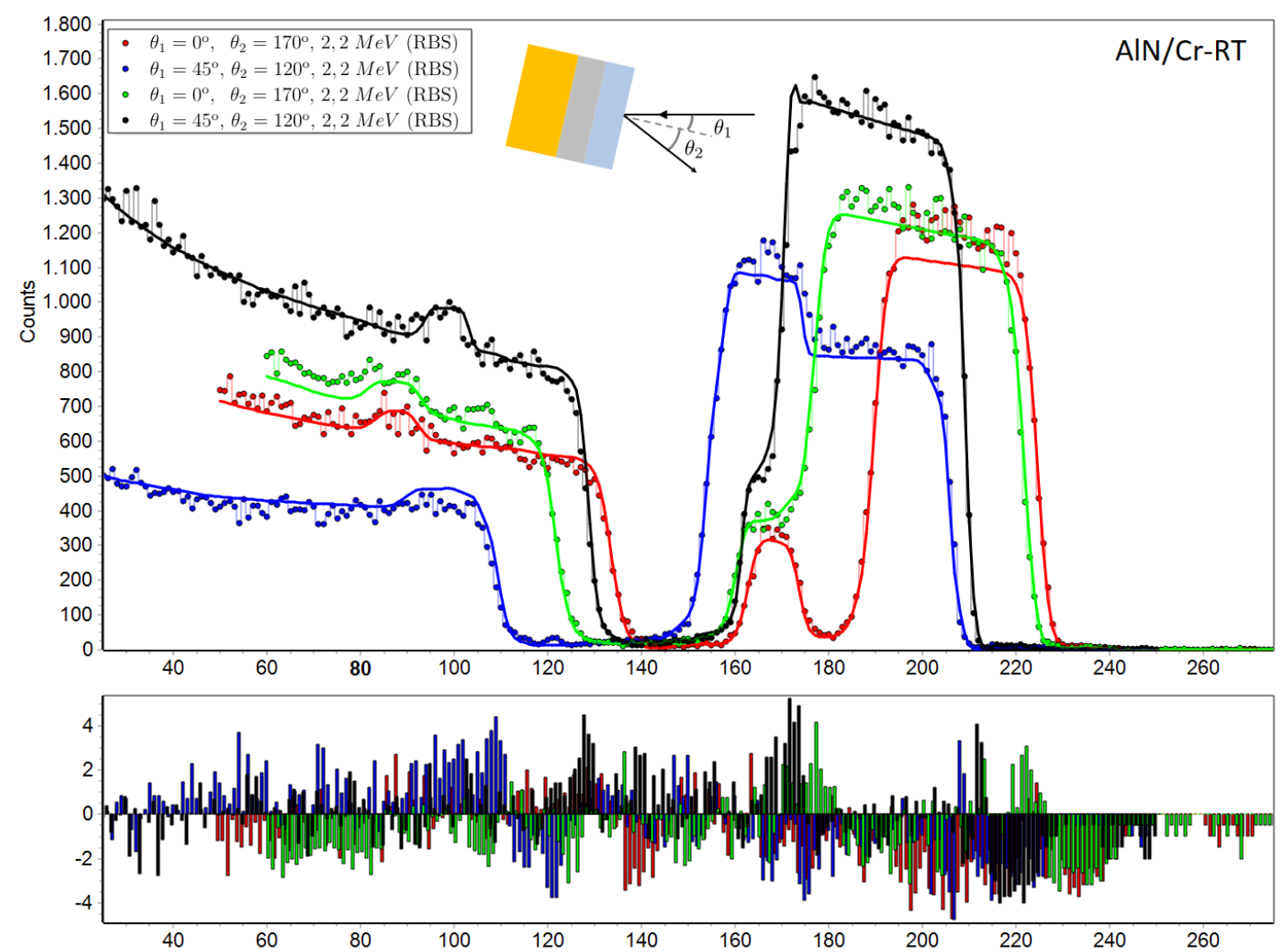

(a)

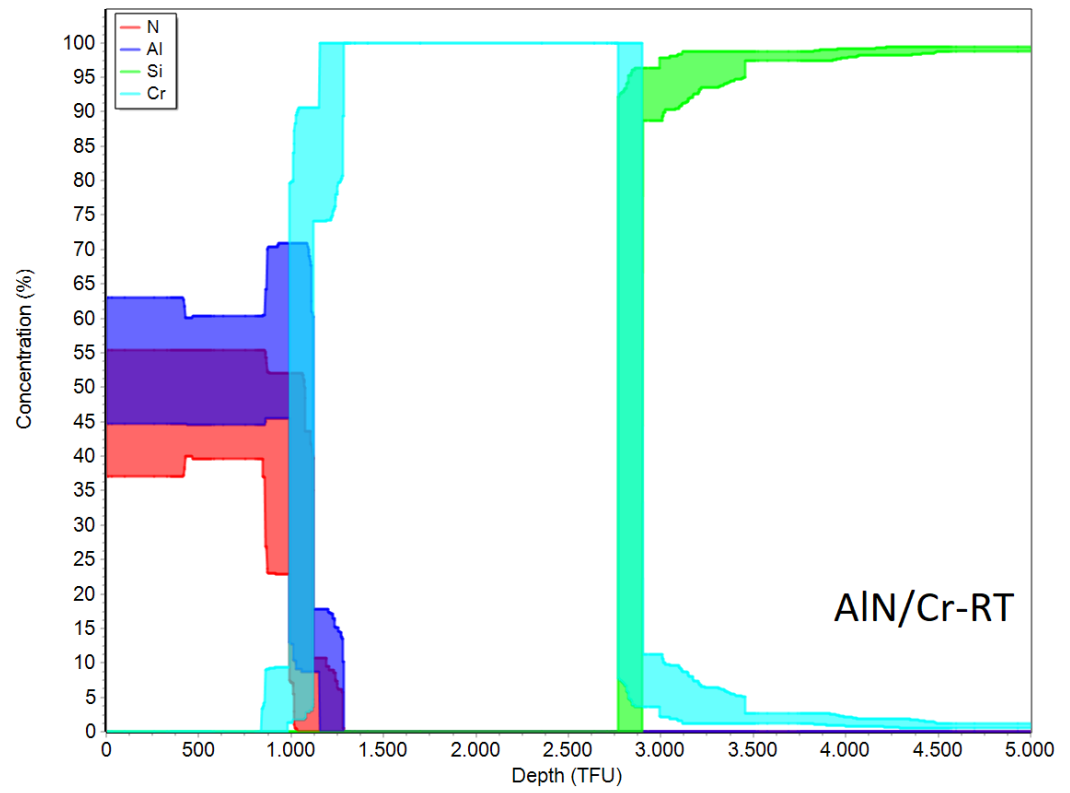

(b)

Figura 4.26: Espectro RBS (acima) e perfil em profundidade (abaixo) da amostra AlN/Cr-RT. O ajuste foi realizado com os softwares SIMNRA ${ }^{[92]}$ e MultiSIMNRA ${ }^{[93]}$. 
Tabela 4.5: Espessura e composição dos filmes finos de algumas amostras de filmes finos adicionais de AlN, obtidas por RBS e GIXRF

Amostra: AlN/Cr-RT

\begin{tabular}{|c|c|c|c|c|c|c|c|c|c|c|c|}
\hline \multicolumn{6}{|c|}{ Resultados do RBS } & \multicolumn{6}{|c|}{ Resultados do ajuste - GIXRF } \\
\hline \multicolumn{2}{|c|}{ Espessura } & \multicolumn{4}{|c|}{ Composição (\%) } & \multicolumn{2}{|c|}{ Espessura } & \multicolumn{4}{|c|}{ Composição (\%) } \\
\hline$\left(\mathrm{TFU}^{*}\right)$ & $\left(\mathrm{nm}^{*}\right)$ & $\mathrm{N}$ & $\mathrm{Al}$ & $\mathrm{Si}$ & $\mathrm{Cr}$ & $\left(\mathrm{TFU}^{*}\right)$ & $\left(\mathrm{nm}^{*}\right)$ & $\mathrm{N}$ & $\mathrm{Al}$ & $\mathrm{Si}$ & $\mathrm{Cr}$ \\
\hline 435,5 & 59,0 & 48,4 & 51,6 & - & - & \multirow{2}{*}{910,6} & \multirow{2}{*}{134} & \multirow{2}{*}{29,5} & \multirow{2}{*}{70,5} & \multirow{2}{*}{-} & \multirow{2}{*}{ - } \\
\hline 424,4 & 58,4 & 45,0 & 55,0 & - & - & & & & & & \\
\hline 152,1 & 18,9 & 27,1 & 63,9 & - & 8,92 & \multirow{2}{*}{100,1} & \multirow{2}{*}{10,7} & \multirow{2}{*}{38,1} & \multirow{2}{*}{45,8} & \multirow{2}{*}{-} & \multirow{2}{*}{16,1} \\
\hline 173,9 & 20,0 & 5,53 & 10,5 & - & 84,0 & & & & & & \\
\hline 1606 & 193 & - & - & - & 100 & 1624 & 195 & - & - & - & 100 \\
\hline 329,3 & 55,6 & - & - & 92,9 & 7,08 & 329,3 & 55,8 & - & - & 93,1 & 6,9 \\
\hline \multicolumn{2}{|c|}{ substrato } & - & - & 100 & - & \multicolumn{2}{|c|}{ substrato } & - & - & 100 & - \\
\hline
\end{tabular}

\begin{tabular}{|c|c|c|c|c|c|}
\hline \multicolumn{6}{|c|}{ Amostra: AlN/Cr-500 } \\
\hline \multicolumn{6}{|c|}{ Resultados do RBS } \\
\hline \multicolumn{2}{|c|}{ Espessura } & \multicolumn{4}{|c|}{ Composição (\%) } \\
\hline$\left(\mathrm{TFU}^{*}\right)$ & $\left(\mathrm{nm}^{*}\right)$ & $\mathrm{N}$ & $\mathrm{Al}$ & $\mathrm{Si}$ & $\mathrm{Cr}$ \\
\hline 926,3 & 126 & 47,8 & 52,2 & - & - \\
\hline 94,2 & 10,8 & 10,8 & 58,5 & - & 30,7 \\
\hline 382,7 & 45,5 & 1,9 & 0,4 & - & 97,7 \\
\hline 1393 & 168 & - & - & - & 100 \\
\hline 1006 & 196 & - & - & 99,0 & 1,0 \\
\hline \multicolumn{2}{|c|}{ substrato } & - & - & 100 & - \\
\hline
\end{tabular}

\begin{tabular}{|c|c|c|c|c|c|}
\hline \multicolumn{6}{|c|}{ Amostra: AlN/Cr-700 } \\
\hline \multicolumn{6}{|c|}{ Resultados do RBS } \\
\hline \multicolumn{2}{|c|}{ Espessura } & \multicolumn{4}{|c|}{ Composição (\%) } \\
\hline$\left(\mathrm{TFU}^{*}\right)$ & $\left(\mathrm{nm}^{*}\right)$ & $\mathrm{N}$ & $\mathrm{Al}$ & $\mathrm{Si}$ & $\mathrm{Cr}$ \\
\hline 966,9 & 131 & 44,5 & 54,9 & - & 0,6 \\
\hline 1718 & 201 & 4,2 & 2,6 & - & 93,2 \\
\hline 231,6 & 41,1 & - & - & 95,3 & 4,7 \\
\hline \multicolumn{2}{|c|}{ substrato } & - & - & 100 & - \\
\hline
\end{tabular}

*Espessura em $\mathrm{nm}$ estimada $\left(\mathrm{TFU}=10^{15}\right.$ átomos $\left./ \mathrm{cm}^{2}\right)$. 


\subsubsection{Fluorescência de raios $\mathrm{X}$ com incidência rasante - GIXRF}

Medidas de GIXRF foram realizadas em algumas amostras de filmes finos adicionais de AlN. O sinal obtido para o $\mathrm{Cr}$ foi bastante satisfatório, o que permitiu realizar uma boa análise. Entretanto, o mesmo não ocorreu para o $\mathrm{Al} \mathrm{e} \mathrm{Si,} \mathrm{pois} \mathrm{as} \mathrm{energias} \mathrm{da} \mathrm{fluorescência}$ desses elementos estavam próximas ao limiar de detecção da instrumentação disponível na linha XRF (LNLS), permitindo apenas uma avaliação qualitativa. Os resultados estão apresentados na figura 4.27 .

De maneira semelhante ao que foi feito para o carbeto de silício, o sinal de fluorescência do Cr obtido por GIXRF foi simulado segundo o procedimento da seção 2.2.3. Para a amostra AlN/Cr-RT, partindo dos dados experimentais provenientes do RBS, foi realizado um ajuste da espessura e composição das camadas, buscando uma melhor convergência com a curva experimental. As linhas contínuas da parte superior da figura 4.27 e a tabela 4.5 apresentam o resultado. Diferentemente do que ocorreu com o carbeto de silício, o sinal de GIXRF do AlN não apresentou oscilações intensas. A ausência dessas assinaturas faz com que o resultado da simulação seja menos conclusivo. No caso da amostra AlN/Cr-900, observa-se um sinal de fluorescência, presente a partir de 0,5 mrad, para todos os elementos. Esse resultado deve-se ao fato da amostra ter perdido a sua planicidade, em decorrência da degradação ocorrida no tratamento térmico (vide figura 3.8). A linha contínua da parte superior da figura 4.27 exibe uma tentativa de simular o resultado experimental. Percebe-se que a falta de planicidade comprometeu a análise quantitativa das medidas dessa amostra.

\subsubsection{Discussão sobre os resultados obtidos com a microlâmpada com} AlN

O nitreto de alumínio (AlN) apresentou boa estabilidade quando a energização não é muito intensa. Entretanto, com o aumento da corrente e do tempo em que é aplicada, um processo de oxidação se inicia, sendo possível observar um ligeiro deslocamento da 


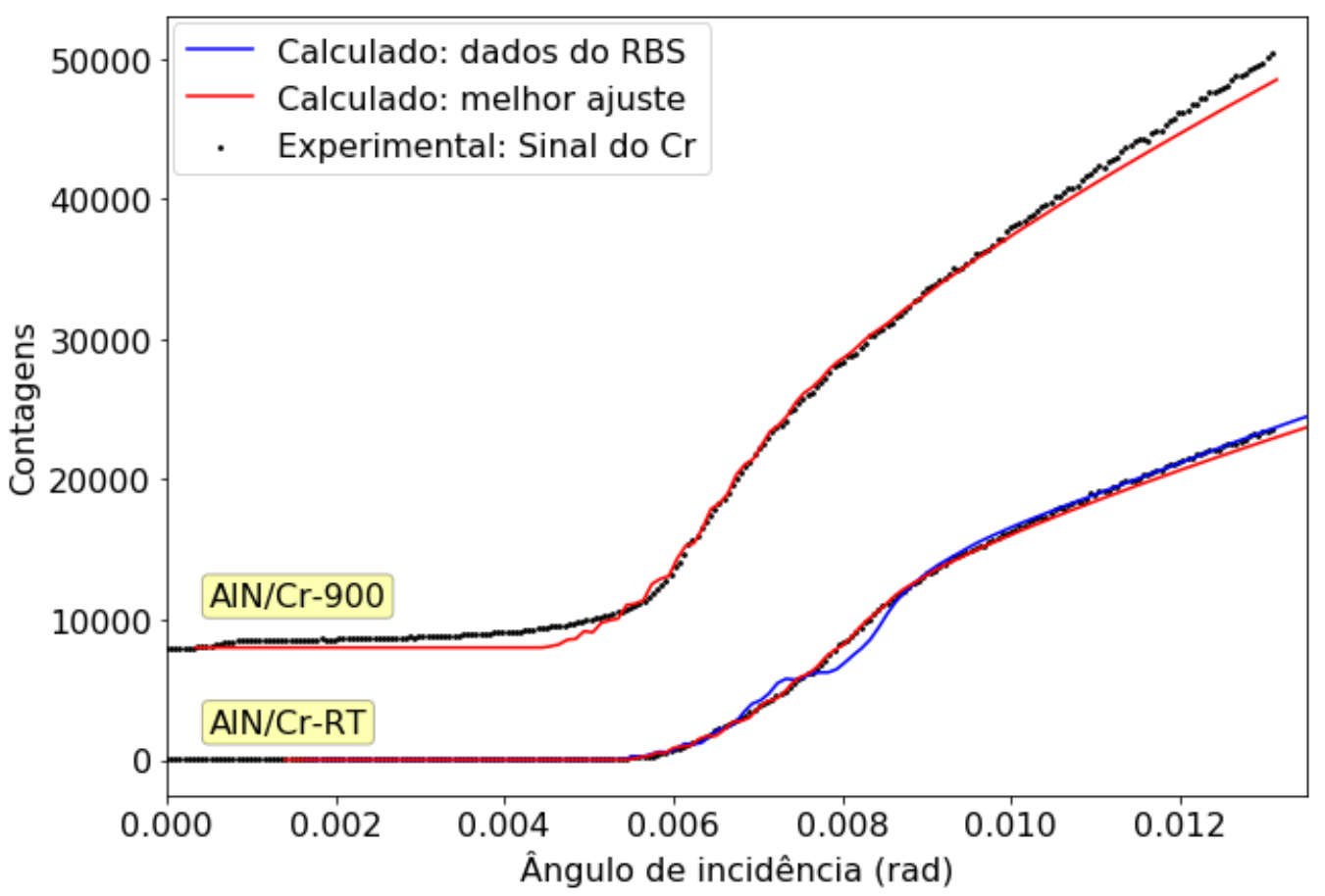

(a)

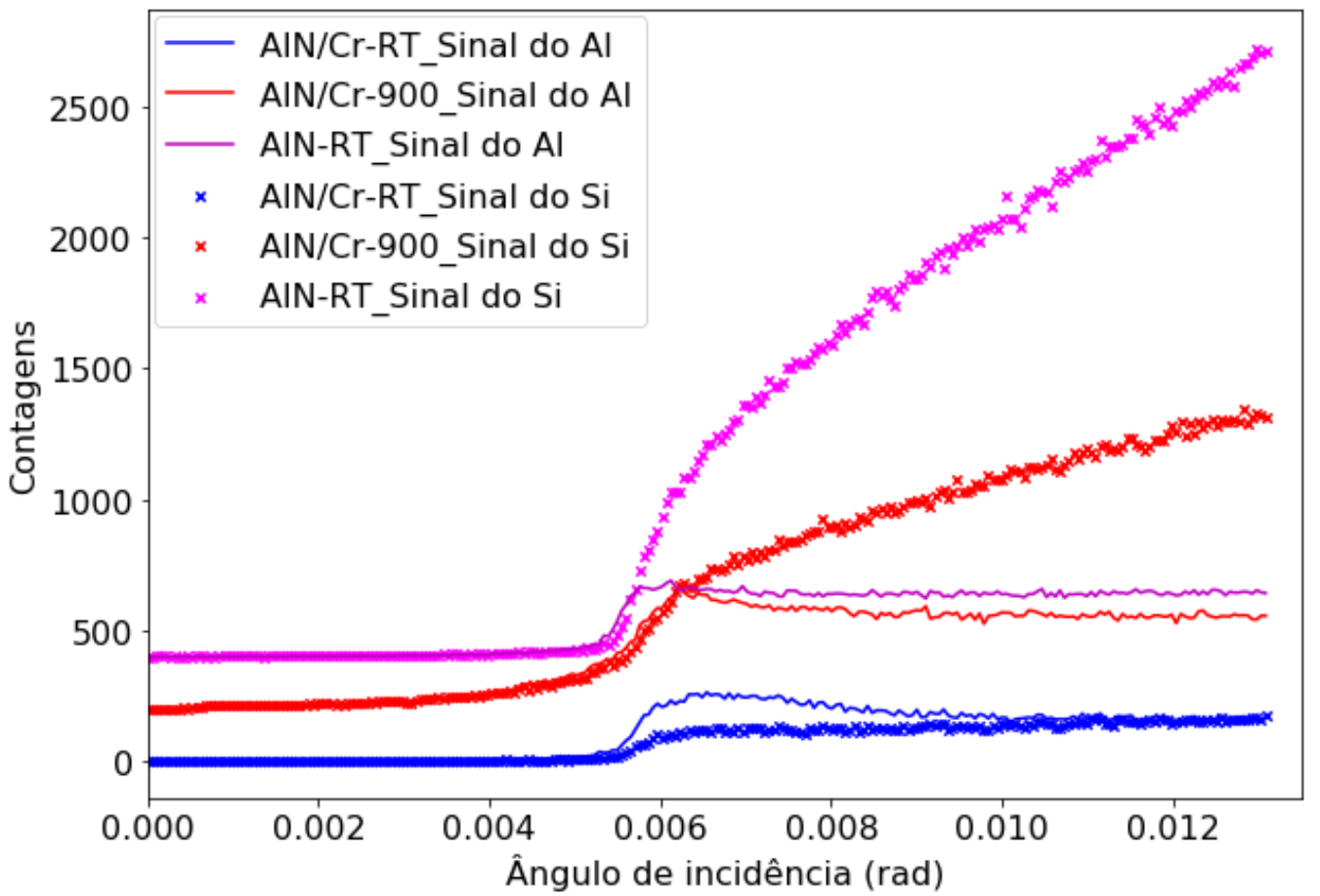

(b)

Figura 4.27: Fluorescência de raios X com incidência rasante das amostras de AlN. Em (a) o sinal do Cr, em (b) os sinais do Si e Al. As linhas contínuas no gráfico superior representam os resultados da simulação. 
borda de absorção. A situação fica mais evidente nas microlâmpadas ML28 e ML31AlN, pois foram energizadas a $40 \mathrm{~mA}$ (ver figuras 4.23 e 4.24 ). Correntes acima desse valor induzem modificação estrutural, mesmo quando o tempo de energização é de alguns segundos, pois há alterações nas intensidades relativas dos picos observadas por XANES, como ocorreu nas microlâmpadas ML70, ML59 e ML62-AlN. A microlâmpada ML37-AN, que queimou quando submetida a uma corrente de $46 \mathrm{~mA}$, apresenta picos adicionais, indicando o início da cristalização do nitreto de alumínio, possivelmente na fase wurtzita. A microlâmpada ML53-AlN (não energizada) não exibe diferenças no espectro XANES em relação ao filme de AlN de referência, depositado sobre $\mathrm{Si}$, juntamente com a camada de proteção da microlâmpada no sputtering, indicando que a cavidade sob o filamento não produziu modificações no material, como o ocorrido no carbeto depositado no PECVD. 


\section{Capítulo 5}

\section{Conclusões}

Quanto ao aspecto tecnológico do dispositivo, verificou-se que o processo empregado foi eficiente na produção de microlâmpadas operacionais, que podem emitir luz visível e que suportam correntes entre 40 e $47 \mathrm{~mA}$, dependendo do material da camada de proteção. Não foi objetivo dessa tese analisar todo o espectro de emissão do dispositivo, tampouco a sua durabilidade. No entanto, foi possível observar que, quando aplicadas correntes menores, podem operar continuamente por, pelo menos, uma hora (vide tabela 3.3).

Dos quatro materiais utilizados como camada de proteção, o oxinitreto de silício $\left(\right.$ a-SiO $\left.\mathrm{S}_{x} \mathrm{~N}_{y}\right)$ e o dióxido de titânio $\left(\mathrm{TiO}_{2}\right)$ se mostraram os mais adequados, pois apresentaram excelente estabilidade estrutural, uma vez que o espectro XANES não revelou alterações significativas em decorrência da operação do dispositivo, o que pode resultar em maior durabilidade da microlâmpada. Por conterem oxigênio na sua composição, não são muito susceptíveis ao processo de oxidação em decorrência do aquecimento do dispositivo o que lhes confere excelente estabilidade química. Nas condições de deposição empregadas, estes são os materiais em que a corrente de energização necessária para a emissão da luz visível, bem como para queimar o filamento, foram as menores, revelando que permitem menor dissipação de calor. Tal condição é vantajosa pois, para uma mesma corrente, a temperatura e a emissão do filamento serão superiores em 
comparação com os demais materiais. A identificação do material mais adequado a ser aplicado como camada de proteção é o principal objetivo da tese. Estudos realizados na microlâmpada com camada de proteção de AlN mostraram que o material apresenta uma pequena oxidação com o aumento da temperatura e, em correntes maiores (acima de $45 \mathrm{~mA}$ ), inicia-se um processo de cristalização. O mesmo foi observado nas amostras de filmes finos adicionais de AlN, depositadas sobre substratos extensos. O espectro XANES, obtido com o a-SiC na região sobre o filamento das microlâmpadas, mostra que o material apresenta modificações estruturais em comparação com o carbeto de silício de referência, crescido com as mesmas condições no PECVD. Análises realizadas com filmes finos adicionais, depositados sobre substratos extensos, e estudos teóricos indicaram que a presença de átomos de $\mathrm{Cr}$ e $\mathrm{O}$, difundidos no material, pode ser responsável pelas alterações no espectro XANES obtido com a microlâmpada. Tal fato é devido à deposição no PECVD fora das condições ideais, provavelmente, em decorrência da cavidade presente sob o filamento da microlâmpada. Sendo um dos objetivos dessa tese, foi então possível compreender as causas das mudanças estruturais decorrentes da energização. Os resultados obtidos com o carbeto de silício apresentados nessa tese demonstram a importância de se estudar os materiais aplicados em MEMS/MOEMS no próprio dispositivo, pois, os detalhes da sua superfície podem induzir modificações em relação aos filmes depositados sobre substratos planos, muitas vezes utilizados como padrão. Isso só pode ser feito com técnicas de detecção localizadas, como a que utiliza raios X com feixe microfoco, disponível em algumas linhas de luz síncrotron, sendo este um dos objetivos deste trabalho.

\subsection{Perspectivas de investigações futuras}

Os resultados dessa tese sugerem a realização de análises complementares. Algumas sugestões de trabalhos futuros são: 
- Avaliar de forma sistemática a durabilidade de microlâmpadas com camadas protetoras de $\mathrm{TiO}_{2}$ e de a- $\mathrm{SiO}_{x} \mathrm{~N}_{y}$ rica em oxigênio.

- Avaliar os melhores dispositivos por técnicas complementares, como as descritas nesta tese, de forma a ter uma caracterização completa dos desempenhos destas microlâmpadas;

- Realizar estas análises nas novas linhas de luz sincrotron Sirius-LNLS, Brasil, que terá feixe microfoco e poderá proporcionar estudos destes dispositivos in operando;

- Analisar o espectro de emissão das microlâmpadas e correlacioná-lo com a camada de proteção aplicada;

- Analisar, para os melhores resultados, os custos de fabricação dessas microlâmpadas e correlacioná-los com os diferentes métodos de preparação, envolvendo sputtering e PECVD.

\subsection{Trabalhos decorrentes dessa tese}

Resultados parciais deste trabalho foram apresentados e publicados no workshop descrito abaixo. O apêndice E traz uma cópia do artigo.

- Apresentação de pôster na $18^{\mathrm{a}}$ conferência Brazilian Workshop on Semiconductor Physics - BWSP18 em 2017.

- Publicação de artigo nos proceedings da $18^{\mathrm{a}}$ conferência Brazilian Workshop on Semiconductor Physics - BWSP18 ${ }^{[116]}$. 


\section{Referências Bibliográficas}

[1] S. D. Senturia, Microsystem Design. Kluwer Academic Publishers, 2002.

[2] N. Maluf, An Introduction to Microelectromechanical Systems Engineering. Artech House, 2000.

[3] S. E. Lyshevski, MEMS and NEMS : systems, devices, and structures. CRC Press, 2002.

[4] J. Liao, C. Chen, C. Yu, and M. Wu, "Mems-based planar incandescent microfilaments with low voltage operation," IEEE Journal of the Electron Devices Society, vol. 8, pp. 640-643, 2020.

[5] J. Tu, D. Howard, S. D. Collins, and R. L. Smith, "Micromachined, silicon filament light source for spectrophotometric microsystems," Appl. Opt., vol. 42, pp. 23882397, May 2003.

[6] Y. Ma, A. M. Robinson, R. P. W. Lawson, and W. Allegretto, "Cmos micromachined low power microlamp vacuum sensor," in 2000 Canadian Conference on Electrical and Computer Engineering. Conference Proceedings. Navigating to a New Era (Cat. No.00TH8492), vol. 2, pp. 971-975 vol.2, May 2000.

[7] F. Hochberg, H. K. Seitz, and A. V. Brown, "A thin-film integrated incandescent display," IEEE Transactions on Electron Devices, vol. 20, pp. 1002-1005, Nov 1973. 
[8] D. O. Carvalho, M. N. P. Carreño, G. P. Rehder, and M. I. Alayo, "Integrated incandescent microlamp coupled to $\mathrm{SiO}_{x} \mathrm{~N}_{y}$ waveguide," Proc. SPIE 7208, MOEMS and Miniaturized Systems VIII, vol. 7208, pp. 72080U1-10, 2009.

[9] P. J. French, "MEMS/MOEMS technology capabilities and trends," in MEMS and MOEMS Technology and Applications (P. Rai-Choudhury, ed.), SPIE Press, 2000.

[10] "Microelectromechanical systems (MEMS) market size \& analysis by application." https://www.grandviewresearch.com/industry-analysis/microeletromechanicalsystems-market, 2015. Acessado em 13/08/2020.

[11] J. Marek, B. Hoefflinger, and U.-M. Gomez, "Mems-micro-electromechanical sensors for the internet of everything," in CHIPS 2020 VOL. 2: New Vistas in Nanoelectronics (B. Höfflinger, ed.), pp. 221-229, Cham: Springer International Publishing, 2016.

[12] D. Tewari and S. Baul, "Microelectromechanical system (MEMS) market by type and application: Global opportunity analysis and industry forecast, 2019-2026." https://www.alliedmarketresearch.com/micro-electromechanicalsystems-MEMS-market, 2019. Acessado em 15/08/2020.

[13] M. A. Mignardi, R. O. Gale, D. J. Dawson, and J. C. Smith, "The digital micromirror device - a micro-optical electromechanical device for display applications," in MEMS and MOEMS Technology and Applications (P. Rai-Choudhury, ed.), SPIE Press, 2000.

[14] C. Gorecki, "Optical waveguides and silicon-based micromachined architectures," in MEMS and MOEMS Technology and Applications (P. Rai-Choudhury, ed.), SPIE Press, 2000. 
[15] "Sandia national laboratories." http://www.sandia.gov/mstc/mems. Acessado em 15/03/2018.

[16] R. Giles, V. Aksyuk, C. Bolle, F. Pardo, and D. J. Bishop, "Silicon micromachines in optical communications networks: tiny machines for large systems," in MEMS and MOEMS Technology and Applications (P. Rai-Choudhury, ed.), SPIE Press, 2000.

[17] M. I. Alayo, G. Rehder, and M. N. P. Carreño, "Mems-based incandescent microlamps for integrated optics applications," Journal of Optics A: Pure and Applied Optics, vol. 10, no. 10, p. 104022, 2008.

[18] G. Rehder, M. I. Alayo, and M. N. P. Carreño, "Incandescent Microlamps based on MEMS and PECVD Materials," AIP Conference Proceedings, vol. 992, no. 1, pp. $743-748,2008$.

[19] R. Prado, M. Fantini, M. Tabacniks, C. V. Cardoso, I. Pereyra, and A. Flank, "Improvements on the local order of amorphous hydrogenated silicon carbide films," Journal of Non-Crystalline Solids, vol. 283, no. 1, pp. 1 - 10, 2001.

[20] R. Prado, T. D'Addio, M. Fantini, I. Pereyra, and A. Flank, "Annealing effects of highly homogeneous a-Si $i_{-x} \mathrm{C}_{x}: \mathrm{H}, "$ Journal of Non-Crystalline Solids, vol. 330, no. 1 , pp. $196-215,2003$.

[21] D. O. Carvalho and M. I. Alayo, "a-SiC:H anti-resonant layer ARROW waveguides," Journal of Optics A: Pure and Applied Optics, vol. 10, p. 104002, aug 2008.

[22] V. Mastelaro, A. M. Flank, M. C. A. Fantini, D. R. S. Bittencourt, M. N. P. Carreño, and I. Pereyra, "On the structural properties of a-Si $i_{1-x} \mathrm{C}_{x}: \mathrm{H}$ thin films," Journal of Applied Physics, vol. 79, no. 3, pp. 1324-1329, 1996. 
[23] M. V. Pelegrini and I. Pereyra, "Characterization of AlN films deposited by r.f. reactive sputtering aiming MEMS applications," physica status solidi $c$, vol. 7, no. 3-4, pp. 840-843, 2010.

[24] D. O. Carvalho, K. F. Albertin, and M. I. Alayo, "Optimized-geometry ARROW waveguides using $\mathrm{TiO}_{2}$ as anti-resonant layer," physica status solidi c, vol. 7, no. 3-4, pp. 716-719, 2010.

[25] K. C. Jorge, M. A. Alvarado, E. G. Melo, M. N. P. C. no, M. I. Alayo, and N. U. Wetter, "Directional random laser source consisting of a hc-arrow reservoir connected to channels for spectroscopic analysis in microfluidic devices," Appl. Opt., vol. 55, pp. 5393-5398, Jul 2016.

[26] K. Albertin and I. Pereyra, "Study of reactive sputtering titanium oxide for metaloxide-semiconductor capacitors," Thin Solid Films, vol. 517, no. 16, pp. $4548-$ 4554, 2009.

[27] W. Scopel, R. Cuzinatto, M. Tabacniks, M. Fantini, M. Alayo, and I. Pereyra, "Chemical and morphological properties of amorphous silicon oxynitride films deposited by plasma enhanced chemical vapor deposition," Journal of Non-Crystalline Solids, vol. 288, no. 1, pp. $88-95,2001$.

[28] D. Criado, M. Alayo, M. Fantini, and I. Pereyra, "Study of the mechanical and structural properties of silicon oxynitride films for optical applications," Journal of Non-Crystalline Solids, vol. 352, no. 23, pp. 2319 - 2323, 2006. Advances in Optical Materials.

[29] M. J. Madou, Fundamentals os Microfabrication and Nanotechnology. CRC Press, 3 ed., 2012.

[30] K. L. Choy, "Vapor processing of nanostructured materials," in Handbook of 
Nanostructured Materials and Nanotechnology (H. S. Nalwa, ed.), Academic Press, 2000.

[31] T.-R. Hsu, MEMS and Microsystems. John Wiley \& Sons, Ltd, 2008.

[32] M. J. Madou, Fundamentals os Microfabrication. CRC Press, 2 ed., 2002.

[33] D. Criado, M. Alayo, I. Pereyra, and M. Fantini, "Structural analysis of silicon oxynitride films deposited by PECVD," Materials Science and Engineering: B, vol. 112, no. 2, pp. 123 - 127, 2004. Current Trends in Nanostructured Materials and Systems.

[34] H. Seidel, L. Csepregi, A. Heuberger, and H. Baumgärtel, "Anisotropic etching of crystalline silicon in alkaline solutions: I . orientation dependence and behavior of passivation layers," Journal of The Electrochemical Society, vol. 137, pp. 36123626, nov 1990.

[35] G. T. A. Kovacs, N. I. Maluf, and K. E. Petersen, "Bulk micromachining of silicon," Proceedings of the IEEE, vol. 86, no. 8, pp. 1536-1551, 1998.

[36] "Harvard MRSEC - Materials Research Science and Engineering Center." http://www.mrsec.harvard.edu/education/ap298r.php. Acessado em 10/04/2018.

[37] T. K. J. A. Cooper, "Introduction," in Fundamentals of Silicon Carbide Technology, ch. 1, pp. 1-10, John Wiley \& Sons, Ltd, 2014.

[38] T. K. J. A. Cooper, "Physical properties of silicon carbide," 2014.

[39] W. Choi, "Chapter 1 - optical, structural, and electrical properties of amorphous silicon carbide films," in Silicon-Based Material and Devices (H. S. Nalwa, ed.), pp. 1 - 71, Burlington: Academic Press, 2001. 
[40] H. Wieder, M. Cardona, and C. R. Guarnieri, "Vibrational spectrum of hydrogenated amorphous Si-C films," physica status solidi (b), vol. 92, no. 1, pp. 99-112, 1979.

[41] E. Pascual, J. Andújar, J. Fernández, and E. Bertran, "Optical and structural characterization of hydrogenated amorphous silicon carbide thin films prepared by r.f. plasma chemical vapour deposition," Diamond and Related Materials, vol. 4, no. 10, pp. $1205-1209,1995$.

[42] S. W. Rynders, A. Scheeline, and P. W. Bohn, "Structure evolution in a-SiC:H films prepared from tetramethylsilane," Journal of Applied Physics, vol. 69, no. 5, pp. 2951-2960, 1991.

[43] T. Jeong, J.-G. Zhu, S. Mao, T. Pan, and Y. J. Tang, "Thermal characterization of $\mathrm{SiC}$ amorphous thin films," International Journal of Thermophysics, vol. 33, p. 1000-1012, 2012.

[44] M. Zhang, J. Yang, C. Si, G. Han, Y. Zhao, and J. Ning, "Research on the piezoelectric properties of AlN thin films for MEMS applications," Micromachines, vol. 6 , no. 9, pp. 1236-1248, 2015.

[45] A. Siegel, K. Parlinski, and U. D. Wdowik, "Ab initio calculation of structural phase transitions in aln crystal," Phys. Rev. B, vol. 74, p. 104116, Sep 2006.

[46] A. A. Elagin, A. R. Beketov, M. V. Baranov, and R. A. Shishkin, "Aluminum nitride. Preparation methods (Review)," Refractories and Industrial Ceramics, vol. 53, no. 6, pp. 395-403, 2013.

[47] L. Hultman, "Thermal stability of nitride thin films," Vacuum, vol. 57, no. 1, pp. 1 $-30,2000$. 
[48] F. Chen, X. Ji, and S. P. Lau, "Recent progress in group III-nitride nanostructures: From materials to applications," Materials Science and Engineering: R: Reports, vol. 142, p. 100578, 2020.

[49] T. Mizoguchi, I. Tanaka, M. Kunisu, M. Yoshiya, H. Adachi, and W. Ching, "Theoretical prediction of ELNES/XANES and chemical bondings of AlN polytypes," Micron, vol. 34, no. 3, pp. 249 - 254, 2003. Zeitler Festschrift.

[50] I. Gorczyca, N. Christensen, P. Perlin, I. Grzegory, J. Jun, and M. Bockowski, "High pressure phase transition in aluminium nitride," Solid State Communications, vol. 79, no. 12, pp. 1033 - 1034, 1991.

[51] A. Soldatov, G. Yalovega, G. Smolentsev, A. Kravtsova, D. Lamoen, C. Balasubramanian, A. Marcelli, G. Cinque, and S. Bellucci, "ALN nanoparticles XANES analysis: Local atomic and electronic structure," Nuclear Instruments and Methods in Physics Research Section A: Accelerators, Spectrometers, Detectors and Associated Equipment, vol. 575, no. 1, pp. 85 - 87, 2007. Proceedings of the XVI International Synchrotron Radiation Conference.

[52] C. Balasubramanian, S. Bellucci, G. Cinque, A. Marcelli, M. C. Guidi, M. Piccinini, A. Popov, A. Soldatov, and P. Onorato, "Characterization of aluminium nitride nanostructures by XANES and FTIR spectroscopies with synchrotron radiation," Journal of Physics: Condensed Matter, vol. 18, pp. S2095-S2104, aug 2006.

[53] X.-H. Xu, H.-S. Wu, C.-J. Zhang, and Z.-H. Jin, "Morphological properties of aln piezoelectric thin films deposited by dc reactive magnetron sputtering," Thin Solid Films, vol. 388, no. 1, pp. 62 - 67, 2001.

[54] A. Madan, I. W. Kim, S. C. Cheng, P. Yashar, V. P. Dravid, and S. A. Barnett, "Stabilization of cubic AlN in epitaxial AlN/TiN superlattices," Phys. Rev. Lett., vol. 78, pp. 1743-1746, Mar 1997. 
[55] F. R. Charvat and W. D. Kingery, "Thermal conductivity: XIII, effect of microstructure on conductivity of single-phase ceramics," Journal of the American Ceramic Society, vol. 40, no. 9, pp. 306-315, 1957.

[56] L. Momenzadeh, B. Moghtaderi, I. V. Belova, and G. E. Murch, "Determination of the lattice thermal conductivity of the $\mathrm{TiO}_{2}$ polymorphs rutile and anatase by molecular dynamics simulation," Computational Condensed Matter, vol. 17, p. e00342, 2018.

[57] Y. Bai, I. Mora-Seró, F. De Angelis, J. Bisquert, and P. Wang, "Titanium dioxide nanomaterials for photovoltaic applications," Chemical Reviews, vol. 114, no. 19, pp. 10095-10130, 2014. PMID: 24661129.

[58] C. Guillén and J. Herrero, " $\mathrm{TiO}_{2}$ coatings obtained by reactive sputtering at room temperature: Physical properties as a function of the sputtering pressure and film thickness," Thin Solid Films, vol. 636, pp. 193 - 199, 2017.

[59] S.-D. Mo and W. Y. Ching, "Electronic and optical properties of three phases of titanium dioxide: Rutile, anatase, and brookite," Phys. Rev. B, vol. 51, pp. 1302313032, May 1995.

[60] D. Dambournet, I. Belharouak, and K. Amine, "Tailored preparation methods of $\mathrm{TiO}_{2}$ anatase, rutile, brookite: Mechanism of formation and electrochemical properties," Chemistry of Materials, vol. 22, no. 3, pp. 1173-1179, 2010.

[61] C. Guillén, J. Montero, and J. Herrero, "Anatase and rutile $\mathrm{TiO}_{2}$ thin films prepared by reactive DC sputtering at high deposition rates on glass and flexible polyimide substrates," Journal of Materials Science, vol. 49, pp. 5035-5042, 2014.

[62] C. Zhang, W. Ding, H. Wang, W. Chai, and D. Ju, "Influences of working pressure on properties for $\mathrm{TiO}_{2}$ films deposited by DC pulse magnetron sputtering," Journal of Environmental Sciences, vol. 21, no. 6, pp. 741 - 744, 2009. 
[63] S. Nezar, N. Saoula, S. Sali, M. Faiz, M. Mekki, N. A. Laoufi, and N. Tabet, "Properties of $\mathrm{TiO}_{2}$ thin films deposited by rf reactive magnetron sputtering on biased substrates," Applied Surface Science, vol. 395, pp. 172 - 179, 2017. Progress in Applied Surface, Interface and Thin Film Science and Solar Renewable Energy News IV.

[64] Y. Shi, L. He, F. Guang, L. Li, Z. Xin, and R. Liu, "A review: Preparation, performance, and applications of silicon oxynitride," Micromachines, vol. 10, p. 552, 2019.

[65] M. G. Burzo, P. L. Komarov, and P. E. Raad, "Thermal transport properties of gold-covered thin-film silicon dioxide," IEEE Transactions on Components and Packaging Technologies, vol. 26, no. 1, pp. 80-88, 2003.

[66] H. O. Pierson, Handbook of Chemical Vapor Deposition. William Andrew, 2 ed., 1999.

[67] F. Habraken and A. Kuiper, "Silicon nitride and oxynitride films," Materials Science and Engineering: R: Reports, vol. 12, no. 3, pp. 123 - 175, 1994.

[68] J. J. Rehr and R. C. Albers, "Theoretical approaches to x-ray absorption fine structure," Rev. Mod. Phys., vol. 72, pp. 621-654, Jul 2000.

[69] G. Bunker, Introduction to XAFS. Cambridge University Press, 2010.

[70] C. S. Schnohr and M. C. Ridgway, "Introduction to x-ray absorption spectroscopy," in X-Ray Absorption Spectroscopy of Semiconductors (C. S. Schnohr and M. C. Ridgway, eds.), Springer, 2015.

[71] S. L. Schroeder, "Towards a 'universal curve' for total electron-yield XAS," Solid State Communications, vol. 98, no. 5, pp. 405-409, 1996. 
[72] M. Kasrai, W. Lennard, R. Brunner, G. Bancroft, J. Bardwell, and K. Tan, "Sampling depth of total electron and fluorescence measurements in Si L- and K-edge absorption spectroscopy," Applied Surface Science, vol. 99, no. 4, pp. 303 - 312, 1996.

[73] S. Calvin, XAFS for Everyone. CRC Press, 2013.

[74] B. Ravel and M. Newville, "ATHENA, ARTEMIS, HEPHAESTUS: data analysis for X-ray absorption spectroscopy using IFEFFIT," Journal of Synchrotron Radiation, vol. 12, no. 4, pp. 537-541, 2005.

[75] T. Ressler, "WinXAS: a Program for X-ray Absorption Spectroscopy Data Analysis under MS-Windows," Journal of Synchrotron Radiation, vol. 5, no. 2, pp. 118$122,1998$.

[76] IUCr, "IUCr Dictionary entries." https://www.iucr.org/IUCr-Dictionary-CXAFSContribution.pdf. Acessado em 08/02/2020.

[77] F. F. Muñoz, L. M. Acuña, C. A. Albornoz, A. G. Leyva, R. T. Baker, and R. O. Fuentes, "Redox properties of nanostructured lanthanide-doped ceria spheres prepared by microwave assisted hydrothermal homogeneous co-precipitation," Nanoscale, vol. 7, pp. 271-281, 2015.

[78] "Software Resources for XAFS." https://xafs.org/Software. Acessado em $15 / 02 / 2020$.

[79] J. J. Rehr, J. J. Kas, M. P. Prange, A. P. Sorini, Y. Takimoto, and F. Vila, "Ab initio theory and calculations of x-ray spectra," Comptes Rendus Physique, vol. 10, no. 6 , pp. $548-559,2009$. Theoretical spectroscopy.

[80] Y. Joly, "X-ray absorption near-edge structure calculations beyond the muffin-tin approximation," Phys. Rev. B, vol. 63, p. 125120, Mar 2001. 
[81] C. Grossmann, H. G. Roos, and M. Stynes, Numerical Treatment of Partial Differential Equations. Springer, 2007.

[82] S. A. Guda, A. A. Guda, M. A. Soldatov, K. A. Lomachenko, A. L. Bugaev, C. Lamberti, W. Gawelda, C. Bressler, G. Smolentsev, A. V. Soldatov, and Y. Joly, "Optimized finite difference method for the full-potential xanes simulations: Application to molecular adsorption geometries in mofs and metal-ligand intersystem crossing transients," Journal of Chemical Theory and Computation, vol. 11, no. 9, pp. 4512-4521, 2015. PMID: 26575941.

[83] O. Bunău and Y. Joly, "Self-consistent aspects of x-ray absorption calculations," Journal of Physics: Condensed Matter, vol. 21, p. 345501, aug 2009.

[84] R. Klockenkämper and A. von Bohlen, "Fundamentals of x-ray fluorescence," in Total-Reflection X-Ray Fluorescence Analysis and Related Methods, ch. 1, pp. 1-78, John Wiley \& Sons, Ltd, 2014.

[85] C. T. Chantler, "Atomic form factors and photoelectric absorption cross-sections near absorption edges in the soft x-ray region," AIP Conference Proceedings, vol. 652 , no. 1 , pp. 370-377, 2003.

[86] J. G. Brown, "Refraction and reflection of x-rays," in X-Rays and Their Applications, pp. 147-156, Boston, MA: Springer US, 1966.

[87] H. J. Sanchez, C. A. Perez, R. D. Perez, and M. Rubio, "Surface analysis by totalreflection x-ray fluorescence," Radiation Physics and Chemistry, vol. 48, no. 3, pp. $325-331,1996$.

[88] E. X. Miqueles, C. A. Pérez, V. I. Suárez, and R. F. Vescovi, "Grazing-incidence XRF analysis of layered samples: Detailed study of amplitude calculation," Computer Physics Communications, vol. 194, pp. 33 - 42, 2015. 
[89] J. A. Leavitt, J. L. C. McIntyre, and M. R. Weller, "Backscattering spectrometry," in Handbook of Moderns Ion Beam Materials Analysis (Y. Wang and M. Nastasi, eds.), ch. 4, MRS, 2 ed., 2009.

[90] M. Nastasi, J. Mayer, and Y. Wang, Ion Beam Analysis. CCR Press, 2014.

[91] L. Palmetshofer, "Rutherford Back-Scattering Spectroscopy (RBS)," in Surface and Thin Film Analysis (H. Bubert and H. Jenett, eds.), Wiley-VCH, 2002.

[92] M. Mayer, "SIMNRA User's Guide, Report IPP 9/113." Max-Planck-Institut für Plasmaphysik, Garching, Germany, 1997.

[93] T. Silva, C. Rodrigues, M. Mayer, M. Moro, G. Trindade, F. Aguirre, N. Added, M. Rizzutto, and M. Tabacniks, "MultiSIMNRA: A computational tool for selfconsistent ion beam analysis using SIMNRA," Nuclear Instruments and Methods in Physics Research Section B: Beam Interactions with Materials and Atoms, vol. 371, pp. 86 - 89, 2016. The 22nd International Conference on Ion Beam Analysis (IBA 2015).

[94] "Ion Beam Analysis Nuclear Data Library (IBANDL), IAEA." http://wwwnds.iaea.org/ibandl/, 2019. Acessado em 18/07/2020.

[95] C. Jeynes and J. L. Colaux, "Thin film depth profiling by ion beam analysis," Analyst, vol. 141, pp. 5944-5985, 2016.

[96] G. P. Rehder, Propriedade termo-mecânicas de filmes finos de a-SiC:H e $\mathrm{SiO}_{x} \mathrm{~N}_{y}$ e desenvolvimento de MEMS. Tese de doutorado, Escola Politécnica da Universidade de São Paulo, 2008.

[97] "Lucia beamline." https://www.synchrotron-soleil.fr/en/beamlines/lucia. Acessado em 10/03/2018. 
[98] M. Abbate, F. C. Vicentin, V. Compagnon-Cailhol, M. C. Rocha, and H. Tolentino, "The soft X-ray spectroscopy beamline at the LNLS: technical description and commissioning results," Journal of Synchrotron Radiation, vol. 6, pp. 964-972, Sep 1999.

[99] C. A. Pérez, M. Radtke, H. J. Sánchez, H. Tolentino, R. T. Neuenshwander, W. Barg, M. Rubio, M. I. S. Bueno, I. M. Raimundo, and J. J. R. Rohwedder, "Synchrotron radiation x-ray fluorescence at the lnls: beamline instrumentation and experiments," X-Ray Spectrometry, vol. 28, no. 5, pp. 320-326, 1999.

[100] "Laboratório nacional de luz síncrotron." http://www.lnls.cnpem.br. Acessado em 10/05/2018.

[101] D. E. Cox, "The Rietveld method. (IUCr Monograph on Crystallography, No. 5) edited by R. A. Young," Journal of Applied Crystallography, vol. 27, pp. $440-$ 441, Jun 1994.

[102] D. Zagorac, H. Müller, S. Ruehl, J. Zagorac, and S. Rehme, "Recent developments in the Inorganic Crystal Structure Database: theoretical crystal structure data and related features," Journal of Applied Crystallography, vol. 52, pp. 918-925, Oct 2019 .

[103] J. Rodríguez-Carvajal, "Recent advances in magnetic structure determination by neutron powder diffraction," Physica B: Condensed Matter, vol. 192, no. 1-2, pp. $55-69,1993$.

[104] "Página da linha de luz síncrotron SXS do LNLS." https://www.lnls.cnpem.br/facilities/sxs/. Acessado em 19/12/2020.

[105] "Laboratório de análise de materiais por feixes iônicos - LAMFI." http://portal.if.usp.br/lamfi/. Acessado em 18/12/2020. 
[106] "Página da linha de luz síncrotron XRF do LNLS." https://www.lnls.cnpem.br/facilities/xrf/. Acessado em 19/12/2020.

[107] S. Gražulis, D. Chateigner, R. T. Downs, A. F. T. Yokochi, M. Quirós, L. Lutterotti, E. Manakova, J. Butkus, P. Moeck, and A. Le Bail, "Crystallography Open Database - an open-access collection of crystal structures," Journal of Applied Crystallography, vol. 42, pp. 726-729, Aug 2009.

[108] G. Kresse and J. Furthmüller, "Efficient iterative schemes for ab initio total-energy calculations using a plane-wave basis set," Phys. Rev. B, vol. 54, pp. 11169-11186, Oct 1996.

[109] G. C. Capitani, S. Di Pierro, and G. Tempesta, "The 6H-SiC structure model: Further refinement from SCXRD data from a terrestrial moissanite," American Mineralogist, vol. 92, pp. 403-407, 022007.

[110] W. a. L. Scopel, A. J. R. da Silva, and A. Fazzio, "Amorphous $\mathrm{HfO}_{2}$ and $\mathrm{Hf}_{1-x} \mathrm{Si}_{x} \mathrm{O}$ via a melt-and-quench scheme using ab initio molecular dynamics," Phys. Rev. $B$, vol. 77, p. 172101, May 2008.

[111] K. Takano, H. Nitta, H. Seto, C. Lee, K. Yamada, Y. Yamazaki, H. Sato, S. Takeda, E. Toya, and E. Iijima, "Volume and dislocation diffusion of iron, chromium and cobalt in CVD B-SiC," Science and Technology of Advanced Materials, vol. 2, no. 2, pp. 381-388, 2001.

[112] K. Danno, M. Saito, A. Seki, K. Sato, T. Bessho, and T. Kimoto, "Solubility and diffusion of chromium in 4h-SiC," Applied Physics Express, vol. 9, p. 061301, may 2016.

[113] K. Danno, H. Saitoh, A. Seki, T. Shirai, H. Suzuki, T. Bessho, Y. Kawai, and T. Kimoto, "Diffusion of transition metals in $4 \mathrm{H}-\mathrm{SiC}$ and trials of impurity gettering," Applied Physics Express, vol. 5, p. 031301, mar 2012. 
[114] P. Wetzel, C. Pirri, J. C. Peruchetti, D. Bolmont, and G. Gewinner, "Formation of $\mathrm{CrSi}$ and $\mathrm{CrSi}_{2}$ upon annealing of $\mathrm{Cr}$ overlayers on $\mathrm{Si}(111), "$ Phys. Rev. B, vol. 35, pp. 5880-5883, Apr 1987.

[115] M. Mogi, T. Yamamoto, T. Mizoguchi, K. Tatsumi, S. Yoshioka, S. Kameyama, I. Tanaka, and H. Adachi, "Theoretical investigation of al k-edge x-ray absorption spectra of $\mathrm{Al}, \mathrm{AlN}$ and $\mathrm{Al}_{2} \mathrm{O}_{3}$," Materials Transactions, vol. 45, pp. 2031-2034, July 2004 .

[116] V. R. S. Cassimiro, R. M. C. Júnior, G. P. Rehder, I. Pereyra, M. N. P. C. no, M. I. Alayo, M. C. A. Fantini, and N. Trcera, "The structural properties of the protective layer of microlamps under polarization," Proceedings of the 18th Brazilian Workshop on Semiconductor Physics, 2017.

[117] J. A. Seibert and J. M. Boone, "X-ray imaging physics for nuclear medicine technologists. part 2: X-ray interactions and image formation," Journal of Nuclear Medicine Technology, vol. 33, no. 1, pp. 3 -18, 2005.

[118] B. Ravel, "A practical introduction to multiple scattering theory," Journal of Alloys and Compounds, vol. 401, no. 1, pp. 118 - 126, 2005. 7th International School and Symposium on Synchrotron Radiation in Natural Science and Proceedings of the International Conference on Experimental and Computing Methods in High Resolution Diffraction Applied for Structure Characterization of Modern Materials HREDAMM.

[119] F. de Groot and A. Kotani, Core level spectroscopy of solids. CRC Press, 2008.

[120] P. A. Lee and J. B. Pendry, "Theory of the extended x-ray absorption fine structure," Phys. Rev. B, vol. 11, pp. 2795-2811, Apr 1975.

[121] J. J. Rehr and R. C. Albers, "Scattering-matrix formulation of curved-wave 
multiple-scattering theory: Application to x-ray-absorption fine structure," Phys. Rev. B, vol. 41, pp. 8139-8149, Apr 1990.

[122] S. I. Zabinsky, J. J. Rehr, A. Ankudinov, R. C. Albers, and M. J. Eller, "Multiplescattering calculations of x-ray-absorption spectra," Phys. Rev. B, vol. 52, pp. 2995-3009, Jul 1995.

[123] A. L. Ankudinov, B. Ravel, J. J. Rehr, and S. D. Conradson, "Real-space multiplescattering calculation and interpretation of x-ray-absorption near-edge structure," Phys. Rev. B, vol. 58, pp. 7565-7576, Sep 1998.

[124] L. G. Parratt, "Surface studies of solids by total reflection of x-rays," Phys. Rev., vol. 95, pp. 359-369, Jul 1954.

[125] R. Klockenkämper and A. von Bohlen, "Principles of total reflection xrf," in TotalReflection X-Ray Fluorescence Analysis and Related Methods, ch. 2, pp. 79-125, John Wiley \& Sons, Ltd, 2014. 


\section{Apêndice A}

\section{A física da estrutura fina de absorção de raios $\mathrm{X}$}

Neste apêndice, algumas considerações sobre os fenômenos físicos envolvendo a estrutura fina de absorção de raios X são apresentadas, assim como uma breve introdução sobre aspectos teóricos considerados quando são feitas as simulações de XAS. Maiores detalhes podem ser obtidos nas referências indicadas ao longo da seção.

\section{A.1 Interação dos raios $\mathrm{X}$ com a matéria}

Quando um fóton penetra na região ocupada por um átomo, além da possibilidade de passar sem interagir, diversos processos podem ocorrer, conforme representado na figura A.1. Os principais processos são:

- Espalhamento coerente. É o processo no qual o fóton, ao interagir com os elétrons do material, faz com que eles vibrem na mesma frequência, irradiando em todas as direções (ondas esféricas) raios X de mesmo comprimento de onda do feixe incidente. O processo também é chamado de espalhamento Rayleigh.

- Espalhamento incoerente. Ocorre quando o fóton colide com os elétrons do 
material, transferindo momento e desviando a sua trajetória. O feixe espalhado tem comprimento de onda maior do que o incidente. Tal processo também é chamado de espalhamento Compton.

- Absorção. Se a energia do fóton é próxima da energia de ligação dos elétrons dos átomos do material, ele pode ser absorvido pelo átomo e um elétron é ejetado (chamado então de fotoelétron). A vacância deixada pelo fotoelétron é posteriormente preenchida quando ocorre a transição de um elétron proveniente de um estado de maior energia. Um fóton com energia correspondente à diferença entre os estados é emitido (fluorescência).

Quando ocorre o processo de absorção, o elétron ejetado (efeito fotoelétrico) pode ser interpretado como uma onda esférica de número de onda $k$ dado pela eq. 2.4. O fotoelétron pode ser espalhado por átomos vizinhos de forma que parte da onda retorna ao átomo absorvedor, ainda em seu estado excitado, como mostra a figura A.2. O

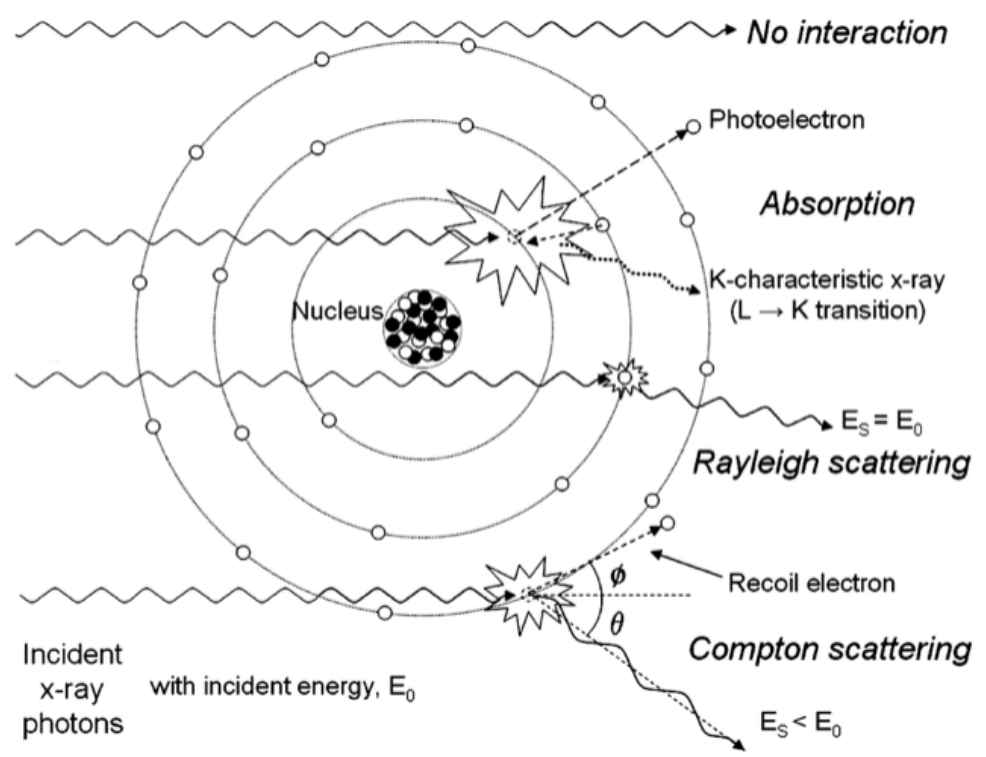

Figura A.1: Interação dos raios X com a matéria ${ }^{[117]}$. 
fenômeno de interferência entre as ondas espalhadas produz variações na densidade eletrônica e afeta a probabilidade da criação do fotoelétron e da própria absorção do raio $\mathrm{X}^{[73,76]}$, o que dá origem às oscilações da estrutura fina de absorção (figura 2.3).

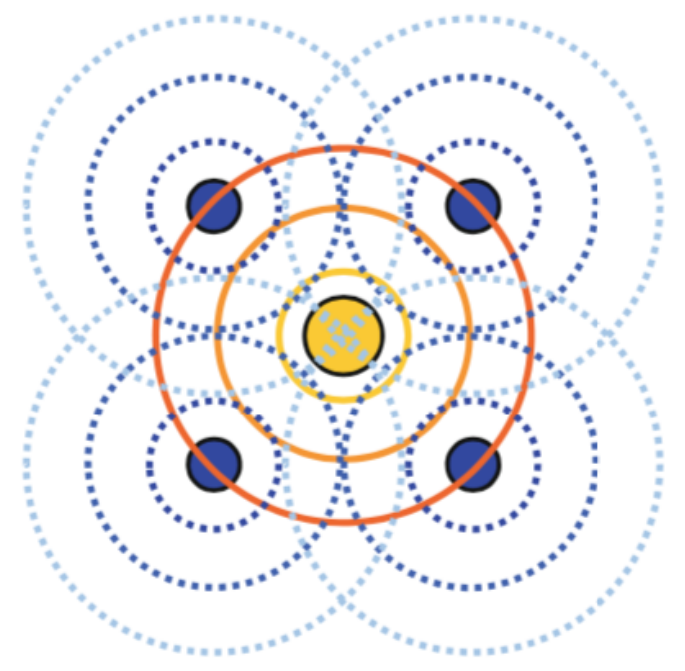

Figura A.2: Representação da interferência das ondas espalhadas do fotoelétron ejetado pelo átomo absorvedor. Alterações da densidade eletrônica dão origem à estrutura fina de absorção ${ }^{[70]}$.

\section{A.2 Introdução à equação EXAFS}

A equação utilizada para modelar as oscilações observadas na região de EXAFS é conhecida como equação de EXAFS ${ }^{[73,76]}$ :

$$
\chi(k)=S_{0}^{2} \sum_{i} N_{i} \frac{f_{i}(k)}{k D_{i}^{2}} e^{-\frac{2 D_{i}}{\lambda(k)}} e^{-2 k^{2} \sigma_{i}^{2}} \operatorname{sen}\left[2 k D_{i}+\delta_{i}(k)\right]
$$

Para deduzir a expressão acima, considera-se a situação simplificada em que há apenas um átomo vizinho ao absorvedor, situado a uma distância $D$ (fig. A.3a). Uma interferência construtiva ocorrerá quando $2 D$ for um número inteiro do comprimento 
de onda $\frac{2 \pi}{k}$, de forma que o sinal XAFS, $\chi(k)$, é modulado por um termo $\operatorname{sen}(2 k D)$, ficando:

$$
\chi(k)=\frac{f(k)}{D^{2}} \operatorname{sen}(2 k D+\delta(k))
$$

O termo $\delta(k)$ corresponde às mudanças de fase na onda quando espalhada, o termo $D^{2}$ é devido ao fato da onda espalhada ser esférica, e $f(k)$ é uma constante de proporcionalidade relacionada à amplitude de espalhamento (fator de forma).

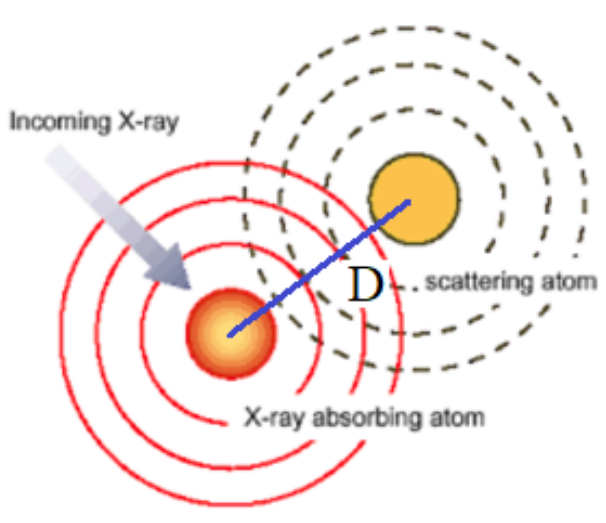

(a)

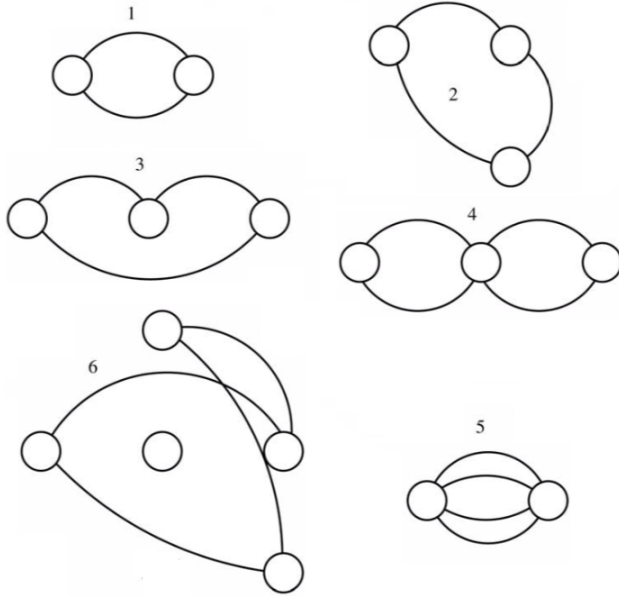

(b)

Figura A.3: (a) Espalhamento por um único átomo. (b) Representação do espalhamento simples em 1, e espalhamento múltiplo nos demais casos (adaptado de ${ }^{[118]}$ ).

Como há múltiplos vizinhos ao átomo absorvedor, diversos átomos participam do espalhamento e contribuem com o processo de absorção. Quando a onda espalhada retorna diretamente para o átomo absorvedor, o evento é chamado de espalhamento simples. Espalhamento múltiplo é a denominação se a onda se espalha em dois ou mais átomos antes de retornar ${ }^{[68,118]}$, como mostra a figura A.3b. O resultado no sinal de 
$\chi(k)$ será a somatória da contribuição de cada diferente caminho $i$, ficando:

$$
\chi(k)=\sum_{i} N_{i} \frac{f(k)_{i}}{D_{i}^{2}} \operatorname{sen}\left(2 k D_{i}+\delta_{i}(k)\right)
$$

Nessa expressão, $D_{i}$ representa a metade da distância total média do caminho $i$, e $N_{i}$ é a degenerescência, ou seja, o número de distintas maneiras que o espalhamento pelo caminho $i$ pode ocorrer, produzindo efeitos idênticos. Para espalhamento simples, $D_{i}$ pode significar o tamanho da ligação química entre os átomos, quando for esse o caso, e $N_{i}$ o número de coordenação.

Os demais elementos da equação de EXAFS (eq. A.1) são:

- fator de redução de amplitude $S_{0}^{2}$. O fator $S_{0}^{2}$ está relacionado com perdas intrínsecas no sinal EXAFS, ou seja, aquelas relacionadas com a formação da vacância e que não dependem significativamente do caminho. Quando o fotoelétron é ejetado, o átomo absorvedor não está mais no estado inicial. A vacância deixada pelo fotoelétron acarreta alterações nos níveis de energia do átomo. Esse efeito leva a uma sobreposição (overlap) imperfeita entre os estados quânticos inicial e final, fato que reduz o sinal de absorção e é modelado, na equação de EXAFS, pelo fator $S_{0}^{2}$. Seu valor é tipicamente de 0,7 a $1,0^{[73,76]}$;

- fator $e^{-\frac{2 D_{i}}{\lambda(k)}}$. O fotoelétron pode interagir com a vizinhança de outras formas, além do espalhamento elástico. Ele pode espalhar inelasticamente, excitar elétrons de valência ou interagir com fônons do cristal. Tais processos são mais prováveis quanto maior a distância percorrida, e reduzem o sinal de EXAFS por um fator $e^{-\frac{2 D_{i}}{\lambda(k)}}$ onde $\lambda(k)$ é o livre caminho médio inelástico do fotoelétron ${ }^{[73]}$. Adicionalmente, o tempo de vida da vacância também reduz o sinal EXAFS com a mesma dependência de $D$, uma vez que, quanto maior a distância percorrida pelo fotoelétron, mais provável será o preenchimento da vacância. Sendo assim, os dois efeitos podem ser considerados no mesmo fator ${ }^{[73]}$. O valor de $\lambda(k)$ varia de 1 a 
$100 \AA^{[76]}$.

- efeito da desordem térmica $e^{-2 k^{2} \sigma_{i}^{2}}$. Mesmo na temperatura ambiente, as vibrações dos átomos correspondem a variações nas posições dos centros espalhadores. Tal efeito é chamado de desordem térmica. O sinal EXAFS é modificado pelo fator $e^{-2 k^{2} \sigma_{i}^{2}}$ onde $\sigma_{i}^{2}$ representa o deslocamento quadrático médio (também chamado de fator Debye-Waller) ${ }^{[73,76]}$. Desordens estáticas presentes em materiais amorfos ou com defeitos, também podem ser modelados pelo mesmo fator. Quanto menor o comprimento de onda do fotoelétron, maior a influência do efeito de Debye-Waller, de forma que ele é essencial em EXAFS, mas pode ser desprezível em XANES, quando $\sigma^{2} k^{2}>>1^{[68]}$.

- fator $1 / k$. O fator $k$ no denominador poderia ter sido absorvido na constante de proporcionalidade $f_{i}(k)$, entretanto, para que se utilize $f_{i}(k)$ em unidades de comprimento (o inverso de $k$ ), o termo $1 / k$ deve ser inserido na equação para que $\chi(k)$ seja adimensional ${ }^{[76]}$. 


\section{Apêndice B}

\section{Fundamentos dos cálculos}

\section{teóricos de XANES e EXAFS}

Esse apêndice apresenta algumas das principais abordagens e aproximações utilizadas nas simulações. Maiores detalhes podem ser encontrados nas referências indicadas.

\section{B.1 A probabilidade de transição e a regra de ouro de Fermi}

O efeito dominante na absorção dos raios X pela matéria, para energias menores que $\approx 50 \mathrm{keV}$, é a excitação de elétrons. Nessa faixa de energia, a seção de choque do efeito Compton é pequena e a produção de pares é proibida (vide figura 2.2 ${ }^{[69]}$. Nesse caso, a interação entre os raios X e a matéria é descrita pela regra de ouro de Fermi. Ela estabelece que a probabilidade de transição $W$ entre o sistema no estado inicial $\psi_{i}$ e final $\psi_{f}$, pela absorção do fóton incidente de energia $\hbar \omega$, é:

$$
W_{f i}=\frac{2 \pi}{\hbar}\left|\left\langle\psi_{f}|T| \psi_{i}\right\rangle\right|^{2} \delta\left(E_{f}-E_{i}-\hbar \omega\right)
$$


onde a função delta tem o objetivo de garantir a conservação de energia, de forma que transições só ocorram se a energia do fóton for igual à energia do estado final $E_{f}$ menos a energia do estado inicial $E_{i}$. Para absorção de raios X, o operador de transição $T$ está relacionado com o termo de perturbação de primeira ordem da Hamiltoniana de interação $\mathbf{p} \cdot \mathbf{A}(\mathbf{r})$, onde $\mathbf{p}$ corresponde ao operador momento e $\mathbf{A}(\mathbf{r})$ o potencial vetor da onda eletromagnética. Desta forma, o coeficiente de absorção, $\mu$, será ${ }^{[119]}$ :

$$
\mu \propto \sum_{f}^{E_{f}>E_{F}}\left|\left\langle\psi_{f}|\mathbf{p} \cdot \mathbf{A}(\mathbf{r})| \psi_{i}\right\rangle\right|^{2} \delta\left(E_{f}-E_{i}-\hbar \omega\right),
$$

onde a somatória é feita sobre todos os estados finais acima da energia de Fermi $E_{F}$.

A interação entre o fóton, de polarização $\hat{\epsilon}$, e o elétron, pode ser representada, na aproximação de dipolo, por $\hat{\epsilon} \cdot \mathbf{r}^{[68]}$. Desta forma, a seção de choque de absorção fica:

$$
\mu \propto \sum_{f}^{E_{f}>E_{F}}\left|\left\langle\psi_{f}|\hat{\epsilon} \cdot \mathbf{r}| \psi_{i}\right\rangle\right|^{2} \delta\left(E_{f}-E_{i}-\hbar \omega\right),
$$

Os estados em XAFS devem ser interpretados de maneira diferente do que em espectroscopia óptica. Em XAFS, o estado inicial do elétron é um estado ligado bem definido (1s para a borda K, por exemplo), enquanto que o estado final, quando acima da borda, corresponde a estados contínuos de alta energia cinética com uma vacância deixada para trás ${ }^{[69]}$. A principal dificuldade nos cálculos ab initio está em determinar os estados finais ${ }^{[80]}$.

\section{B.2 Potencial}

O elétron excitado é considerado como uma quase partícula, movendo-se num potencial, $V(E)$. Tal potencial complexo dá conta das perdas por espalhamento inelástico e das demais interações do elétron com o material, como o espalhamento elástico e mudanças 
de fase. O potencial (chamado de potencial óptico, em analogia à utilização de índice de refração complexo para modelar a absorção na luz em um meio) tem a forma:

$$
V(E)=V_{\text {coul }}+\sum(E)
$$

onde $V_{\text {coul }}$ corresponde ao potencial coulombiano resultante sentido pelo fotoelétron, e $\sum(E)$ é um termo complexo de auto-energia ${ }^{[68]}$. Diferentemente do que é feito nos cálculos de estrutura eletrônica do estado fundamental, o potencial deve levar em consideração o estado excitado do átomo absorvedor e a vacância.

\section{B.2.1 Potencial muffin-tin}

A precisão dos cálculos depende fortemente da escolha do potencial, uma vez que este determina o fator de espalhamento de cada átomo. A maioria dos cálculos teóricos de EXAFS utiliza o chamado potencial muffin-tin, conforme representado esquematicamente na figura B.1. Trata-se de um potencial de espalhamento esfericamente simétrico, centrado nos átomos do material, e com um valor constante na região intersticial entre eles $^{[68]}$.

O potencial muffin-tin é uma aproximação. Perto do núcleo, ele é semelhante ao potencial atômico, de forma que a simetria esférica é bastante adequada. Fora dessa região, a densidade de carga depende da natureza das ligações químicas, e, a simetria é perdida, tornando o potencial mais anisotrópico. No regime de EXAFS, a energia cinética do fotoelétron é alta, de forma que é espalhado principalmente pelo potencial próximo ao núcleo, ficando menos sensível às suas variações da região intersticial, onde movimenta-se de maneira aproximadamente livre. Deste modo, a aproximação muffintin reproduz satisfatoriamente os resultados nessa região longe da borda. Entretanto, na região de XANES, os fotoelétrons têm menor energia cinética, e são mais influenciados pelos detalhes do potencial na região interatômica, de foma que a aproximação muffin- 
tin é menos eficiente ${ }^{[68]}$. A densidade de carga na região muffin-tin deve ser aproximada, de forma a manter a neutralidade de toda a estrutura. Na região dos centros atômicos, a densidade de carga é majoritariamente devida ao átomo central, tendo uma menor contribuição das flutuações na densidade de carga dos átomos vizinhos.
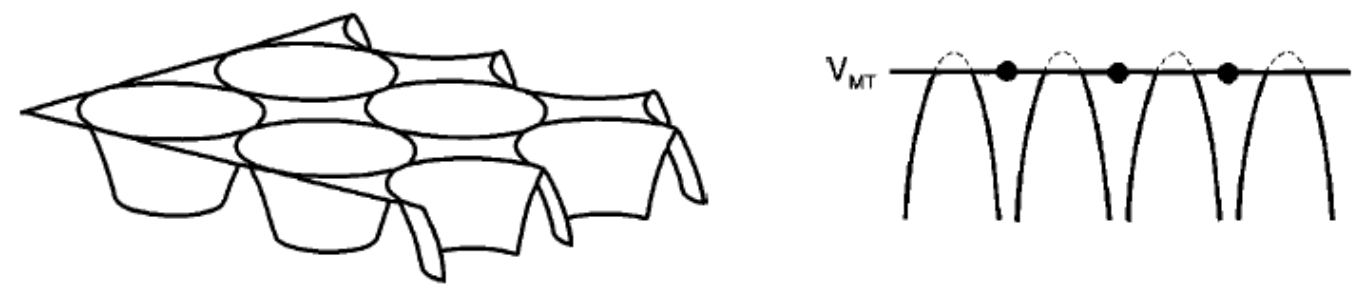

Figura B.1: Representação esquemática de um potencial muffin-tin. Na região intersticial, o potencial é considerado constante, $V_{M T}{ }^{[68]}$.

Métodos auto-consistentes (Self-Consistency-Field-SCF) podem ser utilizados para obter a densidade de cargas e o potencial. Começando com a configuração eletrônica dos átomos isolados, o código (FEFF8 ou FDMNES) calcula o potencial com os átomos nas posições correspondentes da estrutura a ser simulada. O resultado é utilizado para recalcular as densidades eletrônicas dos átomos, e o processo se repete até que um critério de convergência seja atingido ${ }^{[118]}$. Algumas estratégias de simulação foram desenvolvidas sem a aproximação (métodos full potential - FP). Tais cálculos resultam em uma melhor densidade de carga, incluindo todos os detalhes devido às ligações químicas e outras interações com os átomos vizinhos. Entretanto, por serem computacionalmente dispendiosos, são geralmente utilizados em XANES ${ }^{[68]}$.

\section{B.3 Espalhamento múltiplo}

Apesar do espalhamento simples ter influência predominante em XAFS, os efeitos do espalhamento múltiplo (MS) são essenciais para obter resultados teóricos de boa concordância com o experimental. Entretanto, um pequeno agregado com algumas 


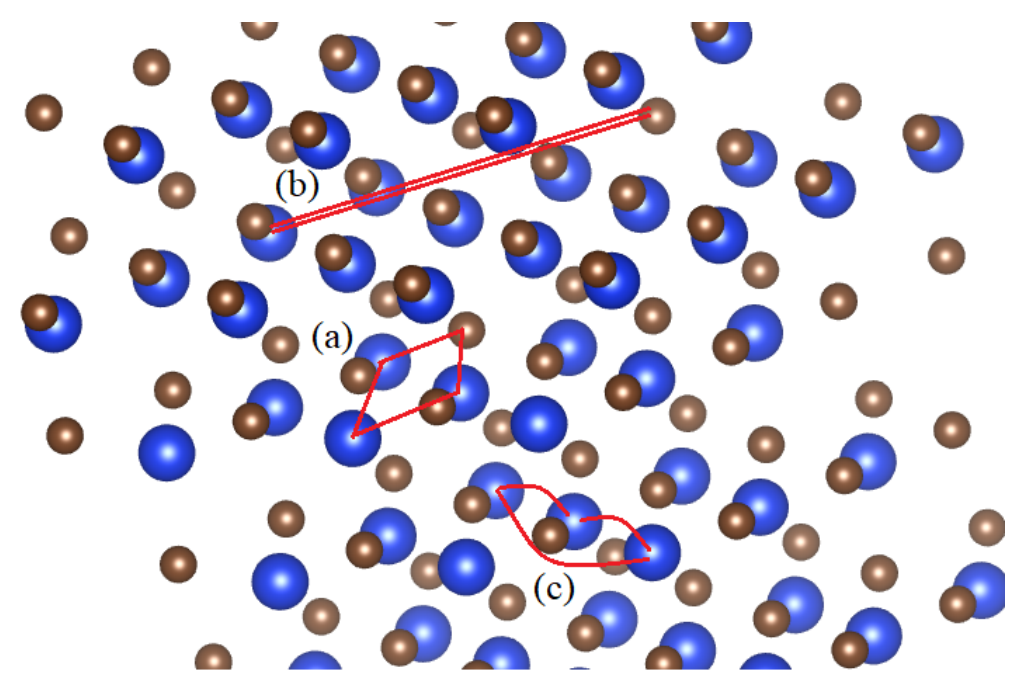

Figura B.2: Representação de alguns tipos de caminhos de espalhamento num agregado de SiC-6H. Em (a) um espalhamento de $3^{\text {a }}$ ordem, cuja distância total média $\left(D_{i}\right)$ pode ser bem menor que alguns casos de espalhamento simples, como o representado em (b). Em (c) um exemplo do espalhamento entre átomos alinhados (focusing).

dezenas de átomos contém algo como $10^{4}$ caminhos de segunda ordem, $10^{6}$ caminhos de terceira ordem e assim por diante, logo, incluir todas as ordens de espalhamento nas simulações é computacionalmente dispendioso.

É notório que muitos caminhos têm pequena influência no processo. O termo $\frac{1}{D_{i}} e^{-\frac{2 D_{i}}{\lambda(k)}}$, da equação de EXAFS (eq. A.1), mostra que o sinal diminui com $D_{i}$ (metade da distância total média do caminho). Sendo assim, os caminhos mais longos vão contribuir pouco para a estrutura fina de absorção. Adicionalmente, os caminhos de ordem mais elevada terão suas contribuições reduzidas pois, cada evento de espalhamento ocorre com uma determinada probabilidade. É importante ressaltar que alguns caminhos de espalhamento múltiplo podem ser mais significativos que caminhos de espalhamento simples quando a distância total média $D$ é grande ${ }^{[73]}$. Além disso espalhamentos múltiplos por átomos em linha podem contribuir com grande intensidade (efeito focusing) ${ }^{[120]}$. A figura B.2 demonstra esses casos.

As primeiras tentativas de cálculos teórico de XAFS com espalhamento múltiplo consideravam, ou a aproximação de onda plana, ou o espalhamento de ondas esféricas 
limitado a estruturas com poucos átomos ou limitados a espalhamentos de até terceira ordem $^{[68]}$. Apenas com o trabalho de Rehr e Albers ${ }^{[121]}$ foi possível obter, com boa precisão, simulações incluindo o espalhamento múltiplo de ondas esféricas para caminhos de ordens elevadas. O método foi implementado no código FEFF6 ${ }^{[122]}$ e, utilizando um algorítimo para gerar e filtrar os caminhos por importância, boa concordância com os resultados experimentais foi obtida, mesmo eliminando do cálculo os de contribuição menor.

\section{B.3.1 Expansão do espalhamento múltiplo}

O tratamento utilizado para o cálculo do espalhamento múltiplo é baseado na teoria da função de Green de uma partícula. Esse formalismo é especialmente interessante em XAFS, uma vez que, naturalmente incorpora perdas inelásticas e evita a necessidade de calcular explicitamente as funções de onda ${ }^{[68]}$. A função de Green de uma partícula pode ser escrita como ${ }^{[69,118]}$ :

$$
G(E)=(E-H+i \Gamma)^{-1}
$$

onde $\Gamma=0^{+}$é um infinitesimal positivo e $H$ a hamiltoniana do sistema:

$$
H=H_{0}+V_{i n t}+\sum_{i} v_{i}
$$

O termo $H_{0}=-\frac{1}{2} \nabla^{2}$ corresponde à hamiltoniana do elétron livre, $V_{\text {int }}$ O potencial mufintin intersticial (vide seção B.2.1) e $\sum_{i} v_{i}$ corresponde ao potencial esferossimétrico dos centros espalhadores.

No formalismo MS, a forma de operador da função de Green, $\sum_{f}|f\rangle G(E)\langle f|$, é utilizada para reescrever a equação B.3 como:

$$
\mu=-\frac{1}{\pi} \operatorname{Im}\left\langle i\left|\hat{\epsilon}^{*} \cdot \mathbf{r} G(E) \hat{\epsilon} \cdot \mathbf{r}\right| i\right\rangle \Theta\left(E-E_{F}\right),
$$


onde $\Theta$ é uma função degrau Heaviside garantindo que $\mu$ seja não nulo apenas acima da energia de Fermi $E_{F}{ }^{[118]}$.

A função de Green, $G$, é o propagador na presença do potencial de espalhamento e é expresso pela equação de Dyson ${ }^{[18]}$

$$
G=G^{0}+G^{0} T G^{0}
$$

onde $G^{0}$ é o propagador do elétron livre

$$
G^{0}=\left(E-H_{0}+i \Gamma\right)^{-1}
$$

e $T$ é a matriz de espalhamento atômico total, que pode ser escrita em função das matrizes de espalhamento de cada centro $t$,

$$
T=t+t G^{0} t+t G^{0} t G^{0} t+\ldots
$$

de forma que, a equação de Dyson pode ser resolvida fazendo ${ }^{[118]}$ :

$$
G=G^{0}+G^{0} t G^{0}+G^{0} t G^{0} t G^{0}+\ldots
$$

e, reconhecendo que se trata de uma expansão de Taylor,

$$
G=\left(1-G^{0} t\right)^{-1} G^{0}
$$

A equação B.11 contém as diferentes formas que o fotoelétron pode espalhar pelos átomos vizinhos, antes que a vacância seja preenchida. $G^{0}$ descreve como o elétron se propaga entre dois pontos no espaço, e $t$ descreve como o fotoelétron espalha em um único átomo ${ }^{[118]}$. Desta forma, $G^{0} t G^{0}$ representa todas as formas em que o espalhamento pode ocorrer por um único átomo (espalhamento simples), $G^{0} t G^{0} t G^{0}$ representa todas 
as formas que o espalhamento pode ocorrer por dois átomos (espalhamento duplo), e assim analogamente nos demais termos da expansão. Expandindo a equação B.11 explicitamente em todos os caminhos, obtém-se:

$$
\begin{aligned}
G= & G_{c}+\sum_{i \neq 0} G_{c} t_{i} G_{c}+\sum_{i, j \neq 0(i \neq j)} G_{c} t_{i} G_{i, j}^{0} t_{j} G_{c} \\
& +\sum_{i, k \neq 0(i \neq j)(j \neq k)} G_{c} t_{i} G_{i, j}^{0} t_{j} G_{j, k}^{0} t_{k} G_{c}+\ldots
\end{aligned}
$$

O propagador $G_{c}$ corresponde ao caminho do átomo absorvedor e algum átomo vizinho, e $G_{i, j}^{0}$ é o propagador entre os átomos $i$ e $j$. Todos os caminhos são fechados, pois iniciam e terminam no átomo absorvedor. As exclusões das somatórias garantem que a propagação do fotoelétron sempre ocorrerá entre átomos diferentes ${ }^{[18]}$.

\section{B.3.2 Espalhamento múltiplo total (Full multiple Scattering)}

Os cálculos teóricos, feitos com a expansão de espalhamentos múltiplos, podem convergir com apenas algumas dezenas de caminhos no regime de EXAFS. Na região de XANES, no entanto, a situação é mais complicada, pois, uma vez que o fotoelétron possui menor energia cinética, a probabilidade de espalhamento por cada átomo é maior e a convergência pode não ocorrer. Adicionalmente, o fator de Debye-Waller $\left(e^{-2 k^{2} \sigma_{i}^{2}}\right)$ reduz menos o sinal na região de XANES, pois $k$ é menor ${ }^{[73]}$. Assim, caminhos com espalhamentos de maior ordem têm importância maior quando comparados com o regime de EXAFS e devem ser considerados. Desta forma, para obter bons resultados nas simulações de XANES, métodos de espalhamento múltiplo total (Full Multiple Scattering - FMS) foram desenvolvidos.

As principais características das simulações utilizando métodos FMS são ${ }^{[68]}$ :

- permitem cálculos auto consistentes da densidade eletrônica de carga e potenciais, sem a necessidade de aproximação de simetria esférica do potencial; 
- permitem o cálculo preciso da energia de Fermi relativa aos estados não ocupados;

- não permitem incluir efeitos de desordem com fatores de Debye-Waller para cada caminho;

- são computacionalmente ineficientes, pois lidam com detalhes sobre a estrutura eletrônica que são eliminados pelos diversos alargamentos e efeitos de tempo de vida presentes nos experimentos;

- são limitados à região próxima da borda, pois, o número de funções e componentes do momento angular orbital que devem ser calculados, cresce rapidamente com a energia acima da borda;

- o cálculo é feito considerando, simultaneamente, todos os caminhos, logo, não permite distinguir e analisar um caminho específico, com o objetivo de obter informações do tamanho e ângulo das ligações.

Diversos métodos FMS têm sido desenvolvidos. Um deles é a obtenção da soma de todas as ordens da expansão em B.13 pela inversão da matriz $\left(1-G^{0} t\right)$, como mostra a expressão B.12 ${ }^{[123]}$. O método utiliza a aproximação muffin-tin e o fato de que o livre caminho médio dos fotoelétrons (da ordem de $5-10 \AA$ ) permite que estruturas de tamanho limitado, alcancem a convergência. Entretanto, tais matrizes podem ser grandes e o cálculo pode ser computacionalmente dispendioso. Tal procedimento foi implementado na versão FEFF8 ${ }^{[79]}$ do código de Rehr et. al. No mesmo código foi incorporado o cálculo auto consistente (SCF) do potencial e da densidade eletrônica, ainda utilizando a aproximação muffin-tin. Outro método que merece destaque é o das diferenças finitas de Joly et. al apresentado na seção 2.1.9. 


\section{Apêndice $\mathrm{C}$}

\section{Intensidade de fluorescência em}

\section{filmes finos sobre um substrato}

A amplitude do campo elétrico dos feixes refletido e transmitido em uma interface é obtida pelas relações de Fresnel ${ }^{[124,125]}$. Nas considerações a seguir, as interfaces foram consideradas homogêneas e perfeitamente planas. As diversas reflexões secundárias (em ziguezague) são desprezadas nesse tratamento, assim como os efeitos decorrentes da rugosidade. O tratamento teórico apresentado aqui é baseado nos trabalhos de Sánchez et al $^{[87]}$ e Miqueles et al ${ }^{[88]}$, e a figura C.1 mostra a notação utilizada.
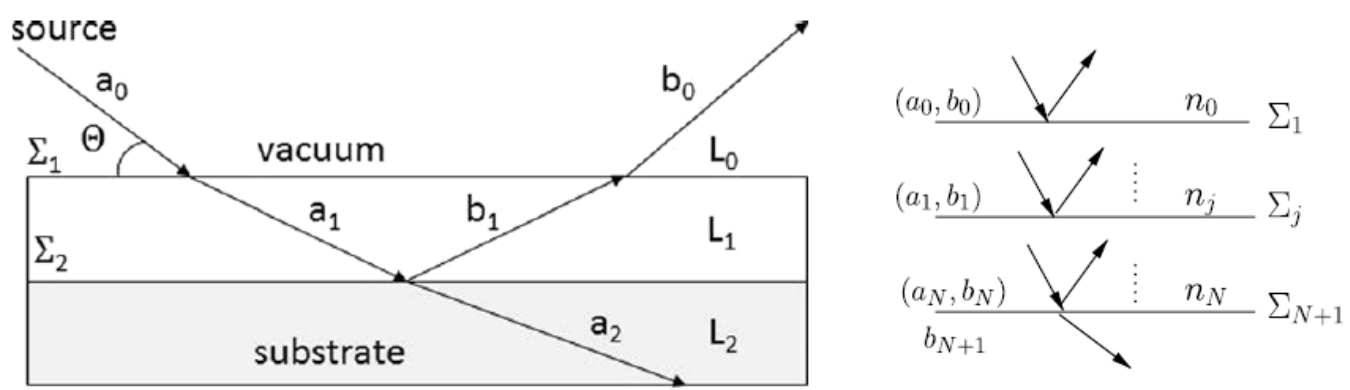

Figura C.1: Amplitudes do campo elétrico dos feixes refletido e refratado em filmes finos sobre um substrato ${ }^{[88]}$. 
Um raio $\mathrm{X}$ de amplitude $a_{0}$ incide, a partir do meio $n_{0}$ (vácuo), sobre a interface $\Sigma_{1}$, com ângulo $\theta$. As amplitudes dos feixes incidente e refletido, no meio $n_{j}$, são denotadas por $a_{j}$ e $b_{j}$. Cada camada de filme possui espessura $h_{j}$ e índice de refração complexo $n_{j}=1-\delta_{j}-i \beta_{j}$. As amplitudes dos campos elétricos dos feixes de raios $\mathrm{X}$ na interface $j$ são relacionadas pelas equações de Fresnel. Os coeficientes de transmissão, $t_{j}=\frac{a_{j+1}}{a_{j}}$, e reflexão, $r_{j}=\frac{b_{j}}{a_{j}}$, para os ângulos pequenos utilizados nessas aplicações, são dados por ${ }^{[88]}$ :

$$
\begin{aligned}
t_{j} & =\frac{2 p_{j-1}}{p_{j-1}+p_{j}} \\
r_{j} & =\frac{p_{j-1}-p_{j}}{p_{j-1}+p_{j}}
\end{aligned}
$$

onde $p_{j}$ é

$$
p_{j}=\sqrt{\theta^{2}-2 \delta_{j}-2 i \beta_{j}},
$$

com $p_{0}=\theta$, o ângulo de incidência do raios $\mathrm{X}$ a partir do vácuo.

A amplitude transmitida pela camada $j$ está relacionada com as amplitudes incidente e refletida (consideradas na interface $j$ ) por ${ }^{[87]}$ :

$$
a_{j}=t_{j} a_{j-1}-r_{j} b_{j},
$$

e, usando o princípio da reversibilidade,

$$
b_{j}=t_{j} b_{j-1}-r_{j} a_{j} .
$$


Colocando as expressões acima na forma matricial, resulta:

$$
\left[\begin{array}{c}
a_{j-1} \\
b_{j-1}
\end{array}\right]=F_{j}\left[\begin{array}{l}
a_{j} \\
b_{j}
\end{array}\right]
$$

onde:

$$
F_{j}=\frac{1}{t_{j}}\left[\begin{array}{cc}
1 & r_{j} \\
r_{j} & 1
\end{array}\right]
$$

Para obter as amplitudes na interface seguinte, deve-se considerar a propagação dos feixes pela camada de espessura $h_{j-1}$, de forma que a equação C.6 deve ser corrigida multiplicando-se pela matriz ${ }^{[87]}$ :

$$
E_{j}=\left[\begin{array}{cc}
\nu_{j-1} & 0 \\
0 & \frac{1}{\nu_{j-1}}
\end{array}\right] \text { com } \quad \nu_{j}=\exp \left(i k p_{j} h_{j}\right)
$$

onde $k=\frac{2 \pi}{\lambda}$. O resultado é:

$$
\left[\begin{array}{c}
a_{j-1} \\
b_{j-1}
\end{array}\right]=E_{j} F_{j}\left[\begin{array}{l}
a_{j} \\
b_{j}
\end{array}\right]
$$

Representando as amplitudes pelo vetor coluna $\mathbf{x}_{\mathbf{j}}=\left(a_{j}, b_{j}\right)$, e expressando o produto das matrizes por $G_{j}=E_{j} F_{j}$, C.9 fica:

$$
\mathbf{x}_{j-1}=G_{j} \mathbf{x}_{j}
$$

Para um conjunto de $N$ filmes sobre um substrato obtém-se um conjunto de $N$ sistemas 
de equações lineares $2 \times 2$.

$$
\begin{aligned}
\mathbf{x}_{0} & =G_{0} \mathbf{x}_{1} \\
\mathbf{x}_{1} & =G_{1} \mathbf{x}_{2} \\
& \vdots \\
\mathbf{x}_{N} & =G_{N} \mathbf{x}_{N+1}
\end{aligned}
$$

Utilizando o formalismo apresentado em ${ }^{[88]}$, o conjunto de equações acima pode ser representado na forma matricial como:

$$
\begin{aligned}
& \mathbf{H}_{\mathbf{U}} \\
& \text { Q }
\end{aligned}
$$

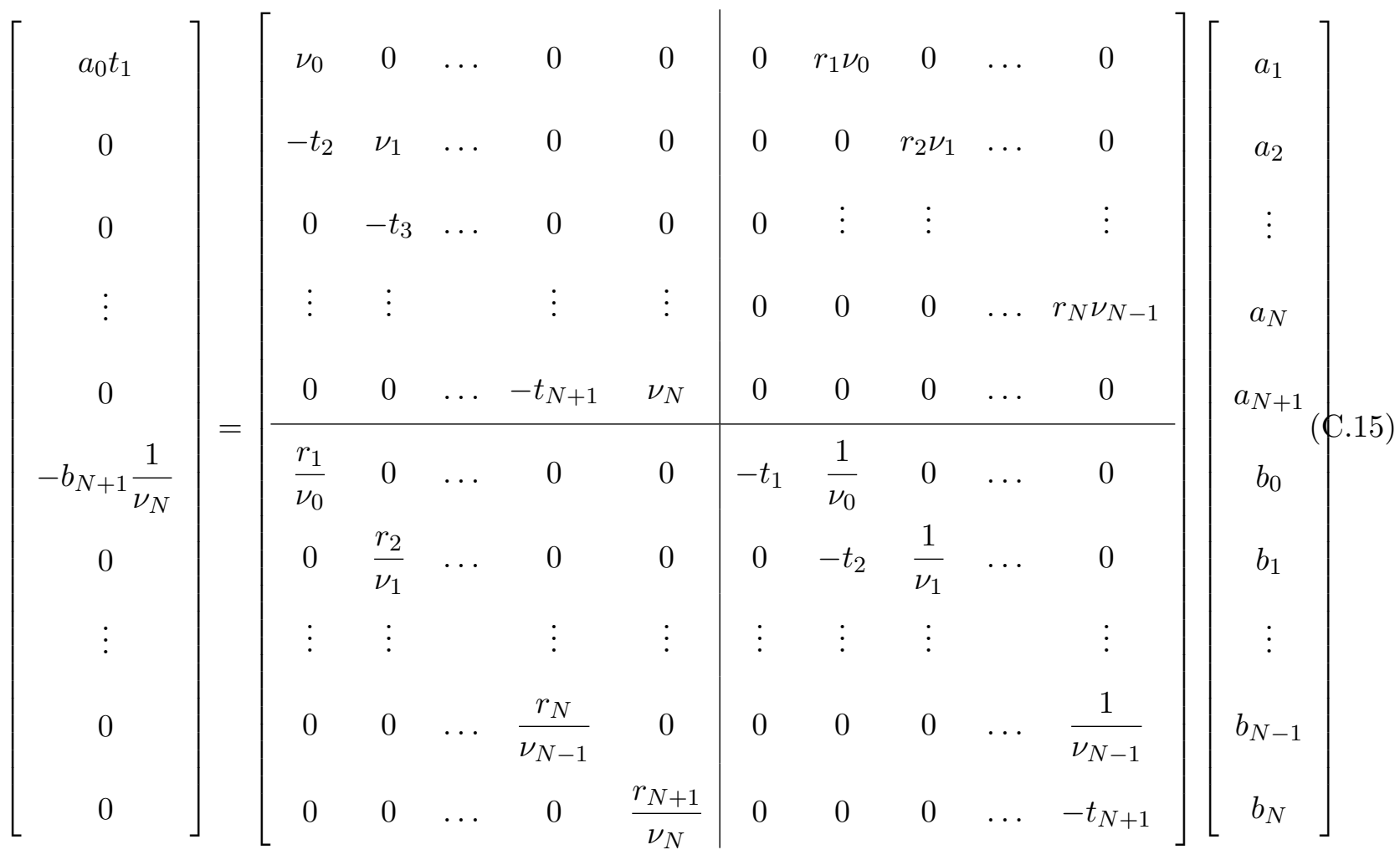$$
\text { D }
$$$$
\mathbf{H}_{\mathbf{L}}
$$

Representando as amplitudes pelos vetores coluna, 


$$
\mathbf{a}=\left[\begin{array}{c}
a_{1} \\
a_{2} \\
\vdots \\
a_{N} \\
a_{N+1}
\end{array}\right] \text { e } \quad \mathbf{b}=\left[\begin{array}{c}
b_{0} \\
b_{1} \\
\vdots \\
b_{N-1} \\
b_{N}
\end{array}\right]
$$

a equação C.15 torna-se ${ }^{[88]}$ :

$$
\left[\begin{array}{c}
a_{0} t_{1} \rho_{\mathbf{1}} \\
\mathbf{0}
\end{array}\right]=\left[\begin{array}{cc}
\mathbf{H}_{\mathbf{U}} & \mathbf{Q} \\
\mathbf{D} & \mathbf{H}_{\mathbf{L}}
\end{array}\right]\left[\begin{array}{l}
\mathbf{a} \\
\mathbf{b}
\end{array}\right]
$$

onde $\rho_{1}$ é o primeiro vetor canônico de dimensão $N+1$, e foi utilizado o fato de que não há reflexões no substrato $\left(b_{N+1}=0\right)$. Na expressão C.17, as matrizes $\mathbf{H}_{\mathbf{U}}, \mathbf{H}_{\mathbf{L}}, \mathbf{Q}$ e D são partes da matriz na equação C.15, conforme indicado.

Essa representação é conveniente, pois resulta no sistema de equações:

$$
\begin{aligned}
& \mathbf{H}_{\mathbf{U}} \mathbf{a}+\mathbf{Q b}=a_{0} t_{1} \rho_{\mathbf{1}} \\
& \mathbf{D a}+\mathbf{H}_{\mathbf{L}} \mathbf{b}=\mathbf{0}
\end{aligned}
$$

que é equivalente a

$$
\mathbf{a}=-\mathbf{D}^{-1} \mathbf{H}_{\mathbf{L}} \mathbf{b}
$$




$$
\left[\mathbf{Q}-\mathbf{H}_{\mathbf{U}} \mathbf{D}^{-\mathbf{1}} \mathbf{H}_{\mathbf{L}}\right] \mathbf{b}=a_{0} t_{1} \rho_{\mathbf{1}}
$$

Desta forma, partindo da amplitude incidente $a_{0}$, pode-se obter o vetor $\mathbf{b}$ com C.21 e depois o vetor a por C.20. O método exposto acima tem se mostrado mais eficaz para a realização de cálculos numéricos por ser mais rápido e propagar menor erro ${ }^{[88]}$.

\section{Intensidade de fluorescência}

A intensidade do raio $\mathrm{X}$ incidente, na profundidade $z$ no interior da camada $j$, é dado por ${ }^{[87,88]}$ :

$$
I\left(\theta, z_{j}\right)=\left|a_{j} e^{i k z p_{j}}+b_{j} e^{i k z p_{j}}\right|^{2},
$$

de forma que a intensidade do sinal de fluorescência para um elemento $m$ é dada por:

$$
F_{m}(\theta)=\sum_{j=1}^{N+1} F_{m}(j, \theta)
$$

onde $F_{m}(j, \theta)$ corresponde à contribuição de cada camada $j$ dada por ${ }^{[87]}$ :

$$
F_{m}(j, \theta)=K \rho_{j} Q_{m, \lambda}^{j} \exp \left(\sum_{s=1}^{j-1} \mu_{s \lambda_{m}} \rho_{s} h_{s}\right) \int_{0}^{h_{j}} I\left(\theta, z_{j}\right) \exp \left(-\mu_{j \lambda_{m}} \rho_{j} z_{j}\right) d z_{j}
$$

$\operatorname{com} Q_{m, \lambda}^{j}=W_{m}^{j} J_{m} \omega_{m} g_{m} \tau_{m, \lambda}$. Os termos da expressão são:

- $K$ - fator instrumental que depende da geometria do arranjo experimental;

- $\rho_{j}$ — densidade da camada $j$;

- $\mu_{j, \lambda}$ - coeficiente de atenuação (de massa) da camada $j$, para raios $\mathrm{X}$ de comprimento de onda $\lambda$;

- $\lambda_{m}$ - comprimento de onda característico da fluorescência do elemento $m$;

- $h_{j}$ - espessura da camada $j$; 
- $W_{m}^{j}$ - concentração do elemento $m$ na camada $j$;

- $J_{m}$ - salto de absorção do elemento $m$;

- $\omega_{m}$ - taxa de fluorescência do elemento $m$ (fluorescence yield);

- $g_{m}$ - probabilidade de emissão de fluorescência do elemento $m$;

- $\tau_{m, \lambda}$ - coeficiente de absorção (de massa) do elemento $m$, para raios $\mathrm{X}$ de comprimento de onda $\lambda$. 


\section{Apêndice D}

\section{Fundamentos da espectroscopia}

\section{de retroespalhamento de}

\section{Rutherford}

Neste apêndice são apresentados dois fundamentos importantes na Espectroscopia de Retroespalhamento de Rutherford (RBS).

\section{D.1 O fator cinemático}

O processo de interação entre o feixe incidente e o material em um experimento de RBS é representado esquematicamente na figura D.1. O projétil, de massa $M_{1}$ e energia $E_{0}$, colide elasticamente com o alvo $M_{2}$, inicialmente em repouso. Após a colisão, a partícula incidente é espalhada sob o ângulo $\theta$, ficando com energia $E_{1}$ e o alvo com energia $E_{2}$. Todos os parâmetros considerados são em relação ao referencial do laboratório.

O fator cinemático $K$, definido como a razão entre as energias do íon espalhado e 


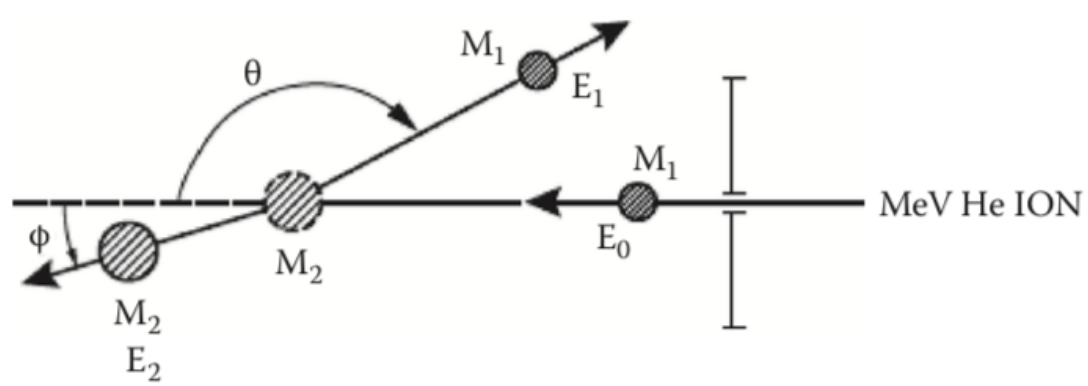

Figura D.1: Colisão entre projétil e alvo no $\operatorname{RBS}^{[90]}$.

do íon incidente, é dado por ${ }^{[89]}$ :

$$
K=\frac{E_{1}}{E_{0}}=\left[\frac{\left(M_{2}^{2}-M_{1}^{2} \operatorname{sen}^{2} \theta\right)^{1 / 2}+M_{1} \cos \theta}{M_{2}+M_{1}}\right]^{2}
$$

Os projéteis que colidirem na superfície do material atingirão o detector com energia $K E_{0}$, o que corresponde a uma variação da energia de $\Delta E_{s}=E_{0}-K E_{0}$. Entretanto, as colisões com os átomos numa profundidade $t$ serão menos energéticas, pois o íon perde energia ao penetrar no material. A figura D.2 representa a diferença entre colisões que ocorrem na superfície e num ponto no interior do material. Até atingir o ponto de colisão, o íon perde a energia $\Delta E_{i n}$, de forma que a energia do íon espalhado, imediatamente após a colisão numa profundidade $t$, será $K E_{t}=K\left(E_{0}-\Delta E_{i n}\right)$. Até atingir o detector, o íon perde também a energia $\Delta E_{\text {out }}$, sendo detectado com $E_{1}$ dado por:

$$
\begin{aligned}
& E_{1}=K E_{t}-\Delta E_{\text {out }}, \\
& E_{1}=K E_{0}-K \Delta E_{\text {in }}-\Delta E_{\text {out }} .
\end{aligned}
$$

Assim, a diferença de energia $\Delta E$ entre os projéteis espalhados na superfície do 
Apêndice D. Fundamentos da espectroscopia de retroespalhamento de Rutherford160

material e os espalhados na profundidade $t$ será:

$$
\begin{aligned}
& \Delta E=K E_{0}-E_{1}, \\
& \Delta E=K \Delta E_{\text {in }}+\Delta E_{\text {out }}
\end{aligned}
$$
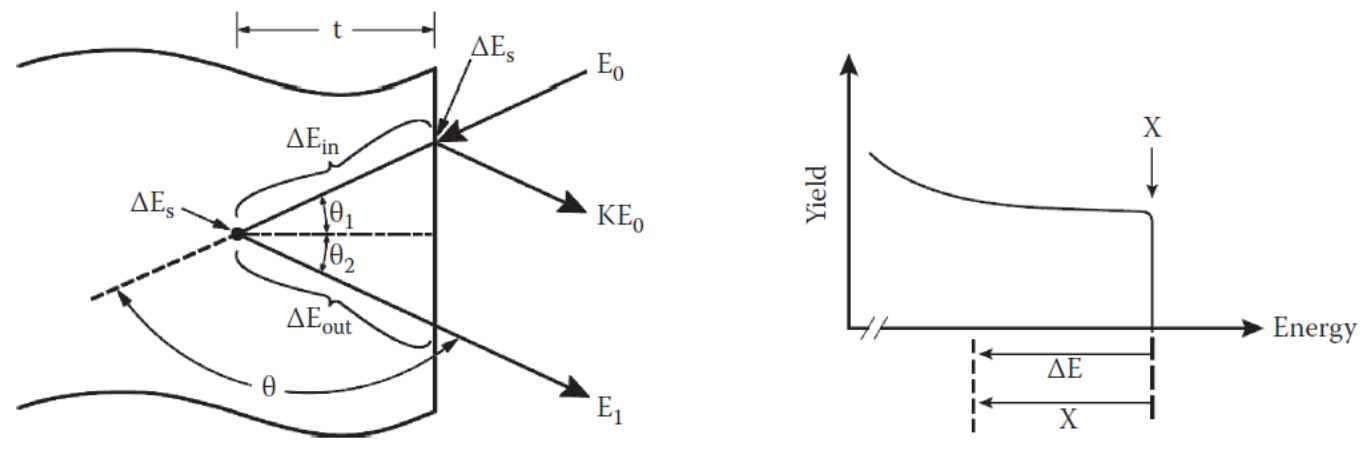

Figura D.2: (esquerda) Esquema da perda de energia do íon em função da profundidade $t$ e a direção de incidência. (direita) Representação de um espectro RBS demonstrando como o eixo da energia pode ser relacionado com a profundidade da amostra ${ }^{[90]}$.

\section{D.2 Poder de freamento}

Ao penetrar na amostra, a taxa de energia perdida pelo íon, por unidade de comprimento, $\frac{\mathrm{d} E}{\mathrm{~d} x}$, é determinada pelas interações entre o íon e os átomos e elétrons do material. Dois mecanismos distintos de perda de energia ocorrem:

- colisões nucleares (elásticas): Processo no qual energia é transferida aos átomos do alvo. Produz deflexão na trajetória do íon e grandes perdas de energia. Esse processo é predominante quando a velocidade dos íons é baixa e seu número atômico é alto.

- colisões eletrônicas (inelástica): Processo no qual os íons perdem energia por excitar ou ejetar elétrons dos átomos do material. Nesse processo as perdas de ener- 
gia são bem menores e a deflexão da trajetória e desprezível. Ele é predominante para íons de elevada velocidade e baixo número atômico.

Tal separação do processo de perda de energia não é perfeitamente distinta, mas uma boa aproximação. Para os valores típicos aplicados em $\mathrm{RBS}\left(\mathrm{He}^{+}\right.$de $1 \mathrm{MeV}$ atingindo um substrato de Si, por exemplo), o processo de colisões nucleares pode ser desprezado, pois, a taxa de energia perdida é algumas ordens de grandeza menor que no processo de colisões eletrônicas ${ }^{[90]}$. A perda de energia é chamada de poder de freamento, S, sendo:

$$
S=-\frac{\mathrm{d} E}{\mathrm{~d} x}
$$

A seção de choque de freamento (stopping cross section) $\epsilon$, associada a um material, corresponde à taxa de energia perdida por unidade de comprimento por centro espalhador. Para um material de densidade atômica $N$ fica:

$$
\epsilon=\frac{1}{N} \frac{\mathrm{d} E}{\mathrm{~d} x}
$$

Para materiais que contêm mais de um elemento, a seção de choque pode ser calculada pela regra de Bragg ${ }^{[90]}$. Se a composição é $A_{m} B_{n}$, a seção de choque de freamento fica:

$$
\epsilon^{A_{m} B_{n}}=m \epsilon^{A}+n \epsilon^{B}
$$

Considerando que as trajetórias percorridas pelo íon na entrada e na saída do material são, respectivamente, $\frac{t}{\cos \theta_{1}} \mathrm{e} \frac{t}{\cos \theta_{2}}$ (vide figura D.2 ), as perdas de energia do projétil ao penetrar $(i n)$ e sair (out) do material são proporcionais à profundidade $t$ 
e estão relacionadas com a direção do espalhamento por ${ }^{[90]}$ :

$$
\begin{aligned}
\Delta E_{\text {in }} & =\left.\frac{t}{\cos \theta_{1}} \frac{\mathrm{d} E}{\mathrm{~d} x}\right|_{\text {in }}, \\
\Delta E_{\text {out }} & =\left.\frac{t}{\cos \theta_{2}} \frac{\mathrm{d} E}{\mathrm{~d} x}\right|_{\text {out }} .
\end{aligned}
$$

A diferença de energia $\Delta E$ da equação D.5 pode ser expressa em função de $\epsilon$ fazendo:

$$
\Delta E=t N\left(\frac{K}{\cos \theta_{1}} \epsilon_{\text {in }}+\frac{1}{\cos \theta_{2}} \epsilon_{\text {out }}\right)
$$

onde $\frac{\mathrm{d} E}{\mathrm{~d} x}$ é considerado constante ao longo da trajetória do íon, tanto ao entrar, como ao deixar o material.

A expressão D.11 mostra uma relação linear entre a perda de energia e a profundidade do material. Por isso, o eixo da energia no espectro RBS pode ser relacionado com a profundidade ou espessura do material (vide figura D.2).

Para compostos com mais de um elemento, deve-se utilizar a expressão D.8 para obter $\Delta E$ resultante da interação com cada elemento. A figura D.3 mostra um espectro RBS típico de um material constituído dos elementos A e B. Como a perda de energia $\Delta E_{s}$ será diferente quando a colisão ocorre com cada elemento, o detector registrará contagens de faixas de energia diferentes, como mostra a figura D.3-b. Se os elementos A e B não forem de número atômico muito próximos, as regiões ficarão bem separadas, sendo facilmente possível identificá-los. 


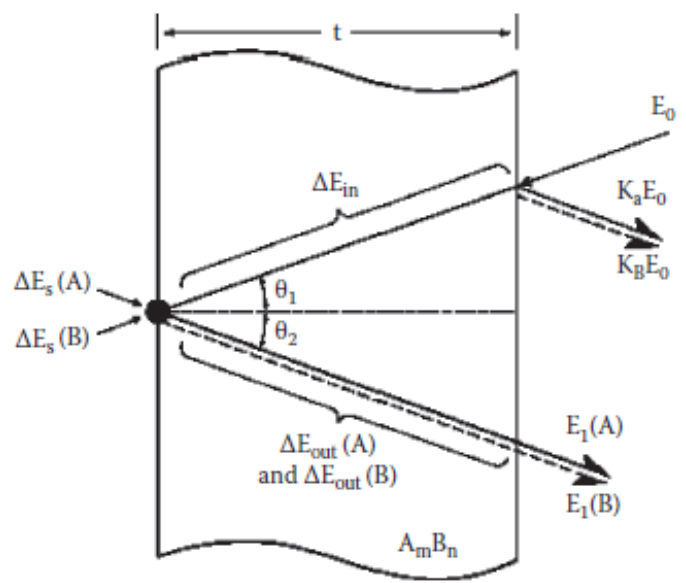

(a)

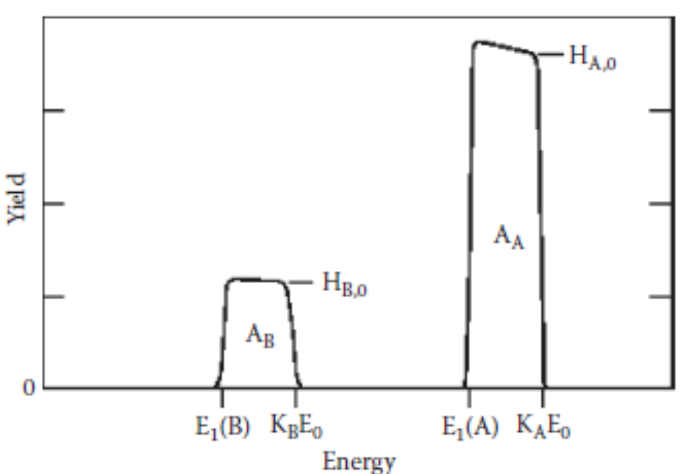

(b)

Figura D.3: (esquerda) Representação do espalhamento do projétil em um material de espessura $t$ e composição $A_{m} B_{n}$, mostrando que as energias dos íons que chegam ao detector são diferentes para cada elemento $\left(E_{1}(A)\right.$ e $\left.E_{1}(B)\right)$, mesmo quando espalhados no mesmo ponto. (direita) Um espectro RBS típico no qual as contribuições correspondentes aos elementos $A$ e $B$ são resolvidas e aparecem como duas regiões distintas (adaptado de ${ }^{[90]}$ ). 


\section{Apêndice E}

\section{Publicação decorrente deste trabalho}

Parte dos resultados desta pesquisa foi publicada nos proceedings da $18^{\mathrm{a}}$ conferência Brazilian Workshop on Semiconductor Physics - BWSP18 ${ }^{[16]}$. O artigo é aqui reproduzido. 


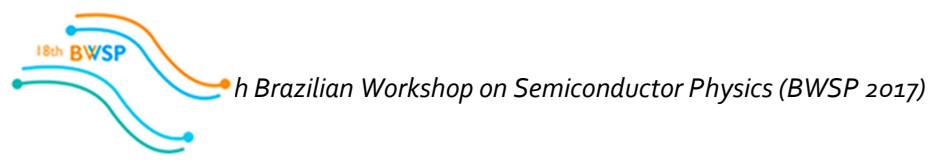

\title{
The structural properties of the protective layer of microlamps under polarization
}

\author{
Vinicius R. S. Cassimiro*, Rubens M. Cunha Júnior**, Gustavo P. Rehder**, Inés Pereyra**, \\ Marcelo N. P. Carreño**, Marco I. Alayo**, Márcia C. A. Fantini*, Nicolas Trcera*** \\ *Instituto de Física, Universidade de São Paulo (USP) \\ ${ }^{*}$ Escola Politécnica, Universidade de São Paulo (USP) \\ ${ }^{* * *}$ Société Civile Synchrotron SOLEIL, Lucia Beamline \\ *cassimiro.vinicius@gmail.com
}

Keywords: Microlamp, Thin-films, XAS

Abstract

This work reports the production of microlamps and their structural properties after modifications induced by the heating process. Their production consists on films deposited by Plasma Enhanced Chemical Vapor Deposition (PECVD) and sputtering over silicon substrates. The filament, composed by a thin chromium wire, is protected against oxidation by a top thin layer. Four different materials were used as protective layer: $\mathrm{SiC}, \mathrm{SiO}_{\mathrm{x}} \mathrm{N}_{\mathrm{y}}, \mathrm{AIN}$ and $\mathrm{TiO}_{2}$. The protective film is heated by the metallic filament and their chemical and structural properties may change, depending on the time interval and intensity of the applied current (up to $2 \mathrm{~h}$ and 50mA). X-ray absorption near edge spectroscopy (XANES) measurements allowed investigating changes on the properties of the microlamps protective films heated under different polarization conditions. The LUCIA beam line of the synchrotron SOLEIL has a microfocus spot $(3 \times 3 \mu \mathrm{m})$, permitting to evaluate the small thermally affected zone. The results showed that the $\mathrm{SiO}_{x} \mathrm{~N}_{y}$ film is thermally stable with negligible changes on the XANES spectra. A slight AIN oxidation is observed as heating rises, which is particularly evident for the sample heated at extreme conditions. $\mathrm{TiO}_{2}$ XANES spectra showed that the material is crystallized with rutile structure and is also thermally stable. SiC thin films were widely affected, showing an oxidation process as the time interval and intensity of the current increased. In addition, once the films were deposited over the $\mathrm{Cr}$ filament, their XANES spectra are quite different from the standard sample (deposited over $\mathrm{Si}$ ), even for the non-polarized microlamp, indicating a $\mathrm{Cr}$ contamination on the $\mathrm{SiC}$ structure.

\section{Introduction}

Microlamps as light sources in optical devices have been studied recently in several technical applications, such as wave-guides, IR micro spectroscopy, calibration of sensors and localized thermal treatment. They consist of a resistive filament heated by Joule effect when an electrical current flows throughout the material. The heated filament emits light with a wide range spectrum of radiation [1-3]. Most of the researches concerning the investigation of structural properties of the materials used in electronic microdevices deals with the study of their thin films alone or the interface between two of them. The investigation made in this work intents to study the top thin film (protective layer) already deposited on the microlamps, using $X$ ray Absorption Spectroscopy with a microfocus source of radiation available at LUCIA beam line of the synchrotron facility SOLEIL. The dimension of the spot $(3 \mu \mathrm{m} \times 3 \mu \mathrm{m})$ allows studying how the films properties are modified during the microlamp operation, exactly on the heat affected zone. It is reasonable to consider that the micro scale 18th Brazilian Workshop on Semiconductor Physics (BWSP 2017) dimensions and the substrate presence could affect the results when compared to the usual techniques.

\section{Methods and Results}

The microlamp produced in this work is shown schematically by figure 1 . It consists of a silicon nitride thin film deposited over silicon $<100>$ wafer substrate where the chromium filament is deposited on. The filament is isolated from the environment by the last protective layer in order to avoid service break down if the filament oxidizes due to contact with air. Four different materials were used to make the protective layer: $\mathrm{SiC}, \mathrm{SiO}_{x} \mathrm{~N}_{y}, \mathrm{AIN}$, and $\mathrm{TiO}_{2}$. The films were deposited by Plasma Enhanced Chemical Vapor deposition (PECVD) and sputtering, following previous studied conditions [4-6]. Table 1 shows the deposition parameters and the film thicknesses. The microlamps were polarized with different current and time, in order to simulate distinct operational conditions and to induce a different heating flow from the filament throughout the protective layer. The legends on figures 2 to 4 indicate the sample tags and polarization conditions. 


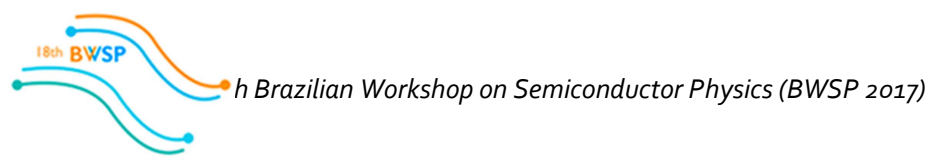

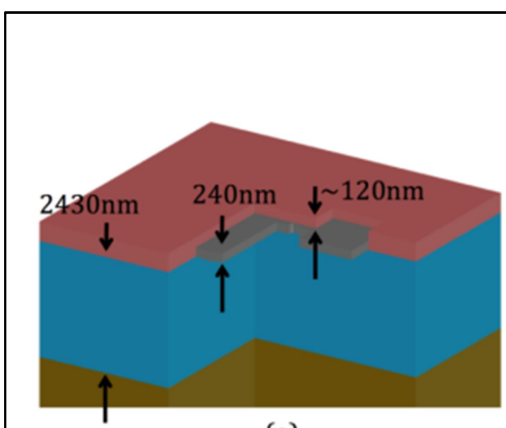

(a)

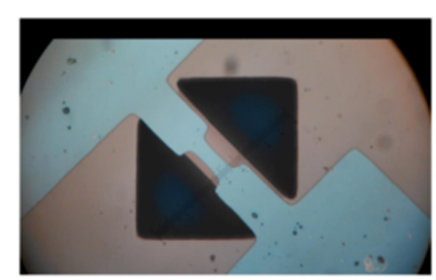

(c)

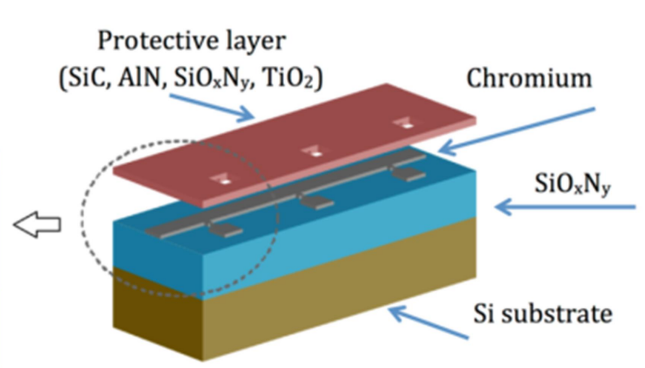

(b)

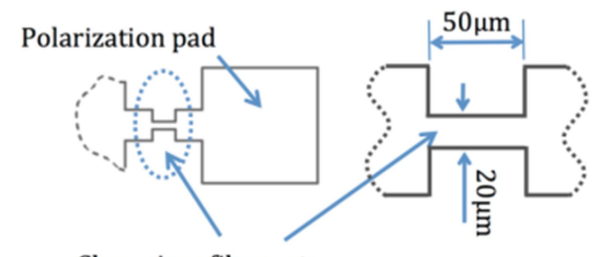

Chromium filament

(d)
Figure 1. Microlamp construction details. (a) and (b) The Cr filament is isolated from the environment by the top protective layer ( $\mathrm{SiC}, \mathrm{AIN}$, $\mathrm{SiO}_{\mathrm{x}} \mathrm{N}_{\mathrm{y}}$ or $\mathrm{TiO}_{2}$ ) and the $\mathrm{SiO}_{x} \mathrm{~N}_{y}$ film. The device was constructed over $\mathrm{Si}$ substrate. (c) and (d) A microscope view of the filament and its main dimensions.
X-ray Absorption Near Edge Structure (XANES) measurements were carried out at synchrotron facility SOLEIL (LUCIA beam line) by Total Electron Yield using the own microlamp pads. The beam has a microfocus spot permitting to assess the protective layer just above the incandescent filament. Reference films were measured as well.

\section{Discussion}

Figures 2 to 4 show the XANES spectra obtained with the four distinct protective layers.

\section{- Silicon Carbide}

The Silicon Carbide XANES spectra are shown in figure 2. It is possible to visualize the changes produced by the heating as the device is submitted under increasing polarization conditions.

\begin{tabular}{|c|c|c|c|c|c|c|c|c|c|}
\hline Film & Material & $\begin{array}{c}\text { Deposition } \\
\text { Process }\end{array}$ & \multicolumn{3}{|c|}{ Flux (sccm) } & $\begin{array}{c}\text { Deposition } \\
\text { Temperature }\end{array}$ & r. f. Power & Deposition Time & Thickness \\
\hline \multirow{2}{*}{ Filament } & $\mathrm{Cr}$ & Sputtering & Air: 10 & & & & $70 \mathrm{~W}$ & $20 \mathrm{~min}$ & $240 \mathrm{~nm}$ \\
\hline & SiOxNy & PECVD & $\mathrm{N}_{2} \mathrm{O}: 45$ & $\mathrm{~N}_{2}: 30$ & $\mathrm{SiH}_{4}: 30$ & $320^{\circ} \mathrm{C}$ & $200 \mathrm{~W}$ & $8 \mathrm{~min}$ & $114 \mathrm{~nm}$ \\
\hline \multicolumn{10}{|l|}{ Protective } \\
\hline \multirow[t]{2}{*}{ layer } & AIN & Sputtering & Air: 70 & $\mathrm{~N}_{2}: 30$ & & & $100 \mathrm{~W}$ & $30 \mathrm{~min}$ & $115 \mathrm{~nm}$ \\
\hline & $\mathrm{TiO} 2$ & Sputtering & Air: 60 & $\mathrm{O}_{2}: 40$ & & & $150 \mathrm{~W}$ & $83 \mathrm{~min}$ & $136 \mathrm{~nm}$ \\
\hline
\end{tabular}

Comparing the samples curves with the references $\left(\mathrm{SiC}\right.$ and $\mathrm{SiO}_{2}$ ), the oxidation process is certainly observed by the increasing height of the peak at $\sim 1847 \mathrm{eV}$. Another interesting feature is the fact that the non-polarized microlamp (ML49-SiC) has a standard sample. The figure 2 (inset) shows a displacement of the edge to lower energies and a broadening of the peak in $\sim 1843 \mathrm{eV}$, what indicates that the fabrication process results in modifications of the structure, possibly because of the presence of the chromium substrate.

\section{- Aluminum Nitride}

Figure 3 reveals that just minor changes are brought in the aluminum nitride XANES spectra by the heating process. The burned out sample (ML37-AIN) shows additional peaks indicating the crystallization shows additional peaks indicating the crystallization
of the film. A carefully comparison among ML53, 59, different spectrum compared to the bulk a-SiC 


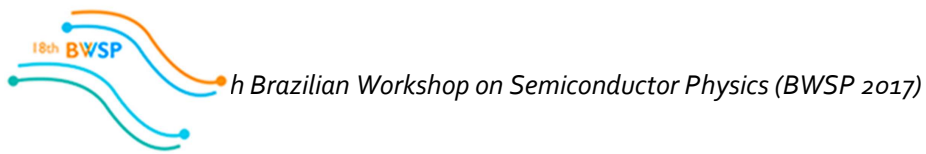

62 and 37-AIN (figure 3 inset) suggests that the crystallization process starts after $45 \mathrm{~mA}$ polarization, when the peak at $1567 \mathrm{eV}$ decreases and the one at $\sim 1572 \mathrm{eV}$ rises.

\section{- Silicon Oxynitride}

The similarity of the curves in figure 4 shows that the silicon oxynitride deposited as protective layer is stable under severe thermal conditions. The main peak in all samples $(\sim 1847 \mathrm{eV})$, when compared to

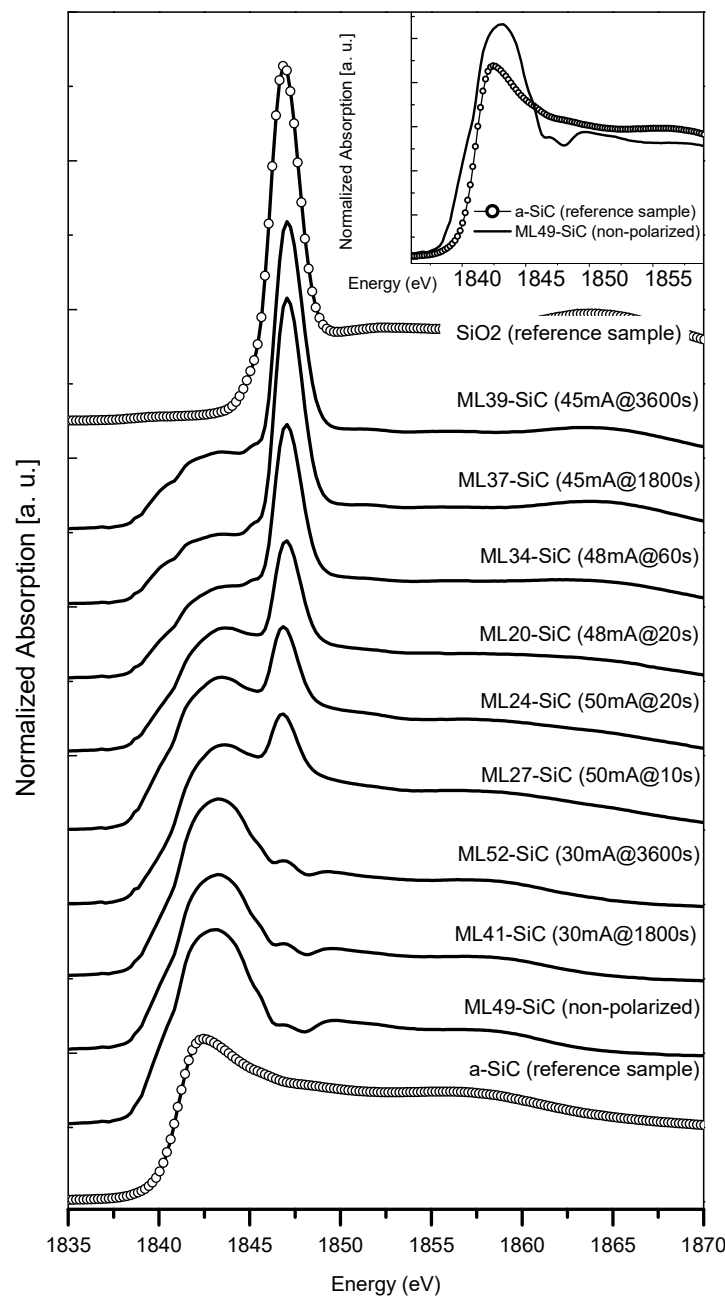

Figure 2. Si-K edge XANES spectra of the microlamps with SiC protective layer and some reference samples. The polarization conditions (electrical current and time) are indicated by the legends (the curves are stacked for better visualization). The inset figure shows non-stacked curves of the reference a-SiC and the non-polarized microlamp (ML-49) in order to facilitate the comparison.

18th Brazilian Workshop on Semiconductor Physics (BWSP 2017) standard $\mathrm{SiO}_{2}$, shows that the material is predominantly silicon dioxide.

\section{- Titanium Dioxide}

The XANES spectra obtained with the titanium dioxide samples indicates that the material is thermally stable as well. Comparing the standard sample with the microlamp spectra, it is possible to conclude that the structure is rutile crystalline.

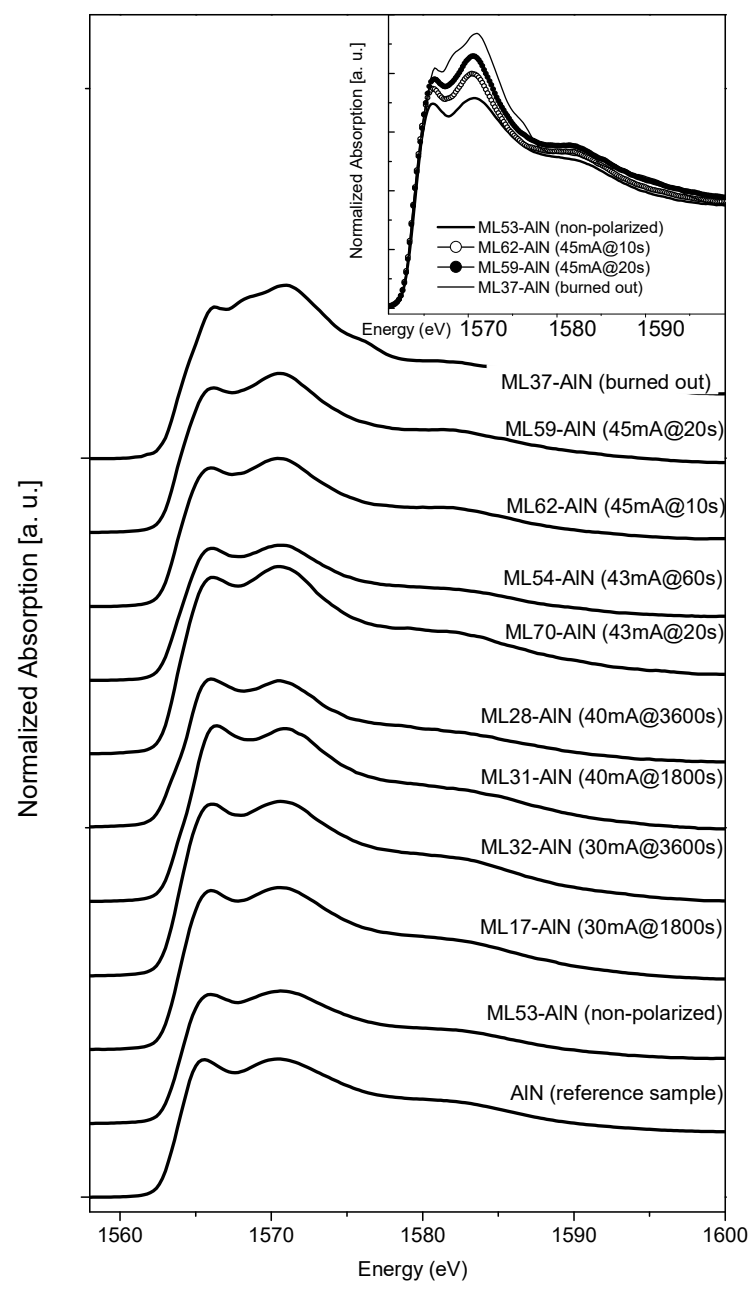

Figure 3. Al-K edge XANES spectra of the microlamps with the AIN protective layer and AIN reference sample. The curves are stacked for better visualization. The inset figure shows non-stacked curves of selected microlamps revealing the crystallization process. The polarization conditions (electrical current and time) are indicated by the legends 


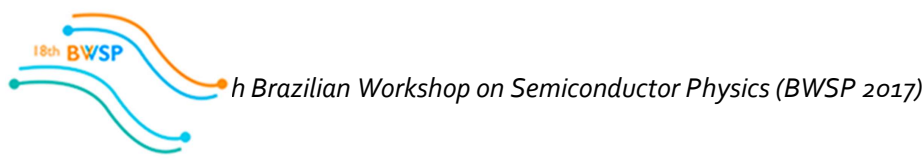

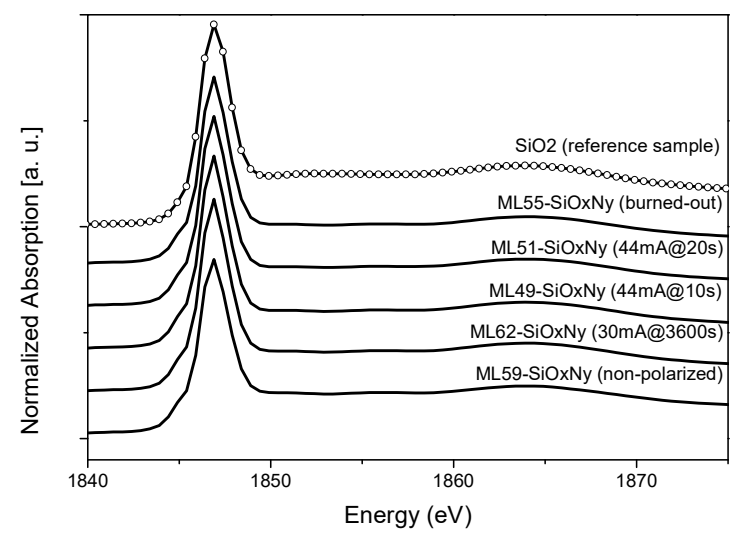

Figure 4. Si-K edge XANES spectra of the microlamps with $\mathrm{SiO}_{x} \mathrm{~N}_{y}$ protective layer and the $\mathrm{SiO}_{2}$ reference sample. The polarization conditions (electrical current and time) are indicated by the legends (the curves are stacked for better visualization).

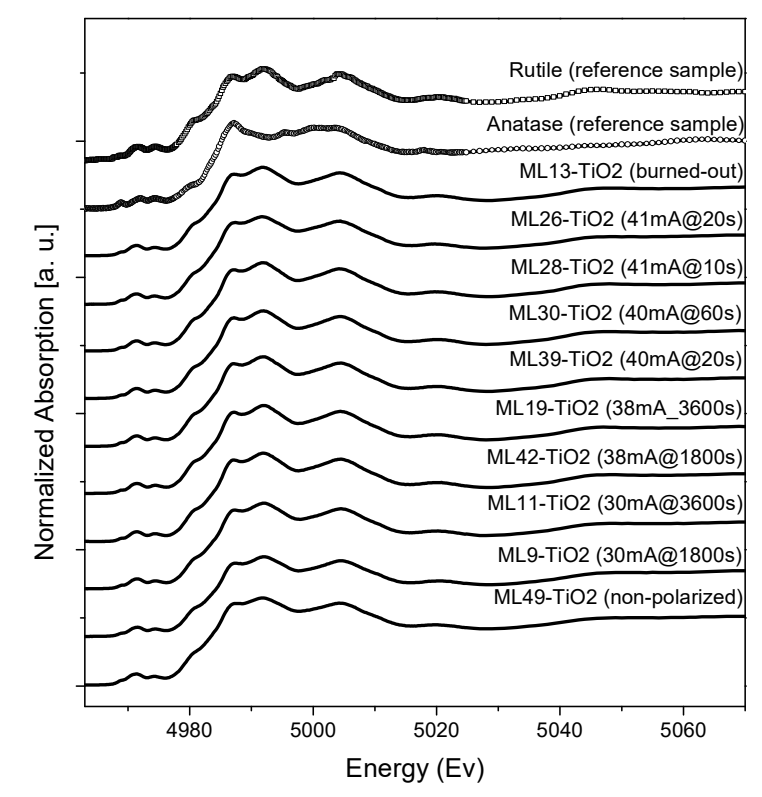

Figure 5. Ti-K edge XANES spectra of the microlamps with $\mathrm{TiO}_{2}$ protective layer and the rutile reference sample. The polarization conditions (electrical current and time) are indicated by the legends (the curves are stacked for better visualization).

\section{Conclusions}

The SiC XANES spectrum of the non-polarized microlamp is quite different than the a-SiC standard sample. This fact indicates that the chromium 18th Brazilian Workshop on Semiconductor Physics (BWSP 2017) substrate provides structural changes on $\mathrm{SiC}$ protective layer deposited over it. The edge displacement for lower energy values suggests that $\mathrm{Si}-\mathrm{Si}$ or $\mathrm{Si}-\mathrm{Cr}$ are present on the sample. After polarization the oxygen presence in the film is evident by the increasing peak at $1847 \mathrm{eV}$.

For the technological purposes the $\mathrm{SiO}_{x} \mathrm{~N}_{y}$ and the $\mathrm{TiO}_{2}$ protective layers are more suitable, considering their thermal stability properties, allowing microlamp long-term operation.

\section{Acknowledgments}

Thanks are due to CNPq and FAPESP for the financial support and SOLEIL Synchrotron Radiation Facility. I. Pereyra, M. C. A. Fantini, M. N. P. Carreño, M. I. Alayo and R. M. Cunha Junior are CNPq fellows and acknowledge its support.

\section{References}

1. D. O. Carvalho, M. N. P. Carreño, G. P. Rehder, M. I. Alayo, Integrated incandescent microlamp coupled to SiOxNy waveguide. Proc. SPIE 7208, MOEMS and Miniaturized Systems VIII, 72080 U

2. M. Ribeiro, I. Pereyra, M.I. Alayo, Silicon rich silicon oxynitride films for photoluminescence applications, Thin Solid Films 426 (2003) 200-204

3. M. I. Alayo, G. Rehder and, M. N. P. Carreño, MEMS-based incandescent microlamps for integrated optics applications, J. Opt. A: Pure Appl. Opt. 10 (2008) 104022

4. R. J. Prado, M. C. A. Fantini, M. H. Tabacniks, C. A. Villacorta Cardoso, I. Pereyra, A. M. Flank, Improvements on the local order of amorphous hydrogenated silicon carbide films. Journal of NonCrystalline Solids 283 (2001) 1

5. D. Criado, M. I. Alayo, I. Pereyra, M. C. A. Fantini, Structural analysis of silicon oxynitride films deposited by PECVD, Materials Science and Engineering B 112 (2004) 123

6. D. Criado, M. I. Alayo, M. C. A. Fantini, I. Pereyra Study of the mechanical and structural properties of silicon oxynitride films for optical applications, Journal of Non-Crystalline Solids 352 (2006) 2319 